ISSUE CROSS-PRESSURES AND ELECTORAL BEHAVIOR

IN WESTERN EUROPE

QingQian He 


\section{Graduation Committee}

Chair Prof. Dr. T. A. J. Toonen, University of Twente

Supervisor Prof. Dr. C. W. A. M. Aarts, University of Twente

Co-Supervisor Dr. M. Rosema, University of Twente

Members

Prof. Dr. J. Green, University of Manchester

Prof. Dr. J. J. M. van Holsteyn, Leiden University

Prof. Dr. T. W. G. van der Meer, University of Amsterdam

Prof. Dr. A. Need, University of Twente

Dr. H. van der Kolk, University of Twente 


\title{
ISSUE CROSS-PRESSURES AND ELECTORAL BEHAVIOR IN WESTERN EUROPE
}

\author{
DISSERTATION
}

to obtain

the degree of doctor at the University of Twente, on the authority of the rector magnificus,

Prof. dr. T.T.M. Palstra

on account of the decision of the graduation committee,

to be publicly defended

on Wednesday 29 November, 2017 at 16:45 p.m.

$$
\text { by }
$$

\section{QingQian He}

born on 11 November, 1987

in Quzhou, Zhejiang, China 
This dissertation has been approved by

Supervisor: $\quad$ Prof. Dr. C. W. A. M. Aarts, University of Twente

Co-Supervisor: Dr. M. Rosema, University of Twente

The work described in this thesis was performed at the Institute for Innovation and Governance Studies (IGS) and the Department of Public Administration (PA) of the University of Twente, PO Box 217, 7500 AE Enschede, the Netherlands.

This research was funded by the China Scholarship Council.

Cover designed by: QingQian He

Printed by: Gildeprint, Enschede

Cover image downloaded from Google Image

ISBN: 978-90-365-4433-7

DOI: $10.3990 / 1.9789036544337$

CQingQian He, 2017

All rights reserved. No part of this book may be reproduced or transmitted, in any form or by any means, electronic or mechanical, including photocopying, microfilming, and recording, or by any information storage or retrieval system, without the prior written permission of the author. 
To my parents and my sister 


\section{ACKNOWLEDGEMENTS}

The day when I left from China to the Netherlands is still vivid in my mind. My mom took me to the Shanghai Pudong Airport, and started to sob when I was boarding with tears. I arrived in the Netherlands around 10:30 pm. It was dark, wet, and a little bit cold. But I was excited and full of curiosity. My colleague, Wenqi, and her husband, Yibo, picked me up at the Amsterdam Schiphol Airport. All things like what happened yesterday. This dissertation, however, indicates that four years has passed.

As the final product of a scientific project, the dissertation not only stands for the end for me as a PhD student, but also the end of a memorable life for me in Enschede and the Netherlands. At this special moment, I would like to take this opportunity to express my gratitude to those who provided me with their invaluable support and accompany throughout the whole journey of my doctoral studies.

Undoubtedly, this dissertation would have not been completed without the guidance and support I received from my supervisors, Kees Aarts and Martin Rosema. They both have been academically and professionally engaged in my project and made remarkable contributions in different and important ways. I always like what Kees told me in our first meeting: interesting questions with high quality are the key points to scientific studies. It has profoundly influenced and inspired my own notion on how to do researches. Kees has always encouraged my independent work, while providing mentorship whenever it is necessary. Despite having been extremely busy after moving to the University of Groningen as the Dean of the faculty of Social Science, Kees has kept active in mentoring my thesis, especially managed to have weekly meetings with me during the later stage of this project. I am highly grateful to Kees.

I would like to extend my gratitude to Martin, who has provided me with wellrounded guidance regarding various aspects of academic life. I would not forget the day when I surprisedly got a bunch of flower from Martin for my first 'R\&R' feedback from an academic journal. That was the first bunch of flower I received, which I had expected would come from a member of my family, while turned out to be from my daily supervisor. "To get paper published likes climbing several mountains.", Martin told me on that day, "The first mountain is the most difficult one since you do not have very much experience. It 
gets easier when you have climbed over two or more mountains. Be patient until there is no mountain in front of you". I am grateful to Martin's considerate mentorship.

I also would like to thank all professors and teachers in the Department of Public Administration for their helpful suggestions and comments at various stages of my project: Ariana Need, Marcel Boogers, Bas Denters, Rene Torenvlied, Ramses Wessel, Shawn Donnelly, Maya van den Berg, Minna van Gerven-Haanpaa, Giedo Jansen, Veronica Junjan, Pieter-Jan Klok, Claudio Matera, Luisa Marin, Guus Meershoek, Irna van der Molen, Ringo Ossewaarde, and Jorgen Svensson. My gratitude also goes to two warm-hearted secretaries: Annette and Manon, for patiently providing all information and materials I needed.

Working on the thesis would have not been so much fun without the accompany of my fellow-PhD colleagues. Evisa, Aline, Wenqi, Amaury, Jasmin, Anna, Ben, Kira, Ann-Kristin, Sedef, Erik, Bengu, Judith, Annemike, Wouter, Joost, Cherelle, Minsi, Tatiana, Elisa and Radu. Thank you for creating the most inspiring, motivating and also entertaining work environment. Especially, Evisa, Aline, and Wenqi, thank you so much for sharing uncountable tips on how to be a good researcher during my first year. Amaury, thank you for your friendship and for making conference trips, Winter and Summer Schools so much fun! Ben, thank you for continuously sharing information on scenic spots and museums in the Netherlands. Jasmin, Kira and Anna, thank you for lunch breaks, Koffie, and talks related to research and beyond.

I further owe thanks to my Master's supervisor, Chengke Bao, for giving me endless encouragement from the beginning of my doctoral studies to the end. Prof. Bao has always welcomed my questions with great patience every time I sent him an email. He has not only cared about my doctoral studies but also my future development after it. My life as a $\mathrm{PhD}$ student would have been much more difficult without Prof. Bao's kindness suggestions to my confusions and anxieties. I am grateful to him. Warm thanks also go to my other Master's professors, Xingming Pan, Jun Liu and Siming Wang for their academic support and encouragement in my pursing a $\mathrm{PhD}$ degree.

During my forth year, I has been writing my $\mathrm{PhD}$ thesis and preparing for my next step simultaneously. It is much more stressful than past three years. At this point my special thanks go to Prof. Xun Pang for strongly encouraging me to apply for a postdoctoral position at Tsinghua University. 
Over past four years, I also had the chance to meet my dear friends in Enschede: Aijie, Lijie, Jinfeng, Yi Wang, Shanqiu, Jie Zhu, Shuqin, Qian Li, Shu Zhang, Yanbo, Bo Hou, Tik Wan, Meylani, Natalia, Nuria, Nikolas, Nabila. I appreciate all the time we have spent together. Thank you for making my life in the Netherlands so interesting! I am greatly happy to meet all of you in my life.

Out of Enschede, I am especially grateful to my two uncles, Shaoqing and Shuijin, for their willingness to be my guarantors which makes my studies in the Netherlands possible; to my uncle, Liping, and his wife, Bingbing, who live in Amsterdam and give me numerous help throughout my whole four years. I also want to thank my fellow master classmate, Beiyun. As a PhD student in Fudan University in China, she is as busy as me. Nevertheless, she has always been there for me whenever I feel stress. Our regular and open-minded exchanges of ideas has motivated me so much about science and methodology. I also would like to extend my gratitude to my other friends who live far away from me but provide me a lot of support and encouragement through QQ and WeChat: Tingting, Huayuan, Huayan, Yiting, Jiexin, Luxi, Min Zhang, Chao Sun, and Xiang Li.

Last but not the least, I would like to express my deepest thanks to my families. I am highly grateful to my father, Zhiwen He, and my mother, Min Xu. As many other famers in China, they do not have very good education background. But they give me and my sister great support and encouragement to do what we want to do. Their openmindedness and willingness to learn new communication technologies, QQ and WeChat, made me never felt really far away. I am also highly grateful to Yaqian He, who is not only my sister but also my best friend. As twin sisters, she and me grow up together and share all happiness and sadness happened in our life. Even though she is a $\mathrm{PhD}$ student in Remote sensing which is far away from my own filed, she has been a major source of motivation when finalizing this project. My warm thanks also extend to my brother in law, Yu Zheng, and my adorable nephew, JunZhe Zheng. Thank you for bringing so much happiness to my sister, my parents and me!

Enschede, November 2017

QingQian He 


\section{Contents}

\section{List of figures}

\section{List of tables}

1-Introduction.................................................................................... 1

1.1 Issue cross-pressures: A by-product of the rise of issue orientation.............................. 3

1.2 Issue cross-pressures in electoral behavior: An overview ....................................... 6

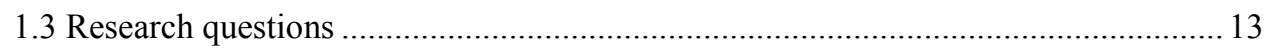

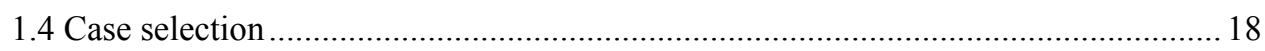

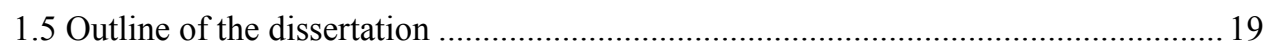

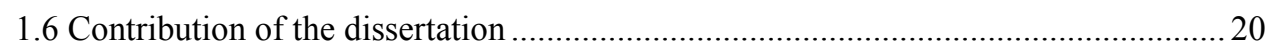

2-A Theory of Issue Cross-pressures.........................................................22

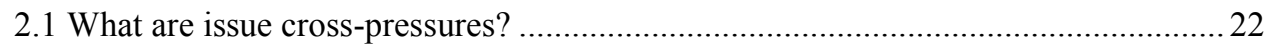

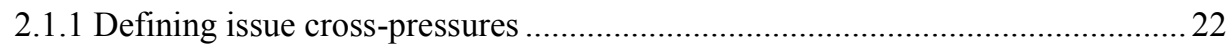

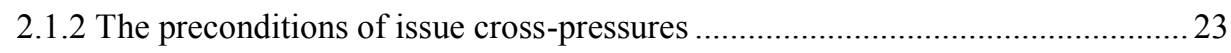

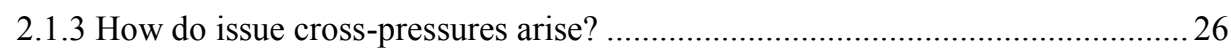

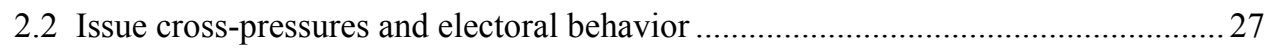

2.2.1 A perspective from cognitive dissonance theory …………………................ 28

2.2.2 A perspective from information processing theory ………………………......... 29

2.2.3 How do issue cross-pressures influence electoral behavior?................................ 31

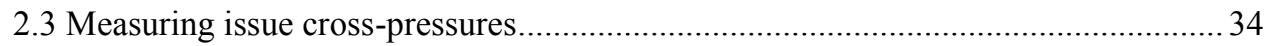

2.3.1 Existing potential measurements for issue cross-pressures in the literature........ 34

2.3.2 The regression-based measurement of issue cross-pressures ............................ 38

2.3.3 The distance/scalar product-based measurement of issue cross-pressures.......... 44

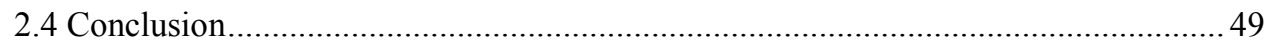

\section{3-Issue Cross-pressures and Issue Voting.....................................................551}

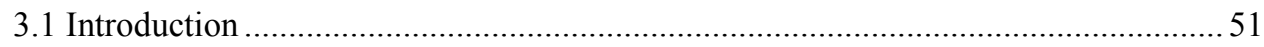

3.2 What moderates the role of issues in voting choice? The place of issue cross-

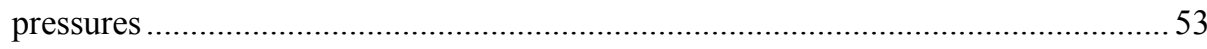

3.3 Issue cross-pressures, information processing and voting choice …………….........56 


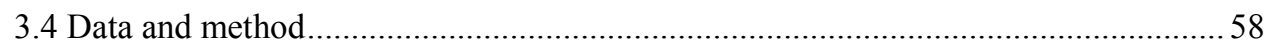

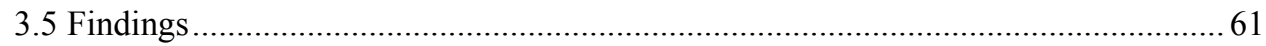

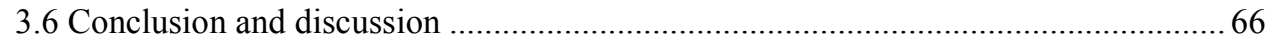

4-Issue Cross-pressures and Turnout ........................................................ 73

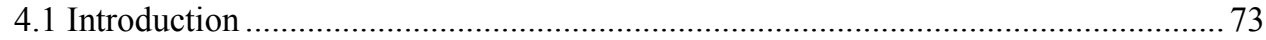

4.2 The place of issue cross-pressures in explaining voter turnout .............................. 75

4.3 Issue cross-pressures, turnout, and the political system ...................................... 78

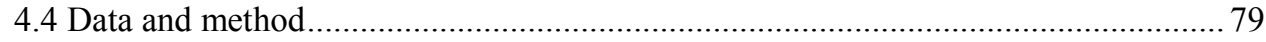

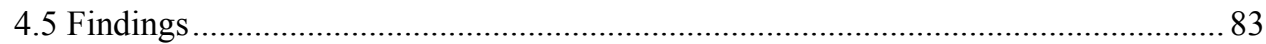

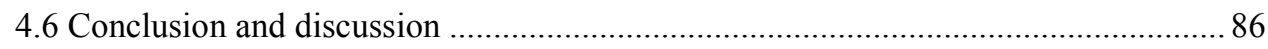

5-Issue Cross-pressures and Vote Switching ...............................................94

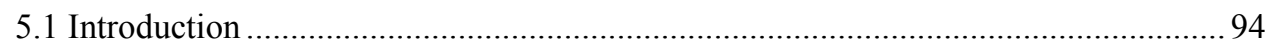

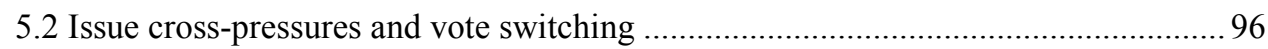

5.3 Cognitive typology, issue cross-pressures and vote switching .............................. 98

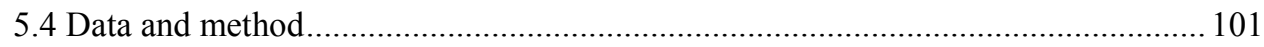

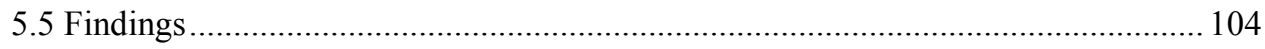

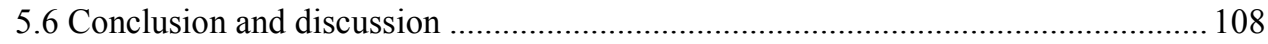

6-Issue Cross-Pressures and Time of Voting Decision .......................... 117

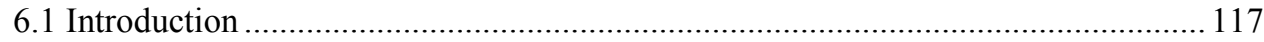

6.2 Background: Issue cross-pressures in explaining voters' time of voting decision?. 120

6.3 Issue cross-pressures, time of voting decision and political systems ....................... 122

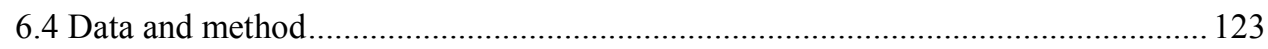

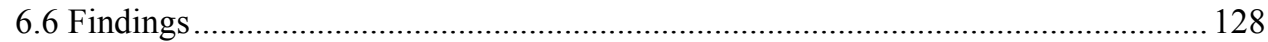

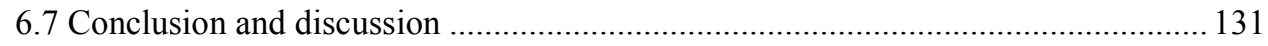

7- Issue Cross-pressures, Electoral Behavior and Democracy ............. 139

7.1 The role of issue cross-pressures in electoral behavior: Answering the research

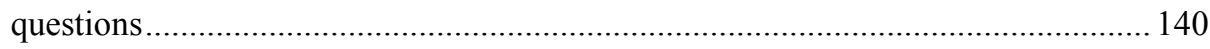

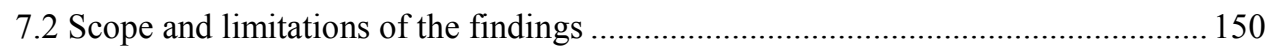

7.3 Issue cross-pressures, democracy and future research: three implications .............. 154

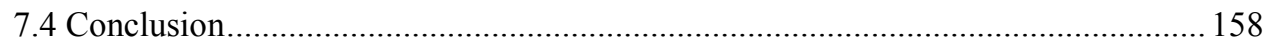

Appendix A: Tables in Chapter 3 ...................................................159 
Appendix B: Issue variables and tables relating to Chapter 4 ............ 161 Appendix C: Description of variables and tables in Chapter 6 ............ 166 Appendix D: Tables in Chapter 7 ................................................................... 177

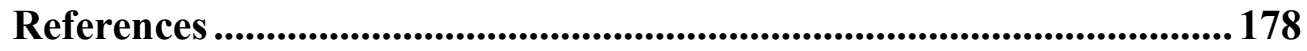

English Summary ........................................................................................ 196

Nederlandse Samenvatting.............................................................................. 201 


\section{List of Figures}

Figure 2-1 Positions distribution on the issue of immigration

Figure 2-2 Positions distribution on the issue of income difference

Figure 2-3 Issue cross-pressures and electoral behavior

Figure 2-4 Simplest situation in measuring issue cross-pressures

Figure 2-5 Moderate situation in measuring issue cross-pressures

Figure 2-6 Complicated situation in measuring issue cross-pressures

Figure 3-1 Issues, issue cross-pressures and voting choice

Figure 3-2 Moderated role of issue cross-pressures in the effect of issues on voting choice: proximity model

Figure 3-3 Moderated role of issue cross-pressures in the effect of issues on voting choice: direction model

Figure 4-1 Issue cross-pressures and turnout, the Netherlands (1994-2012)

Figure 4-2 Issue cross-pressures and turnout, the United Kingdom (1992-2010)

Figure 5-1 Mobilization typology 


\section{List of Tables}

Table 3-1 Issue Cross-pressures and Party Support: Two Groups

Table 3-2 Issue Cross-pressures and Party Support: Interaction

Table 4-1 Turnout in the Netherlands and the United Kingdom

Table 4-2 Issue Cross-pressures and Turnout in the Netherlands and the United Kingdom

Table 4-3 Issue Cross-pressures in the Netherlands and the United Kingdom

Table 5-1 Description of demographic background and political variables: panel of the 2002-2009 election

Table 5-2 Description of demographic variables and political variables: panel of the 2005-2013 election

Table 5-3 Issue Cross-pressures and Vote Switching in Germany

Table 5-4 Mobilization Typology and Issue Cross-pressures in Germany

Table 5-5 Mobilization Typology, Issue Cross-Pressures and Vote Switching in Germany: from the 2002 election to the 2005 election

Table 5-6 Mobilization Typology, Issue Cross-Pressures and Vote Switching in Germany: from the 2009 election to the 2013 election

Table 6-1 Time of Voting Decision in the Netherlands, the United Kingdom and Germany

Table 6-2 Issue Cross-Pressures and Time of Voting Decision in the Netherlands

Table 6-3 Issue Cross-Pressures and Time of Voting Decision in the United Kingdom

Table 6-4 Issue Cross-Pressures and Time of Voting Decision in Germany 



\section{1-Introduction}

When citizens' positions on some issues lead them to support one party while their policy preferences on other issues push them toward another party, how will these kinds of voters behave in elections? Since their issue positions lead them to inconsistent parties, compared to citizens whose positions on most issues generally point to the same party, will they rely less on individual issues and more on other cues such as political performance in order to make a decision? Will they have less motivation to go out to vote? Will they switch their voting choices more often between different elections? And will they even delay their voting decisions until the very last polling day? These are the central questions of this research. Elections have long been considered by political scientists as a key element of representative democracy, through which political power is justified by competition for the people's vote. Consequently, without insight into how citizens arrive at their decisions in elections, we cannot fully understand the functioning of democracies.

The 'funnel of causality' model developed by the Michigan school is the cornerstone in studying how people vote. It describes a chain of variables that contributes to the vote of a particular political candidate or party , such as long-term factors including socio-economic backgrounds, historical patterns, and groups' loyalties; and short-term factors such as issues, candidates, political and economic situations, government performance and campaign events. At the entrance of the funnel are the citizens' sociological characteristics that influence the subsequent element: party identification. Party identification, in turn, determines citizens' evaluation of candidates, issue proposals, government performance, etc. The output of this funnel represents citizens' eventual voting choices. As we can see, long-term factors, especially partisanship, are expected to affect the short-term variables and therefore moderate the effects of the short-term variables on voters' decision making. Thus the 'funnel of causality' model clearly puts the importance of longterm factors ahead of short-term factors which affect electoral behavior.

Party identification, a psychological attachment to a particular party, in the United States and social cleavages, as politically dividing lines in a society, in most Western 
European countries once successfully explained the voting behavior of a large majority of voters. For example, people who are not partisan or who do not self-identify with a particular social group have been found to be more likely to delay their voting decisions (Chafee \& Choe, 1980; Gopoian \& Hadjiharalambous, 1994); change their votes more often between/among elections (Mayer, 2007; Marsh, 2006); and have less motivation to go out to vote (Budge \& Farlie, 1976; Wolfinger \& Rosenstone, 1980) and so on. Before the late 1970s, these empirical findings were greatly meaningful. Since there were only a small number of people who did not attach themselves to a specific party or social group, relying on information about citizens' party identification and social backgrounds could reliably explain voters' various kinds of voting behavior. However, since the late 1970s, the increasing number of people who are not partisan, or who have a loose link to a particular social group (Dalton \& Wattenberg, 2002; Franklin et al., 2009), means that, on the basis of the same information, voting behavior can be predicted much less accurately. In addition, long-term factors such as party identification and social group attachments can tell us a great deal about why one group of citizens behaves in a given way while another group of citizens behaves differently in the same election. However, it can tell us little about why some voters' behavior varies across different elections. This indicates that we must turn to other factors, especially short-term variables, in order to have a better understanding of electoral behavior in contemporary advanced democracies. One possibility is to focus on issue cross-pressures.

Issue cross-pressures are cross-pressures emerging from holding policy preferences across various issues which push voters in conflicting political directions (Therriault et al., 2011). This shift is also important for another reason. Social psychologists long ago noticed that people were prone to experience psychological conflicts in their social lives, and concluded that people did not like inconsistency, which drives them to take actions to reduce that inconsistency. For example, Festinger (1957) developed a theory of cognitive dissonance to clarify how people behave when their cognitions (knowledge of a person's attitude, knowledge of an event, knowledge of a behavior, etc.) are inconsistent with each other. The term 'issue cross-pressures' denotes a psychological tension arising from people's conflicting voting predispositions based on their positions on different issues. Therefore, the study of issue cross-pressures in itself can be interesting, since it will add to 
our knowledge about how citizens deal with inconsistency and its influence in the field of political science. In this dissertation I will answer the following main research question:

\section{Do issue cross-pressures influence citizens' different kinds of electoral behavior, and, if so, how?}

\subsection{Issue cross-pressures: A by-product of the rise of issue orientation}

To answer the question about the influence of issue cross-pressures on electoral behavior, we should first explore the background of the emergence of issue cross-pressures. The occurrence of issue cross-pressures stems from the decline of partisan politics and the rise of importance of citizens' orientation on specific issues in arriving at their vote choices. Party identification and social cleavage have been two central concepts within the literature on voting behavior since the 1960s (Campbell et al., 1960; Lipset \& Rokkan, 1967). Party identification refers to an individual's long-standing psychological association with or opposition to a particular political party (Burden \& Klofstad, 2005; Campbell et al., 1960; Crewe, 1974; Dalton, 2004; Green \& Schickler, 1993, 2009; Miller, 1974). Political scholars have long agreed that partisanship shapes individuals' assessment of a party's or candidate's policies, affects citizens' judgment of government performance, and determine voters' voting behavior in an election (Bartle \& Bellucci, 2009; Budge et al., 1974; Campbell et al., 1960; Dalton, 2013; Green et al., 2002; Miller, 1974; Nie et al., 1979; Van der Eijk \& Franklin, 2009). Cleavage politics emphasizes the importance of cleavage structures in societies. European voters have often been described to vote according to their social background, especially their membership of religious and social classes (Lipset \& Rokkan, 1967).

However, since the 1970s the decline of partisan politics has been observed, characterized by decreasing numbers of party identifiers and the shrinking of traditional social groups such as manual workers and church-goers, as well as the erosion of the influence of party identification and social cleavages on political behavior, attitudes and evaluations (Crewe, 1992; Dalton, 2004; Dalton \& Wattenberg, 2002; Norris, 2011; Franklin et al., 2009). Many factors may account for this process of partisan dealignment, the most influential being social evolution, which mainly includes the proliferation of post- 
materialistic social and political values, the vast expansion in access to education, and the development of information and communication technology.

Post-materialistic values emphasize self-expression values, civil and political liberties, and human diversity (Inglehart, 1977; 1990; 1997; 2008; Inglehart \& Abramson, 1999; Inglehart \& Welzel, 2005). As a result, people who hold post-materialistic values are expected to be less likely to accept or welcome the influence of hierarchical social institutions such as churches, political parties and families. Due to the increased economic and physical security enjoyed by citizens following the Second World War, Western societies have seen the proliferation of post-materialist values (Inglehart, 1977, 1990, 1997, 2008; Inglehart \& Welzel, 2005). Empirical studies have found that people with postmaterialistic values are less likely to develop an identification with a particular party (Dalton, 2004, 2014; Inglehart, 1990, 1997; Norris, 2011). Therefore, cultural shift from materialist values to post-materialist values is regarded as a determinant for partisan dealignment across Western Europe.

Cognitive mobilization, which has mainly been developed by Dalton (1984, 2007, 2012, 2013), is another essential factor expected to drive the gradual decline of partisanship. As Dalton and Wattenberg (2002) write in their influential book Parties Without Partisans, "Increasing education levels have presumably improved the political and cognitive resources of contemporary electorates. With more political information available to a more educated electorate, more citizens now possess the political skills and resources necessary to become self-sufficient in politics. These changes mean that contemporary publics are less likely to defer to party elites or to support a party simply out of habit. Instead, people may question elites or resort to non-partisan forms of political expression" (p. 11). As a result, it is assumed that people with higher levels of education and political information will be less likely to identify with political parties, since they have less need for party identification as a heuristic device for meaningful engagement with the political process (Dalton, 2012, 2013; Kroh \& Selb, 2009; Schmitt-Beck et al., 2006; Van der Eijk \& Franklin, 2009).

As party identification and social cleavage have become less relevant as explanatory variables for electoral behavior, a reconsideration of models of voting behavior is needed. Social evolution across advanced democracies contributes on the one hand to the weakening of traditional ties between citizens and parties. On the other hand, it revives the 
influence of long-ignored short-term factors in electoral behavior, among them one which cannot be neglected: issues.

Campbell and his colleagues (1960) once argued that for voters to cast their vote on the basis of policy consideration, they have to meet at least three requirements:

(1) The voter must have policy preference. He or she must have opinions on which government policies should be implemented in order to solve societal problems; (2) The voter must have knowledge of the parties' policy programs and of the parties' policy records in solving societal problems; (3) The voter must compare his or her own policy preferences with the parties' policy programs and records. Then he or she must vote for the party whose policy program or record is most in agreement with his or her own preferences (p. 169-171).

Given that these requirements are fairly cognitively demanding, the role of issue orientation in citizens' electoral behavior, has been argued, would be small. For example, Converse and Dupeux (1962) revealed that the correlation between the issue positions of party identifiers and their choices of party was very modest, and almost no relationship existed between independents' positions on most issues and the party preferences they held. However, with the expansion of higher education and political information across Western European countries (Fahmy, 2006; Norris, 2001; O’Neill, 2010; Whiteley, 2012;), an increasing number of citizens seem to meet the criteria for issue voting.

When citizens enjoy more education, they will acquire more knowledge of political objects such as political systems, political parties, political polices, and other political phenomena (Hansard, 2012; Whiteley, 2012; Neuman, 1986; Luskin, 1990). In addition, higher education also improves citizens' cognitive ability, which enables them to search for, interpret and absorb political information better (Clarke et al., 2004; Norris, 2002; Sniderman et al., 1991; Verba et al., 1978). Thirdly, empirical studies have shown that education has a positive effect on citizens' interest in politics (Whiteley, 2012; Clarke et al., 2004; Verba \& Nie, 1972), which in turn drives citizens to gather more information on politics and society, thereby fostering citizens' knowledge of political matters. Finally, the revolution in communication technology, especially the Internet, has increased the 
amount of political information available, resulting in a decline in information costs. Therefore, on the one hand, the better-educated citizens will be even more politically sophisticated. On the other hand, even citizens with a lower education background but with greater political interest will have a chance to be more informed about politics.

To summarize, the expansion of education and political information, along with the decline of partisan politics, implies that there should be an increase in the importance of issues in voting choice. This has been found by political scholars in diverse countries, including the United States (Nie et al., 1979; Pomper, 1975), Great Britain (Franklin, 1985; Rose \& McAllister, 1986), and the Netherlands (Van Wijnen, 2001). Currently, although the level of issue voting is still under debate (Aardal \& Van Wijnen, 2005; Clarke et al., 2004; Lewis-Beck et al., 2008; Wessels, 2014), it is generally agreed that issues are an essential factor in citizens' voting choice. It is in this context that issue cross-pressures become possible. As defined above, issue cross-pressures refer to a psychological tension arising from people's conflicting voting predispositions based on their positions on different issues. Therefore, to experience issue cross-pressure, citizens must first take issues into considerations when they are making their voting choice. If citizens' policy preferences across various issues lead them to different candidates or parties, they will be issue crosspressured. In the next section, I will explain why I focus on issue cross-pressures in particular.

\subsection{Issue cross-pressures in electoral behavior: An overview}

Political scientists have long suspected that citizens who are subjected to conflicting political pressures behave differently from those who experience reinforcing pressures. It was Lazarsfeld and his colleagues (1944) who first introduced the concept of crosspressures into political analysis. In their famous book, The People's Choice, they studied the effects of cross-pressures arising from multiple group affiliations (they focus on three group variables: religion, social class, and urban or rural residence) on the voting decision. In studying the survey data from the 1940 presidential election in Erie, Ohio, Lazarsfeld et al. found that voters who were exposed to cross-pressures were likely to show less interest in the election, fluctuate in their voting intentions, and delay their voting decision. In line with The People's Choice was the book titled Voting, in which Berelson and his colleagues (1954) observed a similar effect of cross-pressures on individuals' voting behavior. Six 
years later, the landmark book The American Voter (Campbell et al., 1960) stated that cross-pressures had a great impact on split-ticket voting, the time when the voting decision was made and perceptions of the importance of the election outcome. In the Michigan school (see page 1), the cross-pressures arise from holding conflicting attitudes toward candidates, domestic issues and foreign affairs.

However, in the $1960 \mathrm{~s}$, interest in testing the effects of cross-pressures on voting behavior waned. One possible factor contributing to this trend was the accumulation of negative evidence, especially those subsequent studies which tried but failed to replicate the early findings, either with the same data sets or with new data (Horan, 1971; Knoke 1990; Pool, Abelson \& Pokin, 1965; Wolfinger \& Rosenstone, 1980; see also Mutz, 2002, and Brader et al., 2014, for a review). In response to these negative findings, Horan (1971) theorized that the effect of cross-pressures may be a "product of methodological errors linked to an inadequate theoretical conceptualization" (p. 659). For methodological errors, Horan meant that the traditional approach to analyzing the influence of social crosspressures did not omit the direct effects of social positions on voting behavior, and therefore overestimated the impact of social cross-pressures. In this regard, Wolfinger and Rosenstone (1980) suggested that students of political behavior should throw away the concept of cross-pressures as it was just a once-fashionable notion. Another factor, summarized by Brader et al. (2014), is "the behavioral revolution in political science, whose advocates rejected social determinism in the study of Lazarsfeld and Berelson” (p. 4). A third reason is also given by Brader and his associates (2014) in their paper of Cross Pressures Scores, in which they state that scholarly interest in cross-pressures may have diminished in part due to the poor methodologies adopted by early researchers. With this in mind, they proposed a new way to measure cross-pressures arising from social group affiliations (I will come back to this new measurement in chapter 2).

After critically reviewing half a century's work of studies of cross-pressures, Nilson (2002) wrote in the last sentence in his paper that "However, as indicated before, it seems preferable to look for a modification of the original cross-pressure thesis" (p. 359). In line with this viewpoint, more recent literatures shine a light on the role of crosspressures stemming from a different basis. Some of them focus on the effect of crosspressures emerging from heterogeneous discussion networks (Cappella, Price \& Nir, 2002; Eveland \& Hively, 2009; Huckfeldt \& Sprague, 1995; Jang, 2009; La Due Lake \& 
Huckfeldt, 1998; McClurg, 2006; McLeod, Scheufele \& Moy, 1999; Mutz, 2002; Nir, 2005; Scheufele et al., 2006; Therriault, et al., 2011). Mutz (2002) concluded that this definition and measurement of cross-pressures are more advanced than in the early studies, since

in the early studies, measurement of whether a person was experiencing cross-pressures was typically accomplished using social category memberships (...). Conflicts were defined purely at the level of social categories deemed potentially conflictual by the researchers. Actual interactions that might exert pressure on people were not documented even though interaction was generally the micro-level process assumed to be responsible for producing cross-pressures. Today several data sets that include batteries of items on individuals' political networks make it possible to test this hypothesis in a manner that allows measurement of actual (as opposed to inferred) exposures to cross-pressures and in a manner that allows insight into potential process of influence (p. 839).

However, the empirical analyses of the effect of cross-pressures arising from social networks are inconsistent. Some studies have demonstrated that cross-pressures decrease individuals' political participation (Eveland \& Hively, 2009; McClurg, 2006; Mutz, 2002; Therriault, Tucker \& Brader, 2011), while others have confirmed the positive effect of cross-pressures (Cappella, Price \& Nir, 2002; Jang, 2009; McLeod, Scheufele \& Moy, 1999; Nir, 2005; Scheufele et al., 2006). From the other direction, political scholars have shown an interest in the cross-pressures emerging from holding policy preferences across various issues, which pushes voters in conflicting political directions: namely, issue cross-pressures. As pioneers in studying issue cross-pressures, Hillyus and Shields (2008) demonstrated that more than half of partisans $(67 \%)$ disagreed with their own party but agreed with the opposite party's positions on at least one prominent campaign issue, based on survey data from the 2004 US presidential election. They also traced issue cross-pressured partisans from 1972 to 2004, and their findings showed that the proportion of partisans who are incongruent on at least one issue is consistent through nearly three decades. In the end, they concluded that "Nonetheless, across different national surveys, conducted at different times 
by different investigators, we consistently find that a substantial portion of partisans are conflicted between their party affiliation and policy issues" (p. 72).

In the same vein, relying on survey data from the 2009 European Election Study, Lefkoridi and his colleagues (2014) found that, on average, more than $20 \%$ of citizens hold left-wing economic positions and authoritarian socio-cultural views across 14 European countries. Given that parties tend either to take an economically left-wing and a socioculturally liberal stance or to combine economically right-wing with socio-culturally authoritarian views (Lefkoridi et al., 2014; Thomassen, 2012; Van der Brug \& Van Spanie, 2009), left-authoritarian citizens' stances on economic and socio-cultural ideology will lead them to different parties. As a result, left-authoritarian citizens are issue cross-pressured. The proportions of such respondents are particularly large in Greece, the Netherlands, the UK and Finland, which all exceed 27\%. They are relatively low in Germany and Denmark, at around $8 \%$.

Although a large proportion of the population may experience issue crosspressures in advanced democracies, research into issue cross-pressures and its role in electoral behavior in general is comparatively lacking. By using survey data from the 1993 parliamentary election in Norway, Narud and Valen (1996) found that voters who disagree with their own party on important issues and voters who do not suffer issue cross-pressures do not differ significantly, and the hypothesis that strong identifiers under cross-pressures tend to abstain more often than others during an election has not been confirmed. Based on survey data from the 2004 American presidential election, Hillyus and Shields (2008) demonstrated that issue cross-pressured citizens are more likely to defect during an election campaign, and are thus much more easily persuaded. Using survey data from the 2000 US presidential election, Therriault et al. (2011) confirmed that voters subjected to issue crosspressures are more indifferent between candidates, and are thus less likely to participate in political activities. Relying on the 2009 European Election Studies survey data, Wilson (2012) examined the way in which cross-pressured voters in European Parliament elections reconcile their left/right ideology and positions on European integration when they make a voting choice, and found that the salience of each dimension and the amount of available information are important for cross-pressured voters when reconciling competing ideologies to select a party in EP elections. Lefkofridi et al. (2014) studied the voting choice of citizens who hold a left-wing position on economic ideology and a right-wing 
position on socio-cultural ideology. Their findings showed that those cross-pressured citizens were more likely to vote for the left-liberal parties if they were concerned about the economy, whereas if they were worried about socio-cultural issues they were more attracted to the right-authoritarian parties.

In addition to the relative scarcity of studies on issue cross-pressures, there are several other limitations on current research. Firstly, different definitions of issue crosspressures exist, and the most reliable one has not yet been identified. For example, in the work of Narud and Valen (1996) and Hillyus and Shields (2008), issue cross-pressures are defined as what comes from disagreement with citizens' own party concerning some important issues. To Therriault et al. (2011), issue cross-pressures arise from citizens' contradictory voting predispositions based on their positions on different issues. Wilson (2012) argues that issue cross-pressures rely on citizens' positions on left-right ideology and preferences on European integration. When a citizen is close to one party on the issue of European integration but agrees with a different party on the left-right ideology, or vice versa, the citizen is issue cross-pressured. For Lefkofridi et al. (2014), issue cross-pressures lie in citizens' positions on economic and socio-cultural ideologies. When a citizen holds a left-wing position on economic ideology but a right-wing position on socio-cultural ideology, or the other way around, the citizen will experience issue cross-pressures. Among these definitions, which one is preferable has not been discussed.

Secondly, few of the existing studies on issue cross-pressures unpack the black box between issue cross-pressures and electoral behavior. Where such an analysis is attempted, it is confined to the causal mechanisms which link issue cross-pressures with one particular electoral behavior. Based on the classic model of rational turnout introduced and developed by Downs (1957) and Riker and Ordeshook (1968), Therriault et al. (2011) argue that cross-pressures might influence the likelihood of political participation through “(1) the perceived difference in utilities from each candidates' election; (2) the costs of participation for the individual; (3) the benefits to the individual from the act of participation itself' (p. 12). Therefore, issue cross-pressures may decrease the likelihood that a citizen will participate in political activities because conflicting policy preferences will lead to indifference to candidates or parties, which in turn lowers the instrumental and expressive benefits of participation. Hillyus and Shields (2008) developed a theory of persuadable voters in which they clarified why issue cross-pressured partisans were more 
likely to defect to the opposite party during an election. Building on political psychology researches, Hillyus and Shields (2008) stated that the strength of existing predispositions and the relationship between those predispositions determined whether an individual would change his/her candidate choice during a campaign. Issue cross-pressured partisans were more easily persuaded, as they have competing considerations which pull them in opposing directions. As a result, they would be more responsive to campaign information from the opposition party on those issues about which they were conflicted. Given these differing interpretations, it is clear that a systematical and concrete explanation of how issue crosspressures influence citizens' different kinds of electoral behavior is still lacking. The existing studies employ different theoretical backgrounds to explain how issue crosspressures potentially influence a particular electoral behavior.

Thirdly, different measurements of issue cross-pressures exist but almost all of them clearly have their shortcomings. For instance, the approach proposed by Hillyus and Shields (2008) calculates the number of a respondent's policy preferences that conflict with his/her party identification. The larger the number, the more issue cross-pressures a citizen experiences. However, since in many West European countries citizens do not have a stable party identification (Thomassen \& Rosema, 2009), it would be inappropriate to use this method to measure citizens' issue cross-pressures beyond the United States. In the work of Therriault et al. (2011), when calculating issue cross-pressures, they first categorize every respondent's policy preference on each issue as favoring the Republican candidate (RepPrefs), favoring the Democratic candidate (DemPrefs), or neutral. They then use the mathematical function of

$$
\begin{gathered}
\text { IPC }^{1}=1-\left|\frac{\text { DemPrefs }- \text { RepPrefs }}{\text { DemPrefs + RepPrefs }}\right| \\
\text { or } \\
\text { PVC }^{2}=\left\{\begin{array}{cc}
\frac{\text { DemPrefs }}{\text { DemPrefs }+ \text { RepPrefs }} & \text { if VotePref }=\text { Republican candidate } \\
\frac{\text { RepPrefs }}{\text { DemPrefs }+ \text { RepPrefs }} & \text { if VotePref } \neq \text { Republican candidate }
\end{array}\right.
\end{gathered}
$$

\footnotetext{
${ }^{1}$ ICP, internal policy conflict, estimates the level of conflict among the individual's policy preferences across issues. Detail description see 2.3.1 in Chapter 2.
} 
to calculate citizens' issue cross-pressures. Obviously, these mathematical functions cannot be applied in multi-party systems. Both the method used by Wilson (2012) and that employed by Lefkofridi et al. (2014) only calculate inconsistent voting predispositions based on two dimensions. Therefore, these methods will not be applicable if citizens care about three different issues. All in all, a better measurement of issue cross-pressures is needed which can be used not only in two-party systems but also in multi-party systems, and which has no preconditions regarding who may be studied and how many issues may be included.

In the fourth place, the existing studies only shed light on the role of issue crosspressures in certain kinds of electoral behavior. Narud and Valen (1996) and Therriault et al. (2011) focused on the role of issue cross-pressures in political participation; Hillyus and Shields (2008) concentrated on the effect of issue cross-pressures on changes in vote choice within elections; whilst Wilson (2012) and Lefkofridi et al. (2014) aimed to explain how issue cross-pressured citizens choose which party to vote for. However, what about the effect of issue cross-pressures on other kinds of electoral behavior, such as issue voting, time of voting decision and changes in vote choice across elections?

Finally, the existing studies of the role of issue cross-pressures have had some controversial findings: some suggest that issue cross-pressured citizens behave differently from those who experience no issue cross-pressures, while others support the opposite conclusion. For example, Narud and Valen (1996) did not find a significant relationship between issue cross-pressures and turnout. In contrast, Therriault et al. (2011) showed that issue cross-pressures decrease citizens' motivation to go out to vote. Which findings can we trust? What accounts for the inconsistent findings? As discussed before, these two studies employed different definitions and measurements of issue cross-pressures. Is this the reason? Or is it more pertinent that Narud and Valen (1996) focused on Norway while Therriault et al. (2011) concentrated on United States? Are the effects of issue cross-pressures on electoral behavior different in different political contexts? Is the role of issue crosspressures moderated by party systems?

2 PVC, policy-vote conflict, estimates the incongruence of the individual's policy preferences with their overall candidate preference. Detail description see 2.3.1 in Chapter 2 . 
From the above discussion, we can conclude that there is still a great deal to do in terms of developing the theory of issue cross-pressures and exploring the effect of issue cross-pressures on electoral behavior. This dissertation attempts to clarify whether issue cross-pressures influence citizens' different kinds of electoral behavior, and, if so, how, with a broader scope. In the next section, the specific research questions in this dissertation will be elaborated.

\subsection{Research questions}

To explore the influence of issue cross-pressures on electoral behavior, it is essential to know what issue cross-pressures are, how issue cross-pressures affect electoral behavior, and how to measure issue cross-pressures. However, as discussed in the previous section, in the existing literature on issue cross-pressures the concept and measurement of issue crosspressures and the causal mechanisms linking issue cross-pressures to electoral behavior are not well studied. Therefore, the first set of specific research questions in this dissertation are theoretical and include: (2a) What are issue cross-pressures and which existing definition of issue cross-pressures is better? (2b) What are the preconditions for citizens to experience issue cross-pressures? (2c) How do individuals' issue cross-pressures arise? (2d) How do issue cross-pressures influence citizens' different kinds of electoral behavior, including issue voting, turnout, vote switching and time of voting decision ${ }^{3}$ (2e) How should issue cross-pressures be measured? These questions will be addressed in Chapter 2.

The empirical studies of the impact of issue cross-pressures on different kinds of electoral behavior include the following four parts.

(1) Issue cross-pressures and issue voting. According to the theories of modernization and cognitive mobilization, with the decline of cleavage politics and the development of higher education and communication technology in Western Europe, there should be a boom in issue voting. However, this is not the case in reality. The level of issue voting is far from clear in the existing literature (Dalton et al., 1984; Franklin, 1985; Rose \& McAllister, 1986, 1990; Clarke et al., 2004; Aardal \& Van Wijnen, 2005; Lewis-Beck et al., 2008; Wessels, 2014). Inconsistent empirical findings have led political scholars to

\footnotetext{
${ }^{3}$ The reasons why I focus on these four kinds of electoral behavior in this dissertation are presented on pp.16-18.
} 
explore both demand-side and supply-side moderated factors (Alvarez, 1997; Alvarez \& Nagler, 2004; De Vries, 2010; Edwards III et al., 1995; Fournier et al., 2003; Krosnick, 1988; Lachat, 2009, 2011; Luskin, 1990; Moon, 1990; Palfrey \& Poole, 1987; Sniderman et al., 1993; Weisberg \& Nawara, 2010). This dissertation attempts to contribute to this body of work by examining the strength of issue voting across the levels of issue cross-pressures. Thus the second set of specific research questions in this dissertation is: (3a) Is the role of issues in citizens' voting choice moderated by their issue cross-pressures? This question will be addressed in Chapter 3.

(2) Issue cross-pressures and turnout. In response to the decline of party identification and traditional political cleavages, political scholars are increasingly turning their attention to policy issues since citizens are believed to make their voting choices based on their positions on particular issues in specific elections. In this context, the classic spatial model of abstention becomes particularly important in explaining the fluctuation in turnout. Following Downs' (1957) insight, indifferent voters-people who perceive little to no difference between any of a candidate's or party's policy positions on an issue-will be more likely to abstain. Alienated voters - citizens whose ideal position on an issue is distant from all the candidates' or parties' positions - will also be less likely to vote. These two factors can give us a good understanding of voting choices when voters only care about one issue in an election or when ideology is unidimensional. However, when voters face multiple issues, as they typically do in any election, calculating policy distances between their stances and the stances of candidates or parties is less straightforward (Humphreys \& Laver, 2010). Voters would have to locate themselves and each candidate and/or party as a separate point in multi-dimensional space based on their own and the candidates' or parties' positions on every policy issue. Then they would calculate the Euclidean distance between their own points and the candidates' or parties' points (Davis et al., 1970; Enelow \& Hinich, 1984). This kind of reasoning and calculation is complicated and demanding. This dissertation attempts to avoid the aforementioned shortcomings by studying the relationship between issue cross-pressures and turnout, and therefore offers a third factor for explaining voter abstention: issue cross-pressures that emerge due to policy alternatives provided to voters in the contemporary world. In addition, given inconsistent findings regarding the effect of issue cross-pressures on political participation in existing literature, as discussed in 
the previous section, this dissertation also examines the effects of issue cross-pressures on turnout in different political contexts. Thus the third set of specific research questions in this dissertation is: (4a) Do issue cross-pressures decrease citizens' motivation to turn out to vote? and (4b) Is the role of issue cross-pressures in turnout moderated by the party system? These questions will be addressed in Chapter 4 .

(3) Issue cross-pressures and vote switching. With elections becoming more competitive, swing voters' voting decisions are increasingly important in determining election outcomes (Mayer, 2007; Wong, 2014). Consequently, even though swing voters may only be a small segment of the whole electorate, the question of who swing voters are is increasingly relevant. In enquiring into the question of who swing voters are, political scholars provide many possible answers, but most of them are focused on social background, political sophistication and party identification (Dassonneville, 2012; 2014; Mayer, 2007; Mair, 2005; Zaller, 1992; 2004). The number of studies carried out from the perspective of issues is comparatively lower. Prior research has demonstrated the process of partisan dealignment in most advanced Western countries (Dalton, 1984; Dalton, Flanagan \& Beck, 1984; Franklin, Mackie \& Valen, 1992). This leads to the rising importance of short-term cues in voting choice, especially issues (Boyd, 1972; Dalton et al., 2000; Nie, Verba \& Petrocik, 1976; Pomper, 1972). Given that issue evaluation is one of the three most important factors in electoral studies (the others are party identification and candidate evaluation), it is worth studying citizens' vote switching behavior from the perspective of issues. In addition, among studies on vote switching, one influential explanation begins with political sophistication. Researchers have found that greater political sophistication increases the probability of inter-election volatility (Dassonneville, 2012; 2014). However, the mechanism behind this causal relationship has not been extensively studied. By focusing on vote switching from the perspective of issue cross-pressures, this dissertation attempts to contribute to our understanding of who swing voters are and why politically sophisticated citizens change their votes across elections. Therefore, the fourth set of specific research questions in this dissertation is: (5a) Do issue cross-pressures influence citizens' vote change across elections? and (5b) Is the role of issue cross-pressures in vote 
switching conditioned by different mobilization types $?^{4}$. These questions will be addressed in Chapter 5.

(4) Issue cross-pressures and time of voting decision. Since the era of democratization, there has been a long-term trend of electors delaying their voting decisions until the election campaign, or often even the final polling day (Dalton et al., 2000; Irwin \& Van Holsteyn, 2008a; McAllister, 2002; Schmitt-Beck \& Partheymuller, 2012). With the increasing number of people who delay their voting decisions, the study of who these latedeciding voters are and why citizens delay their votes has attracted the attention of many scholars (Gopoian \& Hadjiharalambous, 1994; Fournier et al., 2004; Irwin \& Van Holsteyn, 2008a; Nir \& Druckman, 2008; Kosmidis \& Xezonakis, 2010; McGregor, 2012; SchmittBeck \& Partheymuller, 2012; Orriols \& Martinez, 2014). This dissertation attempts to provide another perspective to our understanding of the characteristics of later deciders by focusing on issue cross-pressures. In addition, given that the effect of issue cross-pressures is not necessarily the same in different contexts, this dissertation also explores whether or not contextual factors moderate the role of issue cross-pressures in citizens' time of voting decision. The fifth set of specific research questions in this dissertation is: (6a) Is the time of voting decisions affected by issue cross-pressures? and (6b) Is the role of issue crosspressures in time of voting decision conditioned by political systems? These questions will be addressed in Chapter 6.

As is clear from the preceding paragraphs, this dissertation mainly focuses on the role of issue cross-pressures in the four kinds of electoral behavior: issue voting, turnout, vote switching, and the time of voting decision. The main reasons are as follows. First, the aforementioned four kinds of electoral behavior are the main kinds of political behavior across Western European countries, which have experienced a lot of change since the late 1970s. Political scholars have devoted a great deal of attention to an increasingly delayed

4 Mobilization types in this dissertation include party mobilization and cognitive mobilization. Party mobilization means that citizens are mobilized into the political process by party cues. According to Dalton (2012), cognitive mobilization means that 'more people possess the political resources and skills that better prepare them to deal with the complexities of politics and research their own political decisions without reliance on affective, habitual party loyalties or other external cues' (p.37). See detail in Chapter 5. 
time of voting decision (Dalton et al., 2002; Irwin \& Van Holsteyn, 2008; Schmitt-Beck \& Partheymuller, 2012), decreasing turnout (Cox, 2015; Dalton, 2008; Hooghe, 2014; Hooghe \& Kern, 2016; Mair, 2014; Wattenberg, 2008), higher volatility and vote switching (Bischoff, 2013; Dalton et al., 2002; Drummond, 2006; Gallagher et al., 2011; Mair, 2002, 2008; Dassonneville \& Hooghe, 2015) and an inconsistently increasing level of issue voting (Aardal and Van Wijnen, 2005). This dissertation therefore attempts to contribute to this body of work by examining whether or not issue cross-pressures influence the importance of issues in citizens' voting choice, citizens' motivation to go out to vote, vote switching across elections, and the time of voting decision.

Secondly, similar studies on social cross-pressures, attitude conflicts, and social network heterogeneity have found that individuals with inner psychological inconsistency show less interest in the election, make their voting decision later, have a less stable vote intention, are less likely to vote and rely less on issues when making their vote choice (Lazarsfeld et al., 1948; Berelson et al., 1954; Campbell et al., 1960; Mutz, 1998; Lavine, 2001; Therriault, Tucker \& Brader, 2011). As mentioned before, issue cross-pressures stem from holding policy preferences across various issues which push the voter in conflicting political directions. Even though there are differences between the concepts of social crosspressures, attitude conflicts, social network heterogeneity, political ambivalence and issue cross-pressures, they are all related to a person's internal psychological instability. In this regard, we can reasonably expect that citizens' issue cross-pressures may delay their time of voting decision, decrease their motivation to go out to vote, make them more likely to change their vote across elections and condition the role of issues in their voting choice.

Thirdly, the aforementioned four kinds of electoral behavior are the most straightforward behaviors that issue cross-pressures may have an impact on. As will be discussed in detail in Chapter 2, the theory of issue cross-pressures argues that when citizens experience issue cross-pressures, in order to make a voting decision, they will employ different methods to reconcile or alleviate their cross-pressures, including (1) reevaluating their stances on some issues, (2) looking for additional attributes related to parties and (3) reducing the importance of some issues. During this process, the role of issues in citizens' decision making may be conditioned since, as we can see, they may be bearing other factors in mind. Therefore, issue cross-pressures may moderate the role of issues in citizens' voting choice. If issue cross-pressured citizens cannot reconcile their 
cross-pressures successfully after employing the aforementioned three methods, they will continue to struggle to work out which party to vote for, which in turn may influence their motivation to go out to vote at all. In contrast, if issue cross-pressured citizens manage to alleviate their cross-pressures to a certain level, they will cast a vote. However, their voting choices will depend significantly on how they reconcile their cross-pressures. In this regard, issue cross-pressures may influence the stability of citizens' voting choice across different elections. When citizens do not experience issue cross-pressures, they can make a voting choice directly without any additional considerations, whereas when citizens are issue cross-pressured, they have to employ one or more approaches to reconcile cross-pressures in order to reach a satisfactory voting choice. This whole process obviously leads crosspressured citizens to spend much more time on decision making. As such, issue crosspressures may delay citizens' time of voting decision.

\subsection{Case selection}

In this dissertation, I chose the United Kingdom, the Netherlands and Germany-from the beginning of the 1990 s to the 2010 s - as the study's objects. There are several reasons for this selection. In the first place, these three countries are typical of advanced democracies in Western Europe in which there is a trend of the decline of partisan politics (Dalton, 2004; Dalton \& Wattenberg, 2000; Norris, 2011; Crewe et al., 1977; Franklin et al., 2009) and a rise in issue importance in voting choice (Franklin, 1985; Rose \& McAllister, 1986; Van Wijnen, 2001). In addition, as in many other Western European countries, these three countries have experienced phenomena such as the popularization of higher education, the development of Internet/computer technologies and increasing incomes and living standards, which make it easier for citizens to obtain knowledge about candidates' or parties' policy platforms. In sum, these three countries are appropriate examples to test whether or not issue cross-pressures influence citizens' various kinds of electoral behavior.

Secondly, the Netherlands and Germany are both multi-party systems, which means that more than two parties have substantial support from citizens. The United Kingdom is characterized by a two-and-a-half-party system, in which two dominant parties have a realistic chance of winning political power and a third party regularly wins sufficient representation to have a potential effect on national politics. In a multi-party system, each party has a good chance of winning political representation. Conversely, in a two- or two- 
and-a-half-party system, small parties have little chance of winning seats in parliament. Moreover, a different number of parties indicates that there are a different number of salient issues and a different extent of competition in the electoral market. All these factors imply that party systems may moderate the role of issue cross-pressures in electoral behavior. As such, selecting the United Kingdom, the Netherlands and Germany as study objects can make it possible to analyze whether the effects of issue cross-pressures are conditioned by different party systems.

The last reason is the consideration of available data. For this study, several pieces of information are needed, such as vote choice/vote intention (which party a citizen votes for and whether a citizen intends to vote or not), citizens' positions on various issues, time of voting decision, party identification and demographic backgrounds. National election studies from the United Kingdom, the Netherlands and Germany make this dissertation possible. In the next section, I will give an outline of the dissertation.

\subsection{Outline of the dissertation}

In this dissertation I investigate how and whether or not issue cross-pressures influence different kinds of electoral behavior. The dissertation consists of a theoretical part (Chapter 2) and an empirical part (Chapters 3 to 6). The theoretical part addresses a theory of issue cross-pressures, including concept, measurement and causal mechanisms linking issue cross-pressures to electoral behavior. The empirical part tests the possible role of issue cross-pressures in the different kinds of electoral behavior discussed in the theoretical part. Chapter 2 will develop a theory of issue cross-pressures and answer questions $2 \mathrm{a}$ to $2 \mathrm{e}$ : What are issue cross-pressures and which existing definition of issue cross-pressures is better? How do individuals' issue cross-pressures arise? What are the preconditions for citizens to experience issue cross-pressures? How do issue cross-pressures influence issue voting, turnout, vote switching and time of voting decision? What should be taken into account when measuring issue cross-pressures and how should they be measured? Chapter 3 answers question $3 \mathrm{a}$. It deals with issue cross-pressures and the role of issues in citizens' voting choice (i.e. issue voting). Chapter 4 answers questions $4 \mathrm{a}$ and $4 \mathrm{~b}$, examining the relationship between issue cross-pressures and turnout and investigating whether or not the role of issue cross-pressures in turnout is moderated by the party system. Chapter 5 answers questions $5 \mathrm{a}$ and $5 \mathrm{~b}$, as it studies the role of issue cross-pressures in vote switching and 
investigates whether or not the role of issue cross-pressures in vote switching is conditioned by different mobilization types. Chapter 6 answers questions $6 \mathrm{a}$ and $6 \mathrm{~b}$. It explores the influence of issue cross-pressures on citizens' time of voting decision and attempts to answer the question of whether or not the role of issue cross-pressures in time of voting decision is conditioned by political systems. ${ }^{5}$ Finally, in Chapter 7, I present the answers to all the research questions and discuss the findings and their implications.

\subsection{Contribution of the dissertation}

In recent decades, the close observation of electoral behavior has indicated tremendous shifts in almost all characteristics of voting (Wessels et al., 2014; Schmitt-Beck \& Partheymuller, 2012; Hooghe, 2014; Hooghe \& Kern, 2016; Dassonneville \& Hooghe, 2015; Dalton et al., 2002; Franklin et al., 2009). Bartels (2010) even concludes that "contemporary voting research has become increasingly eclectic and opportunistic" (p. 251252). Facing changes and instabilities in electoral behavior across Western Europe, traditional party identification and social cleavages perform increasingly poorly in understanding and explaining the way in which voters make their voting choices. In order to achieve a better understanding of electoral behavior in contemporary advanced democracies, we must turn to other factors. In this vein, this study develops a theory of issue cross-pressures. As discussed before, issue cross-pressures are the by-product of the decline of partisan politics and the increasing importance of issue orientation in electoral behavior. It argues that contemporary Western European citizens may care about multiple issues and their positions on these issues may not all point in the same political direction. When citizens' positions on different issues lead them to different parties - when they are issue cross-pressured - their voting behavior will be different from those whose issue preferences point to a single party. Therefore, the theory of issue cross-pressures offers us a new perspective from which to understand citizens' electoral behavior.

Furthermore, given the fundamental position of elections in democracy (Barber, 2003; Benbabib, 2004; Dewey, 2004; Downs, 1957; Przeworski, 1991; Schumpeter, 2013),

\footnotetext{
${ }^{5}$ The logic of the sequence of Chapter 3 to Chapter 6 may excite curiosity. For example, why does the study of issue cross-pressures and issue voting come before the study of issue cross-pressures and turnout? The reasons are discussed in detail in section 2.2 of Chapter 2 . Briefly, the sequence of Chapter 3 to Chapter 6 is based on the way in which issue crosspressured citizens arrive at their voting decisions.
} 
instabilities and changes in electoral behavior have led scholars of democracy to question whether the quality of representative democracy is experiencing an ongoing erosion. Inglehart and many other political scholars have highlighted the role of transformation in the nature of the demand side of politics (Inglehart \& Welzel, 2009; Norris, 2011; Dalton, 2013). They argue that it is the change in contemporary citizens' expectation and ability which mainly results in their political behavior becoming unstable. If the change in electoral behavior is because of culture shift and cognitive mobilization, we should observe the influence of citizens' issue considerations on voting behavior, which has long been thought by political scholars to be fairly demanding on political resource and skills (Campbell et al., 1960). Therefore, it is quite possible that issue cross-pressures which arise from citizens' issue considerations in arriving at their voting choice will influence electoral behavior. As such, exploring the impact of issue cross-pressures on electoral behavior will contribute to an understanding of the widespread change in electoral behavior across West European countries. It also sheds light on how we should assess the quality of representative democracy and how advanced democracies can cope with the challenges they face in terms of increasing instability in electoral behavior.

Finally, social psychologists have long ago noticed that people were prone to experience psychological conflicts in their social lives, and concluded that people did not like inconsistency, which drives them to take actions to reduce that inconsistency. The theory of issue cross-pressures adds to our knowledge about how citizens deal with inconsistency in the field of political science. 


\section{2-A Theory of Issue Cross-pressures}

The main purpose of this chapter is to develop a theory of issue cross-pressures which will clarify what they are and which existing definition of issue cross-pressures is better; the preconditions for citizens to experience issue cross-pressures; how individuals' issue crosspressures arise; how issue cross-pressures influence citizens' different kinds of electoral behavior; and how issue cross-pressures should be measured. The next section will first discuss the concept of issue cross-pressures.

\subsection{What are issue cross-pressures?}

\subsubsection{Defining issue cross-pressures}

The definition of issue cross-pressures is commonly based on the initial work by Lazarsfeld and his co-workers (1968). Imagine an individual whose Catholic identity makes him/her more likely to vote Democratic in the US, while belonging to the middle class pushes him/her toward voting Republican. By Lazarsfeld et al.'s definition, this middle-class Catholic is cross-pressured. Following the work of the Columbia school, Campbell et al. (1960) described cross-pressures as attitude conflicts, which they defined as inconsistencies among individuals' attitudes toward various political objects. In Campbell et al.'s sense, attitude diversity could create psychological conflict within an individual. As an example, they suggested that those who liked Eisenhower but disliked the Republican position on foreign policy were cross-pressured. The other important concept we can refer to is political ambivalence, which also generates conflict within an individual's psychological field. When a person holds both positive and negative feelings, evaluations, beliefs, or emotions about political objects, such as candidates, parties, or issues, we can describe that person as being politically ambivalent (McGraw et al., 2003). From the above description, we can draw the conclusion that there are several dimensions in people's minds, and when these dimensions point in different directions, people will experience conflicting feelings. Moreover, according to the same logic of these three concepts, it is safe for us to expect that, when issues push voters toward inconsistent candidates or parties, they will suffer inner psychological conflicts, the so-called issue cross-pressures. 
There are two modern definitions that fit the expectation of what issue crosspressures are. The first one is from Hillyus and Shields (2008), who define policy crosspressures as from the result of disagreement with a voter's affiliated party across a range of issues. For example, in the context of the United Kingdom, imagine a voter who is a Conservative identifier. On the taxation issue, however, he/she approves Labour's position rather than the Tory stance. By definition, this voter will experience policy cross-pressures. The obvious limitation of Hillyus and Shields' definition is that it excludes those who do not identify with a party. With the widespread decline of partisan affiliation in contemporary western democracies, this exclusion would confine studies to a very small group of voters. The second definition is from Therriault et al. (2011). They defined issue cross-pressures as emerging from holding policy preferences across various issues that push one in different directions politically. Taking the example of the United Kingdom again, a voter's position on the issue of immigration may point to the Conservative party, while on the taxes issue, the voter prefers Labour. In this situation, such a voter is regarded by Therriault et al. as an issue cross-pressured citizen. This study follows the definition of Therriault et al., mainly because this definition is only concerned with individuals' issue positions, and has no preconditions for who can be studied.

\subsubsection{The preconditions of issue cross-pressures}

Although there will be no preconditions for who can be studied if we follow Therriault et al's definition of issue cross-pressures, there are preconditions for a citizen to experience issue cross-pressures. First, citizens' opinions on different issues should not be comprehensively constricted by a unidimensional ideology. In his landmark book $A n$ economic theory of democracy, Downs (1957) proposed the assumption that citizens behave rationally in politics. They strive to maximize their expected personal utility and minimize any involved costs. Due to the high costs of gaining information in order to form policy preferences and to become acquainted with parties' positions on issues, citizens are inclined to see ideology as heuristic. In Downs' view, ideology has only a single dimension, and therefore the issue positions of parties and voters can be reduced to points on a continuum. As such, voters' issue positions are determined by their ideological orientations, as well as by voter-perceived party positions on issues. If this is the case, we can expect that 
citizens will not experience issue cross-pressures, as their issues preferences are constrained by an ideological dimension, which in turn will lead them to a single party.

Empirical studies on the one hand have shown that although there is a group of ideological voters (around 10\%), many more citizens (around 90\%) do not judge parties in ideological terms (Campbell et al., 1960; Converse, 1964). This indicates that citizens' policy-oriented voting behavior is not simply determined by ideological orientations. On the other hand, studies of political ideology have demonstrated that voters' preferences on various issues, especially on social issues and economic issues, were relatively independent of each other, leading to the conclusion that the belief systems of the mass public are multidimensional rather than unidimensional. Voters who hold conservative preferences on one dimension and liberal preferences on another were thought to be under cross-pressures (Feldman, 2003; Feldman \& Johnston, 2009; Swedlow \& Wyckoof, 2009; Treier \& Hillygus, 2009). These studies together imply that a majority of contemporary citizens meet the first precondition.

Secondly, citizens should care about at least two different issues. If citizens are only concerned about one issue, they will not experience issue cross-pressures. For example, in the context of the Netherlands, imagine a voter who only cares about the issue of immigration, and the distribution of the voter's position and parties' positions on this issue are as in Figure 2-1. According to the proximity theory of issue voting, which states that voters will vote for the party whose position is closest to theirs on an issue, the voter will vote for the VVD (People's Party for Freedom and Democracy). If the voter makes a voting choice based on the directional theory of issue voting, which argues that voters will vote for the party that espouses the same opinion as they do on a given issue and with the strongest intensity, the voter will vote for the PVV (Party for Freedom). As we can see, no matter which model of issue voting the voter relies on, they can only have one clear party preference on the immigration issue, either VVD or PVV. Therefore, the voter will experience no issue cross-pressures. 
Figure 2-1: Positions distribution on the issue of immigration

Issue of Immigration

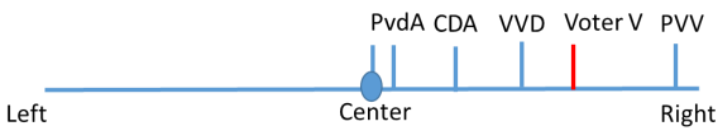

In contrast, if the voter also cares about a second issue, such as the issue of income difference, they may experience issue cross-pressures. For instance, if the voter decides based on the proximity model of issue voting, he/she will clearly vote for the CDA (Christian Democratic Appeal) on the basis of the voter's position on the issue of income difference (see Figure 2-2). Therefore, the voter's positions on the issue of immigration and income difference push him/her toward the VVD and CDA respectively. If the voter relies on the directional model of issue voting, his/her policy preference on the issue of taxes will lead him/her to vote for the PvdA (the Labour Party). As such, the voter's positions on those two issues point to two different parties, namely the PVV and PvdA. From the discussion, we can see that no matter whether the voter follows the proximity theory or the directional theory of issue voting, they will experience issue cross-pressures. In summary, it is only when citizens care about two different issues that they may experience issue crosspressures.

Figure 2-2: Positions distribution on the issue of income difference

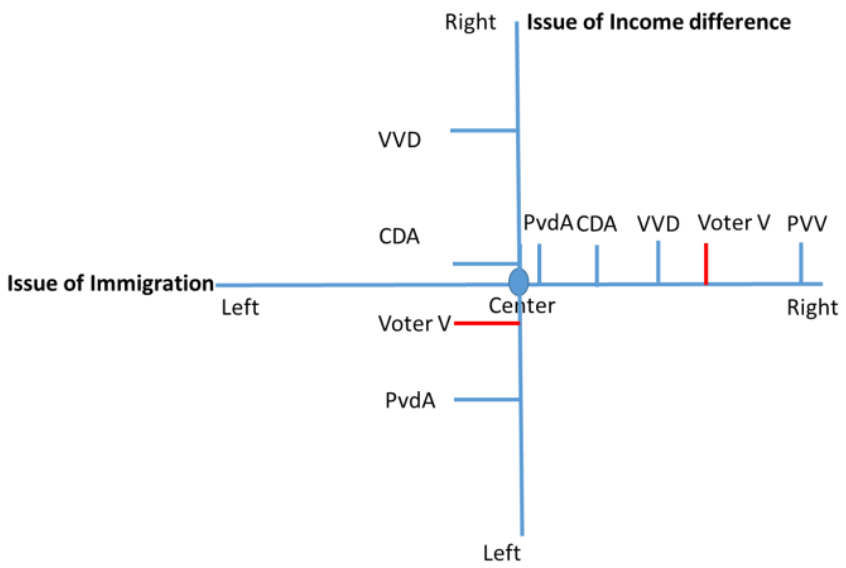


Modernization theories suggest that with the increased economic and physical security in citizens' environment since 1945, there has been a shift in the political values they hold (Inglehart, 1971, 1990,1997, 2008; Inglehart \& Welzel, 2005). Citizens increasingly emphasize factors such as their quality of life, individual freedoms, the environment and lifestyle choices. However, this does not mean that materialist issues totally go away (Inglehart \& Welzel, 2005). Especially when an individual's economic situation is threatened, or in times of financial or security crisis, materialist issues can become salient again. All in all, it is safe for us to conclude that citizens' issue concerns in contemporary Western Europe may be diversified, which in turn may trigger them to experience issue cross-pressures.

\subsubsection{How do issue cross-pressures arise?}

After defining the concept of issue cross-pressures and clarifying the preconditions of issue cross-pressures, one question still remains: how do issue cross-pressures arise? Why do some people suffer from issue cross-pressures while others do not? Two possible explanations exist. The first arises from a psychological perspective. Many scholars have suggested that core values play an important role in structuring people's policy preferences (Hurwitz \& Peffley, 1987; Feldman, 1988; Feldman and Zaller, 1992; Peffley \& Hurwitz, 1993; Sniderman \& Piazaa, 1993). Feldman and Zaller (1992) found that core beliefs about humanitarianism, individualism, and the proper role of government contributed significantly to voters' views on social welfare issues. Hurwitz and Peffley (1987) suggested that core beliefs about militarism and authoritarianism were significant factors in shaping citizens' attitudes to foreign affairs and defense. Since values are assumed to be chronic and stable cognitions, it is safe to say that core values in citizens' minds are hard to change. In this regard, when citizens' core values structure their views on specific political issues which, in turn, lead them toward different candidates or parties, we would say that such voters may suffer from inner conflicts or, according to our definition, issue crosspressures.

The second explanation comes from Downs (1957). Assuming that voters are rational and tend to pursue the maximization of self-interest, when making their voting choices they will examine the utility they would gain from each of the candidates or parties, and vote for the one that benefits them the most. Imagine a voter in the Dutch context who, 
on the issue of tax, wants to vote for the PvdA, as this party offers him the most benefits. However, on the issue of immigration, for the same reason, this voter prefers to vote for the PVV. In this situation, if this voter chooses the PvdA, they can get what they want on the tax issue but will lose what is offered by the PVV on the issue of immigration, and vice versa. In short, for this voter, getting one kind of benefit comes at the cost of forgoing the other. This benefit conflict causes discomfort for individuals, resulting in what we term issue cross-pressures.

People may be curious about why the clinical calculation of the rational voter in terms of costs and benefits can result in cross-pressures. Following Downs' insight, if a voter agrees with PvdA on issue of tax and with PVV on the issue of immigration, this does not necessarily lead to any cross-pressures, but only results in some extra calculation: which party will generate the highest utility on issue of tax and immigration? In other words, voters would have to locate themselves and each candidate and/or party as a separate point in two-dimensional space based on their own and the candidates' or parties' positions on every policy issue. Then they would need to calculate the Euclidean distance between their own points and the candidates' or parties' points (Davis et al., 1970; Enelow \& Hinich, 1984). However, this kind of reasoning and calculation is complicated and demanding. Therefore, when voters face multiple issues, as they typically do in any election, calculating policy distances between their stances and the stances of candidates or parties is less straightforward (Humphreys \& Laver, 2010). The theory of issue crosspressures addresses that when facing more than one issue, voters may consider each issue separately and look at which party best represents them on that issue, rather than seeking a multi-dimensional fit. When voters' positions on different issues lead them to different parties, they may experience issue cross-pressures.

\subsection{Issue cross-pressures and electoral behavior}

The above discusses issue cross-pressures in itself; this section will connects issue crosspressures to citizens' electoral behavior. How do issue cross-pressures influence electoral behavior? To answer this question, we need to open the black box between issue crosspressures and electoral behavior. Or, in other words, we should clarify how issue crosspressured citizens will arrive at their final voting decisions. There are two existing schools 
of thought on this topic. One is the cognitive dissonance theory, and the other is the information processing theory. The discussion will begin with the former.

\subsubsection{A perspective from cognitive dissonance theory}

Festinger (1957) in his famous book A Theory of Cognitive Dissonance, argued that when people believe that two of their cognitions are inconsistent with each other, a state of cognitive dissonance occurs, which is experienced as uncomfortable tension. Cognition is defined as "any piece of knowledge a person may have. It can be knowledge of a behavior, knowledge of one's attitude, or knowledge about the state of the world" (Cooper, 2007, p. 6). According to Festinger, cognitive dissonance is commonly experienced by ordinary people in their social life. For example, imagine that you spent several hours preparing a dinner in anticipation of a pleasant evening. However, what you observed during the dinner was that your guests seemed not to like the food you cooked and much of it was left over. Therefore, the expectation of a great time you were going to have is discordant with your observation of the evening. The inconsistency between your expectation and your experience makes you feel upset. It is the unpleasant state of cognitive dissonance.

Once dissonance is aroused, Festinger further argued, people will take actions to reduce it. Several ways are recommended, beginning with changing some attitudes. In order to reduce dissonance, the most straightforward way is to reduce the discrepancy between two cognitions. Taking the previous case as an example, if the host comes to believe that the guests could not finish their food because the host had cooked too much, the cognitive dissonance will be reduced and the host's feeling will be better. A second recommendation is trying to add consonant cognitions. Dissonance arises because of the discrepancy between the two most relevant cognitions, but it is also influenced by other factors. For example, even though the host finds that the guests do not like the food very much, it is clear that the guests do like the music arranged for the dinner. The host may therefore expect that the guests still enjoyed the evening, regardless of unsatisfactory food. As such, the dissonance is reduced by adding cognitions that are consonant with one of the discrepant cognitions. Thirdly, a person suffering cognitive dissonance could try reducing the importance of some attitudes. The cognitive dissonance is not only determined by the extent of the discrepancy between two cognitions, but also by the importance of the discrepant cognitions. The more important the discrepant cognitions, the more cognitive 
dissonance will be experienced. Therefore, reducing the importance of one of the discrepant cognitions is another way to reduce dissonance. For instance, in the previous example, if the host lowers her expectation of the dinner and treats it just as an ordinary gathering, she may not feel as upset. These are three ways for people to reduce their discomfort when their two cognitions are inconsistent with each other.

With regard to issue cross-pressured citizens, this dissertation argues that they too may employ the three aforementioned methods in order to make a decision. For example, imagine that there is a person $\mathrm{V}$ who realizes that he/she likes party A's stance on economic issues, which leads him/her to vote for party A. On the other hand, on social issues, person $\mathrm{V}$ perceives that party B's stance is more to his/her taste, which pushes him/her toward party B. By definition, the person $\mathrm{V}$ is issue cross-pressured. In order to make a decision, the person $\mathrm{V}$ has to eliminate or at least reduce this kind of cross-pressure. As discussed above, the person $\mathrm{V}$ can (1) re-evaluate his/her own opinion on economic issues to make it more closely resemble party B's position, or re-evaluate his/her own opinion on social issues so that they favor party A's position (changing some attitudes); (2) look for other attributes of party A or party B which he/she really likes, such as an attractive leader or party identification. (adding consonant cognitions); (3) reduce the importance of economic issues or social issues in his/her own mind, and therefore enhance his/her motivation to vote for Party B or Party A (reducing the importance of some attitudes).

\subsubsection{A perspective from information processing theory}

The second school of thought we can refer to in understanding how issue cross-pressures will influence electoral behavior is an information processing theory in political psychology. Lau and Redlawsk (2006) proposed an information processing theory of voter decision making in the book titled How Voters Decide-Information Processing during Election Campaigns. Given that most citizens have cognitive limitations (Simon, 1976; Taylor, 1981; Fiske \& Taylor, 1991), Lau and Redlawsk (2006) argue that it would be better for a theory of voter decision making to focus on how decisions are made using information search and strategies for making choice, compared with the traditional theory of rational choice. In the thesis of Lau and Redlawsk, decision strategies are a key part of decision making and include identifying alternatives, searching for information about them, and identifying a method for making a choice. Reaching a decision, according to Lau and Redlawsk, can be 
seen as a process of avoiding conflict by using different decision strategies. Lau and Redlawsk distinguished two different situations in making a decision. In the first, one alternative is preferred to all other alternatives on every dimension of judgement, and hence there will be no conflict in making a decision. In the second situation, one alternative is preferred on one dimension of judgement but a different alternative is preferred on another dimension of judgement, which creates the potential for tradeoffs. In the opinion of Lau and Redlawsk, the later situation is much more common in an electoral setting (p.30). When citizens experience conflicts in making decision, as Lau and Redlawsk suggest, they can employ different decision strategies, the most important of which are compensatory strategies (p.39).

\begin{abstract}
"Compensatory strategies are cognitively complex information integration rules where decision makers are assumed to assign a value to every salient attribute associated with each alternative. Some of those values can be positive, and others negative, but when they are combined into an overall evaluation or decision, a positive value on one dimension can compensate for or trade off against a negative values on another dimension. Conflict is confronted and resolved in the process of integrating the positive and negative information or values associated with a choice." (p. 31).
\end{abstract}

Depending on the amount of information citizens can take into account in making a decision, there are different specific compensatory strategies. For rational voters, who are willing to spend time and effort to gather as much information as possible, the strategies of the Weighted Additive (WAdd), the Expected Utility Rule (EU) and Additive Difference Rule (AddDif) are proposed (see Lau \& Redlawsk, 2006, pp. 265-270). The basic ideas behind these strategies are that decision makers will search and consider all relevant attributes or outcomes, such as personality, background, party attachment and issue positions. For example, by using WAdd strategy, a voter will learn everything there is about a particular candidate or party, associating a subjective utility and an importance weight to every attribute, and calculating an overall evaluation of the candidate once all the information is gathered. The voter will repeat the process for every candidate or party and 
choose the one got best evaluation (based on utility and importance weight). For limited information processors, simpler and less cognitively demanding compensatory strategies are recommended, such as Take the Few Best (FweBest) (see Lau \& Redlawsk, 2006, pp. 270-272). This strategy suggests that instead of searching and considering all relevant attributes about a particular party, a citizen can take few of them, which he/she cares most, into consideration. If these 'few' attributes point to two or more parties, the citizen will be in a dilemma therefore cannot make a decision. In order to have a clear party choice, the citizen will reconsider the attributes that initially examined, reweight their importance or even eliminate one or more of them.

By definition, issue cross-pressured citizens are those who prefer different parties on different policy issues, and therefore cannot make a coherent decision. In other words, they experience conflict on the dimension of issues. This dissertation argues that issue cross-pressured citizens can also employ compensatory strategies in order to make a decision. According to what Lau and Redlawsk (2006) suggested, issue cross-pressured citizens can take other relevant attributes into account, not only issues but also factors such as political experience, personal personality and party identification. Or they can reevaluate the importance of different issues and make a decision based on these new evaluation.

\subsubsection{How do issue cross-pressures influence electoral behavior?}

As discussed in Chapter 1, few of the existing studies on issue cross-pressures unpack the black box between issue cross-pressures and electoral behavior. Of those that do, they are confined to the causal mechanisms which link issue cross-pressures with one particular electoral behavior, such as turnout (Therriault et al., 2011), or changes in vote choice between elections (Hillyus and Shields, 2008). A systematic and concrete theory on how issue cross-pressures influence citizens' different kinds of electoral behavior is still lacking. This section offers an explanation of how issue cross-pressures influence electoral behavior with a broader scope, based on what was discussed in the previous two sections. It is summarized in Figure 2-3 and clarified in more detail in the following paragraphs.

When citizens realize that their positions on different issues lead them to two or more parties, they will experience issue cross-pressures, which in turn drives them to reduce these pressures in order to make a voting decision. Based on what has been 
suggested by the cognitive dissonance theory and the information processing theory discussed in the previous two sections, there are several ways for issue cross-pressured citizens to reconcile cross-pressures generated by their issue preferences. They may reevaluate their own stances on different issues to make certain that their issue positions point to a single party. They may reduce the importance of one or several of the discrepant issues to ensure that their positions on the most important issues lead them to a same party. They may take several or all relevant attributes of the parties into consideration, such as the personality and political experience of party leaders, party performance in government or party identification, to make themselves favor a particular party more. As we can see, if citizens who experience issue cross-pressures take the third way to reconcile their crosspressures, the role of issues in decision making might be largely moderated, since many other factors are taken into consideration. Therefore, the first potential effect of issue crosspressures is to moderate the role of issues in citizens' voting choice. Chapter 3 will explore this potential effect and examine whether or not issue cross-pressures condition the level of issue voting.

Figure 2-3: Issue cross-pressures and electoral behavior

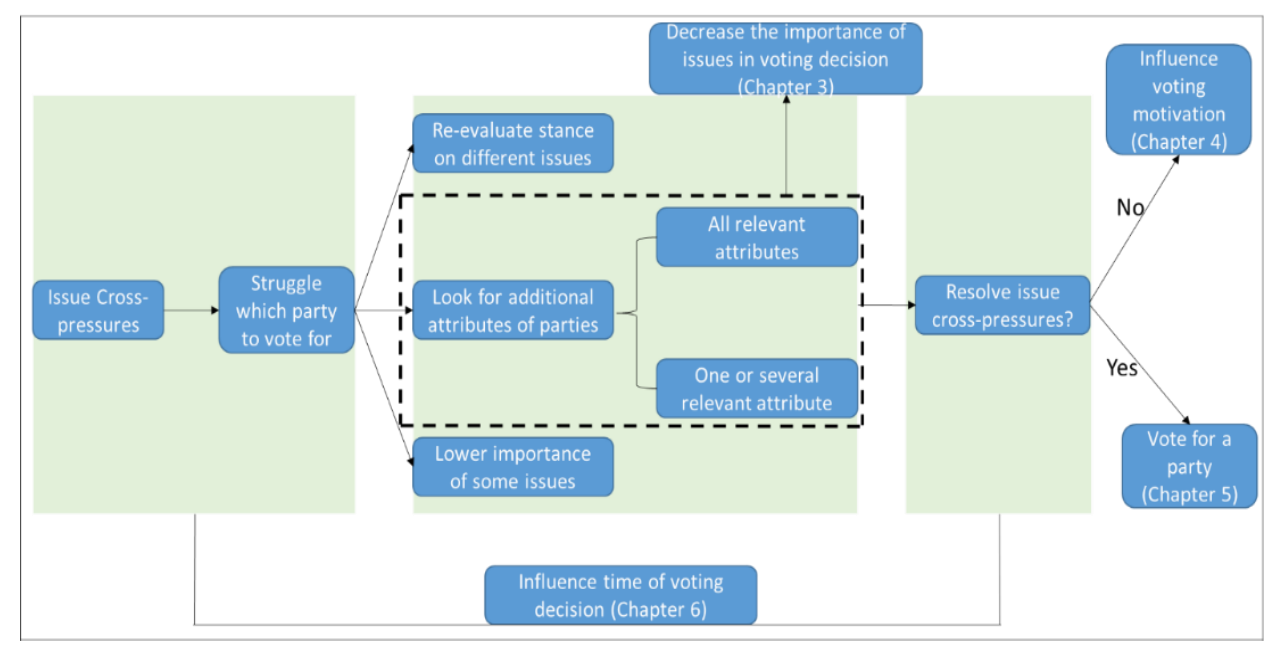

Even though issue cross-pressured citizens can use the above three ways to reconcile or alleviate their cross-pressures, they may not succeed. For example, citizens' opinions on particular issues may not be easily changed, or citizens may care about two or 
more issues equally, meaning that the importance of a particular issue may not be decreased. Alternatively, citizens may only care about parties' policy platforms, and as such other factors cannot enter into their considerations in making their voting decision. In this regard, since issue cross-pressures cannot be alleviated, those citizens will keep on struggling with the decision about which party to vote for, which in turn may influence their motivation to cast a vote. As such, the second potential effect of issue cross-pressures is to decrease citizens' motivation to turn out to vote. Chapter 4 will examine this possible phenomenon and test the causal relationship between issue cross-pressures and turnout.

Nevertheless, issue cross-pressured citizens can also reconcile cross-pressures arising from their issue preferences after employing the above three approaches. In this situation, they will go out to vote for a particular party. However, since their voting choices depend on how they alleviate their cross-pressures in specific elections, the voting choice of issue cross-pressured citizens across elections might be more unstable compared to those whose issue positions push them toward a single party. In this regard, the third potential effect of issue cross-pressures is to influence the stability of citizens' voting choices across different elections. It is addressed and tested in Chapter 5.

When citizens do not experience issue cross-pressures, they can make a voting choice directly without any additional considerations. In contrast, as we can see in Figure 23, when citizens' issue positions lead them to several parties, they have to employ one or more approaches to reconcile cross-pressures in order to reach a satisfactory voting choice. This process obviously leads issue cross-pressured citizens to spend much more time, and therefore to delay the decision about how to vote. As such, the fourth potential effect of issue cross-pressures is to delay the time of citizens' voting decision. Chapter 6 explores the relationship between issue cross-pressures and the time of the voting decision.

Finally, when citizens care comparatively equally about several issues, and when their positions on these issues more clearly lead them to different parties, it is apparent that those individuals will find it more difficult to reconcile their cross-pressures. Therefore, this dissertation argues that issue cross-pressures have a certain magnitude. The more issue cross-pressures citizens experiences, the more likely it is that they will delay the time of their voting decision, change their vote choice between two elections, give up on going out to vote and rely less on issues to make a voting choice. In addition, if we accept that issue cross-pressures have magnitude, it would be interesting to explore whether or not 
contextual factors influence a given citizen's level of issue cross-pressures. This dissertation focuses on party systems. On the one hand, when there are more available parties in an election, citizens may be more likely to experience issue cross-pressures. On the other hand, the different distributions of parties imply different chances to win a seat in parliament, which may moderate the role of issue cross-pressures in electoral behavior. In Chapters 4 and 6 this point is especially clarified.

Before moving on, one thing needs to be mentioned. The theory of issue crosspressures developed in this dissertation only concerns four kinds of electoral behavior: issue voting, turnout, vote switching, and time of voting decision. However, it does not mean that the theory of issue cross-pressures developed here can only be used to explain those four kinds of electoral behavior. It focuses on these behaviors because they are the most straightforward that issue cross-pressures may have an impact on. For other electoral behavior, other factors may need to be considered. For example, issue cross-pressures may also influence split-ticket voting. When issue cross-pressured citizens cannot reconcile their cross-pressures after employing the three aforementioned approaches, they may split their votes in order to make a choice. However, this is only possible when voters have two votes in an election, as is the case in Germany, or when different levels of elections are held at the same time, as in the United States.

\subsection{Measuring issue cross-pressures}

\subsubsection{Existing potential measurements for issue cross-pressures in the literature}

After describing what issue cross-pressures are and how issue cross-pressures will influence citizens' various kinds of electoral behavior, this section discusses how to measure issue cross-pressures. There are five potential measurements in recent studies on cross-pressures.

- The approach of Campbell et al. (1960), which includes three steps:

(1) Dividing respondents into different levels of partisan attitudes, based on how many of the six partisan attitudes the person reported in the survey; ${ }^{6}$

\footnotetext{
${ }^{6}$ This approach refers to the US election of 1956 between Eisenhower and Stevenson. The six partisan attitudes are citizens' attitudes on the personal attributes of Stevenson; the personal attributes of Eisenhower; the groups involved in politics and the questions of group interest affecting them; issues of domestic policy; issues of foreign policy; and the
} 
(2) Excluding people with attitudes on all six dimensions, since there are not enough cases, and people with an attitude on only one dimension or on none, because these people have little chance to experience conflict;

(3) Measuring individuals' degree of attitude conflict by calculating comments the person made in the Democratic and Republican directions across different levels of partisan attitudes. If the partisan attitude tended to point in the same direction, a degree was added; if it pointed in the opposite direction, one was subtracted. In this regard, at each level of partisan attitude, the smaller the score is, the greater the conflict people suffer. As we can see, when replacing attitudes to six classes of political objects with attitudes on different issues, this method can be used as a way to calculate issue cross-pressures.

- The approach of Hillygus and Shields (Hillygus, 2008), which calculates the number of respondents' policy preferences that conflict with their party identification. More specifically, it includes four steps:

(1) Limiting the estimate of policy incongruence to the set of issues on which the candidates or parties held divergent positions;

(2) Restricting the analysis to only those respondents who are self-reported partisans and excluding those who are independent leaners or self-identified independents;

(3) Treating individuals who selected a middle, neutral, or don't-know category in a given question-response format as being congruent with their party affiliation;

(4) Calculating policy incongruence only if an individual stated the personal importance of this issue.

- Two approaches proposed by Therriault and his colleagues (Therriault et al., 2011).

comparative record of the two parties in managing the affairs of government. (see Campbell et al., p. 67). 
- The first measurement, internal policy conflict (IPC), estimates the level of conflict among the individual's policy preferences across issues (p. 12). It involves two steps:

(1) categorizing every respondent's policy preference on each issue as favoring the Republican candidate, favoring the Democratic candidate, or neutral;

(2) creating the mathematical function of IPC $=1-\left|\frac{\text { DemPrefs }- \text { RepPrefs }}{\text { DemPrefs + RepPrefs }}\right|$ to calculate individuals' issue cross-pressures. In this regard, a result of ' 1 ' indicates the highest cross-pressures an individual has since it implies equal policy preference favoring each candidate. A result of ' 0 ' denotes the lowest crosspressures an individual suffers because it implies that all non-neutral policy preferences favor the same candidate (p. 13).

- The second measurement, policy-vote conflict (PVC), estimates the incongruence of the individual's policy preferences with their overall candidate preference ( $\mathrm{p}$. 12). It also involves two steps:

(1) categorizing every respondent's policy preference on each issue as favoring the Republican candidate, favoring the Democratic candidate, or neutral;

(2) creating the mathematical function of PVC $=\left\{\begin{array}{ll}\frac{\text { DemPrefs }}{\text { DemPrefs }+ \text { RepPrefs }} & \text { if VotePref }=\text { Republican candidate } \\ \frac{\text { RepPrefs }}{\text { DemPrefs }+ \text { RepPrefs }} & \text { if VotePref } \neq \text { Republican candidate }\end{array}\right.$ to calculate individuals' issue cross-pressures. In this measurement a result of ' 1 ' also indicates the highest cross-pressures since it implies that all non-neutral policy preferences favor the non-preferred candidates. The result of ' 0 ' denotes the lowest cross-pressures because it implies that all non-neutral policy preferences favor the preferred candidate (p. 14).

- The approach suggested by Brader and his colleagues (Brader et al., 2014). In the paper of Cross Pressure Scores, Brader et al. presented a new approach to estimating cross-pressures emerging from one's social strata and group memberships. There are four steps in total (pp. 8-9 and Figure A1 in the online appendix): 
(1) Regressing individuals' party preferences based on their demographic characteristics in order to capture the relationship between these variables;

(2) Based on the result of step 1, generating predicted probabilities of preferring each party or candidate for each respondent in order to estimate the extent to which an individual's particular social strata and group memberships push them toward one or the other partisan preference;

(3) Calculating the absolute difference/standard deviation in predicted probabilities across each party for each respondent;

(4) Subtracting the difference in step 3 from ' 1 ' so that higher scores correspond with greater cross-pressures. This result is the respondent's social crosspressure score. ${ }^{7}$ Although this approach is used to calculate cross-pressures stemming from individuals' social backgrounds, as we will see below, it can be modified to calculate cross-pressures arising from citizens' policy preferences.

${ }^{7}$ In their online Appendix, the authors share the specific steps used to calculate crosspressures scores in different-sized party systems. They are presented in the following way: (1) For a two-party system, taking the 2004 US election as an example, the process is:

- Modeling the presidential vote for major-party voters (coded $1=$ Kerry, $0=$ Bush) as a function of demographics using a binary logit regression.

- Using these regression results to predict the probability of voting for Kerry for each respondent, then to calculate the probability of voting for Bush $(1-\mathrm{p}$ (vote=Kerry)).

- Calculating the absolute difference between these probabilities, which ranges from ' 0 ' (equal probability of voting for each) to ' 1 ' (certain to vote for one candidate).

- Subtract this difference from ' 1 ' so that higher values indicate more equal probabilities. The resulting quantity is the respondent's CP score.

(2) For systems which include more than two parties, variations of this procedure are employed as described below:

- More than two parties, "top-2 variance" method: Use a multinomial logit regression in step 1 above, with party identification (CSES) or legislative vote choice (PNES) as the dependent variable; use the results to predict probabilities of supporting each party in step 2; across all predicted probabilities, determine the two highest for each respondent and use those in steps 3 and 4.

- More than two parties, "top-3 variance" method: As above for steps 1 and 2; in step 3, determine the three highest predicted probabilities for each respondent and take the standard deviation across them; in step 4, scale this quantity from 0 to 1 , then subtract it from 1 to generate each respondent's CP score.

- More than two parties, "full variance" method: Same as previous for steps 1, 2, and 4; in step 3, take the standard deviation across all parties' predicted probabilities for each respondent. 


\subsubsection{The regression-based measurement of issue cross-pressures}

The above section discusses five potential measurements of issue cross-pressures in the existing literature; this section will describe the main measurement of issue cross-pressures used in this dissertation. As described in the previous section, issue cross-pressures are those that emerge from citizens' policy preferences across various issues. Individuals may feel attracted or pushed to vote for one political party or another when it comes to their positions on specific issues. For instance, if a person's positions on more than two issues lead to a similar direction politically, the voter is more likely to experience reinforcing pressures. Conversely, if the person's positions on various issues point to different directions politically, the individual is more likely to feel conflicting pressures. Therefore the measurement of issue cross-pressures should capture the extent to which a person's issue positions is likely to generate reinforcing or conflicting feelings. The main measurement of issue cross-pressures used in this dissertation is deduced from the approach proposed by Brader et al. (2014), and the process is as follows:

(1) Regressing individuals' party preferences based on their positions on various issues. This step is the foundation of an estimate of whether an individual's issue positions generate consistent or inconsistent partisan pressures. Apparently, voters' policy preferences regarding various issues and their party preferences are independent variables and dependent variables respectively in this step. As a result, to measure citizens' issue cross-pressures, we need to select issues firstly. Generally, there are two kinds of issues. There are position issues, on which several controversial standpoints exist, and there are valence issues on which citizens share the same view, though their evaluations of the parties' competency to deal with said issues differs (Stoke, 1963). This dissertation focuses on position issues and attempts to examine to what extent individuals' stances on various position issues will lead them to different parties which, in turn, influence their various kinds of electoral behavior. With respect to voters' party preferences, Brader et al.(2014) mentioned that party preferences would be vote choice, vote intention and partisanship.

(2) Based on the results of step 1, generating the predicted probabilities of supporting each party for each respondent based on their positions on various 
issues. The distribution of probabilities tells us the extent to which an individual's particular issue positions lead him/her to different party preferences. When probabilities are aggregated at one particular party, for example, it suggests that the voter's issue positions point in the same direction, and it thus implies reinforcing pressures. Conversely, when probabilities are aggregated at two or more parties, it indicates the presence of conflicting pressures.

(3) In order to capture the variation among predicted probabilities, step 3 calculates the absolute difference/standard deviation in predicted probabilities across each party for each respondent. This step will vary depending on the party systems. For two-party systems, since there are only two parties or candidates, all that needs to be done is to subtract one predicted probability from the other, and take the resulting absolute value. Where there are more than two parties, according to Brader et al. (2014), there are several choices. The first option is the so-called "top-2 variance" method, determining the two highest predicted probabilities for each respondent across all predicted probabilities, then calculating the absolute difference between them. The second is the "top-3 variance method", determining the three highest predicted probabilities for each respondent across all predicted probabilities, then taking the standard deviation across them. The third choice, the "full variance method", takes the standard deviation across all parties' predicted probabilities for each respondent. The smaller the difference, the more a person's issue positions push them to two or more parties, which means they experience more issue cross-pressures.

(4) Subtracting the difference/deviation in step 3 from ' 1 ' so that a higher score corresponds to greater issue cross-pressures. This result is the respondent's issue cross-pressures score.

In order to better understand the regression-based measurement of issue cross-pressures, the following description orders the process more specifically from the simplest situation to the most complicated.

- The simplest situation is that there are only two issues and two parties/candidates (see Figure 2-4). For example, there are two issues: issue 1 and issue 2; two parties: party $\mathrm{A}$ and party $\mathrm{B}$; and an individual voter $\mathrm{V}$. On issue 1, voter $\mathrm{V}$ 
favors party A's position, thus issue 1 pushes voter V toward party A. However, on issue 2, voter $\mathrm{V}$ favors party B's position, thus issue 2 pushes voter $\mathrm{V}$ toward party $\mathrm{B}$. In this situation, voter $\mathrm{V}$ is under issue cross-pressures and will get an issue cross-pressures score. Conversely, if voter $\mathrm{V}$ favors the same party's position (both party A or party B) on these two issues, then voter $\mathrm{V}$ suffers no issue cross-pressures and will get an issue cross-pressures score of zero. The issue cross-pressures score can be easily calculated by using the approach stated before, where the steps of the process include:

(1) Modeling voters' voting choice/voting intention (code ' 1 ' = Party A, '0' = Party B) as a function of an individual's positions on two issues by using a binary logit regression;

(2) Using these regression results to predict the probability of voting for party A and party B for each respondent;

(3) Calculating the absolute difference between these probabilities, which ranges from ' 0 ' (equal probability of voting for each party) to ' 1 ' (certain to vote for a particular party);

(4) Subtracting this difference from ' 1 ' so that higher values indicate more equal probabilities. The resulting quantity is the respondent's issue crosspressures score.

Figure 2-4: Simplest situation in measuring issue cross-pressures

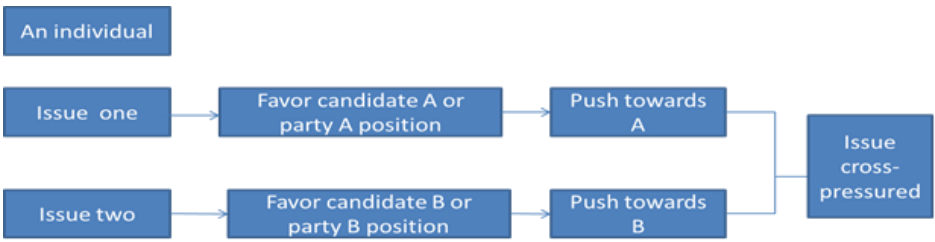

- The moderate situation is that there are several issues but only two parties/candidates (see Figure 2-5). For example, there are five issues: issue 1, issue 2 , issue 3 , issue 4 , issue 5; two parties: party $A$ and party $B$; and an individual voter $\mathrm{V}$. On issue 2 and issue 4, voter $\mathrm{V}$ favors party A's position, thus these two issues push voter $\mathrm{V}$ toward party A. However, on issues 1, 3 and 5, 
voter $\mathrm{V}$ favors party B's position, thus these three issues push voter $\mathrm{V}$ toward party $\mathrm{B}$. In this situation, voter $\mathrm{V}$ is under issue cross-pressures and will get an issue cross-pressures score. Conversely, if voter V favors the same party's positions (all party $\mathrm{A}$ or all party $\mathrm{B}$ ) on all five issues, voter $\mathrm{V}$ will experience no issue cross-pressures and will get an issue cross-pressures score of zero. The calculation of the issue cross-pressures score here is almost same as in the first situation. The only difference is that this situation models voters' voting choice/voting intention as a function of an individual's positions on more than just the two issues in step 1.

Figure 2-5: Moderate situation in measuring issue cross-pressures

\section{An individual}
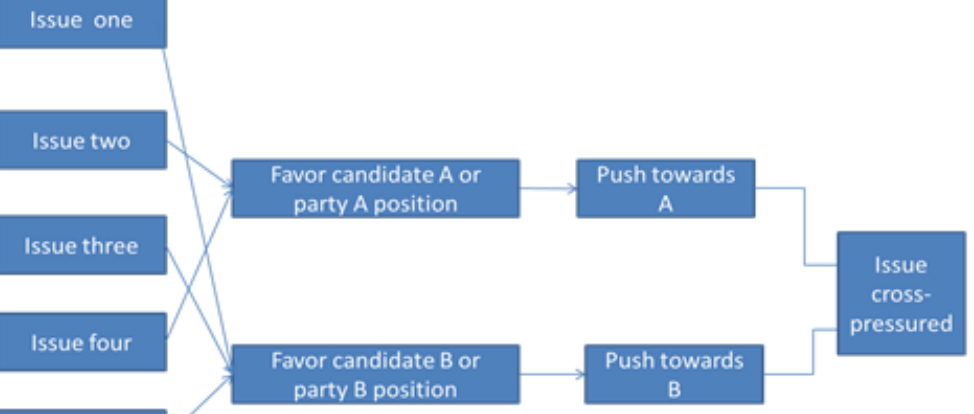

Issue five

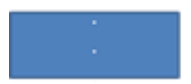

- The most complicated situation is where there are several issues and several parties/candidates (see Figure 2-6). It includes the following three possible modifications:

- More than two parties, "top-2 variance" method: Using a multinomial logit regression as in step 1 above, with voting choice/voting intention as the dependent variable and citizens' positions on different issues as independent variables; using the results to predict the probabilities of supporting each 
party in step 2; across all predicted probabilities, determining the two highest for each respondent and using those in steps 3 and 4 .

- More than two parties, "top-3 variance" method: As above for steps 1 and 2; in step 3, determining the three highest predicted probabilities for each respondent and taking the standard deviation across them; in step 4, scaling this quantity from ' 0 ' to ' 1 ', then subtracting it from ' 1 ' to generate each respondent's issue cross-pressures score.

- More than two parties, "full variance" method: As above for steps 1, 2 and 4; in step 3, taking the standard deviation across all parties' predicted probabilities for each respondent.

Figure 2-6: Complicated situation in measuring issue cross-pressures

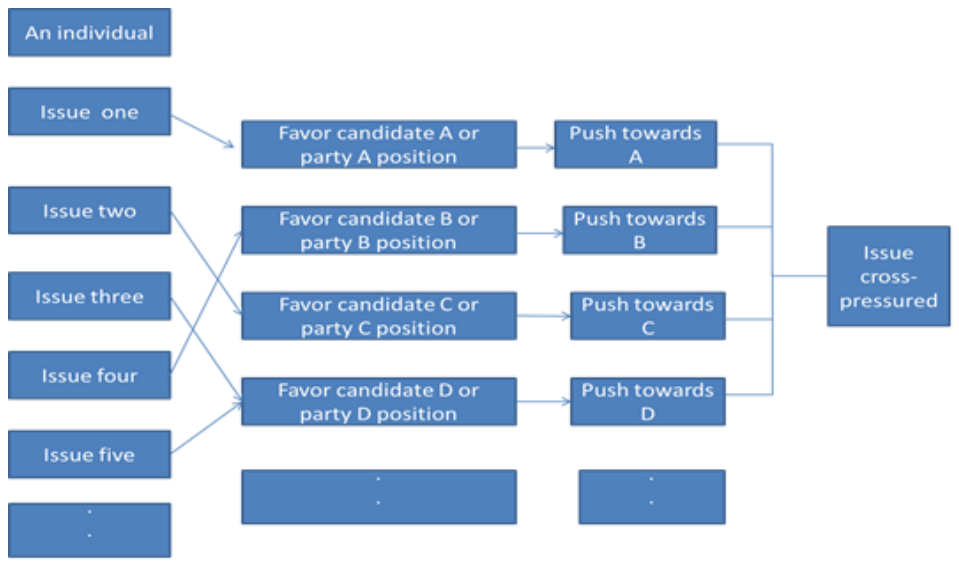

There are several reasons why this dissertation mainly uses the aforementioned method to measure issue cross-pressures. First, regression-based measurement can be used in different political contexts, in both two-party and multi-party systems, whereas from the discussion in the previous section we can see that all four other approaches can only be directly used in two-party systems. For example, with regard to the two approaches suggested by Therriault et al. (2011), the mathematical function of

$$
\mathrm{IPC}=1-\left|\frac{\text { DemPrefs }- \text { RepPrefs }}{\text { DemPrefs }+ \text { RepPrefs }}\right| \text { or }
$$




$$
\text { PVC }= \begin{cases}\frac{\text { DemPrefs }}{\text { DemPrefs }+ \text { RepPrefs }} & \text { if VotePref }=\text { Republican candidate } \\ \frac{\text { RepPrefs }}{\text { DemPrefs }+ \text { RepPrefs }} & \text { if VotePref } \neq \text { Republican candidate }\end{cases}
$$

will not be applicable in multi-parties systems. In terms of the approach of Hillygus and Shields (Hillygus, 2008), since in many West European countries citizens do not have stable party identification (Thomassen \& Rosema, 2009), it would be inappropriate to use this method to measure citizens' issue cross-pressures. The computing process used in the approach of Campbell et al. cannot be directly used in multi-party systems either.

Secondly, regression-based measurement is better because it can capture not only the different importance of various issues to different individuals but also the average importance of various issues to voters as a whole. It is widely acknowledged that issues are not equally important to all individuals: some individuals may place greater weight on economic issues than on foreign policy issues, whereas for others the reverse is true. Some issues will therefore be more influential than others when it comes to citizen's issue crosspressures. For example, an individual's position on economic issues may push him/her to vote for a particular party, while his/her position on foreign policy leads them to another other party. If the two issues are equally important, then the voter will be highly issue cross-pressured. On the other hand, if foreign policy is far more important to the voter than economic issues, then he/she may suffer little or no issue cross-pressures. Therefore, whether or not the voter experiences issue cross-pressures depends on how important each of these two issues are to him/her.

All five methods described above can incorporate personal issue salience with an additional question of issue importance in a survey. For instance, in terms of the approach proposed by Campbell et al., this may be achieved by adding different amounts of weight to different attitudes when calculating the attitudes conflict in step 3 . With respect to the approach of Hillygus and Shields, it can be achieved in the last step when counting the number of policies on which citizens do not agree with their parties. When using the two measurements proposed by Therriault et al., the personal issue salience can be captured by ascribing varying amounts of weight in step 1 when categorizing respondents' policy preferences on each issue as favoring the Republican candidate, favoring the Democratic candidate, or neutral. With regard to the approach suggested by Brader et al., step 1 can 
regress citizen's party preferences based on their positions on various issues with different weights of issue importance.

However, if there are no additional questions on personal issue importance in a survey, which is common in databases of electoral studies, only the approach of Brader et al. can differentiate the importance of various issues to voters as a whole. After step 1, we can see which issues are important to the whole electorate and which are not, and which issues are more important on average and which are less important. More specifically, after running a regression, we can get a regression function in which each issue will have a different coefficient. These coefficients, as we know, indicate the average importance of each issue to voters' party preferences. As a result, these coefficients can tell us which issues are important or unimportant on average (whether or not the coefficients are statistically significant) and which issues are more important or less important on average (coefficients have different values). These different average degrees of importance of each issue are applied to the whole electorate and used to calculate their issue cross-pressures.

\subsubsection{The distance/scalar product-based measurement of issue cross-pressures}

Although the regression-based measurement of issue cross-pressures has many advantages, it may cause confusion when testing whether or not the role of issues in voting choice is conditioned by issue cross-pressures, which is the main purpose of Chapter 3 in this dissertation. As described in the previous section, the regression-based measurement of issue cross-pressures is based on a regression model with citizens' positions on different issues as independent variables and their voting choice/intention as dependent variables. When examining issue voting, it also regresses citizens' voting choice based on their issue preferences. Therefore, in order to avoid ambiguity, Chapter 3 uses the following method to measure issue cross-pressures. As we will see, the distance/scalar product-based measurement of issue cross-pressures can be used in both two-party and multi-party systems, but it can only incorporate issue salience when there is an additional question on issue importance in a survey. It has seven steps in total. 
(1) Calculating the distance (according to the proximity theory of issue voting ${ }^{8}$ ) or scalar product (according to the directional theory of issue voting ${ }^{9}$ ) between voters' and parties' positions on each specific issue.

(2) Calculating the shortest distance (proximity theory) or largest scalar product (directional theory) between voters' and parties' positions on each specific issue.

(3) Targeting the most favored party (shortest distance or largest scalar product) on each specific issue. If one party is most favored on a specific issue, recode as ' 1 ', otherwise recode as ' 0 '. ${ }^{10}$

(4) For each party, calculating the number of issues on which the party is most favored. If two or more parties have a similar number, it implies more strongly

${ }^{8}$ Under the proximity theory of issue voting, voters and candidates/parties are each represented by a point in an issue space. Voting choice is therefore determined by the distance in the space between voters and candidates/parties: the closer they are, the more likely the voter is to choose that party/candidate (Downs, 1957). Mathematically, the model is defined as follows:

$$
U_{i j}=-\left|V_{i k}-C_{j k}\right|=-\left[\sum_{k=1}^{n}\left(v_{i k}-c_{j k}\right)^{2}\right]^{1 / 2}
$$

( $U_{i j}$ is the utility of candidate $j$ for voter $i$; $n$ is the number of issues; $v_{i k}\left(V_{i k}\right)$ is the position of voter i on issue $\mathrm{k}$; $\mathrm{c}_{\mathrm{jk}}\left(\mathrm{C}_{\mathrm{jk}}\right)$ is the position of candidate $\mathrm{j}$ on issue $\mathrm{k}$. The larger the value of $\mathrm{U}_{\mathrm{ij}}$, the more likely it is that voter $\mathrm{i}$ will vote for candidate $\mathrm{j}$.)

${ }^{9}$ Under the directional theory of issue voting, voting choice is determined by direction, denoting which side of an issue the candidate or party generally espouses and the voter usually prefers, and by intensity, which denotes how strongly the candidate or party advocates that option and how strongly the voter holds that preference. Thus a voter tends to vote for the candidate or party who makes strong stands on issues and is most likely to move policy in a direction that most resembles the voter's own preference (Rabinowitz \& Macdonald, 1989). Its mathematical model is defined as follows:

$$
U_{i j}=V_{i k} * C_{j k} \mid=\sum_{k=1}^{n} v_{i k} * c_{j k}
$$

( $U_{i j}$ is the utility of candidate $\mathrm{j}$ for voter $\mathrm{i} ; \mathrm{n}$ is the number of issues; $\mathrm{v}_{\mathrm{ik}}$ and $\mathrm{c}_{\mathrm{jk}}$ are the voter and candidate locations on issue $\mathrm{k} ; \mathrm{V}_{\mathrm{ik}}$ and $\mathrm{C}_{\mathrm{jk}}$ are the vectors of the voter and candidate positions on the $\mathrm{k}^{\text {th }}$ issue space. The larger the value of $\mathrm{U}_{\mathrm{ij}}$, the more likely it is that voter $\mathrm{i}$ will vote for candidate $\mathrm{j}$.)

${ }^{10}$ If two or more parties are most favored on the same issue, according to two theories of issue voting, this means that the voter has no clear party preference on that specific issue. In this situation, all parties are recoded as 'missing value'. This implies that voters who do not have clear preferences on all issues will be excluded. 
that there will be issue cross-pressures. If only one party gets a significant number, it implies the presence of reinforcing pressures, or in other words that no issue cross-pressures will be suffered.

(5) Dividing the number obtained in the previous step for each party by the total number of issues. Therefore, the number obtained by each party will be located between ' 0 ' and ' 1 '.

(6) If it is operating within two-party systems, calculating the absolute difference between the number obtained by two parties for each individual. The smaller the absolute difference, the closer the voter's preferences for voting for the two parties are, and the more issue cross-pressures a person experiences. In multi-party systems, this step is achieved by calculating the standard deviation among the numbers obtained by each party in the previous step for each individual. The larger the standard deviation, the less aggregated the numbers are, and the less a person will suffer issue cross-pressures.

(7) Subtracting the result in step 6 from ' 1 '. A larger score implies higher issue cross-pressures.

Again, in order to better understand the distance/scalar product-based measurement of issue cross-pressures, I describe the process in more detail from the simplest situation to the most complicated one.

- When there are only two issues and two parties/candidates (see Figure 2-4), if the distance/scalar product between voter V's and party A's position on issue 1 is shorter/larger, while the distance/scalar product between voter V's and party B's position on issue 2 is shorter/larger, voter $\mathrm{V}$ is under issue cross-pressures and will get an issue cross-pressures score of ' 1 '. Alternatively, if the distance/scalar product between voter V's and party A's (or party B's) position on both issue 1 and issue 2 is shorter/larger, voter $\mathrm{V}$ will experience no issue cross-pressures and will get an issue cross-pressures score of ' 0 '. The calculating procedures include:

(1) Calculating the distance (proximity theory) or scalar product (directional theory) between voter V's position and party A's/party B's position on each specific issue. 
(2) Scoring the parties by distance/scalar product. If the distance/scalar product between voter V's position and party A's position on issue 1 is shorter/larger than the distance/scalar product between voter V's position and party B's position, party A gets a score of ' 1 ' on issue 1 , while party B gets a score of ' 0 '. If the distance/scalar product between voter $\mathrm{V}$ 's position and party B's position on issue 1 is shorter/larger than the distance/scalar product between voter V's position and party A's position, party B gets a score of ' 1 ' on issue 1 , while party A gets a score of ' 0 '. If the distance/scalar product between voter V's position and party A's position on issue 1 is the same as the distance/scalar product between voter V's position and party B's position, both party A and party B are recorded as "missing value" on issue 1 , which means that no party is preferred on this issue.

(3) Repeating step 2 for issue 2.

(4) Summarizing the scores of party A and party B on issue 1 and issue 2.

(5) Dividing the scores obtained by party A and party B in step 4 by ' 2 ' (the number of issues).

(6) Calculating the absolute difference between the score obtained by party A and that of party B.

(7) Subtracting the result in step 6 from ' 1 '; the result of this equation is the issue cross-pressures score.

- When there are several issues but only two parties/candidates (see Figure 2-5), the situation is moderately complicated. If the distances/scalar products between voter V's position and party A's position on issues 2 and 4 are shorter/larger, while on issues 1,3 and 5 the distances/scalar products between voter V's position and party B's position are shorter/larger, voter $\mathrm{V}$ is under issue crosspressures and will get an issue cross-pressures score greater than zero. In contrast, if the distances/scalar products between voter V's position and party A's (or party B's) position on all five issues are shorter/larger, voter V will experience no issue cross-pressures and will get an issue cross-pressures score of ' 0 '. The first two steps of the measurement of issue cross-pressures score here 
are the same as in the first situation. In step 3, step 2 is repeated for issues 2, 3, 4 and 5. In step 4 , the scores obtained by party A and party B on all five issues are summarized. Step 5 divides the scores obtained by party A and party B in step 4 by ' 5 ' (the number of issues). In step 6 , the absolute difference between the scores obtained by party A and party B are calculated. Finally, in step 7, the result in step 6 is subtracted from ' 1 ', and the result is the issue cross-pressures score.

- When there are several issues and several parties/ candidates (see Figure 2-6), the situation is complicated. If the distance/scalar product between voter V's position and party A's position on issue 2 is shorter/larger, the distances/scalar products between voter V's position and party B's position on issues 1 and 3 are shorter/larger, while on issues 4 and 5 the distances/scalar products between voter V's position and party C's position are shorter/larger, voter $\mathrm{V}$ will be issue cross-pressured and will struggle to choose between three different parties. In this situation, the procedures to calculate issue cross-pressures include:

(1) Calculating the distance (proximity theory) or scalar product (directional theory) between voter V's position and each party's position on each specific issue;

(2) Calculating the shortest distance (proximity theory) or largest scalar product (directional theory) between voter V's position and each party's position on each specific issue;

(3) Targeting the most favored party (shortest distance or largest scalar product) on each specific issue. If one party is the most favored on a specific issue, recode as ' 1 ', otherwise recode as ' 0 ';

(4) For each party, calculating the number of issues on which the party is most favored;

(5) Dividing the number obtained in the previous step for each party by ' 5 ' (the number of issues);

(6) Calculating the standard deviation between the number obtained by the parties for each individual issue; 
(7) Subtracting the result in step 6 from ' 1 '. The result is the issue crosspressures score.

\subsection{Conclusion}

To summarize, this chapter has clarified what issue cross-pressures are and which existing definition of issue cross-pressures is better; the preconditions for citizens to experience issue cross-pressures; how individuals' issue cross-pressures arise; how issue crosspressures influence citizens' different kinds of electoral behavior; and how to measure issue cross-pressures. The definition of issue cross-pressures in this dissertation follows that defined by Therriault et al. (2011), namely that cross-pressures arise from holding policy preferences across various issues that push one in different political directions. For citizens to experience issue cross-pressures, they should care about at least two different issues and their opinions on those issues should not be comprehensively constricted by a unidimensional ideology. Citizens may become aware of issue cross-pressures because of conflicts between core values or in pursuing different self-benefits.

Referring to cognitive dissonance theory in social psychology and information processing theory in political psychology, this dissertation opened the black box between issue cross-pressures and electoral behavior. It argued that when citizens experience issue cross-pressures, in order to make a voting decision, they would employ different methods to reconcile or alleviate their cross-pressures, including re-evaluating their stances on some issues, looking for additional attributes related to parties, and reducing the importance of some issues. During this process, the role of issues in citizens' decision making might be conditioned as they may be bearing other factors in mind. Therefore, issue cross-pressures might moderate the role of issues in citizens' voting choice. If issue cross-pressured citizens could not reconcile their cross-pressures successfully after employing the aforementioned three methods, they would keep on struggling to decide which party to vote for, which in turn might influence their motivation to go out to vote. In contrast, if issue cross-pressured citizens managed to alleviate their cross-pressures to a certain level, they would cast a vote. However, their voting choices would depend significantly on how they reconcile their cross-pressures. In this regard, issue cross-pressures might influence the stability of citizens' voting choice across different elections. If citizens did not experience issue cross-pressures, they could make a voting choice directly without any additional considerations, whereas, if 
citizens were issue cross-pressured, they had to employ one or more approaches to reconcile cross-pressures in order to reach a satisfactory voting choice. This whole process would be very likely to lead cross-pressured citizens to spend much more time on decision making, meaning that issue cross-pressures might delay citizens' time of voting decision.

Finally, based on five potential methods of measuring cross-pressures proposed in the existing literature, this chapter developed the regression-based and the distance/scalar product-based measurements of issue cross-pressures. The next chapter will go on to directly test the first possible role of issue cross-pressures in electoral behavior: issue voting. 


\section{3-Issue Cross-pressures and Issue Voting}

This chapter investigates the first possible role of issue cross-pressures in electoral behavior, that is, issue voting. According to the theories of modernization and cognitive mobilization, with the decline of cleavage politics and the development of higher education and communication technology in Western Europe, there should be a boom in issue voting. However, this is not the case in reality. The level of issue voting is far from clear in the existing literature. Inconsistent empirical findings have led political scholars to explore both demand-side and supply-side moderated factors. The chapter contributes to this body of work by examining the strength of issue voting across the levels of issue cross-pressures. It attempts to study whether or not the role of issues in citizens' voting choice is moderated by their issue cross-pressures. To answer this question, this chapter uses survey data from the 2010 national election study in the United Kingdom.

\subsection{Introduction}

The impact of issue preferences on party support is a key focus of many models of voting choice (Downs, 1957; Rabinowitz \& Macdonald, 1989). However, the variation in the intensity of issue voting across the levels of issue cross-pressures is not well addressed in the literature. A voter is defined as an issue cross-pressured citizen if, for example, on the issue of gay marriage he/she prefers the Conservative party, while on the issue of tax he/she favors the Labor party (Therriault et al., 2011). Will voters rely more strongly on issues in making their voting choice when their issue preferences push them toward a single party? Can inconsistent party preferences stemming from voters' positions on various issues moderate the role of issues in voting choice?

In recent decades, with increased cognitive mobilization on the one hand and the decline of cleavage politics in Western societies on the other, an extensive strand of literature has acclaimed the arrival of reasoned vote choice (i.e., issue voting) (Dalton et al., 1984; Franklin, 1985; Rose \& McAllister, 1986, 1990). However, the extent to which voters make their voting decisions based on issue preferences is far from conclusive. In 
contrast to the optimistic assessment that issue voting has gained in importance, many studies do not find supporting evidence for an increasing relevance of issues to voters' voting choice (Clarke et al., 2004; Aardal \& Van Wijnen, 2005; Lewis-Beck et al., 2008; Wessels, 2014). If the decline of traditional party ties and the increase in advanced education do not lead to a consistently increasing issue-based voting choice, what factors condition the overall level of issue voting?

Inquiring into these questions, political scholars first paid attention to demand-side factors, such as political sophistication (Palfrey \& Poole, 1987; Luskin, 1990; Moon, 1990; Sniderman et al., 1993; Alvarez, 1997; Weisberg \& Nawara, 2010), and the importance voters' attach to individual issues (Krosnick, 1988; Edwards III et al., 1995; Fournier et al., 2003; Lachat, 2009). Recent scholarly attention has focused on the impact of supply-side factors, such as party fragmentation and polarization (Alvarez \& Nagler, 2004; Lachat, 2011), and the issue voting triangle of issue linkage/mobilization/competition (De Vries, 2010). This paper contributes to this body of work by introducing issue cross-pressures, which are pressures that arise from holding policy preferences across various issues which push a person in different political directions (Therriault et al., 2011).

Ambivalence toward two presidential candidates has been found to weaken the influence of issue proximity on summary candidate evaluation (Lavine, 2001). Although there is a difference between the concept of ambivalence and issue cross-pressures, they are both related to human beings' internal psychological conflicts. In addition, according to the information processing theory of voters' decision making formulated by Lau and Redlawsk (2006), voters who examine one set of policies over parties or candidates independently from another set may be unable to make a coherent decision, since they may preferring different parties on different policies. Thus, these voters may use compensatory strategies in order to make a choice (Lau \& Redlawsk, 2006). This implies that, for people whose issue preferences point to multiple parties, their voting propensity may be complemented by other considerations, such as affect, endorsement and voting habit. As a result, we can expect that issue cross-pressures may moderate the role of issues in citizens' voting choice. Therefore, the purpose of this chapter is to answer the question of whether or not the role of issues in citizens' voting choice is moderated by their issue cross-pressures (see Figure 3-1). The basic argument is that the influence of issues on voting choice will be stronger among 
people whose issue positions push them toward a single party than among people whose issue positions lead them to different parties.

In order to answer the research question, this chapter uses survey data from the 2010 British General Election Study and will proceed as follows. Section 1 introduces the background. Section 2 then explains why issue cross-pressures may moderate the level of issue voting. That is followed by section 3, which presents the data and methodology. Section 4 contains the empirical results, and finally section 5 concludes the paper with a discussion of the implications of the study.

Figure 3-1: Issues, issue cross-pressures and voting choice

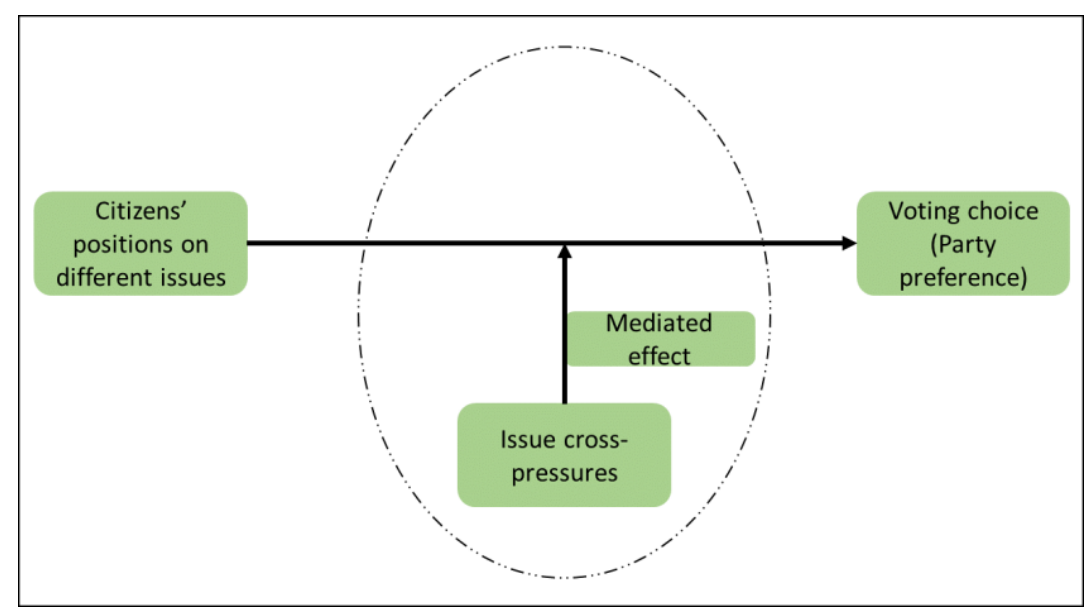

\subsection{What moderates the role of issues in voting choice? The place of issue cross-}

\section{pressures}

Regarding the factors that condition the level of issue voting, political scholars first paid attention to political sophistication, which is often measured by the level of education, political knowledge or political interest. Conventional wisdom dictated that only people with enough cognitive ability could use issues to guide their voting behavior. In the landmark book The American Voter, Campbell and his colleagues (1960) argued that the general public lacked the sophisticated political knowledge and skills needed for issue voting, and that issue-based vote choice was therefore fairly limited within the American electorate as a whole. Converse (1964) further emphasized that voters could not link issues to a specific candidate because they lacked sufficient political sophistication to understand 
these issues. Many subsequent empirical studies consistently found that the higher the level of political sophistication, the greater the role of issues in candidate or party evaluations (Stimson, 1975; Knight, 1985; Palfrey \& Poole, 1987; Moon, 1990; Sniderman et al., 1990; Sturgis and Tilley, 2004; Lavine \& Gschwend, 2007). These studies basically showed that cognitive skill and political knowledge were key prerequisites for issue voting. As a result, with the development of education in Western societies on the one hand and the increase in accessible political information from mass media and the Internet on the other, we should observe a steadily increasing relevance of voters' issue preferences to their vote choice. However, the empirical evidence is controversial to some extent.

On the one hand, issue voting has gained in importance, not only in the United States but also in Europe (Brody \& Page, 1972; Pomper, 1972; Nie et al., 1976; Franklin, 1985; Rose \& McAllister, 1986, 1990). By focusing on British elections from 1964 to 1983, Franklin (1985) argued that issue voting had increased due to the decline of class voting. Rose and McAllister (1986) also asserted that British voters had begun to make their choice based on short-term factors, especially issues. On the other hand, there were dissenting voices. Focusing on valence issues, Aardal and Van Wijnen (2005) analyzed survey data from six Western European countries between the 1970s and 1990s, and showed that there was no secular increase in issue voting over that time. Based on survey data from the British election study, Clarke et al. (2004) demonstrated that the influence of position issues declined between 1974 and 2001. How can we reconcile the mixed findings on issue voting? Why has there been no steady increase in issue voting? Why is the level of issue voting more pronounced in some elections/countries but relatively minor in others?

In order to answer these questions, political scholars turned their attention away from political sophistication to other demand-side factors. One important factor is issue importance. Political scientists argued that only issues which voters considered to be individually important had an impact on voting decisions. Thus, a varying level of issue voting across elections can be attributed to the extent of overall issue importance in particular elections. More specifically, if the overall importance of issues to voters is substantially higher in an election, issues will significantly influence voters' party preferences. Outside of this factor, the effect of issues cannot be clearly observed. While many researchers found that issue importance conditioned issue voting (Rabinowitz et al., 
1982; Krosnick, 1988; Edwards III et al., 1995; Fournier et al., 2003), other researchers failed to do so (Markus \& Converse, 1979; Niemi \& Bartels, 1985; Lachat, 2009).

Both political sophistication and issue importance are demand-side factors (i.e., voter characteristics). Although these two strands of literature provide important insights into why there are variations in the level of issue voting across elections and countries, the overall picture is by no means complete. In an election, voters and parties are definitely equally important. Recent scholarly attention has focused on the suppliers in the electoral market. Alvarez and Nagler (2004) showed that the more distinguishable the choice offered by the parties on any given issue, the more likely the voters would be to weigh that issue in their vote decisions. By focusing on electoral competitiveness, Lachat (2011) found that voters rely more on issues when there are more parties, when the parties' political positions are more polarized, and when electoral system are more proportional. De Vries (2010) proposed the issue voting triangle model which includes issue linkage, issue mobilization and issue competition. Her analysis demonstrated that issue voting is more prominent when the parties' positions on the new policy issue are more divergent (issue competition) and linked to the main dimension of political conflict (issue linkage), and when the parties view new issues as more important (issue mobilization). In short, these studies found that the level of issue voting in a specific election is not only determined by the voters themselves, but also by the active parties in that election.

This paper attempts to contribute to the literature by introducing issue crosspressures. By definition, issue cross-pressures stem from an individual's inconsistent party preferences based on various issues. The basic argument is that the influence of issues on voting choice will be stronger among voters whose issue positions push them toward a single party than among others whose issue positions lead them to different parties. As such, this paper proposes that the level of issue voting in a specific election not only depends on the voters' characteristics and active parties, but also on the extent to which different issues lead voters to a single party. As a result, in contrast to existing studies which attribute the varying level of issue voting to external factors (no matter voter characteristics or context factors), this paper attempts to show that issues themselves may also make a contribution. The next section explains how issue cross-pressures moderate the level of issue voting. 


\subsection{Issue cross-pressures, information processing and voting choice}

How will issue cross-pressures moderate the role of issues in voting choice? Before addressing this question directly, we should look at why voters consider issues when they make voting decision. Behavioral decision theorists have become convinced that most citizens lack the capacity and motivation to consider a large amount of information and are therefore limited information processors (Simon, 1976; Taylor, 1981; Fiske \& Taylor, 2013). As such, when making political decisions, people tend to rely on information shortcuts or heuristics such as party identification, ideology, endorsement and opinion polls (Chaiken, 1980; Fiske \& Neuberg, 1990; Lau \& Redlawsk, 2001, 2006). In this regard, given that issues are much more complicated than these shortcuts and need additional cognitive energy, it can be fairly difficult to include them in the voters' decision process. However, several studies on information processing cite three situations in which issues might be taken into consideration by the voters (Macheswaran \& Chaiken, 1991; Basinger \& Lavine, 2005; Lau \& Redlawsk, 2006).

The first situation is an ideal one in which voters' voting choice is based on explicit, dispassionate calculations of self-interests. These voters are regarded as rational and willing to spend time and effort to gather as much information as possible in order to make an optimal decision. When making voting choices, these voters will calculate and compare the utility they can get from each candidate or party on each issue, and vote for the one that yields the most benefits. For example, imagine a voter who wants to vote for the Conservatives on the issue of tax because this party offers the most benefits. However, calculating benefits on the issue of immigration, this voter prefers to vote for UKIP. In this situation, if this voter votes Conservative, s/he can get what they desire on the tax issue but will lose what is offered by UKIP on the issue of immigration, and vice versa. In short, for this voter, getting one benefit comes at the cost of giving up the other. This benefit conflict results in what we term issue cross-pressures.

The second situation is related to voters' desire to make a good decision. In order to make a correct decision, some voters might seek out and process political information. Therefore, instead of focusing on party identification, ideology or other heuristics, these voters will concentrate on specific issues and examine which parties represent the best of their own preferences on these issues. If voters' preferences on various issues point to two or more parties, they will be under issue cross-pressures. 
The third situation concerns the decision context. Although most voters wish to expend minimal cognitive effort on making a decision, the characteristics of a specific election may trigger citizens to process information in a more systematic way and take issues into account. Election contests usually ensure that plenty of information is available on every party, both positive and negative. Therefore, although voters may not search for political information actively, they still receive a lot of unavoidable information passively. Many studies have shown that citizens cannot usually avoid arguments which conflict with their interests or values (Zaller, 1992; Alvarez \& Brehm, 2002). In order to be confident in their decisions (i.e., to meet a minimum requirement to make a decision; see Eagly \& Chaiken, 1993), voters will be motivated to gather more specific political information. In this situation, issues may be taken into account. If different issues push voters to two or more parties, those voters will experience issue cross-pressures.

How will people behave in order to reach a voting decision when they suffer from issue cross-pressures? Lau and Redlawsk (2006) proposed that compensatory strategies could be employed when people face a dilemma. For rational voters, who are willing to spend time and effort to gather as much information as possible, the strategies of the Weighted Additive (WAdd), the Expected Utility Rule (EU) and Additive Difference Rule (AddDif) are proposed (see Lau \& Redlawsk, 2006, pp. 265-270). The basic ideas behind these strategies are that decision makers will search and consider relevant attributes or outcomes as many as possible, such as personality, background, party attachment and issue positions. For example, by using WAdd strategy, a voter will learn everything there is about a particular candidate or party, associating a subjective utility and an importance weight to every attribute, and calculating an overall evaluation of the candidate once all the information is gathered. The voter will repeat the process for every candidate or party and choose the one got best evaluation (based on utility and importance weight). For limited information processors, simpler and less cognitively demanding compensatory strategies are recommended, such as Take the Few Best (FweBest) (see Lau \& Redlawsk, 2006, pp. 270-272). This strategy suggests that instead of searching and considering all relevant attributes about a particular party, a citizen can take few of them, which s/he cares most, into consideration. If these 'few' attributes point to two or more parties, the citizen will be in a dilemma therefore cannot make a decision. In order to have a clear party choice, the citizen will reconsider the attributes that initially examined, reweight their importance or 
even eliminate one or more of them. No matter what strategy is used, they all imply that the role of issues in citizens' voting choice will be moderated because, as we can see, citizens may bear other factors in mind or reduce importance of some issues. Therefore, we can expect that the influence of issues on citizens' voting choice would be greater if they do not lead citizens to a conflicting situation. The resulting hypothesis is that the more issue crosspressures citizens experience, the less important the role of issues is in their voting choice.

It could be argued that these research questions are tautological. In some sense this is a fair criticism because, at first glance, when citizens' preferences on different issues point to a single party, their party choice will be based more on issues, and factors such as personality will be less relevant. However, this should not be taken as a given. In the first place, many factors affect citizens' voting choice, with issues being just one of them. When categorizing citizens into issue cross-pressured and non-issue cross-pressured, there is no $100 \%$ guarantee that non-issue cross-pressured citizens will rely more on issues to make a voting choice than issue cross-pressured citizens. It is probabilistic rather than determinate to suggest that issue cross-pressured citizens will rely less on issues to make their voting choice compared to those who do not experience issue cross-pressures. It should therefore be supported with empirical evidence. In addition, with the decline of cleavage politics on the one hand and increasing cognitive mobilization on the other hand in advanced Western democracies, political scholars have been optimistic about the rise of issue voting, which has been seen as a characteristic of ideal democracy. However, comparatively few scholars pay attention to the possibility that higher level of education and political information may also cause citizens to be more likely to experience issue cross-pressures (Chapters 4 and 5 provide some empirical support for this, at an aggregate level and an individual level respectively). This in turn decreases the overall level of issue voting and goes against the optimistic view of the consequences of partisan de-alignment. Therefore, even if this study is self-evident, it is still worth investigating its research questions in the context of modernization and cognitive mobilization.

\subsection{Data and method}

The main purpose of this study is to examine whether or not voters' issue cross-pressures moderate the role of issues in their voting choice. The hypothesis is that the role of issues in voting choice will be more pronounced among voters with lower issue cross-pressures than 
among those with higher issue cross-pressures. To test this hypothesis, this paper uses survey data from the 2010 British General Election Study. There are several reasons for the choice of this data source. First, the United Kingdom is a typical advanced industrial democracy in which there is a decline in both party identification and social cleavage and an increase in citizens' cognitive ability (Franklin, 1985; Rose \& McAllister, 1986; Dalton, 2000; Franklin et al., 2009). Secondly, as is the case in many other advanced Western countries, the United Kingdom has not seen a consistent increase in issue voting, as had been expected (Clarke et al., 2004; Aardal \& Van Wijnen, 2005). Additionally, compared to other European countries, the British party system has long been regarded as a two-anda-half-party system. As parties are the main actors setting the issue agenda, there may be fewer salient issues in the election market as a result of the lower number of available parties. In addition, the existence of fewer effective parties may also imply fewer available alternatives, and thus a lower likelihood that voters will find a corresponding party on a specific issue. In this regard, people may have less chance to experience issue crosspressures, which in turn makes it more difficult to observe the moderated role of issue cross-pressures in issue voting. All in all, the United Kingdom is a much safer study object to enable us to generalize the findings to other countries.

The dependent variable in this study is voters' propensity to vote for a given party. Several studies have argued that this type of measure is better than the party choice or party sympathy scale (feeling thermometer), ${ }^{11}$ since it catches the electoral utility more accurately (Tillie, 1995; Van der Eijk et al., 2006). Instead of distinguishing between the party a voter supports and all the others, voting propensity is measured for different parties separately. In the 2010 British election study, voting propensity was determined by asking: "How likely is it that you would ever vote for XXX?" Answers ranged from "0 (very unlikely)" to "10 (very likely)". The analysis in this chapter includes five parties: the

\footnotetext{
${ }^{11}$ Many studies on issue voting use the party sympathy scale or feeling thermometer as a dependent variable (Rabinowitz \& Macdonald, 1989; MacDonald, Listhaug \& Rabinowitz, 1991; MacDonald, Rabinowitz \& Listhaug,1995; Aarts, MacDonald \& Rabinowitz, 1999). In line with these studies, and in order to make this study more robust, this chapter also tests the hypothesis using the feeling thermometer as a dependent variable. The results are presented in Appendix A. As can be seen from Tables 3-1 and 3-2 in Appendix A, the hypothesis in this study is also justified when the feeling thermometer is a dependent variable for a given party.
} 
Conservative Party, Labour Party, Liberal Democrats, Scottish National Party, and Plaid Cymru ${ }^{12}$.

Since the main focus of the paper is to test whether or not voters' issue crosspressures moderate the role of issues in their voting choices, the variable of issue crosspressures is our main concern. As discussed before, issue cross-pressures arise from inconsistent voting predispositions based on various issues. In order to examine how each issue will lead a voter to specific parties, this study employs two of the most important theories in issue voting: the traditional proximity model (Downs, 1957) and the directional model (Rabinowitz \& Macdonald, 1989). In the proximity model, the closer the individual's position to the party's position on a specific issue, the more likely it is that the individual will vote for the party. ${ }^{13}$ In the directional model, the assessment of the party is determined by whether or not the party and the voter agree on the political direction that should be taken and how intense their commitment is. ${ }^{14}$ The measurement of issue crosspressures is based on these two theories as outlined in Chapter $2^{15}$.

\footnotetext{
${ }^{12}$ In the 2010 British Election Study, respondents were asked to give their perceptions of five parties' positions on all three position issues. These five parties are the Conservative Party, Labour Party, Liberal Democrats, Scottish National Party and Plaid Cymru. As we will see below, information about voters' perceptions of the parties' positions on various position issues are necessary when calculating issue cross-pressures and party utility, therefore the paper only focuses on these five parties. In addition, although the Scottish National Party and Plaid Cymru are regional parties which mainly have influence in Scotland and Wales respectively, I argue that citizens living in Scotland and Wales may also be issue cross-pressured between these regional parties and other, national parties, so I have still included these two parties.

${ }^{13}$ For a more detailed description of the proximity theory of issue voting, see footnote 8 in Chapter 2.

${ }^{14}$ For a more detailed description of the directional theory of issue voting, see footnote 9 in Chapter 2.

15 There are seven steps in total (detail see Chapter 2). In the first step, information about voters' and parties' positions on various position issues is necessary. In the 2010 British Election Study, voters were asked to give both their own positions and their perceptions of the parties' positions on three issues. These three issues were tax: either the government should cut taxes and spend much less on health and social services, or the government should raise taxes significantly and spend much more on health and social services; the rights of accused criminals: either reducing crime is more important than protecting the rights of people accused of committing crimes, or protecting the rights of accused people regardless of whether they have been convicted of committing a crime is more important than reducing crime; and black and Asian people: either there is no need for the government to take action to improve opportunities for black and Asian people, or the government
} 
The independent variable in this study is utility from issues. According to the proximity theory, voters and parties are regarded as different points in an issue-space. The shorter the distance between a voter's point and a party's point, the more benefits this voter can get, and thus the more likely it is that they will vote for that specific party. As such, the utility for each voter is measured by the Euclidean distance: the greater the Euclidean distance, the less utility voters can get. In the directional theory, utility is determined by the policy direction that voters and parties prefer and the intensity of the commitment of voters and parties. Thus, utility for each voter is measured by the scalar product: the larger the scalar product, the more utility voters can get, and therefore the more likely it is that they will vote for the party. In addition, in order to make the results more accurate, this study also use pooled regression analysis and controlled for several other factors, including age, gender, income, education, political interest, party identification and social class. ${ }^{16}$

\subsection{Findings}

Before discussing the moderated role of issue cross-pressures in issue voting, we should first examine how many people are under issue cross-pressures. When the issue crosspressures score is calculated using the proximity theory, the analysis shows that there are only $30 \%$ of voters whose preferences on three issues lead them to a single party. This means that there are about $70 \%$ of voters whose positions on different issues push them to two or more parties. When the issue cross-pressures score is calculated using the directional

should make every effort to improve opportunities for black and Asian people. In all three issues, answers were coded on a 0-10-point scale. In this chapter, these three variables are recoded from ' -5 ' to ' +5 '. Voters' perceptions of each party's position on each of the three issues have been adjusted to provide the mean value.

In addition, since more than two parties are involved in this chapter, step six is achieved by calculating the standard deviation among the numbers obtained by each party in the previous step for each individual. One thing to keep in mind is that, because standard deviation is used, when only one party gets a number, the issue cross-pressures score is not 0 , but $0.55(0.55=1-0.45 ; 0.45$ is the standard deviation when only one party gets a number and the other four parties get zero). It means that the base score, indicating that voters experience no issue cross-pressures, is 0.55 .

16 The coding for control variables is as follows. Gender: 1 for "male", 0 for "female". Income: from $1(0-5,000)$ to 15 ( 90,001 and over). Education: 1 for "has education or work qualifications", 0 for "does not have any education or work qualifications". Political Interest: from 1 ("none at all") to 5 ("a great deal"). For Social Class, a category variable with 10 categories, 9 dummy variables were created. Party Identification: a category variable with 10 categories, for which 9 dummy variables were created. 
theory, the results are less striking but still impressive: about $40 \%$ of citizens have inconsistent voting predispositions based on their issue positions, meaning that only around $60 \%$ of individuals have a consistent party preference. Will voters rely more on issues when their positions on various issues push them toward a single party, and less when their issue positions point to inconsistent party preferences?

The hypothesis in this study is that issue cross-pressures will moderate the role of issues in voters' voting decision. The more issue cross-pressures voters suffer, the less pronounced issue voting will be. In order to test this hypothesis, this paper first divides the respondents into two groups based on their issue cross-pressures scores, the so-called "lower issue cross-pressured citizens" and "higher issue cross-pressured citizens". ${ }^{17}$ Secondly, for each group, voting propensity is regressed based on the Euclidean distance or scalar product and all the control variables for each party. ${ }^{18}$ Since the value of voting propensity ranges from 0 to 10 , a linear regression model is used. Thirdly, according to the way of calculating the issue cross-pressures score and the party utility for each individual, the results are categorized into the "Proximity Model" and the "Directional Model".

The results presented in Table 3-1 clearly support the hypothesis. We will first focus on the "Proximity Model" (Table 3-1, left). When party utility is represented by the Euclidean distance, in two out of three models ("Lab-Proximity model" and "Lib-Proximity model"), the coefficients are negative and highly significant among voters with lower issue cross-pressures. In the "Con-Proximity model", even though the coefficient is not significant, its sign is negative as expected. Among voters who suffer higher issue crosspressures, in both the "Lab-Proximity model" and the "Lib-Proximity model", the coefficients of the Euclidean distance are negative, indicating in the expected direction, but neither of them is significant. In terms of the "Con-Proximity model", the influence of proximity distance points in the opposite direction to what was expected and is not

\footnotetext{
${ }^{17}$ People whose issue cross-pressures scores are less than or equal to the median score are regarded as "lower issue cross-pressured citizens", while the rest are regarded as "higher issue cross-pressured citizens".

${ }^{18}$ For the Scottish National Party and Plaid Cymru, there were too few cases to run a regression (each group only has around 30 cases after the first step). Therefore, as we will see below, neither Table I (upper) nor Table II (upper) presents them. However, when carrying out a pooled regression analysis, cases for these two parties are included.
} 
significant. All in all, the results show that the effect of issues on citizens' voting propensity is much stronger when voters experience fewer issue cross-pressures.

\section{[TABLE 3-1 ABOUT HERE]}

When a pooled regression analysis is performed, ${ }^{19}$ the hypothesis is justified again. Among voters with lower issue cross-pressures, the effects of three issues are all in the expected direction, i.e., negatively related to voters' voting dispositions toward a given party. In addition, the influence of the issue of the government's role in helping black people and Asians is highly significant. The adjusted $\mathrm{R}^{2}$ is increased by 0.01 when moving from the base model to the one including issues. In contrast, when voters experience higher issue cross-pressures, the coefficients for all three issues are not significant. In addition, the influence of the issue of the rights of accused criminals does not point in the expected direction. Furthermore, when moving from the base model to the one including issues, the adjusted $\mathrm{R}^{2}$ is decreased by 0.02 . These results confirm the hypothesis that issue voting will be more marked when voters' positions on various issues lead them to a single party.

Let us now turn to the "Directional Model" (Table 3-1, right) to examine whether or not the moderated role of issue cross-pressures can be observed. When issue voting is tested based on the scalar product, in the "Lab-Directional model" and the "Con-Directional model" the coefficients are all positively related to voters' voting propensity, irrespective of the voters' issue cross-pressures. However, their influence is only significant among voters with lower issue cross-pressures. In addition, scalar product can explain about $3 \%$ of the variation in the voting propensity in the "Lab-Directional model" and $1 \%$ of that in the "Con-Directional model" when voters suffer lower issue cross-pressures, while it explains $2 \%$ and $0 \%$ respectively when voters have higher issue cross-pressures. In the "Lib-Directional model", there is no coefficient of the scalar product meeting the expectation among voters with neither lower nor higher issue cross-pressures. In short, it is clear that lower issue cross-pressured citizens are more likely to rely on their issue preferences to make a decision.

\footnotetext{
${ }^{19}$ Pooled regression analysis allows us to examine the overall influence of separate issue variables on party support. Instead of regressing voting propensity on each issue variable and all control variables for each given party, pooled regression analysis in this paper converts wide data form (several voting propensity variables) to long data form (only one voting propensity variable).
} 
In the "Directional pooled regression analysis", a similar trend is observed again in terms of the conditioned role of issue cross-pressures in issue voting. Regarding the lower issue cross-pressured citizens, the influence of all three issues are in the expected direction, i.e., positively related to voters' voting dispositions toward a given party and two of them are highly significant, whereas among higher issue cross-pressured citizens, although the directions of the influence of all three issues meet the expectation, only one issue's coefficient is highly significant. In addition, for lower issue cross-pressured citizens, the adjusted $\mathrm{R}^{2}$ increases by 0.06 when moving from the base model to the one including issues, while it decreases by 0.01 for higher issue cross-pressured citizens.

To further test the hypothesis, instead of dividing people into two groups, this study includes the interaction variables in a regression model - between the issue crosspressures score and issue variables - for each given party. Table 3-2 shows the results, and Figures 3-2 and 3-3 plot the predicted probability of issue voting against the different issue cross-pressures scores. Let us first focus on the "Proximity Model" (Table 3-2, left). In two out of three models ("Lab-Proximity model" and "Lib-Proximity model"), the coefficients of the interaction variable - between the issue cross-pressures score and the Euclidean distance - are positively and significantly related to voters' voting propensity, implying that the role of issues in citizens' voting choice will decrease as issue cross-pressures increase. This can be observed in Figure 3-2 (upper left) and Figure 3-2 (upper right). On the one hand, in most cases, the predicted probability of voting for Labour and Liberal Democrats decreases with the Euclidean distance. On the other hand, when the issue cross-pressures score is smallest $(0.5)$, the slope of the line is steepest, which implies that the role of proximity distance in voting propensity is the most pronounced. The slope then becomes steadier as the issue cross-pressures score increases. Moreover, when the issue crosspressures score reaches the largest value (0.9), the influence of the Euclidean distance does not point in the expected direction.

\section{[TABLE 3-2 ABOUT HERE]}

When the interaction variables are included in the pooled regression analysis, the coefficient of one interaction variable - that between the issue cross-pressures score and the issue of black people and Asians - is highly significant (Table 3-2, left). This indicates that 
the influence of the issue of black people and Asians in voters' voting choice depends on the level of issue cross-pressures, which is shown in Figure 3-2 (lower right). With the increase in voters' issue cross-pressures, the influence of the distance between voters' and parties' positions on the issues of black people and Asians decreases. With respect to the other two interaction variables - between the issue cross-pressures score and the issues of tax and crime respectively - their coefficients are not significant but point in the expected direction. Figure 3-2 (lower left) and Figure 3-2 (lower middle) show that the slope for each line becomes a little steadier and even heads in the opposite direction as the issue crosspressures score increases.

\section{[FIGURE 3-2 ABOUT HERE]}

How about the interaction effect in the "Direction Model"? The trend is still noticeable, but it is not as prominent as in the "Proximity Model". From Table 3-2 (right), we can see that the coefficients of the interaction variable - between issue cross-pressures and scalar product - are not significant in all models. However, their directions all meet the expectation, i.e., negatively related with voting propensity. Among them, Figure 3-3 (upper left) and Figure 3-3 (upper middle) show that the slope of the line for Labour and the Conservatives is a little flatter when moving from lower to higher issue cross-pressures. It implies that the influence of the scalar product on the voting probability for Labour and the Conservatives is stronger when voters' issue cross-pressures are lower. In a pooled regression model, the interaction between the issue cross-pressures score and the issue of black people and Asians has significant influence (Table 3-2, right). From Figure 3-3 (lower left) and Figure 3-3 (lower middle), we can see that even though the other two interaction variables do not have significant influence, issue cross-pressures do slightly moderate the role of issues in citizens' voting propensity. When the issue cross-pressures score is smallest, the influence of both tax and crime is the largest and points in the expected direction. In contrast, when the issue cross-pressures score is largest, the direction of influence of the scalar product does not even meet the expectation. 
From the above analysis, we can conclude that issue cross-pressures moderate the role of issues in people's voting choice. Compared to voters with higher issue crosspressures, those experiencing lower issue cross-pressures are more likely to rely on issues when making voting choices. In addition, the moderated role of issue cross-pressures in issue voting can also be observed when the interaction variable is included. Both the results presented in Table 3-2 and those contained in Figures 3-2 and 3-3 demonstrate that the more issue cross-pressures voters suffer, the less pronounced the role of issues in voting choice will be.

\subsection{Conclusion and discussion}

One of the most important advantages of modern democracy proposed by political theorists is that voters can govern through representatives they elect. Therefore, only those who best represent the citizens' policy anticipations can be elected into government. This in turn suggests that citizens will vote based on their policy preferences on various issues. In this regard, exploring the role of issues in party support has been a key concern in political science.

In recent decades, a significant number of academic publications have addressed the remarkable effect of issues on citizens' voting choice. However, the level of issue voting is far from conclusive. Mixed empirical findings have led political scholars to explore both demand-side and supply-side moderated factors. This paper investigates the relationship between issue cross-pressures and issue voting. The main purpose is to investigate whether or not the role of issues in citizens' voting choice is moderated by their issue cross-pressures. Based on the information processing theory, this paper argues that the more issue cross-pressures citizens experience, the less likely it is that they will depend on issues to make their voting decision.

Analyzing a survey dataset from the 2010 British Election Study, the results meet the aforementioned expectation based on both the traditional proximity theory and the directional theory of issue voting. In both the proximity and directional models, the influence of issues on voting choice is more pronounced among voters who suffer a lower level of issue cross-pressures than among those with a higher level. In addition, in the proximity model, the influence of the interaction variable - between the issue crosspressures score and issue variables - can be clearly observed. In the directional model the 
trend is still noticeable, even though it is not as prominent as in the proximity model. All in all, we can conclude that issue cross-pressures moderate the role of issues in citizens' voting choice, and that the more issue cross-pressures voters experience, the less pronounced issue voting will be.

The main contributions of this paper are as follows. First, and most importantly, this research contributes to our understanding of a pervading puzzle: with the decline of cleavage politics and the increase in cognitive mobilization, why is the level of issue voting not as high as political scholars expected? According to the theories of modernization and cognitive mobilization, with the decline of cleavage politics and the development of higher education and communication technology in Western Europe, there should be a boom in issue voting. However, this is not the case in reality. The level of issue voting is far from clear in the existing literature. Exploring the reasons for this phenomenon, this chapter proposes that modernization and cognitive mobilization on the one hand may make citizens more likely to make a decision independently of political elites and parties, which leads to an increasing of issue voting. On the other hand, the same modernization and cognitive mobilization may also make citizens more likely to realize that their positions on different issues point to different parties, which leads to a decrease in issue voting. Therefore, the overall level of issue voting in a specific election in a particular society is the result of these increasing and decreasing forces. Future studies may therefore focus on the relationship between modernization, cognitive mobilization and issue cross-pressures, using longitudinal data.

In addition to these points, the issues themselves may account for the varying level of issue voting. Previous studies initially argued that the level of issue voting was determined by voters' personal characteristics. Later, it was argued that the level of issue voting depended not only on demand-side factors but also on the election contexts. For example, several studies stated that if parties did not offer voters a clear choice on issues, voters would not use issues to guide their voting choice, even though they had a higher level of political sophistication. This paper shows that the level of issue voting is also determined by whether voters suffer from issue cross-pressures. A better-educated citizen in a highly competitive election may not just depend on issues to make a voting choice if this citizen's positions on different issues point to different parties. 
Furthermore, studying the influence of issue cross-pressures may reconcile the inconsistent findings in the existing studies regarding whether and when voters will rely more on issues in making their voting choice. For instance, Sniderman et al. (1990) found that issue voting was more pronounced among voters with a higher level of education. In contrast, Weisberg and Nawara (2010) showed that issue voting was similar across different levels of education. In order to reconcile these inconsistent findings, issue cross-pressures may give us some additional insights. On the one hand, politically sophisticated citizens may be more likely to find parties whose positions on particular issues are similar to their own. On the other hand, however, this may increase the probability that they will experience issue cross-pressures, which in turn moderates the conditioned role of political sophistication in issue voting. The case is the same for the conditioned role of supply-side factors. If parties' issue mobilization causes people to experience issue cross-pressures, issue voting may not be triggered. All this implies that future studies should focus on the interaction effect among issue cross-pressures, personal characteristics, and election contexts.

Nevertheless, the present study also has some limitations. As was found, the moderated effects of issue cross-pressures in issue voting are different in the proximity and directional models. In the proximity model, the influence of issue cross-pressures can be clearly observed no matter with or without interaction variables- between the issue crosspressures score and issue variables. While, in the directional model, the moderated role of issue cross-pressures is less prominent especially when interaction variables are included. It implies that if relying on directional model, the impact of issues on voting decisions can only be moderately moderated by issue cross-pressures. It in turn decreases the importance of issue cross-pressures for issue voting. In this regard, it is important to explore why results from the proximity and directional models are different, which, however, is not addressed in this study. 


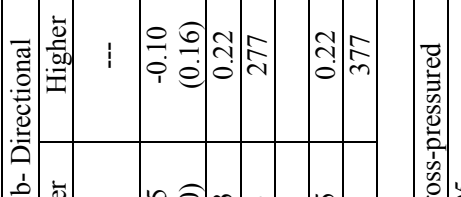

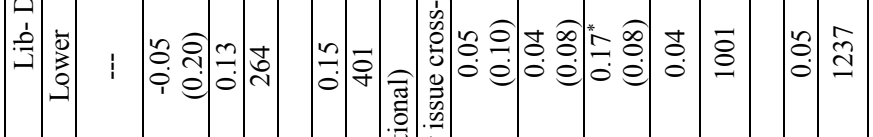

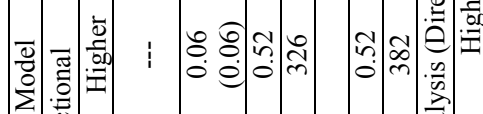

0
0
0
0
0
0
0
0
0
0
0
0
0
0
0
0
0
0
0
0
0
0
0
0
0
0
0

즘.

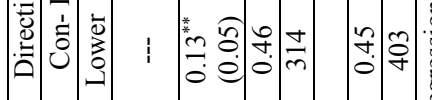

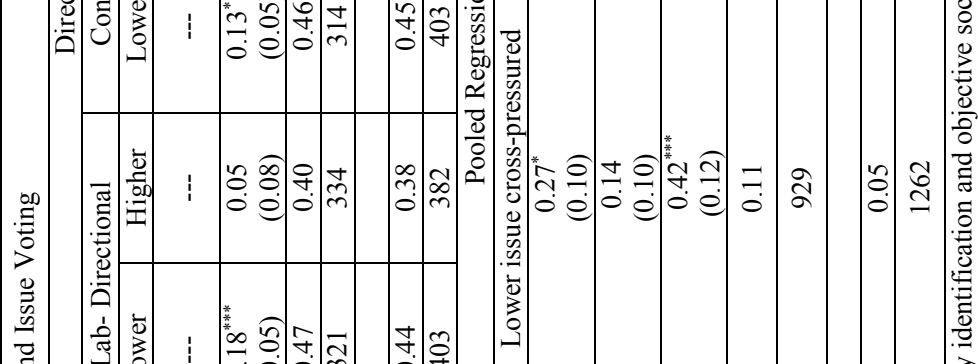

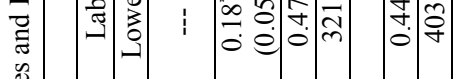

递

.

0
0
0
0
0
3
0
0
$\vdots$
0
0
0
0
0
0
0
0
0
0
0
0
0
0
0
0
0
0
0
0
0
0
1
0
0
0
0
0
0

:

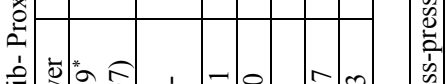

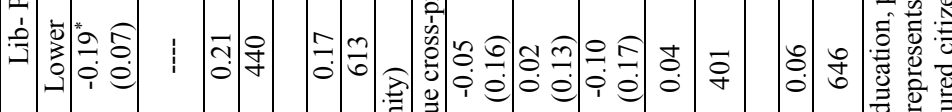

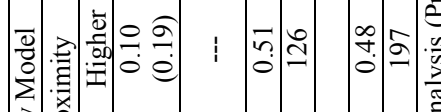

?

気

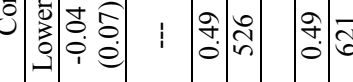

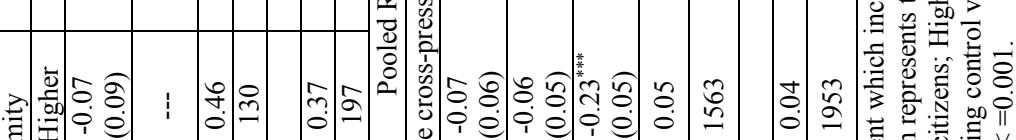

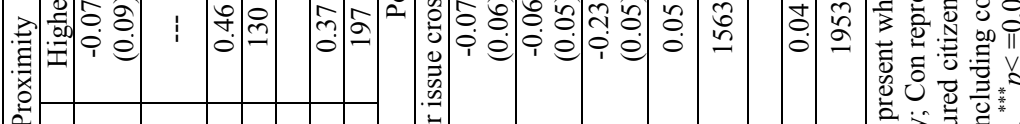

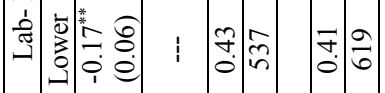

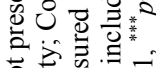

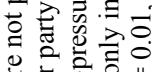

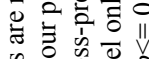

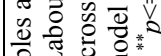

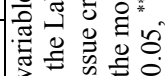

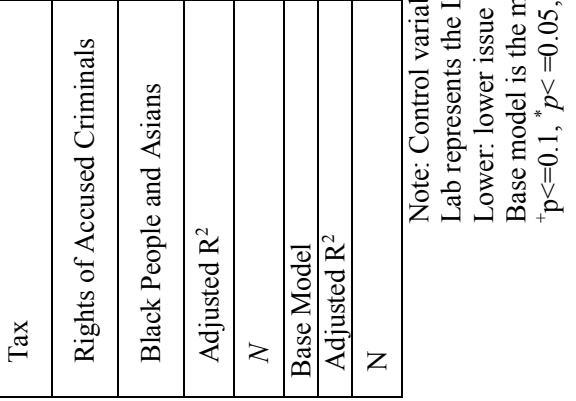

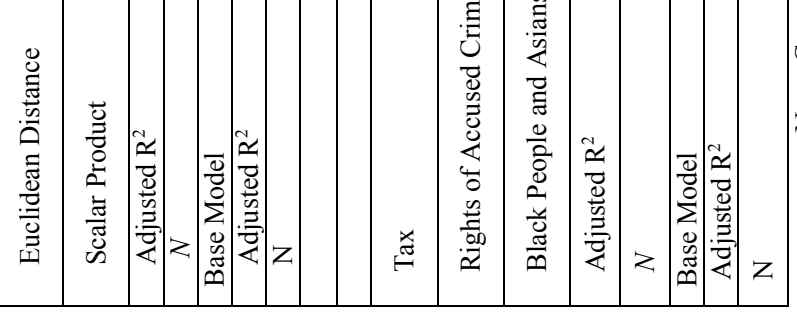




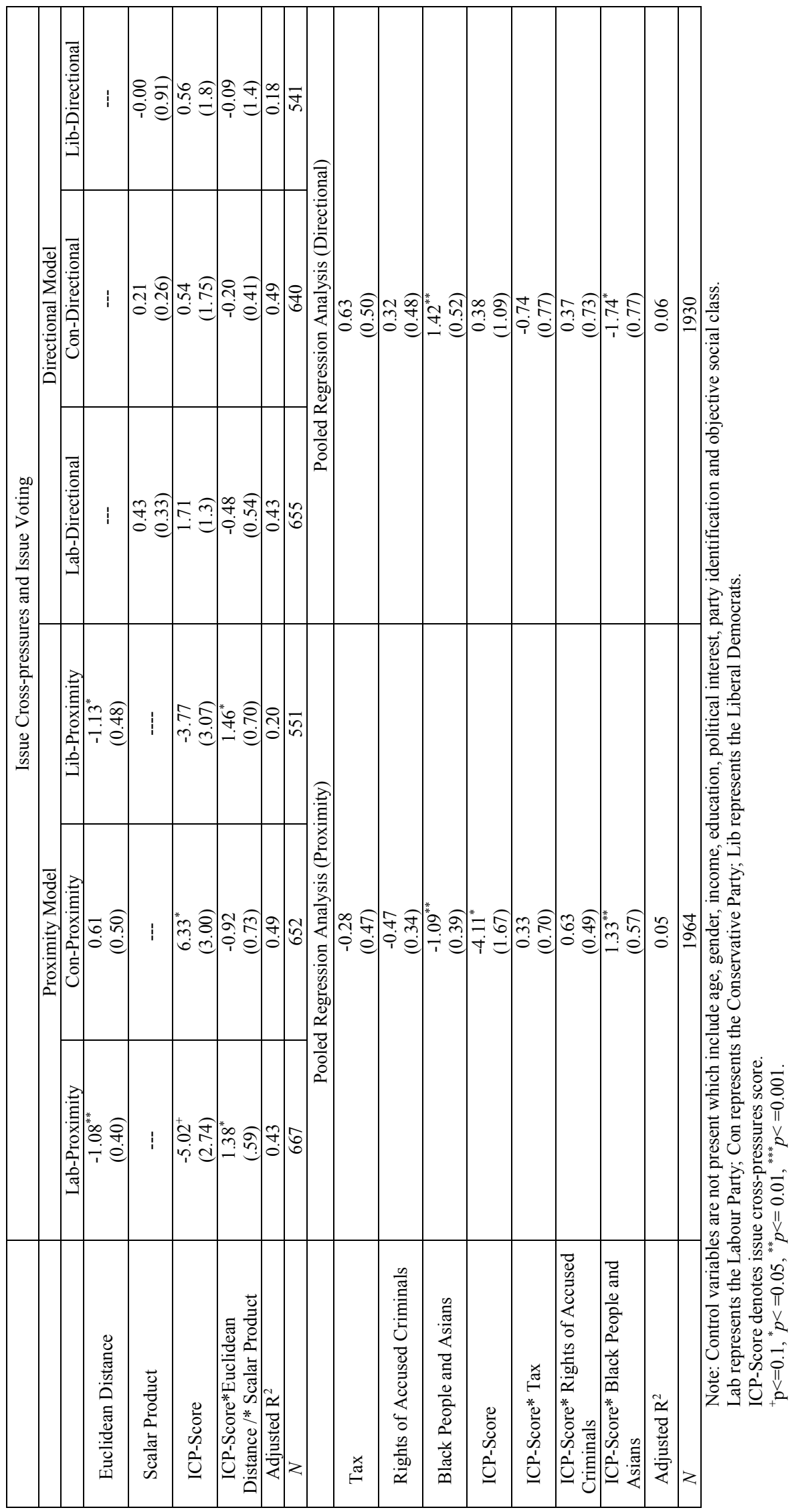


0
0
0
0
0
0
0
0
0
0
0
0
0
0
0
0
0
0
0
0
0
0
0
0
0
0
0

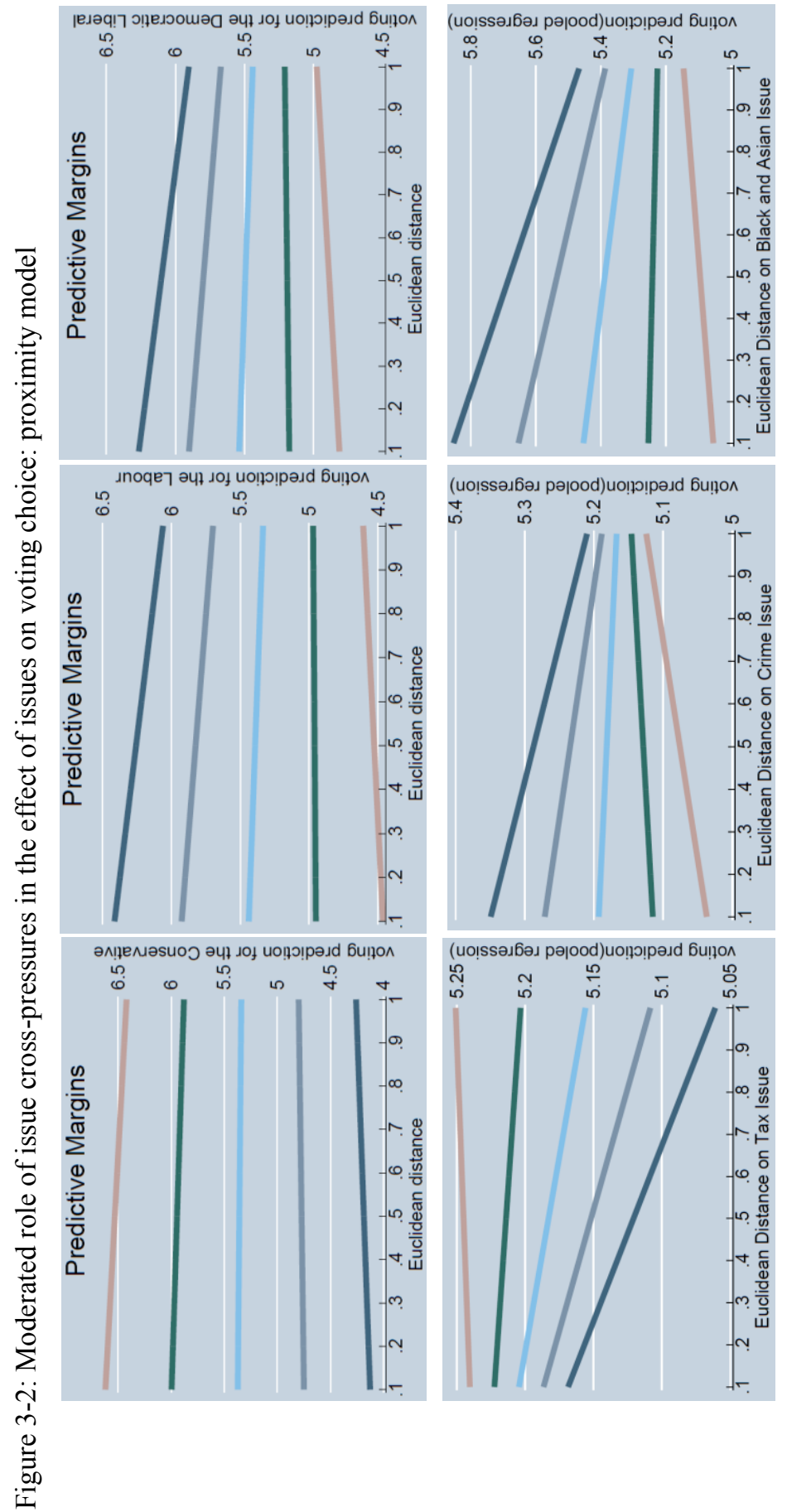

॥.

롤

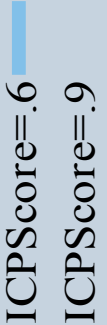

.

플

๙

0

옹

n

$\because \models$

ก $\infty$

넨

ల

Uิ

$\because-$ के

i

党

$\stackrel{0}{\square}$

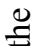

.

ठั.

ใิ

ஜ் 

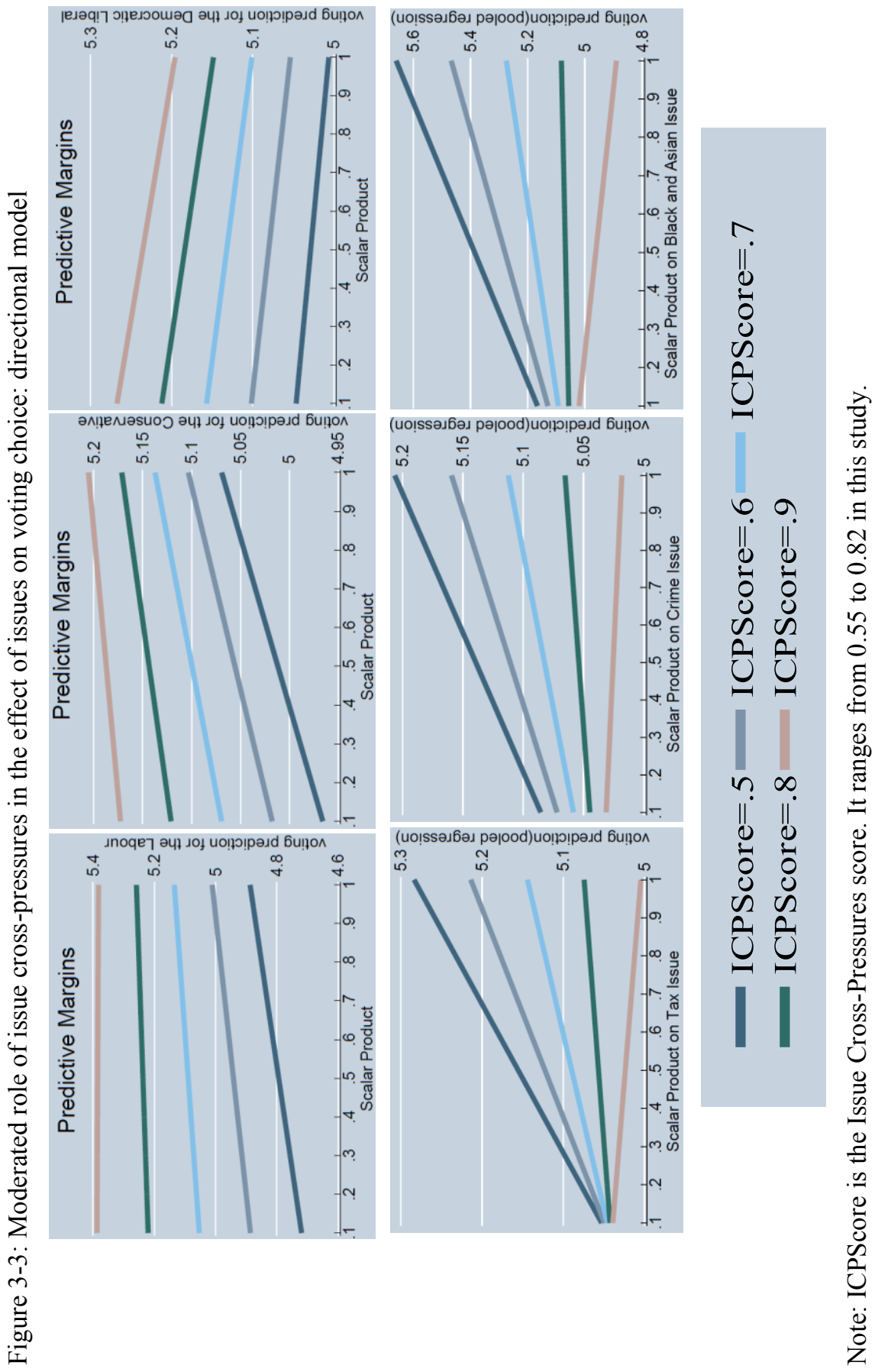


\section{4-Issue Cross-pressures and Turnout}

This chapter examines the second possible role of issue cross-pressures in citizens' electoral behavior, that is, voting motivation. For democratic societies, electoral turnout is often considered an important indicator of democracy. In response to the decline of party identification and traditional political cleavages, political scholars are increasingly turning their attention to policy issues in explaining the fluctuation in turnout. This chapter attempts to offer a new factor for explaining voter abstention: issue cross-pressures that emerge due to policy alternatives provided to voters in the contemporary world. There are two main research questions: (1) whether or not issue cross-pressures decrease citizens' motivation to turn out to vote, and (2) whether or not the role of issue cross-pressures in turnout is moderated by the party system. The data comes from national election studies in the Netherlands (1994-2012) and the United Kingdom (1992-2010).

\subsection{Introduction}

Imagine citizens for whom two issues serve as the most important motivators for voting: immigration policy and social policy. On the issue of immigration policy, they favor Party A's position and want to vote for this party in the general election. However, on the issue of social policy, they prefer Party B's position, which pushes them toward voting for that party instead. How will these citizens behave? Will they turn out to vote or not? Does this kind of inconsistency influence their motivation to vote? These are the main questions this study addresses.

For democratic societies, electoral turnout is often considered an important indicator of democracy. From an institutional viewpoint, turnout is essential to guarantee the legitimacy of political systems and validate the people's control over the composition of their government. For citizens, turning out to vote is a way to influence political bodies. A 
high level of turnout can contribute to moderating the effects of socioeconomic inequality (Perea, 2002; Verba \& Nie, 1972). It is therefore not surprising that political scientists in both the United States and Europe see the decline in turnout as highly pernicious and devote themselves to describing and explaining turnout.

A number of studies have attempted to account for the fact that some individuals vote while others do not and to explain why some voters vote in one election but abstain in the next (Aarts \& Wessels, 2005; Adams et al., 2006; Blais, 2000, 2006; Blais \& Aarts, 2006; Blais \& Rubenson, 2013; Konzelmann et al., 2012; Wolfinger \& Rosenstone, 1980). However, few of them have addressed the role of issue cross-pressures, which Therriault et al. (2011) have defined as pressures that voters feel when they hold policy preferences across various issues that push them in different political directions. Most of the studies on issue cross-pressures have been confined to the United States and focus only on a single election.

Due to the rise of issue voting, issue cross-pressures have become a potential factor to explain fluctuations in turnout. Since the late 1970s, as societies in Western European democracies have developed and individuals have modernized, citizens are thought to be more capable of managing their own political affairs and therefore do not need to rely on parties for political information. As a result, they decide for themselves whether and how to vote from election to election, rather than relying upon party identification and social/religious cleavages (Inglehart, 1977; Dalton, 1984; Dalton et al., 2000; Inglehart \& Welzel, 2005). In this context, the importance of party identification and traditional political cleavage in explaining and understanding citizens' voting behavior has been comparatively weakened. Issues, on the other hand, have become one of the main forces leading individuals to a particular candidate or party. When citizens' policy preferences across various issues lead them to different candidates or parties, they may experience issue cross-pressures. Do citizens' inconsistent party preferences as a result of differential positions on issues indicate lower voting motivation? Will citizens be more likely to vote when their issue positions push them toward a single party rather than multiple parties? Investigating these questions has important normative and theoretical consequences. If issue cross-pressures decrease citizens' motivation to vote, the decline of turnout across advanced Western democracies since the 1980s might partially be the result 
of the rise of citizens' diversified issue preferences and a lack of comprehensively responsive parties.

This study examines the role of issue cross-pressures in turnout by analyzing survey data from the Dutch Parliamentary Election Study (1994-2012) and the British Election/General Election Study (1992-2010). By using data from these two countries, this study seeks to demonstrate whether the role of issue cross-pressures in turnout is conditioned by the type of political system. The study is divided into five sections. The first section describes the background to this study. The second section discusses the possible mediating role of political systems in the relationship between issue cross-pressures and turnout. This is followed in the third section by a presentation of data and methods. The fourth section details the results of the empirical analysis, while, finally, the fifth section discusses the implications of the findings.

\subsection{The place of issue cross-pressures in explaining voter turnout}

On the topic of individuals' turnout, two questions are worth exploring. Why do some voters go

out to vote while others abstain? And why do some voters vote in one election but abstain in the next (Blais, 2000)?

Since turnout studies of socio-demographic (such as gender, age and education) and socio-psychological factors (such as party identification) both concentrate on long-term individual attributes, they can provide a good understanding of which groups of people may vote in an election and which groups may not. However, they add comparatively little knowledge about why many voters fluctuate between voting and abstaining across elections, for example casting a vote in one election but abstaining in the next. In order to fully explain fluctuations in turnout, political scientists should pay attention to the role of political-institutional factors and ask to what degree voting participation is influenced by the options available to individuals.

Two of the main political-institutional factors in turnout studies are indifference and alienation. In response to the decline of party identification and traditional political cleavages, political scholars are increasingly turning their attention to policy issues, as citizens are believed to make their voting choices based on their positions on particular issues in specific elections. In this context, the classic spatial model of abstention becomes 
particularly important in explaining the fluctuation in turnout. Following Downs' (1957) insight, indifferent voters-people who perceive little to no difference between any of the candidates' or parties' policy positions on an issue-will be more likely to abstain. Alienated voters - citizens whose ideal position on an issue is distant from all the candidates' or parties' positions-will also be less likely to vote. Indifference and alienation can provide a better understanding of why some voters' decisions to vote or abstain vary across elections, since the presence or absence of policy alternatives on an issue and the distinctness of policy platforms make a difference to voters.

However, there is one problem with the spatial model of abstention. Most studies on both indifference and alienation only focus on one dimension, such as a specific issue or ideology (Aarts \& Wessels, 2005; Adams et al., 2006; Brody \& Page, 1973; Plane \& Gershtenson, 2004; Zipp, 1985). When voters face multiple issues, as they typically do in any election, calculating policy distances between their stances and the stances of candidates or parties is less straightforward (Humphreys \& Laver, 2010). Voters would have to locate themselves and each candidate and/or party as a separate point in multidimensional space based on their own and the candidates' or parties' positions on every policy issue. Then they would need to calculate the Euclidean distance between their own points and the candidates' or parties' points (Davis et al., 1970; Enelow \& Hinich, 1984). This kind of reasoning and calculation is complicated and demanding. In addition, research on political ideology has demonstrated that voters' preferences on various issues, especially social and economic ones, are relatively independent of each other, meaning that the belief systems of the public are multidimensional rather than unidimensional (Feldman, 2003; Feldman \& Johnston, 2014; Swedlow \& Wyckoof, 2009; Treier \& Hillygus, 2009). These points all imply that, when facing more than one issue, voters may consider each issue separately and look at which party best represents them on that issue, rather than seeking a multi-dimensional fit. If so, can the spatial theory of abstention, whichposits policy-specific indifference and alienation based solely on one issue, fully explain citizens' voting motivation? This study will argue that it cannot.

Imagine a scenario where a voter's position on issue 1 is close to party A's position. Since this voter feels neither indifferent to nor alienated from party A on this issue, the voter is motivated to vote. With respect to issue 2, this voter likes party B's position. Again, this voter is not indifferent to or alienated from party B, and so the voter is 
motivated to vote. However, in most political contexts, each citizen only has one vote and therefore cannot vote for two different parties at the same time in an election. In this kind of situation, the model of abstention due to policy-specific indifference and alienation may not accurately indicate what voters' behavior will be. This study proposes that issue crosspressures be added to the model of abstention as a third factor because of the existence of policy alternatives available to voters.

Issue cross-pressures emerge from inconsistent voting predispositions based on various issues. If voters care about two or more issues that are equally important to them, and if their positions on these issues push them toward different candidates or parties, voters are under issue cross-pressures. However, if voters' positions on these issues push them toward the same candidate or party, then voters will not experience issue crosspressures. Lazarsfeld et al. (1968) suggested that when voters suffer psychological inconsistency, they will avoid making a decision in order to evade the uncomfortable feelings. Additionally, Festinger (1962) argued that people enter a state of cognitive dissonance when two or more of their cognitions are inconsistent with each other. They experience this cognitive dissonance as uncomfortable tensions, which in turn drive them to reduce the dissonance. Accordingly, when voters hold contradictory voting predispositions stemming from different issues, and therefore suffer from inner conflict, those voters may abstain in order to mitigate or circumvent their unpleasant feelings. In other words, this study hypothesizes that issue cross-pressures decrease a person's motivation to vote, and the more issue cross-pressures a person feels, the more likely it is that they will abstain.

Only a few studies explore the role of issue cross-pressures in turnout. Based on survey data from the 2000 US presidential election, Hillyus and Shields (2008) demonstrated that people who disagreed with their own party on several important issues, i.e., policy cross-pressured citizens, were more likely to defect to the opposing party during the election campaign. Although this work does not address the role of issue crosspressures in turnout directly, this result might be extended to issue cross-pressured voters. Since issue cross-pressured voters may not have strong preferences for one candidate over another, their motivation to vote in an election may be weaker than that of voters without cross-pressures. By using survey data from the 1993 parliamentary election in Norway, Narud and Valen (1996) found that the differences in the percentage of abstainers between voters who disagree with their own party in terms of some important issues and voters who 
do not experience issue cross-pressures were not very significant, and the hypothesis that strong identifiers under cross-pressures tend to abstain more often than others during an election was not confirmed. By employing survey data from the 2000 US presidential election, Therriault et al. (2011) confirmed that voters experiencing issue cross-pressures were less likely to participate in political activities, such as turning out to vote, attempting to influence others, and involving themselves in public or private campaigns. From this description, we can see that the existing studies on the role of issue cross-pressures in political participation have controversial findings: some support the view that issue crosspressured citizens behave differently from those who experience no issue cross-pressures, while others do not. What accounts for the inconsistent findings? Narud and Valen (1996) focused on Norway, which has a multi-party system, while Therriault et al. (2011) concentrated on the United States, which has a two-party system. Is the influence of issue cross-pressures moderated by different political systems? This study will test the hypothesized relationship between issue cross-pressures and turnout, relying on survey data from the Dutch Parliamentary Election Study (1994-2012) and the British Election/General Election Study (1992-2010). In this way, it seeks to demonstrate whether or not the role of issue cross-pressures in turnout is conditioned by the type of political system. The next section describes how political systems moderate the role of issue cross-pressures in turnout.

\subsection{Issue cross-pressures, turnout, and the political system}

One element worth considering in the relationship between issue cross-pressures and turnout is the party system context in which elections take place. The party system context might moderate the influence of issue cross-pressures on turnout in a number of ways. First, it may affect the level of issue cross-pressures that a person experiences. As the number of political parties increases, voters may be more likely to experience more issue crosspressures. Since parties are issue providers, when there are more parties campaigning to win a seat in the government, voters may face an increased number of salient issues during an election. A greater number of parties also means a greater number of alignment choices for voters since each party has its own position on a specific issue. Thus, voters are more likely to be pushed toward different parties because they hold different positions on different issues. Therefore, this study also hypothesizes that, as the number of political parties increases, people are more likely to experience more issue cross-pressures. 
The kind of party system may also affect the relationship between issue crosspressures and turnout. When political contexts are equally dominated by several parties, each party has a good chance of winning political representation. In this situation, people whose issue positions push them toward two or more parties may be less willing to abstain, since their abstention might increase the chance of other parties winning parliamentary seats. However, when political contexts are mainly dominated by two parties, small parties will have fewer resources to motivate voters and will thus have fewer chances to win seats in parliament. In this regard, abstention may be more likely for people who are struggling to decide between two dominant parties since they can get at least a part of what they want, regardless of whether they turn out to vote. On the other hand, people who are struggling to decide between one dominant party and one small party may be less likely to abstain and instead decide to vote for the dominant party in order to increase the likelihood of getting what they want. Overall, this study expects that the influence of issue cross-pressures on turnout is less pronounced when a political context is dominated by several parties.

\subsection{Data and method}

Case selection: This study explores the influence of issue cross-pressures and differing political contexts on turnout using an analysis of elections held in the Netherlands and the United Kingdom. These two countries are typical of advanced democracies. They both display the decline of cleavage politics, observed since the late 1970s (Dalton, 1984; Dalton et al., 2000). With increased economic development, the enormous rise of the Internet and mass media, and the growing level of people's education since the 1990s in both countries, citizens are thought to be more capable of managing their own political affairs and knowing their own and candidates' or parties' positions on various issues. Under these circumstances, people could experience issue cross-pressures which, in turn, influence their decision to vote or abstain. Because the numbers of effective parties are 5.5 in the Netherlands and 2.3 in the United Kingdom, ${ }^{20}$ this study expects that Dutch citizens will be more likely to experience higher issue cross-pressures than British citizens, but that the role of issue crosspressures in turnout will be stronger in the United Kingdom than in the Netherlands.

\footnotetext{
${ }^{20}$ The number presented is a mean value. For the specific numbers of parties in each election from the 1990s to the 2010s in the Netherlands and United Kingdom, see http://www.tcd.ie/Political_Science/staff/michael_gallagher/ElSystems/index.php.
} 
Data: To answer the research questions, several pieces of information are needed. First, and most importantly, we need to obtain voters' decisions to vote or abstain. Secondly, to calculate voters' issue cross-pressures, we need to know voters' positions on different issues and their voting intentions. Finally, to make our findings more convincing, we need to control for voters' demographic backgrounds and political attributes. Excellent data from the Dutch Parliamentary Election Study (1994-2012) and the British Election/General Election Study (1992-2010) provides all essential information.

Method: The dependent variable is voters' turnout (vote or abstain). With respect to the Netherlands, respondents were asked: "Did you or did you not vote in the [year] $]^{21}$ parliamentary elections?" The answers were recoded with "Yes" as "1" and "Others" (including "Didn't Vote," "Don't Know," and "No Answer") as "0.,"22 The percentage of people who did not go out to vote ${ }^{23}$ on election day ranged from a low of $14.01 \%$ in the 2012 election to a high of $22.30 \%$ in the 1994 election (see Table 1, left). ${ }^{24}$ In the United Kingdom, respondents were asked: "Did you manage to vote in the general election?" Answers included "Yes," coded as "1," and "Others" (including "Didn't Vote," "Don't Know," and "No Answer"), coded as "0." The percentage of people who did not manage to vote ranged from a low of $12.99 \%$ in 1992 to a high of $43.51 \%$ in 2001 (see Table $4-1$, right).

\section{[TABLE 4-1 ABOUT HERE]}

The independent variable is the issue cross-pressures score, which is taken as a proxy of a person's level of issue cross-pressures. Issue cross-pressures arise from voters' positions on various issues. ${ }^{25}$ From their own positions on particular issues, individuals may feel drawn to supporting one political party or another. If voters' positions on various issues

\footnotetext{
${ }^{21}$ The years are 2012, 2010, 2006, 2002, 1998 and 1994 respectively.

22 The 2003 election is omitted since the survey data from 2003 (NKO2002-2003) does not include the item of "turnout."

${ }^{23}$ In both the Dutch and British cases, people who answered "Didn't vote," "Don't Know," and "No Answer" are regarded as non-voters.

${ }^{24}$ The percentage of turnout is the percentage of turnout in each dataset, not the real turnout in either the Netherlands or the United Kingdom.

${ }^{25}$ This study only focuses on position issues.
} 
direct them toward different parties, and if these issues are equally important to them, voters will be more likely to feel conflicting pressures. If voters' positions on these issues push them to the same party, however, they will not experience cross-pressures. The issue cross-pressures score, discussed below, takes into account not only an individual's positions on various issues but also the extent to which the individual's position on a specific issue is likely to generate reinforcing or conflicting impact in terms of partisan preference.

The calculation of issue cross-pressures score is based on the regression-based measurement described in Chapter 2. Out of the four different steps, we can observe that the first step is fundamental, which involves voters' stances on various position issues and party preferences. The party preferences in this chapter is voting intention (nominal). Voting choice and party identification could also have been chosen as dependent variables in this step. However, if we chose voting choice as the dependent variable, those who did not vote in the elections would be automatically excluded in this step and it would be hard for us to test how issue cross-pressures influence turnout. If we chose party identification as the dependent variable, many respondents would also be excluded since many voters do not have a party identification, especially in European contexts. Therefore, the first priority for the dependent variable in this step is voting intention ${ }^{26}$. In the third step, this chapter chooses the highest two predicted probabilities for each respondent ${ }^{27}$ in order to examine

\footnotetext{
${ }^{26}$ For the analysis of the Dutch elections, the dependent variable in this step was generated by combining the variables of "voting intention" and "vote intention if non-voter is obliged to vote". The 2012 election was omitted since survey data from 2012 (NKO2012) does not include the variable of "voting intention". For the analysis of the British elections, the dependent variable was generated by combining the variables of "Decided-Vote Which Party" and "Undecided-Lean Which Party." The 1992 and 1997 elections were omitted since survey data from 1992 and 1997 (bes92e, besx97e) do not include the variable of "voting intention".

The independent variables in this step are voters' positions on various position issues. There are usually several issue questions in each of the election surveys. However, it is reasonable to assume that, since some respondents only care about some issues, they may not answer all of the issue questions. In those instances, the mean score of respondents' positions on a particular issue is added in place of the missing values. See Table 4-1 and Table 4-2 in Appendix B for the position issues that are included in this study for each election in the two countries.

${ }^{27}$ Brader et al.'s (2014) approach lays out several choices in this step: the two highest predicted probabilities, the three highest predicted probabilities, or all parties' predicted probabilities. This study selects the two highest predicted probabilities for two reasons. First, people's issue cross-pressures scores measured based on different choices are highly
} 
whether voters' issue positions generate reinforcing or conflicting pressures. For more detail information see Chapter 2.

People may argue that, when calculating voters' issue cross-pressures, we should take into account personal issue salience - the differences in the salience of issues among respondents given that the issues an individual considers to be personally important may be more likely to push the person toward a particular party. This can be achieved by incorporating voters' personal issues salience in step $1 .{ }^{28}$ However, the present study does not do this, for two reasons. The first reason is that the widespread measure of personal issue salience, namely the questions asking for the "most important problem," has been found to be problematic (Wlezien, 2005; Johns, 2010), and these questions are the main measure of individual issue salience in the surveys from both the Dutch and British election studies. Second, when this study incorporates personal issue salience into the analysis, the final results are largely consistent with those reported below. ${ }^{29}$ For these reasons, this study only differentiates the importance of various issues to voters as a whole rather than considering personal issue salience.

In order to avoid a spurious relationship between issue cross-pressures and turnout, this study controls for several demographic variables including age (from young to old), gender (male coded as " 1 "; female coded as “ 0 "), social class, ${ }^{30}$ education ${ }^{31}$ and political variables. Political variables include party identification, ideology and political interest. ${ }^{32}$

correlated (almost between 0.7 1.0, see Table 4-5 and Table 4-6 in Appendix B). Second, while we must admit that it is possible for voters to consider three or more parties to vote for in an election, we contend that it is more likely for voters to consider one or two parties at one time. Focusing on voters' two strongest voting predispositions seems more reasonable.

${ }^{28}$ See Table 4-4 in Appendix B.

${ }^{29}$ See Table 4-3 in Appendix B.

${ }^{30}$ Social class refers to subjective self-image social class. In the Netherlands, it is coded from " 1 " (upper class) to " 5 " (working class). In the United Kingdom, in the 2001 election, there is no such variable. In the 2005 and 2010 elections, there are more than $50 \%$ of people who do not state their social class. Therefore the variable is coded as " 1 " (has social class) and " 0 " (does not state).

${ }^{31}$ In the Netherlands, education is coded from " 1 " (elementary) to " 5 " (higher level/university). In the United Kingdom, it is coded as "1" (has education or qualifications) and " 0 "(does not have education or qualifications).

${ }^{32}$ In the Netherlands, political interest is coded from " 0 " (low) to " 4 " (high). In the United Kingdom, around $25 \%$ of people did not state their political interest in each of the three 
Having party identification is coded as " 1 " and no party identification is coded as " 0 ." Ideology is coded as two dummy variables: left ideology and right ideology; the reference group is those who do not have any clear ideology. These variables are assumed to influence turnout, but they may also affect the level of issue cross-pressures or moderate the relationship between issue cross-pressures and voting motivation.

\subsection{Findings}

The task of this study is to examine whether issue cross-pressures influence voters' motivation to vote and to see whether the effect is conditioned by the kind of political system. The first hypothesis is that issue cross-pressures decrease turnout and the more issue cross-pressures voters experience, the less likely they will be to go out to vote. Secondly, this study also hypothesizes that, as the number of political parties increases, people are more likely to experience more issue cross-pressures. However, the relationship between issue cross-pressures and turnout is less remarkable when more parties are equally distributed.

Figures 4-1 and 4-2 show that people who experience higher issue cross-pressures may have less motivation to go out to vote. With respect to the Netherlands, the results presented in Figure 4-1 show that higher issue cross-pressures are linked to less motivation to go out to vote. In three out of five elections, people who abstained from voting have higher mean issue cross-pressures scores compared to those who cast a vote. The scores are 0.84 vs. 0.82 (2010), 0.87 vs. 0.84 (2002) and 0.81 vs. 0.77 (1998). In the other two elections, the mean issue cross-pressures scores of people who abstained and who voted are the same: 0.86 vs. 0.86 (2006) and 0.84 vs. 0.84 (1994). In terms of the United Kingdom, higher issue cross-pressures scores are also related to higher likelihood of abstention, as seen in Figure 4-2. The mean issue cross-pressures scores of people who voted are 0.80 (2010), 0.80 (2005) and 0.69 (2001) while they are 0.84 (2010), 0.82 (2005) and 0.74 (2001) for people who did not vote. In all three elections, people who did not vote have larger mean issue cross-pressures scores than those who did vote.

\section{[FIGURE 4-1 ABOUT HERE]}

elections. Therefore the variable of "Election Interest" is used, coded from "1" (not interested at all) to " 4 " (very interested). 


\section{[FIGURE 4-2 ABOUT HERE]}

Still, the difference between the mean issue cross-pressures scores of people who voted and people who abstained seems fairly small across elections in both countries. Therefore, relying on Figures 4-1 and 4-2 will be unconvincing to conclude that issue crosspressures have an influence on citizens' motivation to vote. In the next test, I put voters' issue cross-pressures scores into a regression model with control variables. Since the dependent variable, turnout, only has two values ( 1 and 0$)$, a binary logistic regression is used. The results are displayed in Table 4-2. With respect to the Netherlands, the coefficients of the issue cross-pressures score in two of the elections (1998 and 2002) are highly significant and in the expected directions. In other words, issue cross-pressures do influence a person's motivation to go out to vote. In addition, the more issue crosspressures a person suffers, the less likely it is that they will go out to vote. In the other three elections (1994, 2006 and 2010), the coefficients of issue cross-pressures scores are not significant. With respect to the United Kingdom, the coefficients in all three elections are negative, which means that the higher issue cross-pressure scores are correlated with less likelihood that a voter will go out to vote. Of these three elections, the effect of issue crosspressures on turnout is strongly significant in 2001 and 2010. The odds ratios for voters to go out to vote decrease by 0.81 and 0.93 , respectively, with every unit increase in the issue cross-pressures score. In summary, the influence of issue cross-pressures is significant and in the expected direction in four out of eight elections, regardless of demographic backgrounds and political attributes. Therefore, we can conclude that issue cross-pressures have an impact on turnout.

\section{[TABLE 4-2 ABOUT HERE]}

We now turn our attention to the role that the kind of political system has in conditioning the effect of issue cross-pressures on turnout. First, this study assumes that, as the number of political parties increases, citizens are more likely to experience more issue cross-pressures. Therefore, we can expect that people in the Netherlands are more likely to experience higher issue cross-pressures than in the United Kingdom. The findings presented in Table 4-3 confirm this hypothesis. The mean issue cross-pressures score across 
five elections from 1994 to 2012 in the Netherlands is 0.83 , while the mean issue crosspressures score across three elections from 2001 to 2010 in the United Kingdom is only 0.78. This result shows that voters suffer more issue cross-pressures in a multi-party, equally-distributed context than in a nearly two-party dominated context.

It could be argued that the above comparison is not appropriate, since the issue cross-pressures scores are calculated based on different issues in these two countries. This study does not rule out the potential influence of the number of issues and the kinds of issues on issue cross-pressures scores. However, I argue that this comparison is still reasonable. First, since it is highly improbable that issues of concern in two different societies would be exactly the same, it is always impossible to perfectly compare the effect of people's issue cross-pressures across different countries via surveys and over systems. Second, it can be somewhat trusted that the influence of the number of issues on issue cross-pressures scores is not great. In four out of five elections in the Netherlands, the number of included issues is the same ( $\operatorname{seven}^{33}$ ) while the mean issue cross-pressures scores in these four elections are different from each other (see Table 4-3). In the United Kingdom, the number of included issues is the same (four ${ }^{34}$ ) in the 2005 and 2010 elections, while the mean issue cross-pressures scores are different (see Table 4-3). Third, the kinds of issues may influence the issue cross-pressures score. For example, if one study includes the issues of income difference and crime while another includes income difference and taxes, we may expect a lower issue cross-pressures score in the second case since income difference and taxes are ideologically more closely related than income differences and crime. In this study, though, this influence is limited. The correlations among different issues included in this analysis are mainly around 0.1 in different elections, both in the Netherlands and in the United Kingdom. ${ }^{35}$

[TABLE 4-3 ABOUT HERE]

Even though Table 4-3 demonstrates that people are more likely to experience more issue cross-pressures when there are more parties, it is not a foregone conclusion that

\footnotetext{
${ }^{33}$ See Table 4-1 in Appendix B.

${ }^{34}$ See Table 4-2 in Appendix B.

${ }^{35}$ See Tables 4-7 to 4-12 in Appendix B.
} 
the influence of issue cross-pressures on turnout will be more pronounced as well. The second element of a party system to pay attention to is the distribution of parties. This study hypothesizes that the relationship between issue cross-pressures and turnout will be less remarkable in a context where there are more parties that are equally distributed. The results displayed in Table 4-2 support this hypothesis. With respect to the Netherlands, in two out of five elections, issue cross-pressures significantly influence a person's motivation to go out to vote. In the United Kingdom, this is the case in two out of three elections. In addition, the coefficients of issue cross-pressures are significant at the 0.05 and 0.01 levels for the two Dutch elections, respectively, but at the 0.001 level for two of the British elections. In sum, the effect of issue cross-pressures on turnout is more pronounced in the United Kingdom (an almost two-party dominated context) than in the Netherlands (a multiparty, equally distributed context).

\subsection{Conclusion and discussion}

Political scholars have long considered that political participation plays an important role in ordinary people's lives. For ancient Greek political philosophers such as Aristotle, political participation was an aspect of a good life and a means of self-fulfillment. According to theories of liberalism, civic involvement is a necessary means of protecting citizens' personal liberty and an important way to choose people to serve in government. With the unparalleled characteristics of universal access, equality of influence and accountability, voting is a unique form of political participation (Rokkan, 1962: 67). It is therefore not surprising that political scientists devote themselves to describing and explaining turnout.

This study focuses on the individual level of turnout and investigates (1) whether or not issue cross-pressures decrease citizens' motivation to turn out to vote, and (2) whether or not the role of issue cross-pressures in turnout is moderated by the party system. To answer these questions, this study analyzed survey data from five Dutch parliamentary elections (1994-2012) and three British general elections (1992-2010). The findings show that, overall, those who abstain during elections are more likely to experience higher issue cross-pressures than those who cast a vote. After regressing voters' turnout on their issue cross-pressures scores and controlling for variables including demographic backgrounds and political attributes, the coefficients of issue cross-pressures scores in six out of eight elections are in the expected directions, that is, negatively related to turnout. Of those six 
elections, issue cross-pressures significantly affected voters' motivations to turn out to vote in two elections in the Netherlands and two elections in the United Kingdom. In total, in four out of eight elections, issue cross-pressures had an significant influence on turnout. We can therefore conclude that issue cross-pressures have an impact on voters' motivations to turn out to vote.

The findings also support the hypothesis regarding the conditioning effect of party system contexts. First, voters experience more issue cross-pressures in multi-party dominated contexts than in almost two-party dominated contexts: the mean issue crosspressures score in the Netherlands is 0.83 , while it is only 0.78 in the United Kingdom. Second, this study finds that in two out of five elections in the Netherlands, the effects of issue cross-pressures scores on turnout are significant at the 0.05 and 0.01 levels. In two out of three elections in the United Kingdom, the effects of issue cross-pressures scores are significant at the 0.001 level. These findings imply that, although people may suffer more issue cross-pressures as the number of parties increases, the influence of issue crosspressures on turnout is more pronounced in almost two-party dominated contexts than in multi-party dominated contexts. The conclusion is that the role of issue cross-pressures in turnout is moderated by the party system.

This study offers a third factor for explaining voter abstention: issue crosspressures that emerge due to policy alternatives provided to voters in the contemporary world. Previous studies have mainly focused on policy-specific indifference and alienation. These two factors can give us a good understanding of voting choices when voters only care about one issue in an election or when ideology is unidimensional. However, when voters face two or more policy issues in a political context or when ideology is multidimensional, both policy-specific indifference and alienation give incomplete pictures of voters' decisions to vote or abstain. In addition, investigating the influence of issue cross-pressures on turnout can result in different recommendations for democratic politics. If voters abstain because they feel indifferent, the problem of low turnout appears to result from the convergence of party positions on specific issues. Indifferent citizens will consider the various options offered by the political parties (Dassonneville \& Hooghe, 2016). However, if they find no significant differences between these alternatives, they may be less willing to turn out to vote. In order to improve turnout, parties would want to provide more distinct stances on each of the campaign issues. If voters abstain because they feel 
alienated, the problem of low turnout is due to the fact that no single party is preferred in terms of issue preferences. If citizens feel all parties or candidates are distant from them, it is pernicious for party legitimacy in the long run (Dassonneville \& Hooghe, 2016). In this situation, parties should move toward citizens' positions on particular issues. However, if voters abstain because they experience issue cross-pressure, low voter turnout could be the result of citizens' diversified issue preferences. Issue preferences have diversified as material conditions have grown more affluent since the $1970 \mathrm{~s}$, when people began to concentrate not only on issues of social class and economic redistribution but also on postindustrial issues such as the environment, multi-culturalism and women's and minority rights (Inglehart, 1977). Low voter turnout due to issue cross-pressured abstention could also be the result of a lack of comprehensively responsive parties in the contemporary electoral market. Improving voter turnout in this situation then relies on parties devoting themselves even more to mapping citizens' various concerns.

The study also points toward two directions for future research. As discussed before, this study mainly focuses on the variations of the role of issue cross-pressures in turnout among different political systems. However, the impact of issue cross-pressures on turnout is different across elections within a country. For example, in the Netherlands, in two out of five elections, issue cross-pressures influence people's motivations to go out to vote. In the other three elections, however, the effects of issue cross-pressures are not significant. Further research is needed to explore the question of when issue cross-pressures influence turnout.

Second, the experience of issue cross-pressures indicates that citizens feel there is no single party that fully represents their policy preferences on all issues. Such issue crosspressured citizens might be unsatisfied with democratic politics as a whole in the long run. In order to systematically assess the consequence of issue cross-pressures, further studies could focus on the relationship between issue cross-pressures and satisfaction with democracy. 

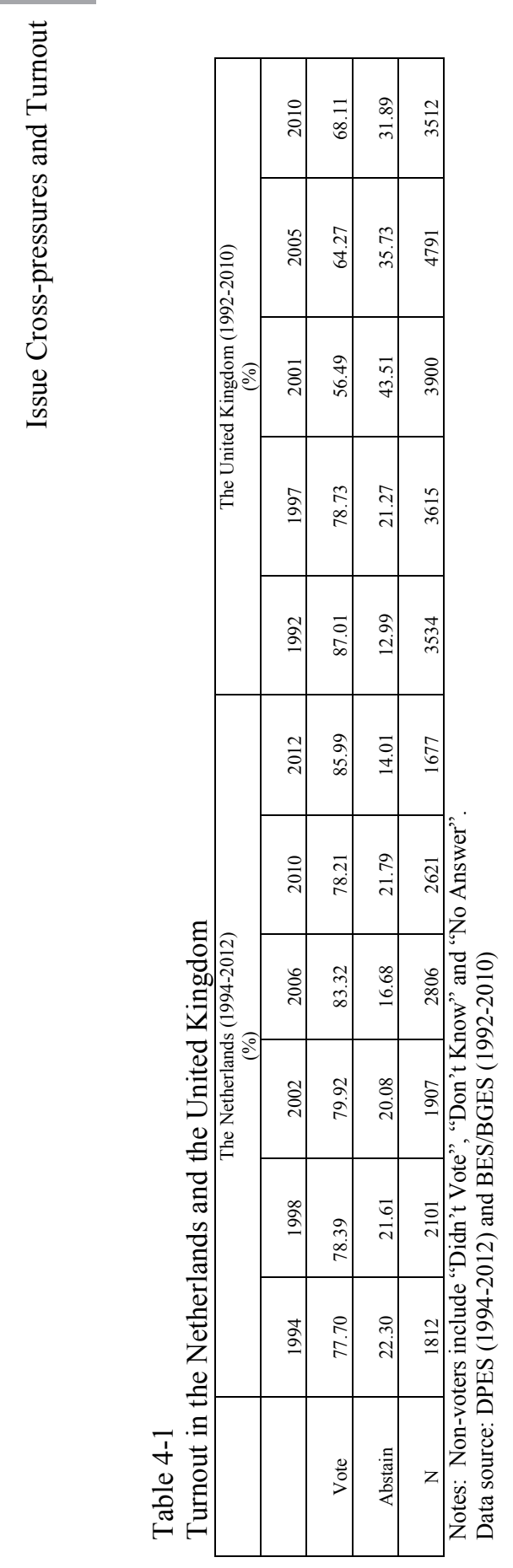


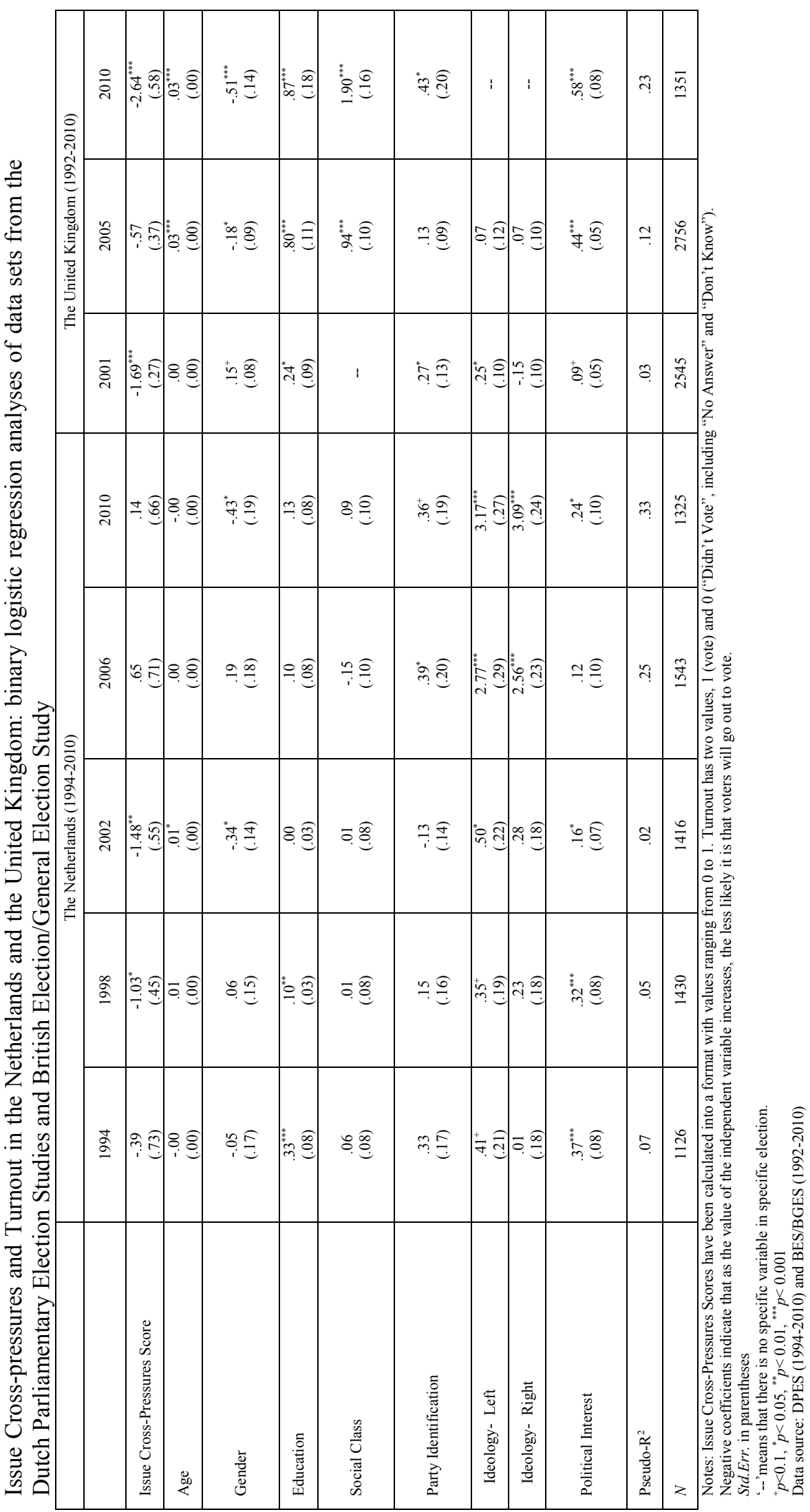



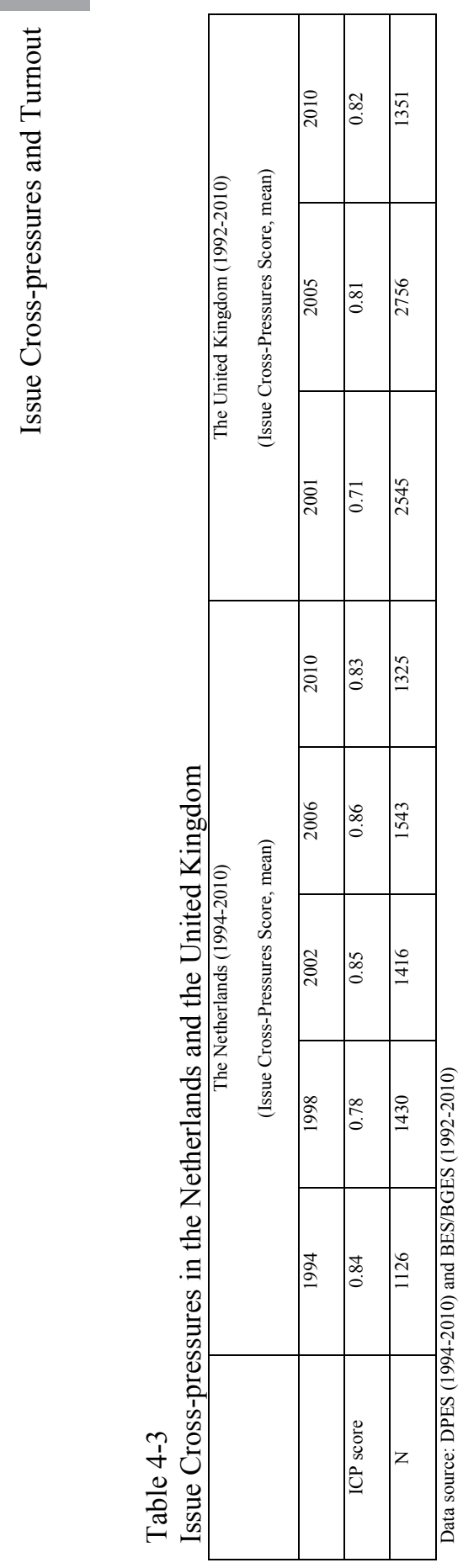

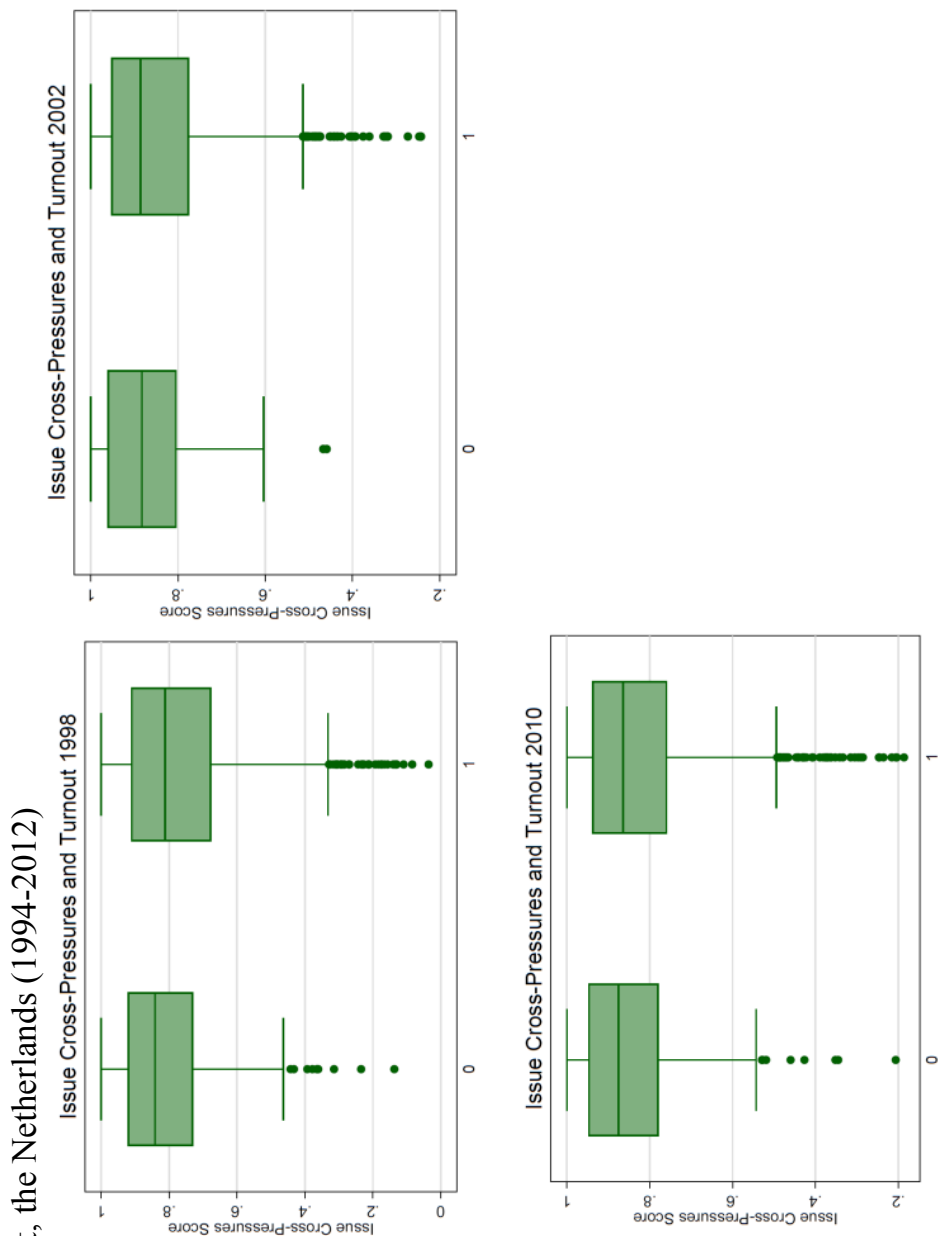

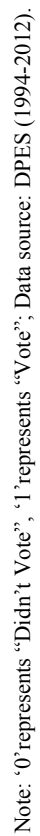



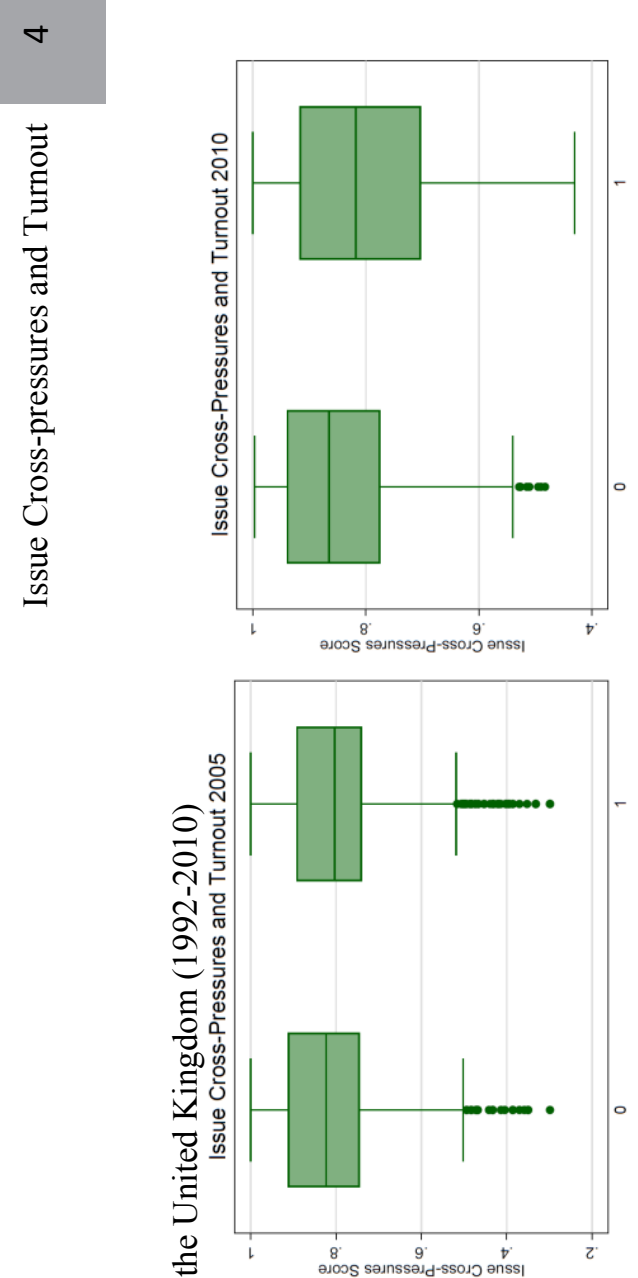

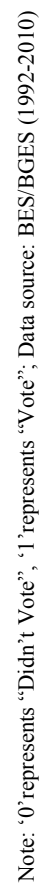




\section{5-Issue Cross-pressures and Vote Switching}

This chapter examines the relationship between issue cross-pressures and vote switching by using survey data from the long-term panel of the 2002-2009 and 2005-2013 German Longitudinal Election Study, each covering three election cycles. Chapter 4 showed that when issue cross-pressures cannot be reconciled or alleviated, citizens will have less motivation to go out to vote. This chapter explores the consequence of issue cross-pressures on electoral behavior when they are reconciled by citizens after following the process of mental reasoning described in Chapter 2. The research questions in this chapter include: (1) whether or not issue cross-pressures influence citizens' vote change across elections; and (2) whether or not the role of issue cross-pressures in vote switching is conditioned by different mobilization types.

\subsection{Introduction}

The idea of the swing voter, defined as someone who switches their vote across elections (Evans, 2004), is an important concept with a long history in political research. More than a half century ago, the pioneers of voting studies at Columbia University launched a 'floating voter' hypothesis, and initially discussed the causes of electoral volatility by focusing on individuals' political interest and information (Lazarsfeld et.al., 1965). The fact that swing voting attracted a lot of scholarly attention is not surprising. On the one hand, with elections becoming more competitive and close, the voting decisions of swing voters are increasingly significant in determining election outcomes (Mayer, 2007; Wong, 2014). On the other hand, for democratic politics, knowing who is most inclined to change their voting choices is quite relevant to the success of democracy (Dassonneville, 2014; Dalton, 2012; 2014). Are they sophisticated citizens who rely on 'sophisticated' considerations, such as policy platforms, and who can make their choice on their own? Or they are superficial citizens who just follow media and campaign efforts, and who are therefore easily manipulated by unscrupulous elites? 
This study explores the relationship between issue cross-pressures and vote switching. Issue cross-pressures are defined as cross-pressures which emerge from holding policy preferences across various issues that push a voter in different political directions (Therriault, Tucker \& Brader, 2011). For example, a voter may favor the party Alternative for Germany (AfD)'s position on the issue of asylum policy, which leads the voter to prefer the AfD; however, on the issue of welfare policy, the voter favors the Social Democratic Party (SPD)'s position, and therefore wants to vote for the SPD. In this situation, we would expect that this voter may feel tension on his/her voting decision if he/she regards the issue of asylum policy and welfare policy as more or less equally important. This is what is defined as issue cross-pressures. Political scholars in the United States have found that issue cross-pressures influence citizens' motivation to defect from their own parties, which means voting for a party that a citizen does not ordinarily identify with; the more issue cross-pressures are experienced, the more likely a voter is to vote against their party identification (Hillygus \& Shields, 2008). Although defecting to other parties is somewhat different from vote switching among different parties between/among elections, they both point to instability in voters' voting choices. We therefore expect that issue cross-pressures may influence a person's motivation to change vote.

In enquiring into the question of who swing voters are, political scholars provide a lot of answers. However, most of them focus on social background, political sophistication and party identification (Dassonneville, 2012; 2014; Mayer, 2007; Mair, 2005; Zaller, 1992; 2004). The number of studies carried out from the perspective of issues is comparatively low. Prior research has demonstrated the process of partisan dealignment in most advanced Western countries (Dalton, 1984; Dalton, Flanagan \& Beck, 1984; Franklin, Mackie \& Valen, 1992). This leads to the rising importance of short-term cues in voting choice, especially issues (Boyd, 1972; Dalton et al., 2000; Nie, Verba \& Petrocik, 1976; Pomper, 1972). Given that issue evaluation is one of the three most important factors in electoral studies (the others are party identification and candidate evaluation), it is worthwhile to study citizens' behavior of vote switching from the perspective of issues. In addition, the existing literature on vote switching usually depends on a recall question of voting in the previous election, which political scholars have found to be insufficiently reliable (Himmelweit, Biberian \& Stockdale, 1987; Waldahl \& Aardal, 2002). In order to avoid the shortcomings of relying on recall data, this paper examines the role of issue cross-pressures 
in vote switching by using the long-term panel data of the 2002-2009 and 2005-2013 German Longitudinal Election Study.

The chapter starts with an overview of the background of this study. Next comes the discussion about the possible conditioning role of cognitive mobilization and party mobilization in the relationship between issue cross-pressures and vote switching. Then data and methods are presented. In the fourth section, the results are interpreted. Finally, the study concludes with a discussion of the implications of the findings and the limitations of the current study.

\subsection{Issue cross-pressures and vote switching}

In answering the question of who swing voters are, one possible perspective can be deduced from Downs (1957). In the landmark book An Economic Theory of Democracy, Downs proposed the idea of rational voting, which assumes that voters are rational: when they are making their voting choice they will compare the policy platforms provided by each party, and vote for the party whose positions are located in a policy space closest to theirs in order to gain maximum self-interest. Following this insight, switching between/among parties across elections should not be surprising, as it is apparently a way for voters to hold governing parties accountable and therefore get what they want. However, this understanding of electoral volatility is not commonly accepted by scholars of voting behavior. On the one hand, the voters in question have neither sufficient information nor sufficient ability to take issues into account when they make their voting decision (Campbell et al., 1960). On the other hand, findings on party switching showed that swing voters are generally those with low political sophistication (Berelson et al., 1963; Lazarsfeld et al., 1965). Given these factors, issues as a potential driving force behind vote switching were somewhat neglected in the decades following these studies. Recently, researchers have mainly focused on factors such as demographic background (Mayer, 2007), partisanship (Zaller, 1992; 2004; Mair, 2005) and political disaffection (Zelle, 1995; Dassonneville, 2012).

Starting from the mid-1970s, the apparent simultaneous steady erosion in citizens' attachments to political parties on the one hand and the rise in education and accessible political information by voters on the other led Dalton et al. (2000) to expect that issues would play a greater role in electoral choice. The possible relationship between issues and 
the long-lasting puzzle of who swing voters are therefore returned to political scholars' thinking. For example, Kedar (2006) proposed a view of strategic voting to understand vote instability. Unlike Downs' original insight, Kedar argued that voters were concerned not only with policy positions but also with policy outcomes. In this regard, voters' voting choices in each election will be determined by whether or not parties direct policy toward their preferred positions. If the parties do this, voters will reward these parties by voting for them again; otherwise, voters will punish them by choosing another party. Therefore, strategic voting on policy outcome is a source of electoral fluctuation.

This study attempts to provide another perspective to understand vote switching regarding issues, namely issue cross-pressures. Political scientists have long suspected that citizens who are subjected to conflicting political pressures behave differently from those who experience reinforcing pressures. In the course of three quarters of a century, scholars have offered several conceptualizations of cross-pressures and examined their roles in various kinds of political activities, such as social cross-pressures (Lazarsfeld et al., 1968; Berelson et al. 1954), conflicting attitudes (Campbell et al., 1960; Lewis-Beck et al., 2008) and network heterogeneity pressures (Mutz, 2002a; Nir, 2005). What has been somewhat missed in those studies, however, is the role of issue cross-pressures which stem from voters' conflicting predispositions based on their issue positions.

Hillygus and Shields (2008) first studied issue cross-pressures systematically and investigated their role in vote defection. Based on data from the 2000 and 2004 presidential elections in the United States, they demonstrated that individuals with higher levels of policy cross-pressures are more likely to defect to the opposite candidate with whom they do not identify, indicating that these citizens are persuadable voters. They ended up with some reservations about the likelihood that the identified role of issue cross-pressures in voting volatility in the United States might be extended to other electoral and institutional contexts. They suspected that parties' campaign efforts would be reduced in proportional electoral systems since parties face fewer hurdles to office, and that there may be fewer divisive issues in elections, both of which influence the chance that voters will experience issue cross-pressures.

However, there are many ways other than campaigning by which voters might become aware of issue cross-pressures, such as introspection: the realization of conflicting feelings by voters themselves; communicating with personal contacts; cues from elites in 
mass media (Brader et al., 2014). On the other hand, elections are becoming more competitive, not only in the United States but in many other advanced Western democracies. In this regard, we would imagine that a lot of salient issues exist in proportional electoral contexts. This leads us to expect that people may experience issue cross-pressures beyond the United States. With respect to vote switching, even though it is not the same as defecting to other parties in a particular election, they both point to instability in voters' voting choice. Therefore, if a voter is simultaneously attracted to two or more parties because of their issue positions, it is reasonable for us to expect that this voter's voting choice may be more likely to be different across elections than that of a voter whose issue positions push them toward a single party. The main hypothesis is thus:

Hypothesis 1: citizens who experience more issue cross-pressures will be more likely to change their voting choices across elections than those with fewer issue crosspressures.

\subsection{Cognitive typology, issue cross-pressures and vote switching}

While the last section proposed that issue cross-pressures may influence citizens' vote switching, this section argues that the role of issue cross-pressures in swing voting might be conditioned by party mobilization and cognitive mobilization. ${ }^{36}$ Party mobilization means that citizens are mobilized into the political process by party cues. Citizens with a given party identification may be less likely to experience issue cross-pressures. Conventional wisdom contends that partisanship is a "perceptual screen" through which individuals interpret and evaluate issues and political events (Campbell et al., 1960; Kelley \& Mirer, 1974; Miller \& Shanks, 1996). Therefore, partisans usually bring their own issue positions into line with their parties' positions (Zaller, 1992; Bartels, 2002). On the other hand, party identification may also influence the relationship between issue cross-pressures and vote switching. Partisanship is defined as a deeply rooted psychological attachment which is similar to religious identification (Campbell et al., 1960; Green, Palmquist \& Schickler, 2002). Thus, in order to avoid feeling that they have betrayed their party, it is possible that

\footnotetext{
${ }^{36}$ Although this chapter focuses on party and cognitive mobilization, this is not to imply that other factors are unimportant. Rather, the two mobilization factors this chapter examines are considered to be more likely to simultaneously influence citizens' issue crosspressures and moderate the relationship between issue cross-pressures and vote switching.
} 
a partisan may still vote for their own party, even though they are attracted by other parties on specific issues. Overall, we can expect that the role of issue cross-pressures in swing voting will be more prevalent among non-partisans than partisans.

In terms of cognitive mobilization, we again expect that individuals' cognitive resource will influence people's level of issue cross-pressures on the one hand and the relationship between issue cross-pressures and citizens' potential to change their votes on the other. Cognitive mobilization, according to Dalton (2012), means that 'more people possess the political resources and skills that better prepare them to deal with the complexities of politics and research their own political decisions without reliance on affective, habitual party loyalties or other external cues' (p. 37). This implies that, first, citizens with higher scores on the cognitive dimension may be more likely to experience issue cross-pressures. Better-educated citizens have been shown to be more capable of evaluating candidates or parties based on issues, while the less educated focus on other heuristics (MacDonald, Rabinowitz \& Listhaug, 1995; Sniderman et al., 1991; Stimson, 1975). Secondly, the role of issue cross-pressures may be greater among people with more political resources and skills. People with lower levels of civic skills and political motivation are more likely to be influenced by other factors, such as mass media and political elites. Therefore, the degree of the effect of issue cross-pressures among those people is very likely to depend on their predispositions, such as party identification, or the context in which they find themselves.

Categorizing citizens by party mobilization and cognitive mobilization, Dalton (1984; 2007; 2012; 2014) provides four ideal concepts, namely apartisans, cognitive partisans, ritual partisans and apolitical independents (see Figure 5-1). With respect to apartisans, they are voters who do not attach themselves to a party but possess sufficient cognitive resources and skills to understand politics. According to what was discussed in the previous two paragraphs, the role of issue cross-pressures in vote switching will be most remarkable in this group of citizens, because they are most likely to experience issue crosspressures and make decisions independently. 
Figure 5-1: Mobilization typology

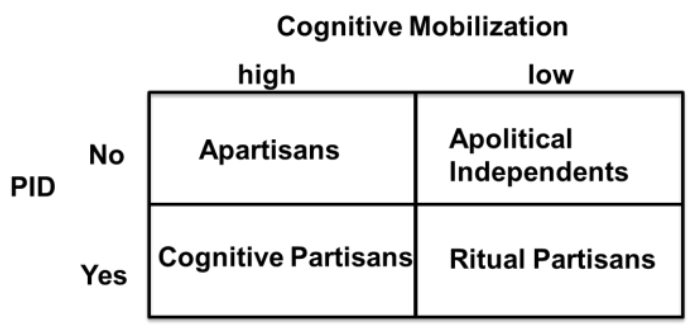

Sources: Dalton, 1984.

Cognitive partisans are those who have both a party identification and a higher level of political skills and resources. At first glance, we may argue that issue crosspressures will not influence vote switching in this group of citizens, because they are partisans. However, at the same time, cognitive partisans are highly involved in politics, and their understanding of politics depends on informed judgements rather than basic partisan loyalties. Moreover, studies on partisanship and policy preference found that, when voters who are aware of parties' differences on an issue and find that issue to be important are confronted with an issue on which they like another party's position, they are very likely to change their party identification (Carsey \& Layman, 2006). We can therefore expect that issue cross-pressures may also influence cognitive partisans' motivation to change their votes between/among elections. However, the effect will be more moderate compared to apartisans.

Ritual partisans are those who are partisan but lack cognitive sophistication. For this group of citizens, party identification takes up a central position and therefore shapes not only voters' attitudes toward political issues but also their political behavior. Furthermore, even though ritual partisans may experience issue cross-pressures, they may simply turn to their parties when they have to make a choice. In this regard, we do not expect issue cross-pressures to have a strong influence on ritual partisans' vote switching.

The last group of citizens consists of apolitical independents, who neither have a party identification nor are cognitively involved in politics. They are not interested in politics, have less political information and lack the ability to explore their own and the parties' issue positions. Their behavior is highly dependent on their external contexts. Therefore, we assume that there is no fixed shared behavioral pattern among apolitical 
independents. However, once they experience issue cross-pressures, apolitical independents are more likely to change their votes than are ritual partisans, since they do not have the predisposition of party identification. In summary, we have one additional hypothesis in this study, as follows:

Hypothesis 2: the effect of issue cross-pressures on vote switching will be most pronounced among apartisans, more moderate among cognitive partisans and least prevalent in apolitical independents and ritual partisans.

\subsection{Data and method}

\section{Case selection}

This study chooses Germany as its study object, for several reasons. First, as in other advanced Western countries, Germany has seen an increasing fluidity in electoral politics over recent decades (Wessels, 2009; Schoen, 2004). In 2005, there were 38.4\% of voters whose voting choices were different from that in 2002. In 2009, this figure was around $41.5 \% .{ }^{37}$ Secondly, Germany is also a typical advanced industrial democracy in which there is a trend of party decline and an increase in people's cognitive ability (Dalton, 2000; Thomassen, 2005; Arzheimer, 2006). Additionally, compared to other European countries, Germany's electoral system is a little unusual. Each voter has two votes, one for a candidate and one for a party. In this situation, if a voter experiences issue cross-pressures, it is possible for them to split their vote and thereby to overcome their conflicting feelings, which in turn weakens the influence of issue cross-pressures on swing voting. In this regard, if we find a positive correlation between issue cross-pressures and vote switching in the context of Germany, it will be safer for us to generalize the findings to other countries. Finally, studies on swing voting usually rely on a recall question on voting in the previous election, which political scholars have found to be insufficiently reliable (Himmelweit, Biberian \& Stockdale, 1987; Waldahl \& Aardal, 2000). Therefore, in order to avoid the shortcomings of relying on recall data, we need long-term panel data. The German Longitudinal Election Study provides excellent datasets which make the measurement of vote switching more reliable.

\footnotetext{
${ }^{37}$ Percentages of vote switching are based on long-term panel data of 2002-2009 (2002 wave and 2005 wave) and 2005-2013 (2005 and 2009 wave). I have only calculated vote switching among parties which received at least $1 \%$ of the vote.
} 


\section{Data}

The data used in this paper is from the long-term panel of the 2002-2009 and 2005-2013 election German Longitudinal Election Study, each covering three election cycles. ${ }^{38}$ With respect to the 2002-2009 panel data, 3,263 respondents participated in the 2002 wave. Among them, 902 were re-interviewed in the 2005 wave, of whom 641 took part in the 2009 wave. The re-participation rate is not high, at only about $28 \%$ from 2002 to 2005 and $20 \%$ from 2002 to 2009 . In terms of 2005-2013 panel data, 2,540 people were interviewed in 2005, and the 2009 wave had 686 respondents, of which 491 were re-interviewed in the 2013 wave. The re-participation rates were around 27\% from 2005 to 2009, and about 19\% from 2005 to 2013. From Tables 5-1 and 5-2, we can see that respondents who are older and male, and who have better income, social status and educational background, more interest in politics and a party identification are more likely to re-participate in the second and third wave in both panels. ${ }^{39}$ As explained in Footnote 2, this study uses only the 20022005 wave in the 2002-2009 panel and only the 2009-2013 wave in the 2005-2013 panel.

\section{[TABLE 5-1 IS ABOUT HERE]}

[TABLE 5-2 IS ABOUT HERE]

\section{Method}

The dependent variable in this study is vote switching. Among current studies on swing voting, swing voters are classified as those who have switched their vote across elections

\footnotetext{
${ }^{38}$ In the 2002-2009 panel data, I use only the 2002 wave and the 2005 wave. As we will see below, issue cross-pressures are calculated at T0 and vote switching is calculated at T1, which involves voting choice at $\mathrm{T} 0$ and $\mathrm{T} 1$. Therefore, in order to explore the relationship between issue cross-pressures and vote switching, we need either or both the 2002-2005 wave and the 2005-2009 wave. However, in the 2005 election, respondents were only asked about two position issues: nuclear power and European unification. So if we measure issue cross-pressures based only on two issues in 2005, it may decrease the percentage of people who experience issue cross-pressures, which would in turn make the findings less reliable. Therefore, in the 2002-2009 panel data, only the 2002-2005 wave is used, and in the 20052013 panel data, only the 2009-2013 wave is used. The reason for this decision is that, in the 2005 election data, as will see below, there are no position issues which are necessary to measure citizens' issue cross-pressures.

${ }^{39}$ In table 5-2, since income and education do not have the same units across the 2005, 2009 and 2013 elections, it is not comparable. Therefore, the arguments regarding income and education here are based solely on Table 5-1.
} 
(Evans, 2004); those who have the potential to switch from the party they previously voted for (Evans, 2004); and those who prefer two parties almost equally (Kroh et al., 2007; Mayer, 2007; Wong, 2014). This study operationalizes swing voting in a strict sense, only referring to switching between different parties in two consecutive elections. If a respondent's voting choice is the same between two elections, we regard them as stable with a value of "0". Otherwise, this person will be seen as a swing voter coded by " 1 ".

The independent variable is issue cross-pressures. Issue cross-pressures will be represented by an issue cross-pressures score from 0 to 1 . " 0 " denotes that an citizen does not suffer issue cross-pressures; " 1 " implies that a voter is completely issue cross-pressured. If a voter's positions on all issues leads him/her to a single party, according to the definition, this voter is not issue cross-pressured and will get a score of " 0 ". Otherwise, this voter may suffer issue cross-pressures and will get a score between 0 (not including " 0 ") and 1 (including “1”). The calculation of individuals' issue cross-pressures scores is based on the regression-based measurement described in Chapter 2.

People may argue that, when calculating voters' issue cross-pressures, we should take into account personal issue salience. Issue salience means that different people care about different issues; in other words, different issues have different importance to different people. Krosnick $(1988,1990)$ suggested that people perceive larger differences between candidates' positions on issues which they feel to be important, and their attitudes to important issues are more accessible in memory than unimportant ones. Many studies have shown that issue salience has an impact on the role of public policy issues in evaluating candidates or parties and deciding electoral choice (Repass, 1971; Rabinowitz, Prothro \& Jacoby, 1982; Krosnick, 1988, 1990; Fournier et al., 2003). Issue cross-pressures come from holding policy preferences across various issues that push a person in different political directions. Even though the definition does not expressly incorporate issue salience, it is necessary to identify issue salience when calculating citizens' issue cross-pressures. The issue cross-pressures score measured in this study captures the average importance of different issues to citizens as a whole (more detail see Chapter 2).

Mobilization typology is a supposed intervening variable in this study, and is made up of party mobilization and cognitive mobilization. In categorizing citizens into four mobilization types: apartisans, cognitive partisans, ritual partisans and apolitical independents, this study will based on the measurement of Dalton (2012). First, party 
mobilization is distinguished between those who have party identification and those who do not. Secondly, cognitive mobilization is joined by education and political interest, both from a low level (coded by “0”) to a high level (coded by "2"). Each respondent, therefore, will get a score from "0" to "4". As Dalton does, I regard "3" as a cut-off point: those whose scores are less than " 3 " are categorized as having low cognitive mobilization, and the others are categorized as having high cognitive mobilization. Finally, apartisans are those who do not have any party identification but whose cognitive scores are greater than " 3 "; cognitive partisans are those who have party ties and whose cognitive scores are greater than " 3 "; ritual partisans are those without party attachment and whose cognitive scores are less than or equal to " 3 "; and apolitical independents are those who do not have party identification and whose cognitive scores are less than or equal to " 3 ".

In order to test the two hypotheses, this study measures individuals' voting behavior (stable or switch) in the 2005 (T1) and 2013 (T1) elections. Correspondingly, voters' issue cross-pressures and mobilization types are measured in terms of the 2002 (T0) and 2009 (T0) elections. This operation is based on the following two considerations. First, if we were to measure both vote switching and issue cross-pressures at the same time point, we could not explore how issue cross-pressures influence people's vote switching. Since vote switching involves both current and previous voting behavior, it is unreasonable to use current information to explain why people's behavior is different from previous behavior. Instead, it is more reasonable to focus on voters' previous information and their current behavior, which is our second consideration. One may argue that, in this way, it is hard to ensure that voters will keep issue cross-pressures in mind and make a decision which is different from the one they made four years earlier. However, this study does not argue that people should keep issue cross-pressures in their memory and recall them after four or five years. What is argued in this study is that once people experience issue cross-pressures, there is a possibility for them to change their votes, and focusing on individual's previous issue cross-pressures at $\mathrm{T} 0$ and their vote switching at $\mathrm{T} 1$ is the best way to test the hypothesis.

\subsection{Findings}

The main research question in this study is: To what extent does an increase in a person's issue cross-pressures lead to a change in that person's voting choice in the context of 
Germany? The hypothesis is that the more issue cross-pressures a person experiences, the more likely it is that they will change their voting choice. The second research question is: Is the role of issue cross-pressures in vote switching conditioned by different mobilization types? This chapter proposes that the influence of issue cross-pressures on vote switching will be most pronounced among apartisans, more moderate among cognitive partisans and least prevalent in apolitical independents and ritual partisans.

We will focus first on the first research question. With respect to the 2002-2005 election, the hypothesis that higher issue cross-pressures are linked to higher motivation to change one's vote across two elections is demonstrated by the results presented in Table 53 (left). From the 2002 election to the 2005 election, among those who had lower issue cross-pressures ${ }^{40}$ in the 2002 election, around $37 \%$ changed their voting choice in the 2005 election. In terms of those with higher issue cross-pressures in 2002 elections, there are $39.4 \%$ of these voters whose voting choices were different in these two elections. With respect to the 2009-2013 elections, the findings in Table 5-3 (right) show a similar trend to that in the 2002-2005 elections. $37.5 \%$ of people with lower issue cross-pressures switched their party choices from 2009 to 2013 , while this figure is about $41 \%$ among voters with higher issue cross-pressures. This all implies that issue cross-pressures have an influence on vote switching and that the higher issue cross-pressures voters experience, the greater the likelihood that their vote choices will be different across two elections.

\section{[TABLE 5-3 ABOUT HERE]}

In the above analyses, however, one fact that we could not ignore is that the difference in vote switching between those with lower issue cross-pressures and those with higher issue cross-pressures is not very large. In the 2002-2005 elections, the difference is about 2.5\%, and between 2009 and 2013, it is about 3.1\%. Furthermore, p-values in both the 2002-2005 and the 2009-2013 elections are greater than 0.1. All of this implies that, overall, the role of issue cross-pressures in vote switching is very slight. It is in this context

\footnotetext{
${ }^{40}$ In this study, people with lower issue cross-pressures are defined as those whose issue cross-pressures scores are less than or equal to the mean issue cross-pressures score of all respondents. People with higher issue cross-pressures are defined as those whose issue cross-pressures scores are greater than the mean issue cross-pressures score of all respondents.
} 
that this paper attempts to explore whether or not the influence of issue cross-pressures on swing voting is conditioned by external factors, in particular mobilization typology.

Before turning our attention to the second hypothesis, we should shed some light on the relationship between mobilization typology and issue cross-pressures. As discussed in the third section of this chapter, we would expect that, first, highly cognitive citizens will suffer more issue cross-pressures than less cognitive citizens. This is in fact the result shown in Table 5-4. Among people with higher cognitive ability (apartisans and cognitive partisans), more than $67 \%$ and $59 \%$ of people, respectively, had higher issue crosspressures in the 2002-2005 and 2009-2013 elections, whereas only $54.5 \%$ and $56.0 \%$ of people with lower cognitive ability (apolitical independent and ritual partisans) experienced higher issue cross-pressures.

Secondly, we would expect that people with a given party identification would be less likely to experience issue cross-pressures than non-partisans. This, too, is confirmed by the results presented in Table 5-4. In the 2002-2005 election, around $60 \%$ of partisans (cognitive partisans and ritual partisans) have higher issue cross-pressures, while the figure is about $63 \%$ among people without party identification (apartisans and apolitical independents). We can find similar trend in the 2009-2013 election, at 57.3\% and $62.5 \%$.

We would further expect that apartisans would be most likely to experience issue cross-pressures, followed by cognitive partisans, then by apolitical independents and ritual partisans. The results in Table 5-4 more or less confirm this expectation. In the 2002-2005 election, $66.0 \%$ of apartisans experienced higher issue cross-pressures, compared with $68 \%$ among cognitive partisans and $61.7 \%$ and 52.4\% among apolitical independents and ritual partisans respectively. In the $2009-2013$ election, more than $70 \%$ of apartisans experienced higher issue cross-pressures, which is far more than the percentages in the other three groups: $57.8 \%$ among cognitive partisans, $56.6 \%$ among ritual partisans and $52.6 \%$ among apolitical independents. When we combine the results in the 2002-2005 and the 2009-2013 elections, the percent of people with higher issue cross-pressures among apartisans is more than $67 \%$, while it is about $63 \%$ among cognitive partisans, $60 \%$ among apolitical independents and $53.6 \%$ among ritual partisans. Overall, we can say that the third expectation has been more or less confirmed. 
We now explore the question of whether or not the role of issue cross-pressures in vote switching is conditioned by mobilization typology. The results displayed in Tables 5-5 and 5-6 confirm the second hypothesis, that apartisans are more likely to change their party choices once they experience issue cross-pressures, followed by cognitive partisans and then by apolitical independents and ritual partisans. With respect to the 2002-2005 election, among apartisans only $23.5 \%$ of people with lower issue cross-pressures switched their votes, whereas this figure is about $52 \%$ among apartisans with higher issue cross-pressures. The difference is around $30 \%$. In addition, the p-value is smaller than 0.1 . With respect to the 2009-2013 election, we find a similar trend. $73.3 \%$ of people with higher issue crosspressures changed their votes, while there was no corresponding switch among people with lower issue cross-pressures. The p-value is significant at the 0.01 level. This indicates that the influence of issue cross-pressures among apartisans is large.

In terms of cognitive partisans, in both the 2002-2005 and the 2009-2013 elections, there was more switching of votes among voters with higher issue cross-pressures. In the 2002-2005 election, $28.2 \%$ of voters with lower issue cross-pressures changed their votes, $4.6 \%$ more than voters who experienced higher issue cross-pressures. In 2009-2013, the difference was very small, at only $0.1 \%$. Overall, we can see that the difference among those with higher issue cross-pressures and lower issue cross-pressures was not very wide, and p-values were not significant in both elections. The role of issue cross-pressures in swing voting was very slight among cognitive partisans compared with apartisans.

With respect to ritual partisans, the difference in vote switching from 2002 to 2005 between those with higher issue cross-pressures and those with lower issue cross-pressures was $3.7 \%$, whereas from 2009 to 2013 the effect of issue cross-pressures pointed in the opposite direction. Among those with lower issue cross-pressures, 12.1\% more people switched their votes than people with higher issue cross-pressures. This leads us to conclude that issue cross-pressures do not have a stable influence among ritual partisans.

Neither do we find a stable effect of issue cross-pressures among apolitical independents. In the 2002-2005 election, the percentage of people who changed their votes among those with lower issue cross-pressures was $15.7 \%$ larger than that among people with higher issue cross-pressures. This implies that the role of issue cross-pressures does not confirm our first hypothesis. In the 2009-2013 election, the percentage of people who changed votes across two elections among those with higher issue cross-pressures was 
much more larger than among those with lower issue cross-pressures, with a difference of $56.7 \%$. Furthermore, the p-value is less than 0.05 , which implies that issue cross-pressures influence people's motivation to change their vote. This confirmed what we argued before, that when they experience issue cross-pressures, apolitical independents are more likely than ritual partisans to change their votes.

[TABLE 5-5 ABOUT HERE]

[TABLE 5-6 ABOUT HERE]

\subsection{Conclusion and discussion}

Since the 1970s, as in other Western European countries, Germany has seen an increasing percentage of the public who switch their votes across elections (Wessels, 2009; Schoen, 2004). By the 2000 s, there are about $40 \%$ of voters whose voting choices are different from those in previous elections. At the same time, Germany is experiencing a slow but steady erosion of party attachments which has been going on for decades (Dalton, 2000; Thomassen, 2005). At the beginning of the $1970 \mathrm{~s}$, there around $75 \%$ of people felt an attachment to a particular party, while in 2005 the figure was about 67\% (Dalton, 2012). Many political scholars have therefore paid attention to the relationship between party identification and swing voters, and argued that people without party ties are more likely to be swing voters and that the stronger a person's party identification is, the less likely it is that they will change their vote (Beck et al., 1992; Karp et al., 2002; Kedar, 2006; Marsh, 2006). However, given that more than $30 \%$ of people in Germany are currently nonpartisans, if we only focus on party identification, we cannot fully understand who swing voters are.

This chapter focuses on issue cross-pressures and attempts to examine (1) whether or not issue cross-pressures influence citizens' vote change across elections, and (2) whether or not the role of issue cross-pressures in vote switching is conditioned by different mobilization types. Issue cross-pressures, which stem from an individual's holding positions on various issues that push them toward different parties, is a by-product of the rise of issue voting. If a person's issue positions are the principal motivation behind voting, then conflicts among these stances, which push people toward different political objects, may make the person's voting decision more unstable across elections. 
In order to answer these two research questions, this study analyzes the survey data from the long-term panel of the 2002-2009 and 2005-2013 German Longitudinal Election Study, each covering three election cycles. The findings show that, overall, the increase in a person's issue cross-pressures leads to a slight change in their voting choice. The difference in the percentages of vote switching between those with lower issue crosspressures and those with higher issue cross-pressures is not very large. In the 2002-2005 election it was only $2.5 \%$, and in the 2009-2013 election it was 3.1 percent. In addition, the p-values in both the 2002-2005 and the 2009-2013 elections are larger than 0.1. In terms of the conditioned role of party mobilization and cognitive mobilization, the findings in this paper confirmed the second expectation, that the influence of issue cross-pressures on vote switching is most pronounced among apartisans, more moderate among cognitive partisans and least prevalent in apolitical independents and ritual partisans. This suggests that the relationship between issue cross-pressures and the potential for vote change is not linear but curvilinear. In conclusion, even though this study does not find a strong relationship between issue cross-pressures and vote switching, it does show that the influence of issue cross-pressures on vote switching is conditioned by different mobilization types. The impact of issue cross-pressures is strong and significant among people without party identification and with high cognitive ability, namely apartisans. Given that the number of apartisans is optimistically predicted to keep on rising in the future (Dalton, 2012), the role of issue cross-pressures in vote switching as a whole may increase as well.

Nevertheless, the relatively small effect of issue cross-pressures on vote switching should not be too surprising. As described in Chapter 2, when citizens experience issue cross-pressures, they will employ three different ways to reconcile them: re-evaluating their stances on different issues, looking for additional attributes of parties and reducing the importance of some issues. They may or may not reconcile their cross-pressures successfully. It is only when issue cross-pressures are alleviated to a certain level that an issue cross-pressured citizen will cast a vote. Chapter 2 shows that issue cross-pressures play a significant role in turnout, implying that many issue cross-pressured citizens cannot reconcile their cross-pressures, and therefore give up on voting. In addition, even when issue cross-pressured citizens can alleviate their cross-pressures successfully, their voting choices will highly depend on how they reconcile their cross-pressures. As such, their 
voting choices may or may not be similar across two elections. All of this suggests that issue cross-pressures may not have a strong impact on vote switching.

The contributions of this study mainly consist of the following three aspects. First, political scholars provide a variety of answers to the question of who swing voters are. One influential explanation begins with political sophistication. Studies on vote switching have found that political sophistication increases the probability of inter-election volatility (Dassonneville, 2012; 2014). However, the mechanism behind this causal relationship has not been extensively studied. This study attempts to provide greater understanding in this area. Politically sophisticated persons might recognize parties' positions on various issues more easily (Sniderman et al., 1991; Stimson, 1975), and might therefore be more likely to experience issue cross-pressures, which in turn could influence their motivations to change their votes across elections.

Another prevalent way to understand electoral volatility is through party identification (Beck et al., 1992; Karp et al., 2002; Kedar, 2006; Marsh, 2006). However, this method leaves several questions unanswered. A remarkable one is: Why do partisans change their votes? The findings in this study show that when partisans suffer issue crosspressures, which means that they are equally attracted to two or more parties because of their issue positions, there is a possibility that these people with party identification may change their votes. Even so, it must be admitted that the possibility is not very significant.

Furthermore, political scholars agree that swing voters are not a group of homogeneous people but rather are heterogeneous. This study further verifies this consensus. The swing voting of apartisans can be largely explained by the level of issue cross-pressures voters suffer, while for apolitical independents and ritual partisans, issue cross-pressures could not give a stable explanation. This situation leaves a question open for future study: why do those with lower cognitive ability change their votes? Is it because they are superficial citizens who are easily persuaded by the media or campaign efforts? This topic requires further investigation.

The main limitation of this study lies in the quality of the dataset. As described before, the re-participation rate was not high in the panel data from 2002-2009 and 20092013. Those who have a party identification, more political interest and a higher educational background were more likely to re-participate in the second and third wave in 
both panels, which affected the distribution of people with different cognitive mobilizations and party mobilizations. 


\begin{tabular}{|c|c|c|c|c|c|c|c|c|}
\hline & $\stackrel{x}{\Sigma}^{x}$ & $\bar{\sigma}$ & $\mid$ & 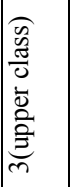 & 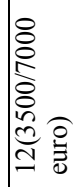 & 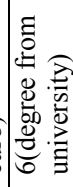 & 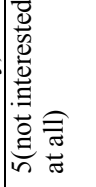 & 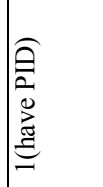 \\
\hline & $\Xi$ & ㄱ. & 这. & 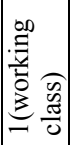 & 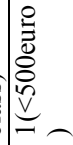 & 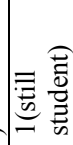 & 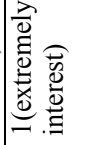 & 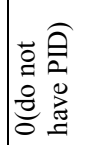 \\
\hline ठे & $\vec{D}$ & $\begin{array}{l}\infty \\
\dot{\Xi} \\
\dot{D}\end{array}$ & 足 & గn & $\stackrel{0}{i}$ & 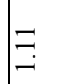 & ن & $\begin{array}{l}0 \\
0 \\
0\end{array}$ \\
\hline & $\sum_{\Sigma}^{\mathbb{E}}=$ & $\mid \begin{array}{ll}0 \\
\ddot{8} & \\
0\end{array}$ & $\stackrel{f}{Z}$ & $\stackrel{\infty}{\infty}$ & స్ & $\underset{\sim}{\infty}$ & $\stackrel{\infty}{\stackrel{\infty}{\sim}}$ & $\begin{array}{l}2 \\
\infty \\
0\end{array}$ \\
\hline & 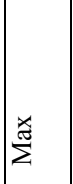 & $\infty$ & $\mid$ & 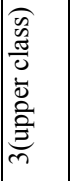 & 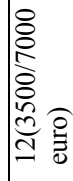 & 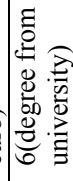 & 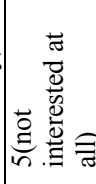 & 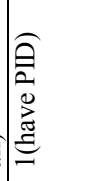 \\
\hline 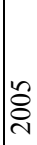 & $\Xi$ & 2 & 离 & 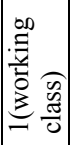 & 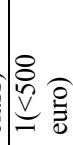 & 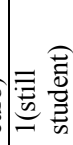 & 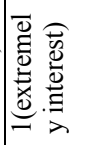 & 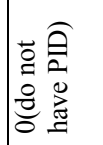 \\
\hline & 苟 & $\stackrel{0}{0}$ & : & $\tilde{n}$ & $\begin{array}{l}\bar{\infty} \\
\stackrel{\lambda}{i}\end{array}$ & $\stackrel{0}{0}$ & Oे & 竎 \\
\hline & $\stackrel{\mathbb{J}}{\Sigma}^{\mathbb{E}}$ & $\begin{array}{l}\vec{\infty} \\
\dot{\sim} \\
\dot{n}\end{array}$ & 号. & . & 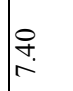 & $\stackrel{n}{\stackrel{\sim}{r}}$ & in & $\stackrel{+}{\stackrel{0}{0}}$ \\
\hline & 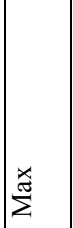 & 2 & 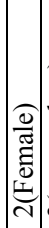 & 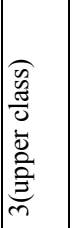 & 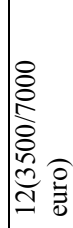 & 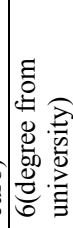 & 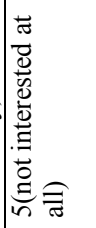 & 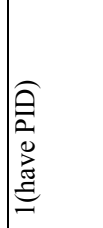 \\
\hline 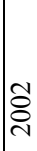 & 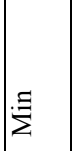 & $\because$ & 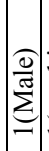 & 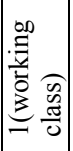 & 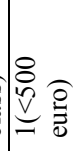 & 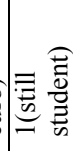 & 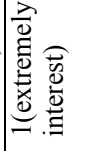 & 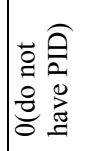 \\
\hline & $\vec{B}$ & $\begin{array}{l}\stackrel{0}{\pi} \\
\infty \\
\infty\end{array}$ & 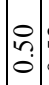 & $\hat{n}$ & 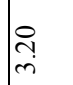 & $=$ & $\underset{-}{\stackrel{\theta}{0}}$ & $\stackrel{\infty}{\stackrel{\infty}{0}}$ \\
\hline & 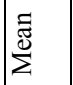 & 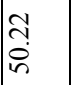 & 守 & ñ & กู & $\begin{array}{l}\infty \\
\infty \\
\sim \\
\sim\end{array}$ & $\mid \begin{array}{l}\infty \\
i\end{array}$ & 苞. \\
\hline & & $\underset{<}{8}$ & : & $\begin{array}{l}n \\
\tilde{\sigma} \\
\frac{\sigma}{0} \\
\frac{\sigma \pi}{0} \\
\tilde{0} \\
\tilde{n}\end{array}$ & 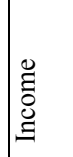 & 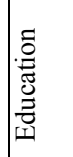 & 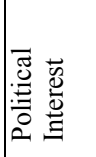 & ס \\
\hline
\end{tabular}



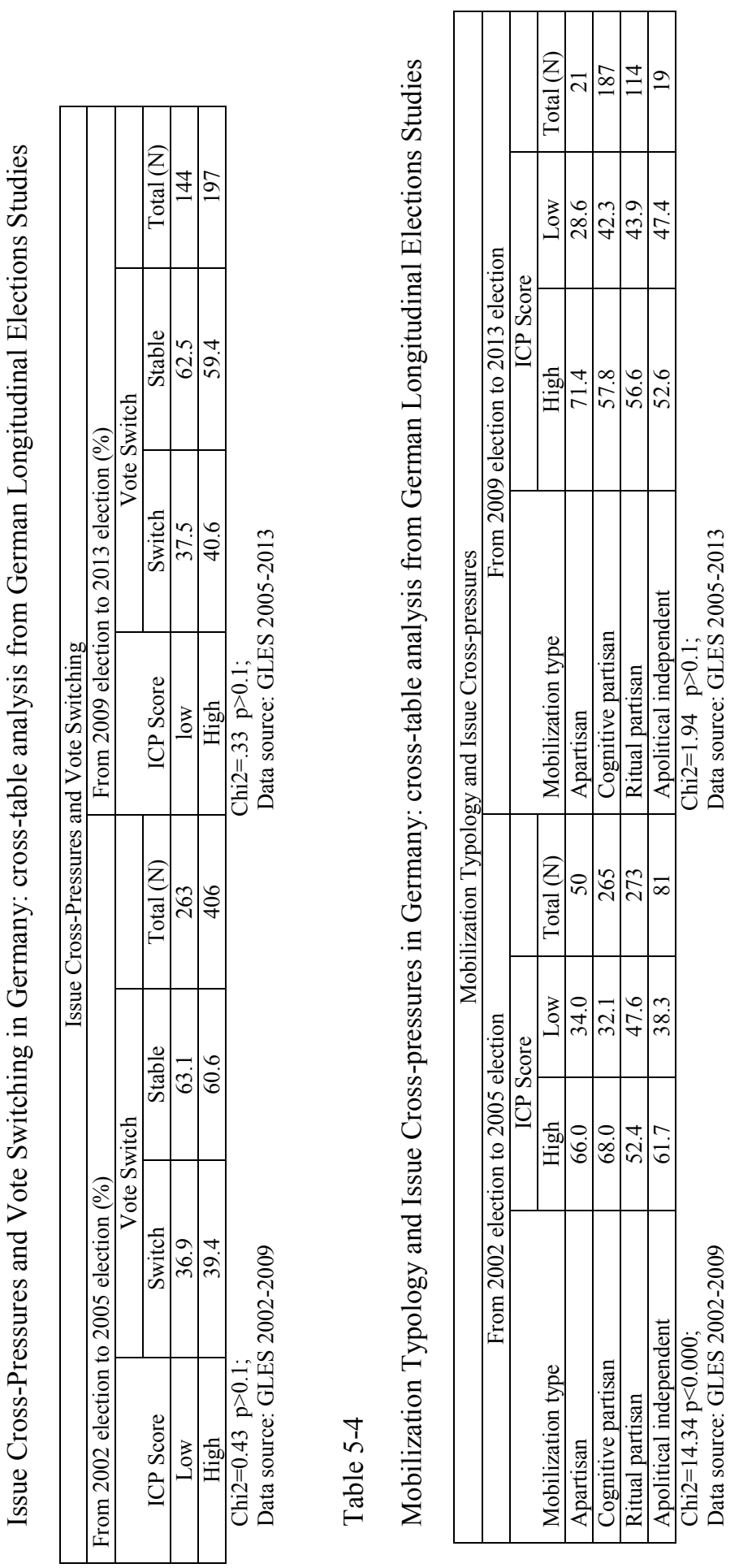


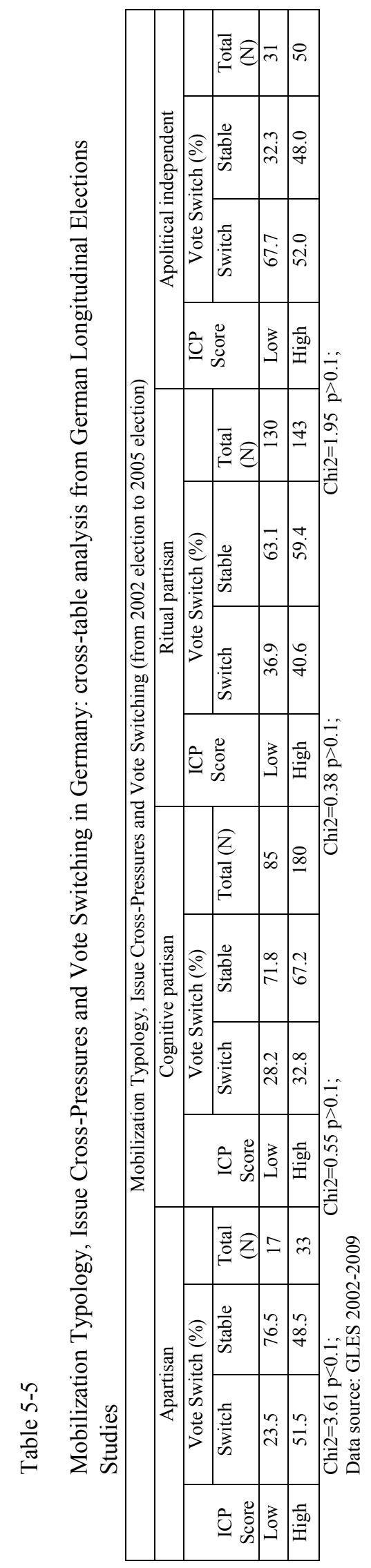




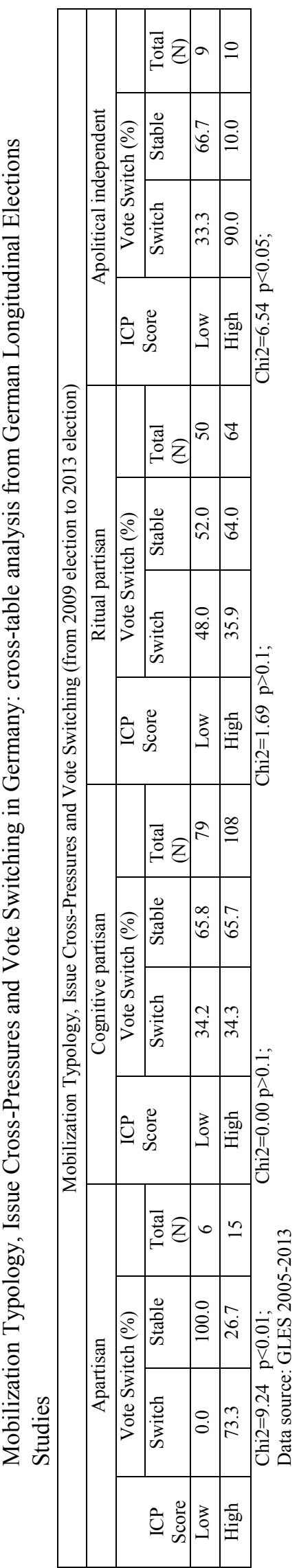




\section{6-Issue Cross-Pressures and Time of Voting Decision}

This chapter ${ }^{41}$ examines the fourth possible role of issue cross-pressures in citizens' electoral behavior, that is, time of voting decision. As discussed in chapter 2, when citizens do not experience issue cross-pressures, they can make a voting choice directly without any additional considerations. While when citizens' issue positions lead them to several parties, they have to employ one or more approaches to reconcile cross-pressures in order to reach a satisfied voting choice. They can re-evaluate stances on some issues, look for additional attributes related to parties, and lower importance of some issues. If they can alleviate cross-pressures to an certain level, they will go out to vote and make a voting choice. If they cannot, they may keep on struggling on what to do even until the last moment comes. This whole process, obviously, will very probably lead issue cross-pressured citizens to spend much more time on decision making. There are two main research questions in this chapter: (1) whether or not the time of voting decisions are affected by issue crosspressures, and (2) whether or not the role of issue cross-pressures in time of voting decision is conditioned by political systems. The data comes from national election studies in three countries: the Netherlands (1994-2012), Germany (1994-2013) and the United Kingdom (1992-2010).

\subsection{Introduction}

Since the era of democratization, there has been a long-term trend of electors delaying their voting decisions until the election campaign, or often even the final polling day. The proportion of late-deciding voters has increased considerably in recent decades in all 12 democracies analyzed by Dalton et al. (Dalton et al., 2000), except in Denmark. The Netherlands, the United Kingdom and Germany are no exception to this rule. With respect

\footnotetext{
${ }^{41}$ This chapter is based on the following article: He,QingQian. (2016) Issue Cross-pressures and Time of Voting Decision. Electoral Studies 44: 362-373.
} 
to the Netherlands, the share of late deciders has increased from 10 percent in 1971 to more than 40 percent in 2006 (Irwin and Van Holsteyn, 2008a). The most recent Dutch election studies $(2010,2012)$ even point to a majority of voters who made up their mind in the last week of the campaign. In the United Kingdom, only 12 percent of voters in 1970 reported that they made their decision in the final days before Election Day, while the figure was 26 percent in 1997 (McAllister, 2002). The trend is similar in Germany: between the federal elections of 1965 and 2009, the proportion of voters making up their minds in the latter stages of the campaign increased from less than 5\% to $40 \%$ (Schmitt-Beck and Partheymuller, 2012).

With the increasing number of people who delay their voting decisions, the study of who these late-deciding voters are has attracted the attention of many scholars (Gopoian and Hadjiharalambous, 1994; Fournier et al., 2004; Irwin and Van Holsteyn, 2008a; Nir and Druckman, 2008; Kosmidis and Xezonakis, 2010; $\mathrm{M}^{\mathrm{c}}$ Gregor, 2012; Schmitt-Beck and Partheymuller, 2012; Orriols and Martinez, 2014). Late deciders are found to be less partisan, less interested in politics and more easily persuaded by campaign information and media coverage. As a result, late-deciding voters are regarded by political actors especially parties and candidates - as the group that determines the outcome of the election (Lazarsfeld et al., 1968; Wolfinger and Rosenstone, 1980).

This chapter attempts to study voters' time of voting decision by focusing on the effect of cross-pressures emerging from holding policy preferences across various issues that push a person in different directions politically: the so-called issue cross-pressures (Therriault et al., 2011). Going back in history, the decline of party identification and social cleavages has been confirmed by various scholars since the 1970s (Dalton et al., 1984; De Graaf et al., 2001; Berglund et al, 2005; Oskarson, 2005; Arzheimer, 2006; Irwin and Van Holsteyn, 2008b; Franklin et al., 2009;). General models of political behavior perform increasingly poorly in understanding and explaining the way in which voters make their voting choices. Political scientists responded by turning their attention to short-term cues, especially issues (Borre, 2001; Van Wijnen, 2001; Clarke et al. 2004; Aardal and Van Wijnen, 2005; Wessels, 2014). Although the findings with regard to the extent of issue voting are inconsistent, the consensus is that issues are significant motives behind voting choice, at least for some particular voters. It is in this context that issue cross-pressures get their meaning in understanding voting behavior. 
The important role of issue cross-pressures in determining the time of voting decision can be deduced from two dominant schools in voting behavior. In the sociological model of electoral behavior, Lazarsfeld and his colleagues (1968) suggested that individual voting choice was largely determined by socio-demographic factors. Simultaneously, they argued that if a person's social group affiliation was the predominant factor influencing his/her voting choice, conflicts and inconsistencies among these variables would make the person's voting choice more difficult. With respect to the Michigan school, scholars developed a socio-psychological model in which party identification was assumed to be in the core position. They also argued that, if party identification was most important to voters' voting decision, individuals with varying levels of party identification would differ considerably in the time of voting decision. According to the reasoning of both the Columbia School and the Michigan School, we can expect that, if a person's issue positions are the principal motivations behind voting, conflicts among these stances (i.e., pushing people towards different political objects) may lead to late decision. However, scholars have seldom paid attention to the aforementioned question. This chapter attempts to explore to what extent issue cross-pressures influence the time of voting decision.

Before continuing the study, it is important to bear in mind that the effect of issue cross-pressures on time of voting decision is not necessarily the same in different contexts. This study observes three different countries, using survey data from the Dutch Parliamentary Election Study (DPES) (1994-2012), the British Election Study (BES/BGES) (1992-2010), and the German Election Study (GES/GLES) (1994-2013). On the one hand, with the number of parties increasing, voters may be more likely to experience higher issue cross-pressures. On the other hand, when political contexts are equally dominated by several parties, those who suffer from issue cross-pressures may hesitate more between two or more parties. Due to the varying average effective number of parties from the 1990s to the 2010s in the Netherlands (5.5), Germany (3.8) and the United Kingdom (2.3), these three countries are ideal cases to demonstrate whether or not the role of issue crosspressures in time of voting decision is conditioned by political systems.

In order to answer the research questions, this study will be divided into five sections. The first section discusses the factors that influence people's time of voting decision. The next part elaborates the possible moderated role of political systems in the effect of issue cross-pressures on time of voting decision. In the third section, data and 
methods are presented. The fourth section provides the results of the empirical analysis. The final section concludes with the implications of the findings.

\subsection{Background: Issue cross-pressures in explaining voters' time of voting decision?}

Undecided voters are often regarded by political parties and candidates as the group that determines the outcome of an election. When the election are close, those who vote during the later stages of a political campaign, or even on polling day, can determine who wins the election. As Hillygus and Shields (2008) said, "as many elections are decided at the margins, moving even a few votes during the campaign can make all the difference" (p.8). In this regard, political scientists have never questioned the importance of late deciders and have long examined the factors that determine if voters make their decisions late in the campaign.

Lazarsfeld and his co-workers (1968) were the pioneers in studying why individuals make their voting decisions when they do. Based on the survey data from the 1940 US presidential election in Erie, Ohio, Lazarsfeld et al. found that voters' time of voting decisions differed significantly. While exploring possible explanations for this phenomenon, Lazarsfeld et al. focused on cross-pressures arising from multiple socio-demographic affiliations. Their findings showed that voters exposed to cross-pressures were more likely to delay their voting decisions. In the landmark book: The American Voter, Campbell et al. (1960) contended that those who decided early differed from those who decided late primarily in the degree to which they experienced cross-pressures. In the Michigan school, the cross-pressures stem from holding conflicting attitudes towards candidates, issues and groups.

Yet in the late 1960s, as negative evidence regarding the effects of cross-pressures on voting behavior increased (Pool et al., 1965; Horan, 1971; Wolfinger and Rosenstone, 1980; Knoke 1990), its explanation of the time of voting decision waned. Instead, scholars started focusing their attention on the other attributes of late deciders. Among these, partisanship was the main concern. Party identification has been a central factor in understanding and explaining voters' voting behavior. Therefore, many researchers argued that voters' time of voting decision was mainly determined by their partisanship; voters with partisan identities would make their decisions earlier, before the campaign, even. By 
contrast, those without or with weak party identification would make up their minds at a very late stage in an election (Gopoian and Hadjiharalambous, 1994; Fournier et al., 2004).

However, since the 1970s, partisan dealignment has set in. One remarkable feature of dealignment is the decreasing number of party identifiers. With younger generations being less partisan than older generations, the proportion of non-partisans is likely to further increase in the future (Dalton, 2014). It can thus be expected that party identification will perform increasingly worse as a predictor of citizens' voting behavior. For that reason, it is worthwhile to look elsewhere for insight into voters' time of voting decision. This chapter attempts to study voters' time of voting decision from the perspective of issue cross-pressures. As a response to dealignment, scholars in political science concentrated on the significant role of issues, and highlighted individual issue positions as one of the most predominant factors for voting choices. When voters' issue positions lead them to different candidates or parties, we can expect these conflicts to point to a late decision. However, this phenomenon was seldom studied.

Nevertheless, some of the literatures concerning individuals' inner psychological conflict imply that issue cross-pressures may be an important factor influencing people's time of voting decision. Firstly, researchers on political ambivalence have found that people with ambivalent views were less stable (Armitage and Conner, 2000; Conner and Sparks, 2002), more easily persuaded (Armitage and Conner, 2000), and their behavior was harder to predict (Conner et al., 2002). These results suggest that, compared to unambivalent individuals, those who hold competing attitudes towards a candidate or party are more likely to change their minds during the election campaign, which by definition makes them late deciders.

Secondly, inspired by the work of Lazarsfeld et al. on socio-demographic crosspressures, scholars focusing on cross-pressures stemming from heterogeneous discussion networks found that cross-pressures had a negative effect on the time of voting decision. Based on two representative national surveys from the 1992 election, Mutz (2002) found that people whose network involved greater political disagreement were more likely to make up their minds later on in the campaign. By conceptualizing political disagreement in a person's social network as exposed to two conflicting points of view, Nir (2005) found that mixed messages from network discussants affected the time of voting decision but said influence would be moderated by ambivalence. 
Thirdly, political scientists working on campaign effects have contributed to an understanding of how issue cross-pressures may affect a person's decision time as well. Nir and Druckman (2008) studied the role of cross-pressures coming from mass-moderated contexts in people's time of voting decision based on data from the 2000 Minnesota Senate campaign. Their findings showed that, when ambivalent voters had been exposed to mixed campaign information, their voting decisions were delayed. By stating that cross-pressures came not only from external heterogeneous information, but also from counter-attitudinal coverage, Matthes (2012) demonstrated that people who held uncertain initial views and were then exposed to news that opposed their own opinions would delay their voting decisions.

As was mentioned before, issue cross-pressures stem from holding policy preferences across various issues that push people in opposite directions politically. Although there are differences between the concepts of socio-demographic cross-pressures, attitude conflict, political ambivalence, network heterogeneity pressures, mass-moderated pressures and issue cross-pressures, they are all related to a person's inner psychological inconsistency. We therefore expect that issue cross-pressures may delay the time of vote decision. The resulting hypothesis is that the more issue cross-pressures a person suffers from, the later his/her voting decision will be.

\subsection{Issue cross-pressures, time of voting decision and political systems}

This chapter aims to explore the influence of issue cross-pressures on voters' time of voting decision. In addition, the study also attempts to examine whether or not the effect of issue cross-pressures on decision time is conditioned by different political systems. The political system is expected to influence the role of issue cross-pressures in time of voting decision through two different elements. The first one is the number of parties. On the one hand, more parties indicate stronger competition. One important characteristic of party competition in contemporary Western Europe is issue competition (Green-Pedersen, 2007). With an increasing number of parties, it is reasonable to expect that the number of salient issues in electoral campaigns will increase as well, and voters therefore might face more issues during an election. On the other hand, more parties imply more available alternatives and a higher likelihood for voters to find a corresponding party on a specific issue. Therefore, voters with different policy preferences on various issues are more likely to 
potentially find themselves in a situation in which their issue positions lead them towards different parties. In this regard, we can expect that voters in multi-party systems have a greater chance to experience issue cross-pressures than those in a two-party system.

Although people may experience more issue cross-pressures with the increasing number of parties, we cannot conclude that the effect of issue cross-pressures on time of voting decision is more notable in a multi-party system. We should pay attention to the second element of political systems, namely the distribution of parties. This distribution is expected to moderate the relationship between issue cross-pressures and time of voting decision. When political contexts are dominated by several parties, each party has similar opportunities to win a seat in parliament. Therefore, voters who suffer issue cross-pressures may be more hesitant and may struggle between choosing from among two or more parties until the last moment. Conversely, when political contexts are mainly dominated by two parties, parties need to get a relatively high percentage of votes in order to gain a seat, and small parties therefore have little chance to win. Voters whose policy preferences simultaneously push them towards a large party and a small party may make a decision more quickly: vote for the large party, as it has a better chance of getting executive power. In summary, this study expects that the role of issue cross-pressures in the time of voting decision may be more pronounced in multi-party dominated contexts than in two-party dominated contexts.

\subsection{Data and method}

Case selection: This chapter aims to explore the influence of issue cross-pressures on voters' time of voting decision. In addition, the study also attempts to examine whether or not the effect of issue cross-pressures on decision time is conditioned by different political systems. The Netherlands, the United Kingdom and Germany are highly suitable cases for answering the research questions. From 1990s to 2010s, the average effective number of parties ${ }^{42}$ in

\footnotetext{
${ }^{42}$ Effective number of parties is an adjusted number of political parties taking account of voting support. Voting support is calculated by vote share (effective number of parties at the electoral level) and seat share (effective number of parties at the parliamentary level) (Laakso and Taagepera, 1979). Here I use the effective number of parties because I think this concept captures not only the number of parties in a political context, but also the distribution of parties. This means it is possible to compare the difference among these three countries. In this case, I am focusing on the effective number of parties at the
} 
elections in the United Kingdom was 2.3. In Germany, the average effective number of parties was 3.8. In the Netherlands, across seven elections from 1994 to 2012, the average number was 5.5. Comparing the average effective number of parties in these three countries, in the context of what was discussed previously, this study expects that the role of issue cross-pressures in time of voting decision will be most pronounced in the Netherlands, more moderate in Germany and least prevalent in the United Kingdom.

Data: This chapter attempts to study the influence of issue cross-pressures on voters' time of voting decisions. In the Netherlands, this can be examined with the survey data from the Dutch Parliamentary Election Studies (1994-2012), which include measures of time of voting decision, issue positions, and voting choice. With respect to the United Kingdom, the analysis will be based on the British Election Study (1992-2010), which includes similar data of the same concepts. Finally, for Germany, this study focuses on four parliamentary elections from 1994 until 2013 ${ }^{43}$. The data set of the 1998 election was obtained from the German Election Studies 1949-2009 ${ }^{44}$. The other three data sets were obtained from the German Longitudinal Election Study ${ }^{45}$. The survey data from these four elections provide all the information necessary for the purpose of this study.

Method: The dependent variable in this study is voters' time of voting decision. With respect to the Netherlands, respondents were asked: "When did you decide to vote for this party?" The answers included "much earlier" "Last months", "Last weeks", "Last days",

parliamentary level. I have obtained these figures from Trinity College Dublin: Electoral systems:

http://www.tcd.ie/Political Science/staff/michael gallagher/ElSystems/index.php

${ }^{43}$ The 1994 election and the 2005 election omitted, since the survey data from 1994 and 2005 (ZA3065 :Political Attitudes, Political Participation and Voter Conduct in United Germany 1994; ZA4332: Citizens and Parties in a Changed World 2005; ZA5321: longterm Panel 2005-2009-2013 (2005 wave)) does not include position issues or time of voting decision which are the main variables in this study.

44 The name of the data set is ZA3066: Political Attitudes, Political Participation and Voter Conduct in United Germany 1998.

${ }^{45}$ The names of the data sets are ZA532: long-term Panel 2002-2005-2009(2002 wave is used), ZA5302: Pre- and Post-election Cross-Section 2009, ZA5702: Pre- and Post-election Cross-Section 2013. 
and "Election Day" (coded from 5 to 1$)^{46}$. The percentage of people who made their voting choice during earlier stages of the election decreased from 43\% in 1994 to 35\% in 2012 . Simultaneously, the number of people who did not make up their mind until the last few days/election day increased from $25 \%$ to $40 \%$ (see table $6-1$ left). In the United Kingdom, the question was worded as follows: "How long ago did you decide to vote the way you did?" Answers included "A long time ago", "Sometime last year", "Sometime this year", and "During the campaign"(coded from 4 to 1). The percentage of people who made their final decision in the later stages of the election ranged from $24 \%$ in 1992 to $34 \%$ in 2010 . While the percentage of those who made their voting choice a long time ago was as high as $60 \%$ in 1992, this number decreased to $45 \%$ in 2012 (see table 6-1 center). In Germany, the question about voters" time of voting decisions was "When did you decide how to vote in these federal elections?" Respondents replied with "a long time ago", "a few months ago", "in the last weeks before the elections", "in the last days before the elections", and "on election day" (coded from 5 to 1). The trend of people's time of voting decision in Germany is similar to that in the Netherlands and the United Kingdom. The number of late deciders increased every year from 1998 to 2013. By contrast, those who made their voting choice a long time before the election decreased from $65 \%$ to $53 \%$ (see table $6-1$ right).

People may doubt the reliability of time-of-voting-decision recall. However, Fournier and his colleagues (2001) found it was quite reliable in the context of Canada. They argued that, if respondents' answers to time-of-voting-decision questions were accurate, it was reasonable to expect that there would be more stability in vote choice (pre and post-election: vote intention vs. vote choice) among those who were interviewed after the reported time of decision than among those who were interviewed before that time. Analyzing data from the 1997 Canadian Election Study, their findings supported this argument. The results showed only little stability in vote choice (below 50 percent) among those who were interviewed before the time of decision. Conversely, this number was over 80 percent among those who were interviewed after the reported time of decision. Given the similarities between the Netherlands, the United Kingdom, Germany and Canada in terms of their parliamentary

\footnotetext{
${ }^{46}$ In the survey data of 1994, there is no option of "Election day".
} 
electoral systems and short campaign periods, we can conclude that the time-of-votingdecision recall is reliable. ${ }^{47}$.

\section{[TABLE 6-1 ABOUT HERE]}

The independent variable is the issue cross-pressures score. The calculation of individuals' issue cross-pressures is based on the regression-based approach described in Chapter 2. Out of the four different steps, we can observe that the first step is fundamental. Therefore, information about voters' policy preferences regarding various issues and party preferences, which are independent variables and dependent variables respectively in step 1, is necessary. This chapter attempts to examine to what extent individuals' stances on various position issues will lead them to different parties which, in turn, influence their time of voting decision. The selection of issues is based on two considerations: (1) their salience in society in each of the three countries mentioned. (2) The surveys in the three countries from the 1990 s to the 2010s, which include these issues, as well as measurements of respondents' positions ${ }^{48}$.

With respect to voters' party preferences, as described in Chapter 2, party preferences would be vote choice/intention and partisanship. In this chapter, vote choice

\footnotetext{
${ }^{47}$ I replicated the cross-table analysis of Fournier et al. (2001) by using survey data from 1994, 1998, 2002, 2006 and 2010 DPES and 2001, 2005 and 2010 BES (I did not replicate the other data sets used in this paper, since they do not have information on vote intention before elections, which is necessary in order to examine validation of time-of-votingdecision recall). In all cases, the stability of vote choice among those who were interviewed after their time of decision is far greater than that among those who were interviewed before/during their reported time of voting decision. Therefore, we can be confident in the reliability of time-of-voting-decision recall. For detailed information, see table 6-4 in Appendix C.

${ }^{48}$ With respect to the Netherlands, the issues chosen in this paper include: income differences, European unification, crime fighting, foreigners' adaptation, nuclear plants, euthanasia, asylum seekers, minorities, social benefits. In the United Kingdom, the issues are about taxes, crime right, EU membership, EU currency, blacks and Asians, unemployment and inflation, nationalization and privatization, income redistribution, women's rights, jobs and standard of living. In Germany, they are socio-economic, Libertarian-authoritarian, climate change, nuclear power, immigration, European unification. In all three countries, there are some differences in specific issues chosen in each election. In the Appendix $\mathrm{C}$, there is an example of how the questions regarding these issues are worded.
} 
was chosen, because many people do not have any party identification, especially in a European context. Consequently, choosing partisanship as the dependent variable in the first step would have resulted in the exclusion of a large number of people. In Germany, citizens have two votes in every election: one for the candidate, the other for the party. However, since the party vote is more essential in determining the distribution of parties in parliament, this study only concentrates on the party vote. In addition, this choice makes the analysis consistent with that in the Netherlands and the United Kingdom, namely party choice rather than candidate choice.

With the above information, we can now calculate a person's issue cross-pressures score based on the regression-based approach described in Chapter 2. Since the variables of vote choice in all three countries have more than two options, a nominal regression model has been chosen in step 1. We also need to pay close attention to step 3. After obtaining the predicted probabilities of each party for each individual in step 2 , there are three choices to capture the variation among these predicted probabilities, namely selecting the two highest predicted probabilities, the three highest predicted probabilities, or all parties' predicted probabilities. In this study, the first option was chosen, because people's issue crosspressures score measured based on different choices are highly correlated ${ }^{49}$, and the final findings have not changed ${ }^{50}$. In order to remain concise, this study calculates people's issue cross-pressures scores based only on the two strongest voting dispositions.

In order to make the examinations regarding the relationship between issue crosspressures and time of voting decision more convincing, several other variables should be controlled. One important factor among them is the consideration set ${ }^{51}$, meaning the parties

\footnotetext{
${ }^{49}$ Only in 1 out of 16 elections; the correlations between issue cross-pressures calculated by the "top-2 variance method", the "top-3 variance method" and the "full variance method" are less than 0.5 . In other elections, the correlations are all between 0.7 and 0.99 . For detailed information, see table 6-5 to table 6-7 in Appendix C.

${ }^{50}$ Once the issue cross-pressures score has been calculated based on the "top-2 variance method", the "top-3 variance method", and the "full variance method", in the Netherlands, there are 4 out of 7 elections, 5 out of 7 elections, and 5 out of 7 elections, respectively, in which the issue cross-pressures score is highly significant at 0.05 . This is the case in 2 out of 5 elections, 3 out of 5 elections and 3 out of 5 elections, respectively, in the United Kingdom. In Germany, the score is highly significant in 1 out of 4 elections in all cases. For detailed information, see table 6-8 to table 6-10 in Appendix C.

${ }^{51}$ Only elections in the Netherlands and partial elections in United Kingdom have this variable. Nevertheless, the results presented in table II and table IV show that the influence
} 
citizens are aware of and are considering voting for (Schmitt-Beck and Partheymüller, 2016; Vassil et al., 2016). Several studies showed that, with the increasing number of choices in people's minds, people will delay their decisions (Greenleaf and Lehmann 1995). In addition, this study also controls demographic variables: age, gender, social class and education, and political variables: party identification and political interest ${ }^{52}$.

\subsection{Findings}

The main aim of this chapter is to try to answer the question of whether or not issue crosspressures affect voters' time of voting decision. The hypothesis is that the more issue crosspressures a person suffers from, the later his/her voting decision will be. This study first focuses on the Dutch Parliamentary elections. In order to test the hypothesis, the study generates voters' issue cross-pressures scores based on their issue positions and voting choices. It then estimates two ordered logistic regression models ${ }^{53}$ with citizens' time of voting decision as the dependent variable (Table 6-2). Model 1 only includes an independent variable: a person's issue cross-pressures score. The results in the first model clearly live up to the prediction, that is, higher issue cross-pressures linked to a later time of voting decision. Model 1 demonstrates that, for six elections (1994, 1998, 2002, 2006, 2010, 2012), the coefficients on the issue cross-pressures score are negative and strongly significant. In the subsequent rows, estimated outcomes are provided if all voters were at the $10^{\text {th }}, 50^{\text {th }}$ and $90^{\text {th }}$ percentiles in terms of issue cross-pressures score. When focusing on

of issue cross-pressures in time of voting decision is not moderated by consideration set size.

${ }^{52}$ Coding of control variables, see Appendix C.

${ }^{53}$ As the results in table 6-2, table 6-3 and table 6-4 demonstrate, with respect to models without control variables, Brant tests are passed in 14 out of 16 elections. By contrast, once control variables are added, only 7 out of 16 elections meet the assumption of proportional odds. Therefore, for models with control variables, I performed a generalized ordered logistic regression analysis. The results are not very different compared to those from ordered logistic regression analysis. More specifically, once the issue cross-pressures score is not significant in the ordered logistic model, it is not significant in most cases in the generalized ordered logistic model either. On the contrary, if it is significant in the ordered logistic model, it is also significant in most cases in the generalized ordered logistic model. In addition, the final findings and conclusions do not change when relying on results from the generalized ordered logistic regression analysis. In order to remain concise and to keep the results more straightforward, this chapter will use ordered logistic regression. For detailed information about the results from the generalized ordered logistic regression analysis, see table 6-11 Appendix C. 
these margins, the results clearly show that electoral decisions are delayed by $11.09 \%$, $2.44 \%, 2.24 \%, 2.47 \%, 4.40 \%$ and $5.78 \%$ respectively in moving from the $10^{\text {th }}$ to the $90^{\text {th }}$ percentile of the issue cross-pressures score. All these show that issue cross-pressures lead to a delayed time of voting decision.

In order to ensure that the relationship between issue cross-pressures and the time of voting decision shown in the first model is not spurious, respondents' consideration set size, demographic background and political attributes are controlled (Table 6-2). The results are reported in model 2. In the 2002 and 2006 elections, the coefficients of issue cross-pressures score are in the expected direction, but they are not significant. However, the coefficients of the issue cross-pressures score in the other four election years (1994, 1998, 2010 and 2012) are still highly significant, and all point in the predicted direction. The margins shown in the following rows also meet expectations. Voting decisions are delayed when moving from the $10^{\text {th }}$ to the $90^{\text {th }}$ percentile of the issue cross-pressures score. In summary, in 4 out of 7 elections, issue cross-pressures have a significant effect on voters' time of voting decision regardless of whether control variables are added. This implies that the effect of issue cross-pressures on the time of voting decision of Dutch voters is robust, and is not moderated by consideration set size, or demographic and political variables.

\section{[TABLE 6-2 ABOUT HERE]}

We will now turn our attention to the British general election to see if the role of issue cross-pressures in a different political system can be observed. Our hypothesis, namely that a person's voting decision is delayed as issue cross-pressures increase, is strongly supported by the data shown in model 3. The coefficients for four elections (1992, 1997, 2005 and 2010) all meet expectations, in that they are negative and highly significant. The margins reported in the following rows also point in the predicted directions. For the time of voting decision, when moving from the $10^{\text {th }}$ to the $90^{\text {th }}$ percentile of the issue crosspressures score, the effect is delayed by $10.91 \%, 18.07 \%, 5.64 \%$ and $7.71 \%$ respectively.

The next test is whether the effect of issue cross-pressures in the time of voting decision is remarkable by adding control variables to the model (Table 6-3, Model 4). Observing the coefficients of the issue cross-pressures score displayed in model 4, we can find that three of them (1992, 1997 and 2010) are still significant and point in the expected 
direction. The margins reported in the following rows are also in line with those in model 3. Time of voting decision is delayed by $8.35 \%$ in $1992,14.84 \%$ in 1997 , and $5.37 \%$ in 2010 when moving from the $10^{\text {th }}$ to the $90^{\text {th }}$ percentile of the issue cross-pressures score. Overall, the coefficients of the issue cross-pressures score in 3 out of 5 elections always remain significant, which shows that issue cross-pressures influence British citizens' time of voting decision.

\section{[TABLE 6-3 ABOUT HERE]}

Regarding Germany, the question is whether we are able to observe a similar effect of issue cross-pressures on the time of voting decision From Model 5, we can see that some of the results reported meet the original prediction. In the election of 2009, the coefficient of individuals' issue cross-pressures scores is significant and related to people deciding late, as expected, even though the magnitude of the estimated effects are quite modest. Time of voting decision is delayed by $0.64 \%$ when moving from the $10^{\text {th }}$ to the $90^{\text {th }}$ percentile of the issue cross-pressures score. By contrast, voters' issue cross-pressures scores in 1998, 2002 and 2013 appear irrelevant for the time of voting decision. The coefficients in these three models are all insignificant. After adding control variables to the analysis, the results from model 6 are similar to those in model 5. The coefficients of voters' issue cross-pressures scores in 2009 are still significant and negative. However, in 1998, 2002 and 2013, the role of issue cross-pressures cannot be observed. All of this information suggests that the effect of issue cross-pressures on the time of electoral decision in Germany is not as great as is the case in the Netherlands and the United Kingdom.

\section{[TABLE 6-4 ABOUT HERE]}

Following the discussion in the previous section, this study expects that, with the increasing number of parties in a system, the influence of issue cross-pressures might become even more pronounced. The findings partially support the expectation. Firstly, with respect to the Netherlands and Germany, it is expected that the role of issue cross-pressures in time of voting decision is more pronounced in the Netherlands than in Germany. The results in Table 6-2 and Table 6-4 confirm this prediction. The effects of issue cross- 
pressures are significant in 4 out of 7 elections in the Netherlands after controlling consideration set size, demographic and political variables. However, this is the case in only 1 out of 4 elections in Germany.

Secondly, the results from the Dutch parliamentary election and the British general election also support expectations. The effects of issue cross-pressures are notable in 3 out of 5 elections in the United Kingdom, which are a little bit larger compared to those in the Netherlands (4 out of 7). However, in the Netherlands, the coefficients of the issue cross-pressures score in those 4 elections are all significant at the 0.01 level. With respect to the United Kingdom, one of them is significant at the 0.1 level, and the other two are significant at the 0.01 level. In addition, comparing the coefficients of the issue crosspressures scores in model 2 to those in model 1, the directions of their changes are mixed. The coefficient increases in the elections of 1998 and 2012, and decreases in elections of 1994 and 2010. However, after adding control variables into model 4, we can find that the absolute value of the issue cross-pressures score's coefficients all decrease in 1992, 1997 and 2010 when compared to model 3. These results imply that the effect of issue crosspressures on time of voting decision in the Netherlands is slightly stronger than is the case in the United Kingdom.

Thirdly, in the United Kingdom and Germany the results do not support the hypothesis. The results in Table IV show that issue cross-pressures have a significant effect on people's time of voting decision in only 1 out of 4 elections in Germany, regardless of whether control variables are added or not. However, in the United Kingdom, the effect is significant in 4 out of 5 elections without controlling variables. And it is significant in 3 out of 5 elections when control variables are added. This comparison illustrates that the role of issue cross-pressures in decision time in Germany is more moderate than in the United Kingdom.

\subsection{Conclusion and discussion}

Since the late 1970s, the electorate among the long-standing European democracies has become less stable than before. One of the reasons is the increasing number of people who make their voting decisions at a very late stage in the campaign. Due to the important role of undecided voters in determining the outcome of an election, political scholars have long worked on the question of what factors influence voters' time of voting decisions. 
This chapter attempts to examine (1) whether or not the time of voting decisions are affected by issue cross-pressures, and (2) whether or not the role of issue crosspressures in time of voting decision is conditioned by political systems. In order to achieve this goal, this study uses the survey data from the Dutch Parliamentary Election Study, the British Election Study, and the German Election Study. Analyses of seven Dutch parliamentary elections (1994-2010), five British general elections (1992-2010) and four German parliamentary elections (1994-2013) have shown that issue cross-pressures do influence people's time of voting decisions regardless of their consideration set size, demographic background and political attributes. In the model without control variables, individuals' issue cross-pressures scores in 11 out of 16 elections are strongly related to late deciding, as expected. When control variables are added, the role of issue cross-pressures disappears in some elections; however, it remains significant in 8 out of 16 elections. Therefore, the conclusion is that issue cross-pressures have an impact on citizens' time of voting decisions.

One thing to note is that McKelvey-Zavoina $\mathrm{R}$-square ${ }^{54}$ is not very high across Table 6-2 to Table 6-4. This implies that, even though issue cross-pressures have a significant influence, they do not explain much of the variations in voters' time of voting decisions. However, there are a number of reasons as to why issue cross-pressures should not be expected to explain a great deal. Firstly, the issue cross-pressures score in this paper is a political variable, in the sense that it is based on political content (policy issues, ideological differences), while the dependent variable is not about political content. Furthermore, after including party identification in the analysis, the value of McKelveyZavoina $\mathrm{R}$-square ${ }^{2}$ is still only about 0.15 , while partisanship is considered a strong influence on virtually all elements of electoral behavior. So, apparently, time of voting decision is a phenomenon that is just difficult to explain. In addition, several measures of the issue cross-pressures score exist. The one used in this paper is based on the regression model, making deductions from the procedure proposed by Brader et al. (2014). It is possible for the Pseudo- $\mathrm{R}^{2}$ to be different with another measurement of issue crosspressures.

${ }^{54}$ McKelvey-Zavoina $\mathrm{R}^{2}$ is one kind of Pseudo- $\mathrm{R}^{2}$ for ordinal outcomes, which has been agreed by scholars is most closely approximates the $\mathrm{R}^{2}$ in liner regression model (Hagle and Mitcheel, 1992; Windmeijer, 1995; Long and Freese, 2005). 
The findings partially confirmed that the influence of issue cross-pressures in time of voting decision might be conditioned by party systems. This study expects that the role of issue cross-pressures in time of voting decision is the largest in the Netherlands, followed by Germany and finally the United Kingdom. However, the results only partially support this prediction. Looking at the models with control variables, we find that, in Germany, citizens' issue cross-pressures scores are significantly related to late deciding in only 1 out 4 elections. By contrast, this figure in the United Kingdom is 3 out of 5, and 4 out of 7 in the Netherlands. Additionally, the coefficients of the issue cross-pressures score in the Netherlands are all significant at the 0.01 level in those 4 elections. In the United Kingdom, only two are significant at the 0.01 level. These findings suggest that the effect of issue cross-pressures in the Netherlands is most pronounced, a little bit more moderate in the United Kingdom, and weakest in Germany. This implies that variations in the effect of issue cross-pressures on the time of voting decision in different political contexts can be partially explained by party systems.

This study provides us with a new perspective in understanding voters' voting behavior: the decision time of voters. Because of dealignment, party identification is losing its appeal in predicting citizens' political behavior. In this regard, if we only focus on partisanship, we may not fully understand and explain the political behavior of voters in the future. Therefore, turning our attention to short-term factors is worthwhile. Issue crosspressures is one of these factors.

Furthermore, the present study suggests several follow-up questions. Firstly, as was found in this paper, variations in the effect of issue cross-pressures on time of voting decision in different political contexts can only be partially explained by party systems. This implies that we need to look into why the role of issue cross-pressures in different political systems differs. Electoral rule would need to be taken into account. The German electoral system is distinct from those in the Netherlands and the United Kingdom. The members of Bundestag are elected in two separate ways. Half of the members (299) are elected based on a proportional representation rule by using party lists, while the other half are elected directly from 299 constituencies based on a First-Past-The-Post rule. As a result, each voter has two votes in the German parliamentary election. The first vote is cast for a candidate, choosing which candidate is sent to parliament on the behalf of their local constituencies. The second vote, allowing voters to vote for a party list, determines the 
allocation of seats in parliament. Since both votes count, it provides an opportunity for voters to split their voting when they feel attracted to two parties simultaneously. This might be a reason why the influence of issue cross-pressures is weakest in Germany compared to the Netherlands and the United Kingdom.

Secondly, we can observe that the role of issue cross-pressures in time of voting decision not only varies among countries, but also among elections within a country. As the long-term tie between voters and parties is waning, issues are increasingly important for voters' voting choices. In this regard, we would expect that the role of issue cross-pressures on time of voting decision will continuously increase in each country. However, our findings suggest otherwise. More specifically, in the Netherlands the coefficient of issue cross-pressures was not significant in the 2002, 2003 and 2006 elections, but it was significant in the 1994, 1998, 2010 and 2012 elections. In the United Kingdom, issue crosspressures had an effect on decision time in the 1992, 1997 and 2010 elections, but they did not influence a person's motivation to postpone his/her voting decision in the 2001 and 2005 elections. In Germany, in the 2009 election, issue cross-pressures played a role, while in the 1998, 2002 and 2013 elections, they were not significant. Future studies should therefore examine under what kinds of conditions issue cross-pressures will influence voters' time of voting decision.

Thirdly, political scholars have spent a great deal of time studying late deciders from the perspective of what they are waiting for. Generally, the common wisdom is that they are waiting for more information related to the candidates and/or parties. This study shows that issue cross-pressured citizens are late deciders. It is therefore possible that (1) those late deciders are waiting for nothing, but just keep on hesitating which party or candidate to vote for until the last moment and make a choice randomly.(2) On the other hand, it is also possible that when people suffer from issue cross-pressures, they will seek to reduce the feeling of inconsistency. There are several possible ways of doing so, such as understating the importance of some issues for themselves, re-evaluating the candidates' or parties' issue positions, adding other attributes which they adore to parties/candidates, like leadership. All in all, this study gives us some other ideas about what late deciders are waiting for other than just additional information concerning the parties or candidates. 
6

0
0
0
0
0
0
00
00
0
0
0
4
0
0
0
0
0
0
0
0
0
0
0
0
0
0
0
0
0
0
0
0
0

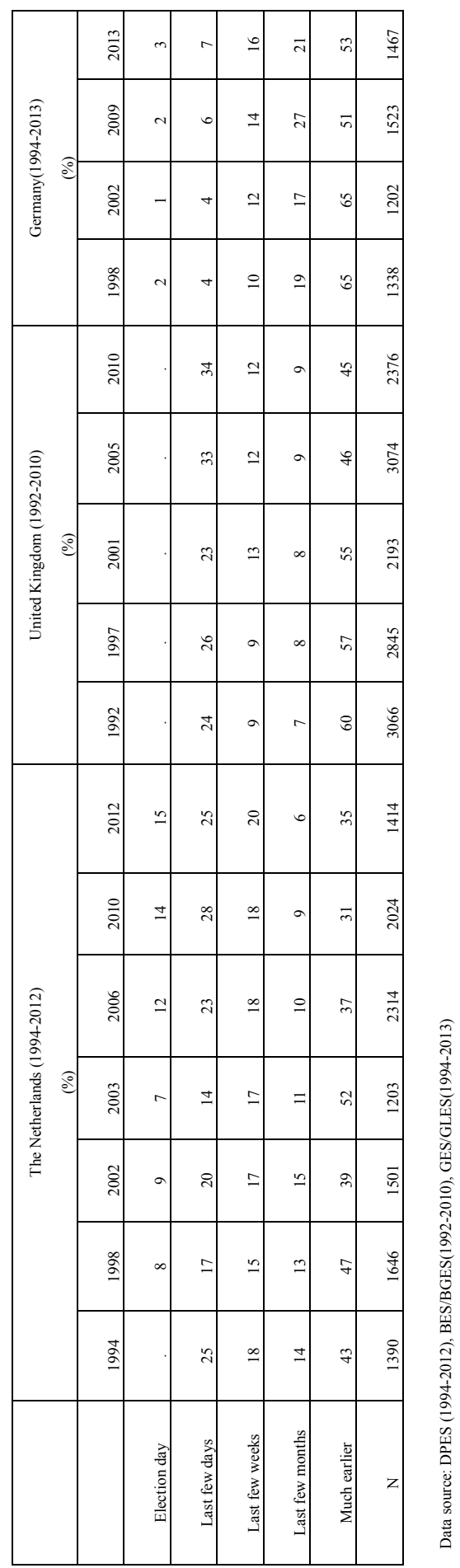




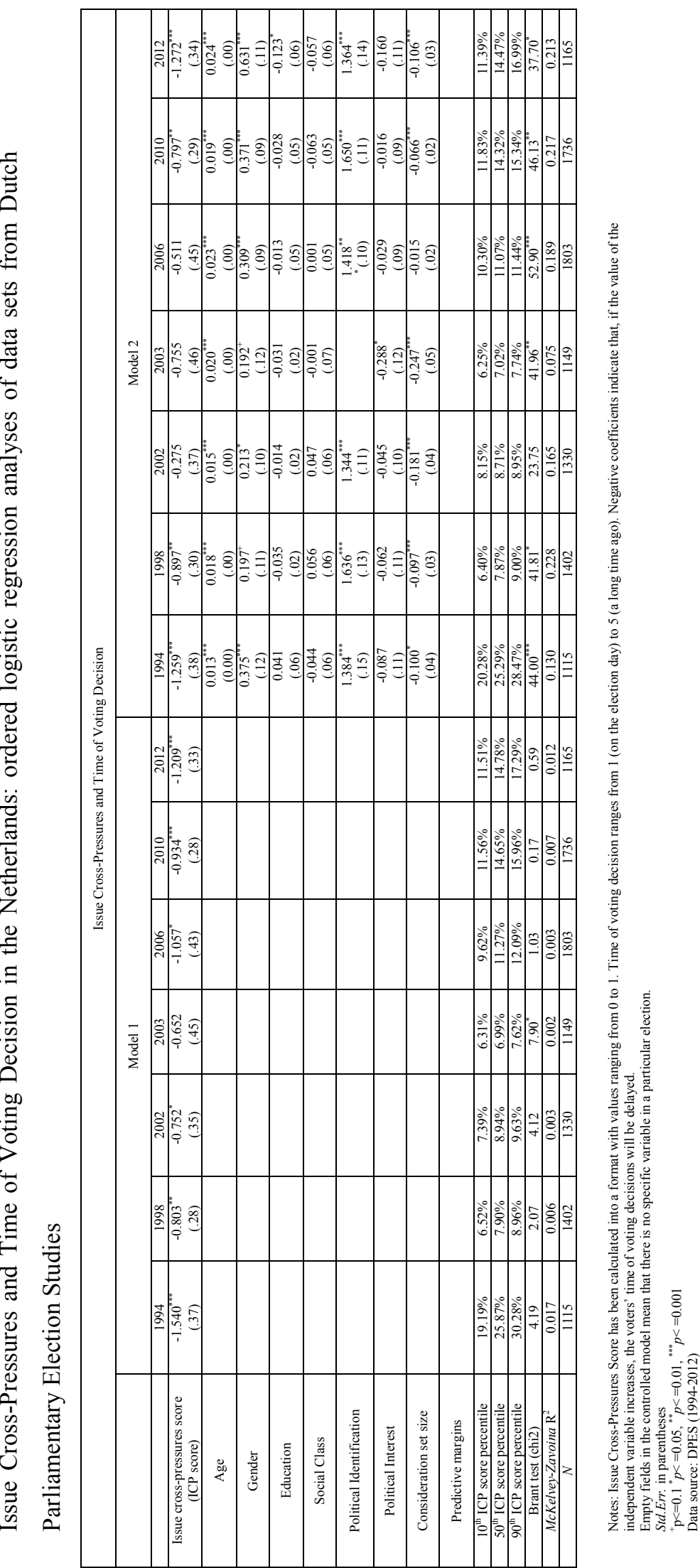




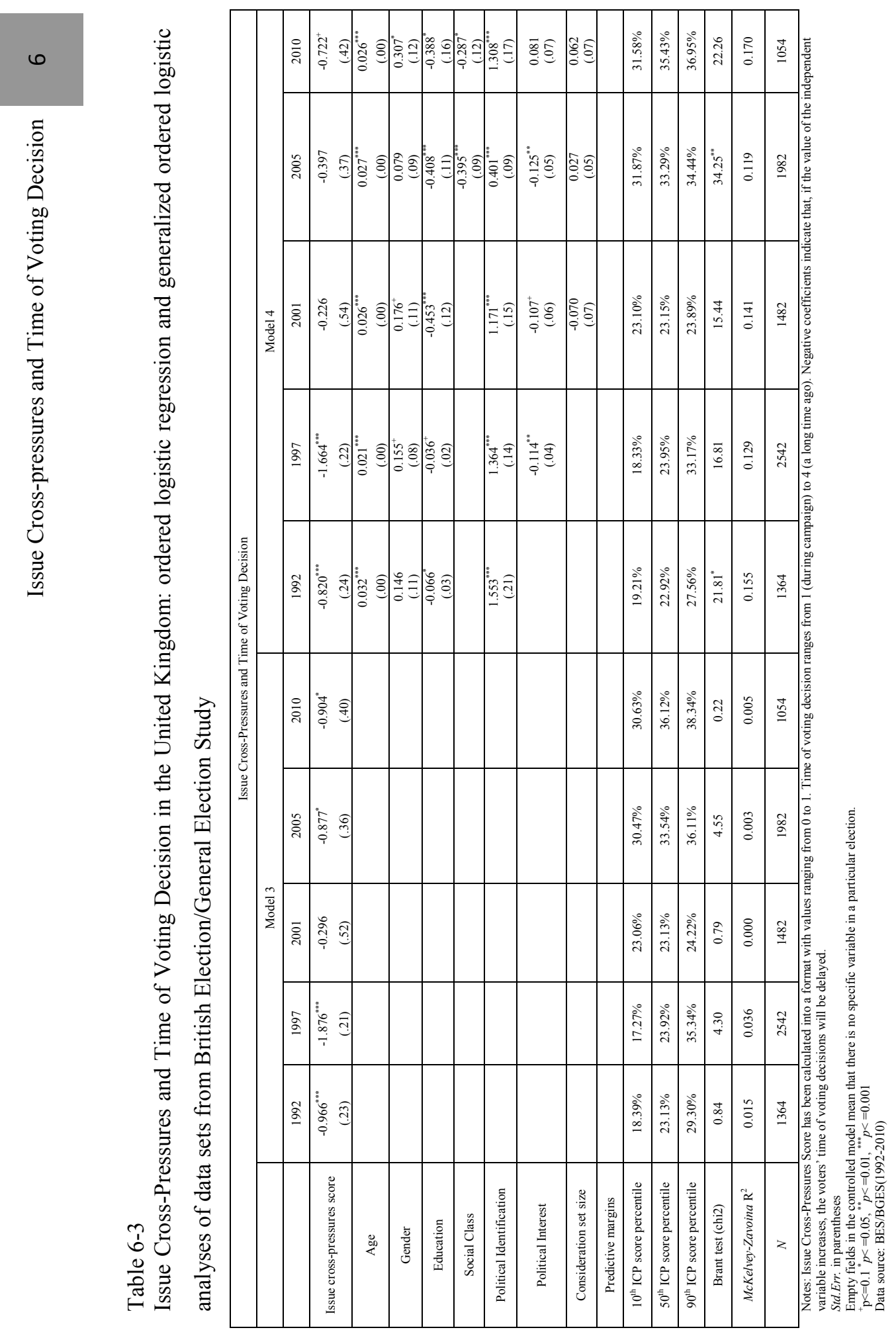




\section{Table 6-4}

Issue Cross-Pressures and Time of Voting Decision in Germany: ordered logistic regression analyses and generalized ordered logistic of data sets from German Election/Longitudinal Election Studies

\begin{tabular}{|c|c|c|c|c|c|c|c|c|}
\hline \multicolumn{9}{|c|}{ Issue Cross-Pressures and Time of Voting Decision } \\
\hline & \multicolumn{4}{|c|}{ Model 5} & \multicolumn{4}{|c|}{ Model 6} \\
\hline & 1998 & 2002 & 2009 & 2013 & 1998 & 2002 & 2009 & 2013 \\
\hline \multirow{2}{*}{ Issue cross-pressures score } & -0.387 & -0.117 & $-1.544^{* *}$ & -0.412 & -0.257 & -0.151 & $-1.545^{* *}$ & -0.555 \\
\hline & $(.56)$ & $(.45)$ & $(.53)$ & $(.37)$ & $(.58)$ & $(.46)$ & $(.56)$ & $(.38)$ \\
\hline$\Delta$ & & & & & $0.014^{* * *}$ & $0.013^{\circ}$ & $0.026^{* * * *}$ & $0.020^{* * * *}$ \\
\hline Age & & & & & $(.00)$ & $(.01)$ & $(.00)$ & $(.00)$ \\
\hline Gender & & & & & $\begin{array}{c}0.079 \\
(.13)\end{array}$ & $\begin{array}{c}-0.293^{*} \\
(.13)\end{array}$ & $\begin{array}{c}-0.133 \\
(.11)\end{array}$ & $\begin{array}{c}0.224^{*} \\
(.11)\end{array}$ \\
\hline \multirow{2}{*}{ Education } & & & & & $-0.234^{* * *}$ & -0.061 & -0.060 & $-0.200^{* *+*}$ \\
\hline & & & & & (.06) & $(.04)$ & $(.06)$ & $(.06)$ \\
\hline Social Class & & & & & $\begin{array}{c}0.085 \\
(.12)\end{array}$ & $\begin{array}{c}-0.016 \\
(.13)\end{array}$ & $\begin{array}{c}0.064 \\
(.07)\end{array}$ & $\begin{array}{c}-0.051 \\
(.06)\end{array}$ \\
\hline Political Identification & & & & & $\begin{array}{c}1.095^{* * *} \\
(.13)\end{array}$ & $\begin{array}{c}-0.003^{+} \\
(.00)\end{array}$ & $\begin{array}{c}1.715^{* * *} \\
(.13)\end{array}$ & $\begin{array}{c}1.312^{* * * *} \\
(.13)\end{array}$ \\
\hline Political Interest & & & & & $\begin{array}{c}-0.169^{*} \\
(.07)\end{array}$ & $\begin{array}{c}-0.377^{* * *} \\
(.08)\end{array}$ & $\begin{array}{c}-0.148^{\circ} \\
(.07)\end{array}$ & $\begin{array}{c}-0.190^{* *} \\
(.07)\end{array}$ \\
\hline \multicolumn{9}{|l|}{ Consideration set size } \\
\hline \multicolumn{9}{|l|}{ Predictive margins } \\
\hline $10^{\text {th }}$ ICP score percentile & $1.88 \%$ & $1.28 \%$ & $1.35 \%$ & $2.33 \%$ & $1.91 \%$ & $1.27 \%$ & $1.37 \%$ & $2.25 \%$ \\
\hline $50^{\text {th }}$ ICP score percentile & $1.99 \%$ & $1.32 \%$ & $1.60 \%$ & $2.60 \%$ & $1.98 \%$ & $1.32 \%$ & $1.62 \%$ & $2.61 \%$ \\
\hline $90^{\text {th }}$ ICP score percentile & $2.08 \%$ & $1.34 \%$ & $1.99 \%$ & $2.71 \%$ & $2.05 \%$ & $1.34 \%$ & $2.00 \%$ & $2.74 \%$ \\
\hline Brant test (chi2) & $7.66^{+}$ & 3.04 & 1.19 & 0.31 & $33.75^{*}$ & 11.14 & 19.44 & 18.92 \\
\hline McKelvey-Zavoina $\mathrm{R}^{2}$ & 0.001 & 0.000 & 0.007 & 0.001 & 0.112 & 0.053 & 0.216 & 0.155 \\
\hline$N$ & 1210 & 1066 & 1287 & 1329 & 1210 & 1106 & 1287 & 1329 \\
\hline
\end{tabular}

Notes: Issue Cross-Pressures Score has been calculated into a format with values ranging from 0 to 1 . Time of voting decision ranges from 1 (on the election day) to 5 (a long time ago). Negative coefficients indicate that if the value of the independent variable increases, the voters' time of voting decisions will be delayed. Empty fields in the controlled model mean that there is no specific variable in a particular election.

Std.Err. in parentheses

${ }^{+} \mathrm{p}<=0.1{ }^{*} p<=0.05,{ }^{* *} p<=0.01,{ }^{* * * *} p<=0.001$

Data source: GES/GLES(1994-2013) 


\section{7- Issue Cross-pressures, Electoral Behavior and Democracy}

For theorists of democracy, the electoral regime is fundamental, since elections are the most visible expression of popular sovereignty (Barber, 2003; Benbabib, 2004; Dewey, 2004; Downs, 1957; Przeworski, 1991; Schumpeter, 2013). Fair elections guarantee that the representatives in legislature are elected by the represented. During election campaigns, parties or candidates compete for people's votes in various ways. For example, they make policy proposals and explain how these policies would affect citizens' benefits and citizens decide which parties or politicians to charge with political power based on factors such as the parties or candidates' policy platforms. In addition, the competition depends on voters' own decisions: by deciding whether or not to cast a vote again, the governed have an opportunity to hold the governors responsible for the results of their past actions.

In recent decades, close observation of electoral behavior has revealed tremendous shifts in almost all characteristics of voting. Recent developments include an increasingly delayed time of voting decision (Dalton et al., 2002; Irwin \& Van Holsteyn, 2008; SchmittBeck \& Partheymuller, 2012), decreasing turnout (Cox, 2015; Dalton, 2008; Hooghe, 2014; Hooghe \& Kern, 2016; Mair, 2014; Wattenberg, 2008), greater volatility and vote switching (Bischoff, 2013; Dalton et al., 2002; Dassonneville \& Hooghe, 2015; Drummond, 2006; Gallagher et al., 2011; Mair, 2002, 2008) and less cleavage voting (Franklin et al., 2009; Oskarson, 2005). These kinds of instabilities and changes in electoral behavior have led scholars of democracy to question whether the quality of representative democracy is experiencing an ongoing erosion.

From the perspective of the 'demand side' of politics, two broad schools of thought seem to exist in the literature on decreasing stability in determinants and patterns of electoral behavior. One rather pessimistic idea highlights the role of citizens' growing concern for private pursuits at the expense of traditional political virtues, such as civic duty, accompanied by modernization (Putnam, 2000; Mair, 2013; Wattenberg, 2015). With the decline of traditional associations (such as a club, family or labor union), the diffusion of television and the Internet as mass media of both information and entertainment, and other 
trends, citizens have retreated into private life and moved into a more individualistic and self-absorbed society. Consequently, citizens are less interested in politics and do not have sufficient political knowledge, and therefore make their voting decision more randomly.

An alternative explanation ties changing patterns of behavior to a different aspect of modernization theory. Since the end of the Second World War, Western European countries have undergone unprecedented economic and social development. Citizens therefore enjoy new heights of economic prosperity and physical security. Consequently, advanced democracies see a growing emphasis on self-expression values and civil and political liberties (Inglehart, 1977, 1990; Inglehart \& Welzel, 2005). At the same time, with the expansion of higher education and with political information becoming increasingly available (Fahmy, 2006; Norris, 2001; O’Neill, 2010; Whiteley, 2012), more citizens now possess the political skills and resources necessary to become self-sufficient in politics (Dalton, 1984; Dalton \& Wattenberg, 2000). All of these factors point to the conclusion that decreasing stability in determinants and patterns of voting behavior is not a result of political apathy but a result of a transformation in the nature of the demand side of politics.

While the above two explanations are not necessarily inconsistent with one another, they hold very different implications with respect to the function of representative democracy. If the changing electoral behavior is due primarily to de-politicization, the prospects for reviving representative democracy are bound to be bleak. If, on the other hand, the current instability in electoral behavior is due more to a transformation in citizens' expectations and ability, the scope for addressing this challenge may be larger. It is concerns such as these that motivate this dissertation.

The following sections summarize and reflect all the findings of this study. Section 1 summarizes previous chapters, including their findings. Section 2 briefly describes the scope and limitations of this study. Section 3 discusses the implications of the findings for electoral behavior and democracy in general. It also suggests future avenues of research that follow from the current study. Section 4 concludes this chapter.

\subsection{The role of issue cross-pressures in electoral behavior: Answering the research questions}

Facing changes and instability in electoral behavior across Western Europe, traditional 
party identification and social cleavages perform increasingly poorly in understanding and explaining the way in which voters make their voting choices. In order to gain a better understanding of electoral behavior in contemporary advanced democracies, we must turn to other factors which should account for not just one type of electoral behavior but several. One possibility is to focus on issue cross-pressures. As discussed in chapter 1, issue crosspressures are the by-product of the decline of partisan politics and the rise of the importance of issue orientation in voting behavior. To experience issue cross-pressure, citizens first need to take issues into consideration when making their voting choice. Therefore, if the changes in electoral behavior are due to de-politicization, we should not expect that issue cross-pressures will affect citizens' various kinds of electoral behavior. In contrast, only because of culture shift and cognitive mobilization can we possibly observe the influence of issue cross-pressures on citizens' voting behavior. As such, exploring the impact of issue cross-pressures on electoral behavior will contribute to our understanding of the implications of the widespread change in electoral behavior across West European countries. It in turn sheds light on how we should assess the quality of representative democracy and how to cope with the challenges faced by advanced democracies in terms of changes in electoral behavior.

In addition, the study of issue cross-pressures in itself is interesting, as it will explain how citizens deal with inconsistency arising from their issue preferences and the influence of this inconsistency on their political behavior. Scholars in political science have often examined the role of cross-pressures in citizens' electoral behavior. To date, however, most of the existing literature has focused on the influence of cross-pressures stemming from citizens' social background, group memberships and social networks. Political scientists know comparatively little about the effect of cross-pressures emerging from holding contradictory voting predispositions based on various issues. On the other hand, it has long been argued that citizens' concerns about issues or problems were multidimensional rather than unidimensional. For example, in the studies of party formation, one of the reasons why political parties cannot simply be seen as the reflection of social and economic interests is that voters care about multiple issues and their positions on these issues are not necessarily correlated in the same political direction (Boix, 2007). However, comparatively few studies have developed a theory and explored the consequences of citizens' having multiple concerns about issues in electoral politics. Therefore, the main 
research question in this dissertation is: Do issue cross-pressures influence citizen's different kinds of electoral behavior, and, if so, how?

To answer the above question, the dissertation has been separated into a theoretical part (Chapter 2) and an empirical part (Chapters 3 to 6). The theoretical part focused on theoretical questions namely: (2a) What are issue cross-pressures and which existing definition of issue cross-pressures is better? (2b) What are the preconditions for citizens to experience issue cross-pressures? (2c) How do individuals' issue cross-pressures arise? (2d) How do issue cross-pressures influence issue voting, turnout, vote switching and time of voting decision 55 ? and (2e) How should issue cross-pressures be measured? The empirical part pertained to the empirical studies of the impact of issue cross-pressures on electoral behavior. The research questions included: (3a) Is the role of issues in citizens' voting choice moderated by citizens' issue cross-pressures? (4a) Do issue cross-pressures decrease citizens' motivation to turn out to vote? (4b) Is the role of issue cross-pressures in turnout moderated by the party system? (5a) Do issue cross-pressures influence citizens' vote change across elections? (5b) Is the role of issue cross-pressures in vote switching conditioned by different mobilization types? (6a) Is the time of voting decisions affected by issue cross-pressures? and (6b) Is the role of issue cross-pressures in the time of voting decision conditioned by political systems? In this section, I first present answers to the research questions investigated in each specific . Later, I will present answers to the main research question.

Chapter 2 developed a theory of issue cross-pressures to address theoretical questions $2 \mathrm{a}$ to $2 \mathrm{e}$. It began with the definition of issue cross-pressures. Based on existing literature, this study followed the definition developed by Therriault et al. (2011), namely that cross-pressures result from holding policy preferences across various issues that push one in different political directions (2a). For citizens to experience issue cross-pressures, they should care about at least two different issues and their opinions on those issues should not be comprehensively constricted by a unidimensional ideology (2b). Citizens' awareness of issue cross-pressures could come about because of conflicts between/among core values or in pursuing different self-benefits (2c). Referring to cognitive dissonance theory in social

\footnotetext{
55 The reasons why I focus on these four kinds of electoral behavior in this dissertation are presented on pp. 14-16 in Chapter 1.
} 
psychology and information processing theory in political psychology, this study opened the black box between issue cross-pressures and electoral behavior (2d). It argued that when citizens experience issue cross-pressures, in order to make a voting decision they will employ different methods to reconcile or alleviate their cross-pressures, including: reevaluating their stances on some issues, looking for additional attributes related to the parties, and reducing the importance of some issues. During this process, the role of issues in citizens' decision making might be conditioned since, as we can see, they might bear other factors in mind. Therefore, issue cross-pressures might moderate the role of issues in citizens' voting choice. If issue cross-pressured citizens cannot reconcile their crosspressures successfully after employing the aforementioned three methods, they will continue struggling to decide which party to vote for, which in turn might influence their motivation to go out to vote. In contrast, if issue cross-pressured citizens manage to alleviate their cross-pressures to a certain level, they will cast a vote. However, their voting choices will very much depend on how they reconcile their cross-pressures. In this regard, issue cross-pressures might influence the stability of citizens' voting choice across different elections. If citizens do not experience issue cross-pressures, they can make a voting choice directly without any additional considerations, whereas, when citizens are issue crosspressured, they must employ one or more approaches to reconcile cross-pressures in order to reach a satisfactory voting choice. This whole process would very probably lead crosspressured citizens to spend much more time on decision making. Issue cross-pressures might thus delay citizens' time of voting decision. Finally, based on five potential methods of measuring cross-pressures in the existing literature, Chapter 2 developed the regressionbased and the distance/scalar product-based measurements of issue cross-pressures (2e).

Chapters 3 to 6 examined the relationship between issue cross-pressures and issue voting, turnout, voter switching and time of voting decision. Chapter 3 explored the relationship between issue cross-pressures and issue voting to answer question $3 \mathrm{a}$ : Is the role of issues in citizens' voting choice moderated by citizens' issue cross-pressures? The theory of issue cross-pressures in this chapter assumed that when citizens experience issue cross-pressures, they will try to reconcile them in order to make a decision. They might reevaluate their own stances on different issues to make certain that their issue positions point to a single party. They might reduce the importance of one or several of the issues in 
question to ensure that their positions on the most important issues lead them to a single party. They might consider several more or all relevant attributes of the parties, such as the personality and political experience of party leaders, the party's performance in government and party identification, to align themselves more with a particular party. If citizens who experience issue cross-pressures employ the third way to reconcile their cross-pressures, the role of issues in decision making might be largely moderated, since many other factors are taken into consideration. Therefore, Chapter 3 argued that the role of issues in citizens' voting choice might be conditioned by their intensity of issue cross-pressures, and the more issue cross-pressures citizens experienced, the less likely they would be to depend on issues to make their voting decision. Analyzing survey data from the 2010 British Election Study, the results met the aforementioned expectation based on both the traditional proximity theory and the directional theory of issue voting. In both the proximity and directional models, the influence of issues on voting choice was more pronounced among voters who suffered a lower level of issue cross-pressures than among those with more issue crosspressures. In addition, in the proximity model, the influence of the interaction variable between the issue cross-pressures score and issue variables - could be clearly observed. In the directional model, the trend was still noticeable, even though it was not as prominent as in the proximity model. All in all, Chapter 3 concluded that issue cross-pressures moderated the level of issue voting, and that the more issue cross-pressures voters experience, the less pronounced issue voting will be (3a).

The study of issue cross-pressures and issue voting in Chapter 3 contributed to our understanding of a pervading puzzle: despite the decline of cleavage politics and the increase of cognitive mobilization, the level of issue voting is not as high as political scholars had expected. This chapter showed that modernization and cognitive mobilization might make citizens more likely to make a decision independently of political elites and parties, which leads to an increase in issue voting. However, on the other hand the chapter demonstrated that modernization and cognitive mobilization might also make citizens more likely to realize that their positions on different issues point to different parties, which leads to a decrease in issue voting. Therefore, the overall level of issue voting in a specific election in a particular society was the reconciling result of these increasing and decreasing forces. 
Chapter 4 examined the relationship between issue cross-pressures and turnout to answer questions 4a and 4b: Do issue cross-pressures decrease citizens' motivation to turn out to vote? and Is the role of issue cross-pressures in turnout moderated by the party system? When citizens experience issue cross-pressures, they will seek to reduce these pressures in order to make a voting choice. As discussed before, citizens can employ three different methods to alleviate their cross-pressures when their positions on different issues lead them to different parties. However, this does not mean that issue cross-pressured citizens can always reduce their cross-pressures and manage to make a decision. Chapter 4 argued that when issue cross-pressured citizens cannot reconcile their cross-pressures successfully, they will keep on struggling to decide which party to vote for, which might influence their motivation to go out to vote. To test this position, Chapter 4 analyzed survey data from five Dutch parliamentary elections (1994-2012) and three British general elections (1992-2010). The findings showed that, overall, those who abstain during elections are more likely to experience higher issue cross-pressures than those who cast a vote. After regressing voters' turnout based on their issue cross-pressures scores and controlling for variables including demographic backgrounds and political attributes, the coefficients of issue cross-pressures scores in six out of eight elections were in the expected directions, that is, negatively related to turnout. Of those six elections, issue cross-pressures significantly affected voters' motivations to turn out to vote in two elections in the Netherlands and two elections in the United Kingdom. In a total of four out of eight elections, issue cross-pressures had a significant influence on turnout. Chapter 4 therefore concluded that issue cross-pressures had an impact on voters' motivations to turn out to vote $(4 a)$.

In terms of the conditioned role of the party system, Chapter 4 argued that as the number of political parties increases, people are more likely to experience more issue crosspressures, and that the impact of issue cross-pressures on turnout will be less pronounced when a political context is dominated by several parties. The findings in Chapter 4 showed that citizens experience more issue cross-pressures in multi-party contexts than in almost two-party dominated contexts. The mean issue cross-pressures score in the Netherlands was 0.83, while it was only 0.78 in the United Kingdom. In addition, this chapter also demonstrated that in two out of five elections in the Netherlands, the effects of issue crosspressures scores on turnout were significant at the 0.05 and 0.01 levels. In two out of three 
elections in the United Kingdom, the effects of issue cross-pressures scores were significant at the 0.001 level. These findings implied that, although people might suffer more issue cross-pressures as the number of parties increases, the influence of issue cross-pressures on turnout will be more pronounced in almost two-party dominated contexts than in multiparty contexts. Therefore, it was concluded from these findings that the party system moderates the role of issue cross-pressures in turnout (4b).

The study of issue cross-pressures and turnout in Chapter 4 offered a third factor to explain voter abstention: issue cross-pressures that emerged due to policy alternatives provided to voters in the contemporary world. Previous studies had mainly focused on policy-specific indifference and alienation. These two factors can give us a good understanding of voting choices when voters only care about one issue in an election or when ideology is unidimensional. However, when voters face two or more policy issues in a political context or when ideology is multidimensional, both policy-specific indifference and alienation give incomplete pictures of voters' decisions to vote or abstain. Issue crosspressures fill this gap.

Chapter 5 studied the role of issue cross-pressures in vote switching to answer questions 5a and 5b: Do issue cross-pressures influence citizens' vote change across elections? and Is the role of issue cross-pressures in vote switching conditioned by different mobilization types? According to the theory of issue cross-pressures, if issue crosspressured citizens manage to reconcile or alleviate their cross-pressures to a certain level, they will cast a vote. However, their voting choices will very much depend on how they reconciled their cross-pressures. Therefore, Chapter 5 suggested that issue cross-pressures might be a factor behind citizens' vote switching across elections. In other words, it argued that the voting choice of issue cross-pressured citizens across elections would be more unstable compared to those whose issue positions pushed them toward a single party. Based on the survey data from the long-term panel of the 2002-2009 and 2005-2013 German Longitudinal Election Study, Chapter 5 found that, overall, the increase of a person's issue cross-pressures leads to only a slight change to their voting choice. However, this chapter confirmed that the influence of issue cross-pressures on vote switching was most pronounced among apartisans, more moderate among cognitive partisans and least prevalent in apolitical independents and ritual partisans. It demonstrated that the 
relationship between issue cross-pressures and the potential to change one's vote is not linear but curvilinear. In conclusion, even though this chapter did not find a strong relationship between issue cross-pressures and vote switching (5a), it did show that the influence of issue cross-pressures on vote switching was moderated by different mobilization types (5b). This influence was strong and significant among people without party identification and with higher cognitive ability, namely apartisans. Given that it has been optimistically predicted that the number of apartisans will continue to increase in the future (Dalton, 2012), the role of issue cross-pressures in vote switching as a whole might increase as well.

The study on issue cross-pressures and vote switching in Chapter 5 provided a way to understand why politically sophisticated citizens change their votes across elections. Political scholars have suggested various answers to the question of who swing voters are. One influential explanation begins with political sophistication, as studies on vote switching have found that political sophistication increases the probability of inter-election volatility. However, the mechanism behind this causal relationship has not been extensively studied. The findings in Chapter 5 suggested that political sophisticated citizens might be more likely to experience issue cross-pressures, which in turn influence their motivations to change their votes across elections.

Chapter 6 focused on the influence of issue cross-pressures on citizens' time of voting decision to answer questions $6 \mathrm{a}$ and $6 \mathrm{~b}$ : Are the time of voting decisions affected by issue cross-pressures? and Is the role of issue cross-pressures in the time of voting decision conditioned by political systems? As discussed in Chapter 2, when citizens do not experience issue cross-pressures, they can make a voting choice directly without any additional considerations, whereas, when citizens' issue positions lead them to several parties, they must employ one or more approaches to reconcile cross-pressures in order to reach a satisfactory voting choice. This process would obviously lead issue cross-pressured citizens to spend much more time on their decision, thereby delaying their time of voting decisions. Chapter 6 examined the relationship between issue cross-pressures and the time of voting decision. It argued that issue cross-pressures influence citizens' time of voting decision, and that the more issue cross-pressures citizens experience, the later their voting decision will be. This assumption was tested using the survey data from the Dutch 
Parliamentary Election Study, the British Election Study, and the German Election Study. Analyses of seven Dutch parliamentary elections (1994-2010), five British general elections (1992-2010) and four German parliamentary elections (1994-2013) showed that issue cross-pressures did influence people's time of voting decisions, regardless of their consideration set size, demographic background and political attributes. In the model without control variables, individuals' issue cross-pressures scores in 11 out of 16 elections were strongly related to late deciding, as expected. When control variables were added, the role of issue cross-pressures disappeared in some elections; however, it remained significant in 8 out of 16 elections. Chapter 6 therefore confirmed that issue cross-pressures influence citizens' time of voting decision, and the more issue cross-pressures citizens experience, the later their voting decision will be (6a).

The findings in Chapter 6 partially confirmed that the influence of issue crosspressures on the time of voting decision might be conditioned by party systems (6b). This chapter anticipated that the role of issue cross-pressures in the time of voting decision would be largest in the Netherlands, followed by Germany and finally the United Kingdom. However, the results only partially supported this prediction. Looking at the models with control variables, it showed that, in Germany, citizens' issue cross-pressures scores were significantly related to late deciding in only one out of four elections. By contrast, the figures in the United Kingdom and the Netherlands were three out of five and four out of seven respectively. Additionally, the coefficients of the issue cross-pressures score in the Netherlands were all significant at the 0.01 level in those four elections. In the United Kingdom, only two were significant at the 0.01 level. These findings suggested that the effect of issue cross-pressures was most pronounced in the Netherlands, a little more moderate in the United Kingdom, and weakest in Germany. This implies that variations in the effect of issue cross-pressures on the time of voting decision in different political contexts could be partially explained by party systems.

Nevertheless, the distinctive German electoral system might be a factor in this phenomenon. In the German elections studied, the members of the Bundestag were elected in two separate ways. Half the members (299) were elected based on a proportional representation system using party lists, while the other half were elected directly from 299 constituencies based on a first-past-the-post system. As a result, each voter had two votes in the German parliamentary elections. The first vote was cast for a candidate, choosing which 
candidate was to be sent to parliament on behalf of their local constituency. The second vote, allowing voters to vote for a party list, determined the allocation of seats in parliament. Since both votes count, it provided an opportunity for voters to split their vote when they felt attracted to two parties simultaneously. This might be a reason why the influence of issue cross-pressures was weakest in Germany compared to the Netherlands and the United Kingdom.

The study of issue cross-pressures and time of voting decision in Chapter 6 offered some other ideas about what late deciders were waiting for, other than simply additional information concerning the parties or candidates. Political scholars have spent a great deal of time studying late deciders from the perspective of what they are waiting for. Generally, the common wisdom was that they were waiting for more information related to the candidates and/or parties. Chapter 6 showed that issue cross-pressured citizens were late deciders. It was therefore possible that those late deciders were not waiting for anything, but simply continued to hesitate about which party or candidate to vote for until the last moment and made a choice randomly. On the other hand, it was also possible that late deciders were included in the finding that, when people suffer from issue cross-pressures, they seek to reduce the feeling of inconsistency. There are several possible ways of doing so, such as re-evaluating the personal importance of some issues, re-evaluating the candidates' or parties' issue positions, or including other attributes which they approve of in parties/candidates, such as leadership. All in all, this chapter added to our knowledge on late deciders.

Finally, based on the findings in each chapter discussed above, this section will present answers to the main research question in this dissertation: Do issue cross-pressures influence citizens' different kinds of electoral voting, and, if so, how? The answers were as following: when citizens experience issue cross-pressures, in order to make a voting decision, they employ different ways to reconcile or alleviate cross-pressures, which include re-evaluating their stances on some issues, looking for additional attributes related to parties and reducing the importance of some issues. This process in turn influences citizens' various kinds of electoral behavior, including issue voting, turnout, vote switching, and time of voting decision. Compared to citizens whose issues positions point to a single party, issue cross-pressured citizens rely less on issues to make a decision, have less 
motivation to go out to vote, switch their voting choices more often between two elections (at least for those who do not have party ties and with a higher educational background), and delay their voting decisions even until the last polling day.

\subsection{Scope and limitations of the findings}

Scope: Throughout the study, I have focused on elections in three Western European countries: the United Kingdom, the Netherlands and Germany. As discussed in Chapter 2, to experience issue cross-pressures which in turn influence their electoral behavior, citizens should care about at least two different kinds of issues and their opinions on these issues should not be comprehensively constricted by a unidimensional ideology. Therefore, if the findings in this study are extended to other countries, the aforementioned two requirements must be met. In addition, issues should be important factors behind citizens' voting choices. Only citizens who took issues into consideration when they were making voting choices could suffer issue cross-pressures.

As in the United Kingdom, the Netherlands and Germany, other Western European countries have also seen a trend of the decline of partisan politics and increasing issue importance in voting choice (Aardal \& Van Wijnen, 2005; Dalton et al., 1984; Dalton \& Wattenberg, 2000). Although the findings with regard to the extent of issue voting were inconsistent, the consensus was that issues were significant motives behind voting choice across advanced Western democracies. Moreover, as in the three countries this study focused on, other Western European countries have also experienced increased economic and physical security; a slow but steady shift from traditional culture to values of selfexpression which emphasize aspects such as quality of life, civil and political liberties and human diversity (Inglehart, 1971; Inglehart \& Welzel, 2005); the popularization of higher education; and the development of mass communication technologies. All of these made it possible for citizens to improve their knowledge about their own and the parties' policy platforms. In sum, it is safe to generalize the findings in this study to other Western European countries.

However, in terms of the United States, even though it shares the characteristics described in the previous paragraph with most Western European countries, one fact should not be neglected: in contrast to most Western European countries, American politics has undergone marked partisan polarization over the past several decades (Abramowitz \& 
Saunders, 2007; Hetherington, 2009; McCarty, Poole \& Rosenthal, 2006). As addressed before, for citizens to experience issue cross-pressures, their opinions on different issues should not be decided by a unidimensional ideology. Many existing studies have shown an increasing consistency in liberal and conservative views in the mass public in the United States (Abramowitz \& Saunders, 2008; Hetherington, 2009). In other words, American voters are increasingly bringing their issue preferences on both social and economic dimensions into line with their partisanship. This implies that, in the long run, US citizens might be less likely to experience issue cross-pressures than their contemporaries in Western European countries. Therefore, any generalization of the findings in this study to the United States should be attempted only with caution. However, this does not mean that issue cross-pressures do not exist and cannot influence American voters' voting behavior. In 2008, Hillygus and Shields demonstrated that more than half of American partisans disagreed with their own party's position but agree with the opposite party's positions on at least one prominent campaign issue, and that the proportion of these kinds of partisans did not change significantly from 1972 to 2004. They also found voters who held issue positions that run counter to their party identification were more likely to vote for the opposite party in a specific election. Therefore, what needs to be recognized is the extent to which issue cross-pressures influence different kinds of electoral behavior in the United States, especially in the long term.

The findings in this study cannot readily be extended to new democracies in regions such as Latin America, Central and Eastern Europe, South Asia and sub-Saharan Africa. The most important reason for this is that the relationships between parties and voters are often fragile and fluid (Hagopian, 2007). In many countries, parties are still agents of state patronage and most of citizens' support for a party arose from clientelism or the pork barrel. It is thus unclear how important issues are in citizens' voting choices in these emerging democracies, which in turn makes it doubtful that citizens will experience significant issue cross-pressures.

Limitations: The main limitation of this study lies in the methodological part. As discussed in Chapter 2, this study develops two kinds of measurements of issue cross-pressures, namely the regression-based and the distance/scalar product-based measurements of issue cross-pressures. However, what is missing in this study is an empirical comparison to 
determine which method is better in measuring citizens' issue cross-pressures. Therefore, we cannot say that the findings in this study are based on the best measurement of issue cross-pressures. This study mainly uses the regression-based approach, which was used in three out of four empirical chapters (Chapters 4, 5 and 6). The distance/scalar productbased method is only used in one chapter (Chapter 3) ${ }^{56}$ It was thought that the regressionbased approach could capture both the different levels of importance of different issues to voters as a whole and the extent to which different issues push citizens toward different parties, which were essential elements in calculating citizens' issue cross-pressures. However, this did not mean that the distance/scalar product-based measurement did not have its own merits. For example, by using the distance/scalar product-based method, we could calculate the number of respondents who were issue cross-pressured, which could not be achieved using the regression-based method.

It was of course important to empirically determine which method was better in measuring citizens' issue cross-pressures. Not only could this make findings in this study even more convincing, it could also provide more accurate information about issue crosspressured citizens in a society, such as how many citizens were issue cross-pressured and on which issues. This study ultimately did not achieve this, mainly because of the lack of necessary data. To assess which measurement was better in capturing issue cross-pressures in reality, it is necessary to have standard criteria for how many citizens experienced issue cross-pressures in a specific election, and to what extent. This study argues that this could be achieved by adding the following two questions to a survey. First, 'How important is [issue] to you?' This question would differentiate the importance of different issues to different citizens. The second question, 'Which party do you prefer on this issue?', would

\footnotetext{
${ }^{56}$ One thing to note is that when I used the regression-based approach in Chapter 3, the findings were similar to those obtained using the distance/scalar produce-based method (see Appendix D). As discussed in Chapter 2, the main reason why Chapter 3 used a different measurement of issue cross-pressures from those employed in the other three chapters were as follows: although the regression-based measurement of issue cross-pressures had many advantages, it might cause confusion when testing whether or not the role of issues in voting choice was conditioned by issue cross-pressures, since the regression-based measurement of issue cross-pressures was based on a regression model with citizens' positions on different issues as independent variables and their voting choice/intention as dependent variables. When examining issue voting, it also regressed citizens' voting choices on their issue preferences. In order to avoid ambiguity, Chapter 3 used the distance/scalar product-based method to measure issue cross-pressures.
} 
directly capture how different issues lead citizens to different parties. Comparing the results from these new survey questions with the results from the regression-based and the distance/scalar product-based measurements would enable us to judge which measurement is better. In sum, the main limitation of this study is that it did not compare the efficiency of two different measurements of issue cross-pressures. Evaluating different methods is a recommended direction for future studies on issue cross-pressures.

The second limitation lies in findings in each empirical chapters. As summarized in the previous section, overall, issue cross-pressures moderate the role of issues in citizens' voting choice, decrease citizens' motivation to go out to vote, increase citizens' vote switching between two elections, and delay citizens' time of voting decisions. However, what cannot be neglected are that these findings are not always consistent with expectations.

In Chapter 3, the moderated effects of issue cross-pressures in issue voting are different in the proximity and directional models. In the proximity model, the influence of issue cross-pressures can be clearly observed no matter with or without interaction variables- between the issue cross-pressures score and issue variables. While, in the directional model, the moderated role of issue cross-pressures is less prominent especially when interaction variables are included. It implies that if relying on directional model, the impact of issues on voting decisions can only be moderately moderated by issue crosspressures. It in turn decreases the importance of issue cross-pressures for issue voting. In this regard, it is important to explore why results from the proximity and directional models are different, which, however, is not addressed in this dissertation.

In Chapter 4, the impact of issue cross-pressures on turnout is different across elections within a country. In the Netherlands, in two out of five elections, issue crosspressures influence voters' motivations to go out to vote. In the other three elections, however, the effects of issue cross-pressures are not significant. In the United Kingdom, in two out of three elections, issue cross-pressures influence turnout, while in the other one election, the impact of issue cross-pressures cannot be observed. Why are the effects of issue cross-pressures on turnout significant for some elections but not for others? Answering this question is important to more accurately assess how important issue crosspressures are to citizens' motivation of voting. However, it is not explored in this dissertation. 
Chapter 5 only finds limited influence of issue cross-pressures in vote switching. However, the findings need further verification with datasets having better quality. As discussed in Chapter 5, the re-participation rate was not high in the long-term panel data from 2002-2009 and 2005-2013 German longitudinal election study. Those who have a party identification, more political interest and a higher educational background were more likely to re-participate in the panels, which affected the distribution of people with different cognitive mobilizations and party mobilizations.

Similar with Chapter 4, in Chapter 6, we can observe that the role of issue crosspressures in time of voting decision not only varies among countries, but also among elections within a country. In the Netherlands the coefficient of issue cross-pressures was not significant in the 2002, 2003 and 2006 elections, but it was significant in the 1994, 1998, 2010 and 2012 elections. In the United Kingdom, issue cross-pressures had an effect on decision time in the 1992, 1997 and 2010 elections, but they did not influence a person's motivation to postpone his/her voting decision in the 2001 and 2005 elections. In Germany, in the 2009 election, issue cross-pressures played a role, while in the 1998, 2002 and 2013 elections, they were not significant. As the long-term tie between voters and parties is waning, issues are increasingly important for voters' voting choices. In this regard, we would expect that the role of issue cross-pressures on time of voting decision will continuously increase in each country. However, the findings suggest otherwise. It is remained to study under what kinds of conditions issue cross-pressures will influence voters' time of voting decision.

\subsection{Issue cross-pressures, democracy and future research: three implications}

Under the ideal theory of democracy, parties or candidates made policy proposals during election campaign, and explained how these policies would affect citizens' welfare; citizens evaluated these policy proposals, decided which of these proposals they wanted implemented and voted for the corresponding parties. Furthermore, by assessing whether governments followed their policy platforms, citizens could reward or punish them appropriately. Policy issues appeared to be in a central position in the ideal model of democracy. In this regard, with the weakening of traditional politics of cleavages such as religion and social class, political scholars acclaimed the arrival of issue voting. This study developed a theory based on citizens' issue concerns, the so-called theory of issue cross- 
pressures. It argued that citizens might care about multiple issues and that their positions on these issues might not be correlated in the same political direction. When citizens' positions on different issues led them to different parties - when they were issue cross-pressured their voting behavior might be different from those whose issue preferences point to a single party. The empirical part of this study showed that issue cross-pressures moderate the extent to which citizens rely on issues to make a voting choice, decrease citizens' motivation to cast a vote, delay citizens' time of voting decision, and increase the likelihood that citizens will switch their vote across elections, at least for those who do not have party identification and have a good educational background. The analyses also found that political context plays a role: the type of party system moderates the role of issue crosspressures in citizens' political behavior. All these findings have important implications for research on electoral behavior and democracy as a whole, which are summarized in the following three points.

(1) The important role of issues in electoral behavior. Traditional studies on the importance of issues in electoral behavior have mainly focused on the extent to which issues determine citizens' voting choice. In recent decades, with cognitive mobilization on the one hand and the decline of cleavage politics in Western societies on the other, an extensive part of the literature has acclaimed the arrival of issue voting (Dalton et al., 1984; Franklin, 1985; Rose \& McAllister, 1986, 1990). However, in contrast to the initial optimistic assessment that issue voting had gained in importance, many studies did not find supporting evidence for an increase in the relevance of issues to voters' voting choice (Clarke et al., 2004; Aardal \& Van Wijnen, 2005; Lewis-Beck et al., 2008; Wessels, 2014). Political scholars focusing on the short-term factor of issues hold an pessimistic view of the important role of issues in electoral behavior.

This study developed a theory of issue cross-pressures in which citizens' preferences on different issues are at the core, and empirically examined the role of issue cross-pressures in several kinds of electoral behavior beyond voting choice. The findings showed that cross-pressures arising from citizens' inconsistent voting predispositions based on their positions on various issues significantly affect the level of issue voting, turnout, vote switching (at least for some voters) and time of voting decision. As such, this study noted that, although the impact of issues on citizens' voting choices is not as great as 
expected, the important role of issues in electoral politics is still remarkable and must not be neglected. Future studies could further explore the influence of issue cross-pressures on other kinds of electoral behavior, such as split-voting or vote switching during a campaign.

(2) The combined consequences of modernization and cognitive mobilization for democratic politics. With increased modernization and cognitive mobilization in advanced Western democracies, political scholars had been optimistic about the arrival of issue voting, which was seen as a characteristic of the ideal model of democracy. However, modernization and cognitive mobilization might on the one hand make citizens more likely to make a decision independently of political elites and parties, which leads to an increase in issue voting; while on the other hand modernization and cognitive mobilization might also make citizens more likely to realize that their positions on different issues point to different parties, which could cause them to experience more issue cross-pressures. This might in turn decrease the overall level of issue voting, which goes against the optimistic view of the consequences of modernization and cognitive mobilization.

The findings in Chapter 5 provided some empirical support at an individual level for the aforementioned arguments. Table 4 in Chapter 5 denoted that highly cognitive citizens experienced more issue cross-pressures than less cognitive citizens. Among people with higher cognitive ability (apartisans and cognitive partisans), more than $67 \%$ and $59 \%$ of people had higher issue cross-pressures in the 2002-2005 and the 2009-2013 elections, respectively, whereas these figures were only $54.5 \%$ and $56.0 \%$ among people with lower cognitive ability (apolitical independents and ritual partisans). Nevertheless, these findings needed to be further confirmed using more advanced statistical methods with control variables that may also influence the level of issue cross-pressures, such as party identification.

On an aggregate level, Table 3 in Chapter 4 partially supports the aforementioned arguments. With factors such as the popularization of higher education and the development of mass communication technologies, it was expected that citizens would be more likely to experience more issue cross-pressures now than before. In the United Kingdom, the mean issue cross-pressures score did show a pattern of increasing, as it went up from 0.71 in 2001 to 0.82 in 2010 . However, in the Netherlands, the mean issue crosspressures score did not show a sustained pattern. It decreased from 0.84 in 1994 to 0.78 in 
1998, then increased to 0.85 in 2002 and 0.86 in 2006, and decreased again to 0.83 in 2010 . Nevertheless, it is not necessarily a requirement that citizens' issue cross-pressures should increase election by election. What is more important is that there should be a trend of increasing. To explore whether or not such a trend exists, the time period examined should be extended to the 1960 s or even earlier, when the levels of industrialization and cognitive mobilization were lower than that after the 1990s.

(3) Mixed prospects for the functioning of contemporary Western democracy. The findings in this study indicate that the decreasing stability in determinants and patterns of voting behavior is at least partially a result of a transformation in the nature of the demand side of politics. Citizens are not mere superficial actors with so little political knowledge and political interest that they make their voting decisions randomly. Rather, with the development of society and culture shifting, citizens have become more politically informed and gained better cognitive ability, meaning that they can take 'sophisticated' considerations (such as issue policies) into account when making a decision and distinguish which party represents their preference best on each of issues that they care about, which in turn influences their various kinds of electoral behavior. As such, the prospects for contemporary Western democracy are as pessimistic as de-politicization theses have suggested.

However, this does not mean that contemporary Western democracy faces no challenges. From Chapter 4 and 5, we can see that the effect of issue cross-pressures on turnout is more significant than on vote switching. In other words, when citizens are aware of the appeal of different parties on different issues, they are more likely to give up on voting altogether rather than to switch their votes across elections. This implies that citizens are more likely to look for a party which fully represents their policy preferences on all issues when they are making voting decisions. In this sense, abstaining could be seen as an expression of dissatisfaction, which in the long run may influence the quality of democratic politics as a whole. In addition, given that a large group of issue cross-pressured citizens have not been fully captured by established parties across Western European countries, small parties will get a chance to develop and new parties will have an opportunity to emerge. Therefore, party systems in contemporary Western democracies might become unstable in the foreseeable future. To comprehensively evaluate the consequences of issue 
cross-pressures to democracy, further studies could focus on, for example, the relationship between issue cross-pressures and satisfaction with party democracy.

\subsection{Conclusion}

This dissertation developed a theory of issue cross-pressures and examined the influence of issue cross-pressures on different kinds of electoral behavior. It not only clarified what issue cross-pressures are, how issue cross-pressures can influence electoral behavior and how to measure citizens' issue cross-pressures (Chapter 2), but it also provided empirical support for the impact of issue cross-pressures on issue voting (Chapter 3), turnout (Chapter 4), vote switching (Chapter 5) and time of voting decision (Chapter 6). Compared to citizens whose issues positions point to a single party, those whose issue preferences lead them to different parties rely less on issues to make a decision, have less motivation to go out to vote, switch their voting choices more often between two elections (at least for those who do not have party ties and have a higher educational background) and delay their voting decisions even until the last polling day. The theory developed in this dissertation and the empirical findings it presents can safely be generalized to other Western European countries, but should be applied only with caution to the United States and are not readily applicable to emerging democracies. This dissertation has shown that, although the impact of issues on citizens' voting choices is not as great as expected, the important role of issues in electoral politics is still remarkable and cannot be neglected. Therefore, issue crosspressures are linked to the successful functioning of democratic politics. 
飞
$\frac{x}{0}$
$\frac{0}{0}$
$\frac{0}{2}$

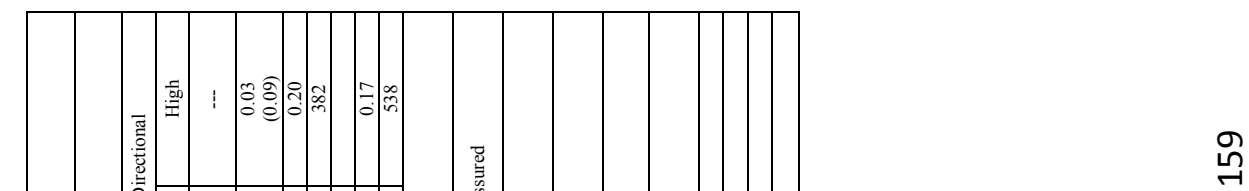

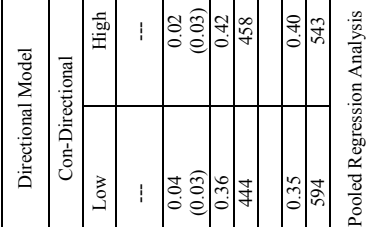

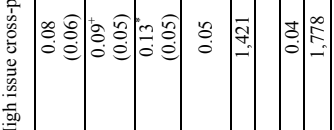

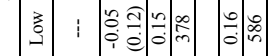

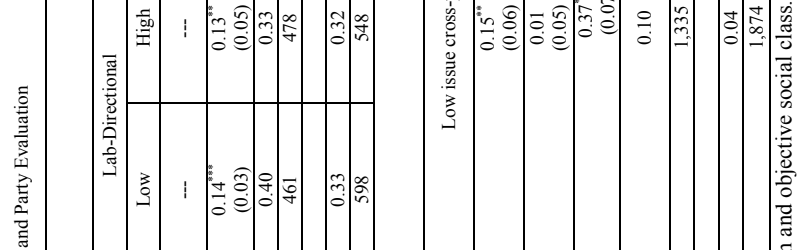

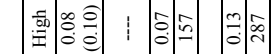

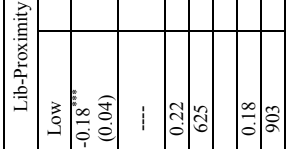

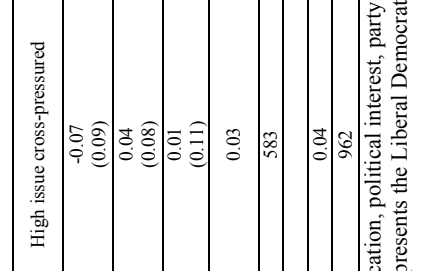

\begin{tabular}{lll|l}
0 \\
$\vdots$ \\
0 \\
0
\end{tabular}

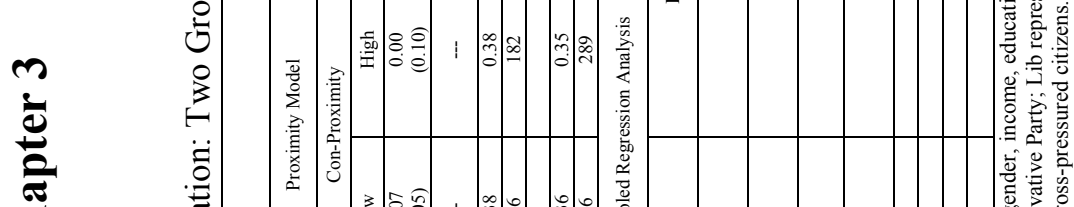

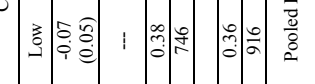

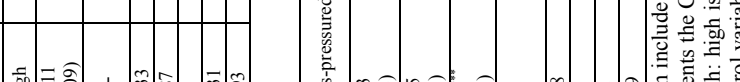

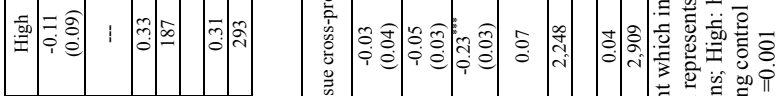

率

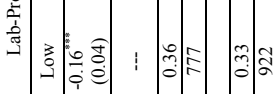

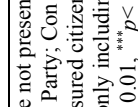

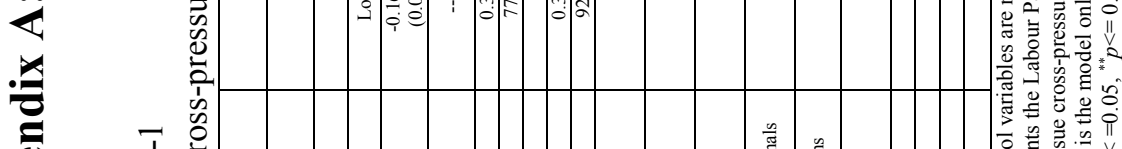

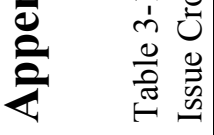

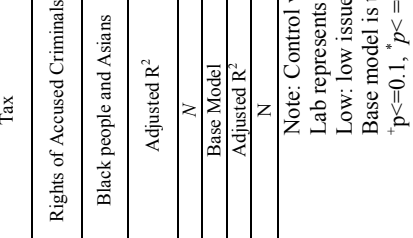




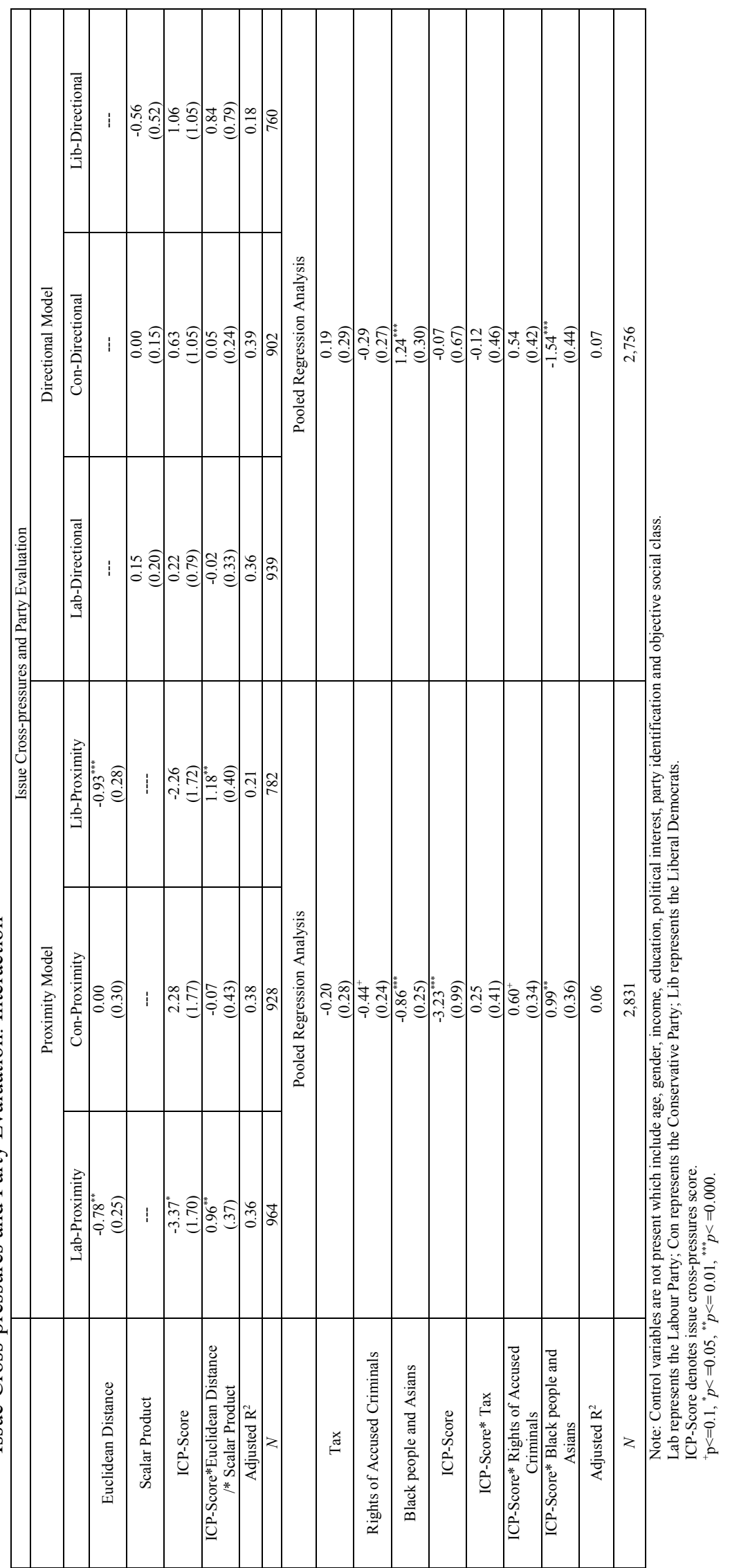




\section{Appendix B: Issue variables and tables relating to Chapter 4}

Table 4-1: Description of issue variables - the Netherlands

\begin{tabular}{|c|c|c|c|}
\hline Election & Issue variables & Description & Score \\
\hline \multirow[t]{6}{*}{1994} & Euthanasia (var061) & Forbid euthanasia to allow euthanasia & $1-7$ \\
\hline & Crime (var066) & Much tougher to tough enough & $1-7$ \\
\hline & Income difference (var071) & Larger differences to smaller differences & $1-7$ \\
\hline & Nuclear plants (var076) & More nuclear plants to no nuclear plants & $1-7$ \\
\hline & Ethnic minorities (var081) & Keep own culture to adjust completely & $1-7$ \\
\hline & European unification (var331) & Going too fast to as fast as possible & $1-7$ \\
\hline \multirow[t]{7}{*}{1998} & Euthanasia (v0116) & Forbid euthanasia to allow euthanasia & $1-7$ \\
\hline & Income difference (v0123) & Larger differences to smaller differences & $1-7$ \\
\hline & Asylum seekers (v0130) & Admit more to send back asylum seekers & $1-7$ \\
\hline & European unification (v0137) & Unification should go further to unification has gone too far & $1-7$ \\
\hline & Ethnic minorities (v0144) & $\begin{array}{l}\text { Preserve cultural customs to completely adjust to Dutch } \\
\text { culture }\end{array}$ & $1-7$ \\
\hline & Social benefits (v0736) & Much too low to much too high & $1-7$ \\
\hline & Nuclear plants (v0743) & More nuclear plants to no nuclear plants & $1-7$ \\
\hline \multirow[t]{7}{*}{2002} & Euthanasia (v0209) & Forbid euthanasia to allow euthanasia & $1-7$ \\
\hline & Income difference (v0215) & $\begin{array}{l}\text { Differences should be increased to differences should be } \\
\text { decreased }\end{array}$ & $1-7$ \\
\hline & Asylum seekers (v0221) & Admit more to send back asylum seekers & $1-7$ \\
\hline & Crime (v0227) & $\begin{array}{l}\text { government acts too tough on crime to government should act } \\
\text { tougher on crime }\end{array}$ & $1-7$ \\
\hline & Nuclear plants (v0875) & More nuclear plants to no nuclear plants & $1-7$ \\
\hline & Ethnic minorities (v0882) & $\begin{array}{l}\text { Preserve customs of own culture to completely adjust to } \\
\text { Dutch culture }\end{array}$ & $1-7$ \\
\hline & European unification (v0889) & Unification should go further to unification has gone too far & $1-7$ \\
\hline \multirow[t]{7}{*}{2006} & Euthanasia (V135) & Forbid euthanasia to allow euthanasia & $1-7$ \\
\hline & Income difference (V145) & Should be bigger to should be smaller & $1-7$ \\
\hline & Asylum seekers (V155) & Admit more to send back asylum seekers & $1-7$ \\
\hline & Crime (V165) & Too strict to more strict & $1-7$ \\
\hline & Nuclear plants (V175) & Build more to no more building & $1-7$ \\
\hline & Foreigners(V185) & Keep own culture to adjust to Dutch culture & $1-7$ \\
\hline & European unification (V195) & Unification should go further to unification has gone too far & $1-7$ \\
\hline \multirow[t]{7}{*}{2010} & Euthanasia (v136) & Forbid euthanasia to allow euthanasia & $1-7$ \\
\hline & Income difference (v146) & Should be bigger to should be smaller & $1-7$ \\
\hline & Asylum seekers (v156) & Admit more to send back asylum seekers & $1-7$ \\
\hline & Crime (v166) & Too strict to more strict & $1-7$ \\
\hline & Foreigners(v176) & Keep own culture to adjust to Dutch culture & $1-7$ \\
\hline & Nuclear plants (v686) & Build more to no more building & $1-7$ \\
\hline & European unification (V195) & Unification should go further to unification has gone too far & $1-7$ \\
\hline
\end{tabular}




\section{Appendix B}

Table 4-2: Description of issue variables - the United Kingdom

\begin{tabular}{|l|l|l|l|}
\hline Election & Issue variables & Description & Score \\
\hline 2001 & Tax (aq26a) & Cut taxes to spend more & $0-10$ \\
\hline & Euro currency (aq23) & $\begin{array}{l}\text { Definitely join; join if conditions right; out for at least } \\
4-5 \text { years; rule out on principle; }\end{array}$ & $1-4$ \\
\hline 2005 & Euro currency (aq29) & $\begin{array}{l}\text { Definitely join; join if conditions right; out for at least } \\
4-5 \text { years; rule out on principle; }\end{array}$ & $1-4$ \\
\hline & EU membership (aq30a) & Definitely get out to definitely stay in & $0-10$ \\
\hline & Tax (aq31a) & Cut taxes to increase services & $0-10$ \\
\hline & Crime (bq40a) & Reduce crime to protect rights of accused & $0-10$ \\
\hline & Tax (aq35_1) & Cut taxes to increase service & $0-10$ \\
\hline & Crime (aq38_1) & Reduce crime to protect rights & $0-10$ \\
\hline & Euro currency (bq38) & $\begin{array}{l}\text { Definitely join; join if conditions right; out for at least } \\
4-5 \text { years; rule out on principle; }\end{array}$ & $1-4$ \\
\hline & Black and Asian (bq74_1) & $\begin{array}{l}\text { Government should not take action to help to } \\
\text { government should make every effort }\end{array}$ & $0-10$ \\
\hline
\end{tabular}

Table 4-3

Issue Cross-pressures incorporating issue salience and turnout in the Netherlands and the United Kingdom

\begin{tabular}{|c|c|c|c|c|c|c|c|c|}
\hline & \multicolumn{5}{|c|}{ The Netherlands (1994-2010) } & \multicolumn{3}{|c|}{ The United Kingdom (1992-2010) } \\
\hline & 1994 & 1998 & 2002 & 2006 & 2010 & 2001 & 2005 & 2010 \\
\hline \multicolumn{9}{|l|}{$\begin{array}{l}\text { Issue cross-pressures score } \\
\text { incorporating }\end{array}$} \\
\hline a. Most important problem ${ }^{57}$ & -- & -- & -- & -- & -- & $\begin{array}{l}-1.36^{* * *} \\
(0.25) \\
\end{array}$ & $\begin{array}{c}-.62 \\
(0.41) \\
\end{array}$ & $\begin{array}{l}-2.74^{* * *} \\
(0.61) \\
\end{array}$ \\
\hline $\begin{array}{l}\text { b. Most important five to } \\
\text { seven problems } \text { s }^{58}\end{array}$ & $\begin{array}{c}0.14 \\
(0.69)\end{array}$ & $\begin{array}{l}-1.39^{*} \\
(0.69)\end{array}$ & -- & $\begin{array}{l}.01 \\
(.91)\end{array}$ & $\begin{array}{l}-5.72^{* * *} \\
(1.43)\end{array}$ & -- & - & - \\
\hline $\begin{array}{c}\text { c. Importance of a specific } \\
\text { problem }^{59}\end{array}$ & -- & $\begin{array}{c}-4.71^{* * *} \\
(0.67)\end{array}$ & $\begin{array}{l}-1.16^{*} \\
(0.57)\end{array}$ & -- & -- & -- & -- & -- \\
\hline$N$ & 1,126 & 1,430 & 1,416 & 1,543 & 1,325 & 2,545 & 2,756 & 1,351 \\
\hline
\end{tabular}

Notes: The Issue Cross-pressures Score has been calculated using a format with values ranging from 0 to 1 . Turnout has two values, 1 (Vote) and 0 (Didn't Vote, including No Answer and Don't Know). Negative coefficients indicate that as the value of the independent variable increases, the less likely it is that voters will go out to vote.

Control variables are not present which include age, gender, education, social class, party identification, ideology and political interest.

Std.Err. in parentheses

${ }^{+} p<0.1, " p<0.05,{ }^{* *} p<0.01,{ }^{* * *} p<0.001$

Data source: DPES (1994-2010) and BES/BGES (1992-2010)

\footnotetext{
${ }^{57}$ In step 1 of calculating the issue cross-pressures score, before performing nominal regression, position issues (see Appendix I: Tables 1 and 2) that were mentioned by a respondent as being the most important problem were given a weight of ' 2 '; position issues not mentioned by a respondent as the most important problem were given no weight. For the question wording, see Table 4-4.

${ }^{58}$ In step 1 of calculating the issue cross-pressures score, before performing nominal regression, position issues that were mentioned by a respondent as the most important problem were given a weight of ' 5 ' 0 ' ' 7 '; position issues mentioned by a respondent as the second most important problem were given a weight of ' 4 ' or ' 6 '... and position issues which were mentioned by a respondent as being the fifth or seventh most important problem were given a weight of ' 1 '. For the question wording, see Table 4-4.

${ }^{59}$ In step 1 of calculating the issue cross-pressures score, before performing nominal regression, position issues were weighted by the importance of the issue to each respondent from ' 1 ' to ' 10 '; position issues which were mentioned by a respondent as being important were given a weight of ' 2 ', otherwise no weight was assigned. For the question wording, see Table 4-4.
} 
Table 4-4

Description of the issue importance question in the Netherlands and the United Kingdom

\begin{tabular}{|c|c|}
\hline Election & lestion wording \\
\hline $\begin{array}{l}1994 \text { Dutch } \\
\text { Election }\end{array}$ & $\begin{array}{l}\text { Most important five to seven problems--And now, I would like to ask you what you think are the most important problems in } \\
\text { our country: first answer (var016), second answer (var017), third answer (var018), fourth answer (var019), and fifth answer } \\
\text { (var020). }\end{array}$ \\
\hline \multirow[b]{2}{*}{$\begin{array}{l}1998 \text { Dutch } \\
\text { Election }\end{array}$} & $\begin{array}{l}\text { Most important five to seven problems--And now, I would like to ask you what you think are the most important problems in } \\
\text { our country: first answer (v0045), second answer (v0046), third answer (v0047), fourth answer (v0048), and fifth answer } \\
\text { (v0049). }\end{array}$ \\
\hline & $\begin{array}{l}\text { Importance of a specific problem-v0660 income difference; v0661 integration ethnic minorities; v0662 nuclear plants; } \\
\text { v0663 heavy traffic on highways; v0664 environment pollution; v0665 unemployment; v0666 euthanasia; v0667 European } \\
\text { Union; v0668 financial deficit of the state; v0669 level social benefits; v0670 securing good provision for old age; v0671 } \\
\text { misusing social benefits; v0672 seeking asylum,; v0673 crime; v0674 health care. Scale: from very unimportant ' } 1 \text { ' to very } \\
\text { important '10'. }\end{array}$ \\
\hline $\begin{array}{l}2002 \text { Dutch } \\
\text { Election }\end{array}$ & $\begin{array}{l}\text { Importance of a specific problem-Important national problem: v0037 abortion/euthanasia; v0038 resignation of government; } \\
\text { v0039 poverty; v0040 asylum seekers/foreigners; v0041 bureaucracy; v0042 corruption; v0043 crime/crime fighting; v0044 } \\
\text { economy; v0045 euro; v0046 European integration; v0047 mobility/traffic; v0048 lack of tolerance; v0049 tolerance policy; } \\
\text { v0050 health care; v0051 inflation; v0052 youth; v0053 environment (pollution); v0054 lack of norms and values; v0055 } \\
\text { education/shortage of teaching staff; v0056 public transport; v0057 rise of Pim Fortuyn; v0058 death of Pim Fortuyn; v0059 } \\
\text { social relations between people; v0060 social provisions; v0061 safety; v0062 ageing of population; v0063 } \\
\text { discrimination/racism; v0064 housing; v0065 elderly care; v0066 employment/unemployment; v0067 politics in general; } \\
\text { v0068 elections/electoral behavior; v0069 division of poor and rich; v0070 the Netherlands is becoming too full; v0071 } \\
\text { Disability Insurance Act; v0072 police; v0073 taxation system; v0074 other; v0075 no answer. Answer format: mentioned: } \\
\text { '1', not mentioned: '0'. }\end{array}$ \\
\hline $\begin{array}{l}2006 \text { Dutch } \\
\text { Election }\end{array}$ & $\begin{array}{l}\text { Most important five to seven problems--And now, I would like to ask you what you think are the most important problems in } \\
\text { our country: first answer (V041), second answer (V042), third answer (V043), fourth answer (V044), fifth answer (V045), } \\
\text { sixth answer (V046) and seventh answer (V047). }\end{array}$ \\
\hline \multirow[t]{2}{*}{$\begin{array}{l}2010 \text { Dutch } \\
\text { Election }\end{array}$} & $\begin{array}{l}\text { Most important five to seven problems--And now, I would like to ask you what you think are the most important problems in } \\
\text { our country: first answer (v041), second answer (v042), third answer (v043), fourth answer (v044), fifth answer (v045) and } \\
\text { sixth answer (v046). }\end{array}$ \\
\hline & Iost important problem—v0084: And what do you think is the single most important national problem? \\
\hline $\begin{array}{l}2001 \text { British } \\
\text { Election }\end{array}$ & $\begin{array}{l}\text { Most important problem--aq2: I'd like to ask you a few questions about the issues and problems facing Britain today. As far } \\
\text { as you are concerned, what is the single most important issues facing the country at the present time? }\end{array}$ \\
\hline $\begin{array}{l}2005 \text { British } \\
\text { Election }\end{array}$ & $\begin{array}{l}\text { Most important problem--aq2: I'd like to ask you a few questions about the issues and problems facing Britain today. As far } \\
\text { as you are concerned, what is the single most important issues facing the country at the present time? }\end{array}$ \\
\hline $\begin{array}{l}2010 \text { British } \\
\text { Election }\end{array}$ & $\begin{array}{l}\text { st important problem--aq2: I'd like to ask you a few questions about the issues and problems facing Britain today. As far } \\
\text { gou are concerned, what is the single most important issues facing the country at the present time? }\end{array}$ \\
\hline
\end{tabular}




\section{Appendix B}

Table 4-5

Correlations between issue cross-pressures scores calculated using three alternative methods in the Netherlands

\begin{tabular}{|l|l|l|l|l|l|l|l|l|l|l|l|l|l|l|l|}
\hline & \multicolumn{3}{|c|}{1994} & \multicolumn{3}{c|}{1998} & \multicolumn{3}{c|}{2002} & \multicolumn{3}{c|}{2006} & \multicolumn{3}{c|}{2010} \\
\hline & Top-2 & Top-3 & Full & Top-2 & Top-3 & Full & Top-2 & Top-3 & Full & Top-2 & Top-3 & Full & Top-2 & Top-3 & Full \\
\hline Top-2 & 1.00 & & & 1.00 & & & 1.00 & & & 1.00 & & & 1.00 & & \\
\hline Top-3 & 0.88 & 1.00 & & 0.94 & 1.00 & & 0.90 & 1.00 & & 0.81 & 1.00 & & 0.93 & 1.00 & \\
\hline Full & 0.75 & 0.91 & 1.00 & 0.87 & 0.92 & 1.00 & 0.73 & 0.79 & 1.00 & 0.76 & 0.93 & 1.00 & 0.83 & 0.93 & 1.00 \\
\hline
\end{tabular}

Table 4-6

Correlations between issue cross-pressures scores calculated using three alternative methods in the United Kingdom

\begin{tabular}{|c|c|c|c|c|c|c|c|c|c|}
\hline & \multicolumn{3}{|c|}{2001} & \multicolumn{3}{c|}{2005} & \multicolumn{3}{c|}{2010} \\
\hline & Top-2 & Top-3 & Full & Top-2 & Top-3 & Full & Top-2 & Top-3 & Full \\
\hline Top-2 & 1.00 & & & 1.00 & & & 1.00 & & \\
\hline Top-3 & 0.90 & 1.00 & & 0.85 & 1.00 & & 0.85 & 1.00 & \\
\hline Full & 0.90 & 0.99 & 1.00 & 0.85 & 0.98 & 1.00 & 0.63 & 0.85 & 1.00 \\
\hline
\end{tabular}

Table 4-7

1994 Dutch parliamentary election

\begin{tabular}{|c|c|c|c|c|c|c|}
\hline & Euthanasia & Income difference & Nuclear plant & Minorities & European Union & Crime \\
\hline Euthanasia & 1.00 & & & & & \\
\hline Income difference & 0.06 & 1.00 & & & & \\
\hline Nuclear plant & 0.07 & 0.31 & 1.00 & & & \\
\hline Minorities & 0.06 & -0.11 & -0.09 & 1.00 & & \\
\hline European Union & 0.10 & -0.02 & -0.06 & -0.08 & 1.00 & \\
\hline Crime & 0.10 & 0.21 & 0.15 & -0.26 & 0.05 & 1.00 \\
\hline
\end{tabular}

Table 4-8

1998 Dutch parliamentary election

\begin{tabular}{|c|c|c|c|c|c|c|c|}
\hline & Euthanasia & Income difference & Asylum & Nuclear plant & Minorities & European Union & Social benefit \\
\hline Euthanasia & 1.00 & & & & & & \\
\hline $\begin{array}{c}\text { Income } \\
\text { difference }\end{array}$ & 0.15 & 1.00 & & & & & \\
\hline Asylum & 0.07 & -0.11 & 1.00 & & & & \\
\hline Nuclear plant & 0.03 & 0.18 & -0.12 & 1.00 & & & \\
\hline Minorities & -0.00 & -0.11 & 0.50 & -0.11 & 1.00 & & \\
\hline European Union & -0.10 & 0.06 & 0.19 & -0.02 & 0.21 & 1.00 & \\
\hline Social benefit & -0.04 & -0.21 & 0.21 & -0.14 & 0.18 & 0.01 & 1.00 \\
\hline
\end{tabular}


Table 4-9

2002 Dutch parliamentary election

\begin{tabular}{|c|c|c|c|c|c|c|c|}
\hline & Euthanasia & Income difference & Asylum & Crime & Nuclear plant & Minorities & European Union \\
\hline Euthanasia & 1.00 & & & & & & \\
\hline $\begin{array}{c}\text { Income } \\
\text { difference }\end{array}$ & 0.08 & 1.00 & & & & & \\
\hline Asylum & 0.01 & -0.23 & 1.00 & & & & \\
\hline Crime & 0.02 & -0.07 & 0.43 & 1.00 & & & \\
\hline Nuclear plant & 0.04 & 0.19 & -0.16 & -0.09 & 1.00 & & \\
\hline Minorities & -0.05 & -0.15 & 0.43 & 0.31 & -0.15 & 1.00 & \\
\hline European Union & -0.04 & -0.01 & 0.16 & 0.17 & -0.01 & 0.23 & 1.00 \\
\hline
\end{tabular}

Table 4-10

2006 Dutch parliamentary election

\begin{tabular}{|c|c|c|c|c|c|c|c|}
\hline & Euthanasia & Income difference & Asylum & Crime & Nuclear plant & Foreigners & European Union \\
\hline Euthanasia & 1.00 & & & & & & \\
\hline $\begin{array}{c}\text { Income } \\
\text { difference }\end{array}$ & 0.08 & 1.00 & & & & & \\
\hline Asylum & 0.07 & -0.10 & 1.00 & & & & \\
\hline Crime & 0.08 & -0.00 & 0.34 & 1.00 & & & \\
\hline Nuclear plant & 0.03 & 0.27 & -0.05 & -0.01 & 1.00 & & \\
\hline Foreigners & 0.03 & -0.09 & 0.49 & 0.39 & -0.01 & 1.00 & \\
\hline European Union & -0.00 & 0.12 & 0.22 & 0.17 & 0.12 & 0.22 & 1.00 \\
\hline
\end{tabular}

Table 4-11

2010 Dutch parliamentary election

\begin{tabular}{|c|c|c|c|c|c|c|c|}
\hline & Euthanasia & Income difference & Asylum & Crime & Nuclear plant & Foreigners & European Union \\
\hline Euthanasia & 1.00 & & & & & & \\
\hline $\begin{array}{c}\text { Income } \\
\text { difference }\end{array}$ & 0.12 & 1.00 & & & & & \\
\hline Asylum & 0.12 & -0.03 & 1.00 & & & & \\
\hline Crime & 0.05 & 0.02 & 0.43 & 1.00 & & & \\
\hline Nuclear plant & 0.00 & 0.23 & -0.08 & -0.08 & 1.00 & & \\
\hline Foreigners & 0.04 & -0.02 & 0.54 & 0.45 & -0.07 & 1.00 & \\
\hline European Union & 0.00 & 0.06 & 0.28 & 0.24 & 0.06 & 0.29 & 1.00 \\
\hline
\end{tabular}

Table 4-12

British general election

\begin{tabular}{|c|c|c|c|c|c|c|c|c|c|c|c|c|}
\hline 2001 & & & 2005 & & & & & 2010 & & & & \\
\hline & Taxes & $\begin{array}{l}\text { Euro } \\
\text { currency }\end{array}$ & & Taxes & $\begin{array}{l}\text { EU } \\
\text { membership }\end{array}$ & $\begin{array}{l}\text { Euro } \\
\text { currency }\end{array}$ & Crime & & Tax & Crime & $\begin{array}{l}\text { Euro } \\
\text { currency }\end{array}$ & $\begin{array}{l}\text { Black } \\
\text { people } \\
\text { and } \\
\text { Asians }\end{array}$ \\
\hline Tax & 1.00 & & Tax & 1.00 & & & & Tax & 1.00 & & & \\
\hline \multirow[t]{3}{*}{$\begin{array}{l}\text { Euro } \\
\text { currency }\end{array}$} & -0.10 & 1.00 & $\begin{array}{l}\text { EU } \\
\text { membership }\end{array}$ & 0.12 & 1.00 & & & Crime & 0.08 & 1.00 & & \\
\hline & & & Euro currency & -0.10 & -0.59 & 1.00 & & $\begin{array}{l}\text { Euro } \\
\text { currency }\end{array}$ & -0.08 & -0.12 & 1.00 & \\
\hline & & & Crime & 0.09 & 0.10 & -0.11 & 1.00 & $\begin{array}{l}\text { Black } \\
\text { people } \\
\text { and } \\
\text { Asians }\end{array}$ & 0.09 & 0.20 & -0.24 & 1.00 \\
\hline
\end{tabular}




\section{Appendix C: Description of variables and tables in Chapter 6}

1.The wording of issue questions:

As an example, with respect to the Netherlands, five issue variables were chosen in 2012. They are V106 (Income difference: Some people think that the differences in income in our country should be increased. Others think that they should be decreased. Where would you place yourself on a scale of 1 to 7 , where 1 means differences in income should be increased and 7 means that differences in income should be decreased?); V113 (European Unification: Some people and parties think that European unification should go further. Others think that European unification has already gone too far. Where would you place yourself on a scale of 1 to 7, where 1 means that European unification should go even further, and 7 means that unification has already gone too far?). V114 (Crime fighting: People think differently about the way the government fights crime. Where would you place yourself on a scale of 1 to 7, where the beginning of the line entails the parties that think the government is acting too tough on crime, and the end of the scale entails the parties that think the government should be tougher on crime?); V115 (Foreigner adaptation- In the Netherlands, some think that foreigners should be able to live in the country while preserving their own culture. Others think that they should fully adapt to Dutch culture. Where would you place yourself on a scale of 1 to 7, where 1 means the preservation of foreigners' own culture, and 7 means that they should fully adapt?); V116 (Nuclear plants: Some people think that nuclear power plants are the solution to a shortage of energy in the future. Others think nuclear power plants should not be built, because the dangers are too great. Where would you place yourself on a scale of 1 to 7 , where 1 means nuclear power plants should be built quickly, and 7 means that they should not be built?). For other specific information about the issues and how their questions are worded in each of the three countries, see Appendix G.

\section{Coding of control variables}

Consideration set:

Based on the question of propensity to vote (PTV), "I will now name some parties for you. Please indicate on a scale of 1 to 10 how likely it is that you will ever vote for that party. 1 means that you will never vote for this party; 10 means that you will certainly vote for this party sometime. How likely is it that you will ever vote for xxx (a specific party name)?". A party which gets a PTV score of 8 or higher is regarded as having high probability of receiving votes, which is why it is included in respondents' consideration sets. Thus the value of the consideration set size is the number of parties with a PTV score of 8 or above.

Gender: "1" male, "0" female.

Social class:

This paper uses the self-image of social class to measure individuals' social status. In the Netherlands, it ranges from "1" (upper class) to " 5 " (working class). In Germany, in the 2009 and 2013 elections, it ranges from "1" (upper class) to " 6 " (underclass). In the 1998 and 2002 German elections, it is coded from " 1 " (upper class) to "3" (working class). 
In the United Kingdom, only the 2005 and 2010 elections have this variable, and it is coded as "0" (not belonging to a social class), "1" (belonging to a social class).

Education:

In the Netherlands, education is coded from lower level to higher level, varying from " 1 " to " $5 / 10 / 11$ ". In the United Kingdom, in the 1992 and 1997 elections, it is coded from "1" (no qualification) to " 7 " (higher degree qualification). In the 2001, 2005, and 2010 elections, it is coded as " 1 " (has education or professional qualifications) and " 0 " (does not have education or professional qualifications). In Germany, it is coded from " $0 / 1$ " (still a student, lowest certification) to " 5 " (university degree).

Party identification:

"1" have party identification, "0" do not have party identification. (In the United Kingdom and Germany, since there are many miss cases, those who refuse and do not know are regarded as non-partisan.)

Political interest:

These answers range from " 1 " (very interested) to " $3 / 5$ " (not interested at all). 


\section{Appendix C}

\section{Table 6-1}

Description of issue variables - the Netherlands

\begin{tabular}{|c|c|c|c|}
\hline Election & Issue variables & Description & Score \\
\hline \multirow[t]{6}{*}{1994} & Euthanasia (var061) & Forbid euthanasia to allow euthanasia & $1-7$ \\
\hline & Crime (var066) & Much tougher to tough enough & $1-7$ \\
\hline & Income difference (var071) & Larger differences to smaller differences & $1-7$ \\
\hline & Nuclear plants (var076) & More nuclear plants to no nuclear plants & $1-7$ \\
\hline & Ethnic minorities (var081) & Keep own culture to adjust completely & $1-7$ \\
\hline & European unification (var331) & Going too fast to as fast as possible & $1-7$ \\
\hline \multirow[t]{7}{*}{1998} & Euthanasia (v0116) & Forbid euthanasia to allow euthanasia & $1-7$ \\
\hline & Income difference (v0123) & Larger differences to smaller differences & $1-7$ \\
\hline & Asylum seekers (v0130) & Admit more to send back asylum seekers & $1-7$ \\
\hline & European unification (v0137) & $\begin{array}{l}\text { Unification should go further to unification has } \\
\text { gone too far }\end{array}$ & $1-7$ \\
\hline & Ethnic minorities (v0144) & $\begin{array}{l}\text { Preserve cultural customs to completely adjust to } \\
\text { Dutch culture }\end{array}$ & $1-7$ \\
\hline & Social benefits (v0736) & Much too low to much too high & $1-7$ \\
\hline & Nuclear plants (v0743) & More nuclear plants to no nuclear plants & $1-7$ \\
\hline \multirow[t]{7}{*}{2002} & Euthanasia (v0209) & Forbid euthanasia to allow euthanasia & $1-7$ \\
\hline & Income difference (v0215) & $\begin{array}{l}\text { Differences should be increased to differences } \\
\text { should be decreased }\end{array}$ & $1-7$ \\
\hline & Asylum seekers (v0221) & Admit more to send back asylum seekers & $1-7$ \\
\hline & Crime (v0227) & $\begin{array}{l}\text { Government acts too tough on crime to } \\
\text { government should act tougher on crime }\end{array}$ & $1-7$ \\
\hline & Nuclear plants (v0875) & More nuclear plants to no nuclear plants & $1-7$ \\
\hline & Ethnic minorities (v0882) & $\begin{array}{l}\text { Preserve customs of own culture to completely } \\
\text { adjust to Dutch culture }\end{array}$ & $1-7$ \\
\hline & European unification (v0889) & $\begin{array}{l}\text { Unification should go further to unification has } \\
\text { gone too far }\end{array}$ & $1-7$ \\
\hline \multirow[t]{4}{*}{2003} & Euthanasia (x0124) & Forbid euthanasia to allow euthanasia & $1-7$ \\
\hline & Income difference (x0125) & $\begin{array}{l}\text { Differences should be increased to differences } \\
\text { should be decreased }\end{array}$ & $1-7$ \\
\hline & Asylum seekers (x0133) & Admit more to send back asylum seekers & $1-7$ \\
\hline & Foreigners (x0149) & Keep own culture to adjust to Dutch culture & $1-7$ \\
\hline \multirow[t]{7}{*}{2006} & Euthanasia (v135) & Forbid euthanasia to allow euthanasia & $1-7$ \\
\hline & Income difference (v145) & Should be bigger to should be smaller & $1-7$ \\
\hline & Asylum seekers (v155) & Admit more to send back asylum seekers & $1-7$ \\
\hline & Crime (v165) & Too strict to more strict & $1-7$ \\
\hline & Nuclear plants (v175) & Build more to no more building & $1-7$ \\
\hline & Foreigners (v185) & Keep own culture to adjust to Dutch culture & $1-7$ \\
\hline & European unification (v195) & $\begin{array}{l}\text { Unification should go further to unification has } \\
\text { gone too far }\end{array}$ & $1-7$ \\
\hline \multirow[t]{7}{*}{2010} & Euthanasia (v136) & Forbid euthanasia to allow euthanasia & $1-7$ \\
\hline & Income difference (v146) & Should be bigger to should be smaller & $1-7$ \\
\hline & Asylum seekers (v156) & Admit more to send back asylum seekers & $1-7$ \\
\hline & Crime (v166) & Too strict to more strict & $1-7$ \\
\hline & Foreigners (v176) & Keep own culture to adjust to Dutch culture & $1-7$ \\
\hline & Nuclear plants (v686) & Build more to no more building & $1-7$ \\
\hline & European unification (v696) & $\begin{array}{l}\text { Unification should go further to unification has } \\
\text { gone too far }\end{array}$ & $1-7$ \\
\hline \multirow[t]{5}{*}{2012} & Income difference (V106) & Should be bigger to should be smaller & $1-7$ \\
\hline & Crime (V114) & Too strict to more strict & $1-7$ \\
\hline & Foreigners (V115) & Keep own culture to adjust to Dutch culture & $1-7$ \\
\hline & Nuclear plants (V116) & Build more to no more building & $1-7$ \\
\hline & European unification (V113) & $\begin{array}{l}\text { Unification should go further to unification has } \\
\text { gone too far }\end{array}$ & $1-7$ \\
\hline
\end{tabular}


Table 6-2

Description of issue variables - the United Kingdom

\begin{tabular}{|c|c|c|c|}
\hline Election & Issue variables & Description & Score \\
\hline \multirow[t]{4}{*}{1992} & $\begin{array}{l}\text { Unemployment and inflation } \\
\text { (va35a) }\end{array}$ & $\begin{array}{l}\text { Government should make keeping jobs its first } \\
\text { priority to Government should make keeping prices } \\
\text { down its first priority }\end{array}$ & A-K \\
\hline & Tax (va36a) & Cut taxes to increase service & $\mathrm{A}-\mathrm{K}$ \\
\hline & $\begin{array}{l}\text { Nationalization } \\
\text { privatization (va37a) }\end{array}$ & $\begin{array}{l}\text { Government should nationalize many more private } \\
\text { companies to Government should sell off many more } \\
\text { nationalized industries }\end{array}$ & A-K \\
\hline & EU membership (va39a) & Definitely get out to definitely stay in & A-K \\
\hline \multirow[t]{6}{*}{1997} & $\begin{array}{l}\text { Unemployment and inflation } \\
\text { (rjbprc_q341) }\end{array}$ & $\begin{array}{l}\text { Government should make keeping jobs its first } \\
\text { priority to Government should make keeping prices } \\
\text { down its first priority }\end{array}$ & A-K \\
\hline & Tax (rtxspd_q359) & Cut taxes to increase services & A-K \\
\hline & $\begin{array}{l}\text { Nationalization and } \\
\text { privatization (rprnat_q377) }\end{array}$ & $\begin{array}{l}\text { Government should nationalize many more private } \\
\text { companies to Government should sell off many more } \\
\text { nationalized industries }\end{array}$ & A-K \\
\hline & EU membership (recind_q413) & Definitely get out to definitely stay in & A-K \\
\hline & $\begin{array}{l}\text { Women's } \\
\text { (rwhom2_q433) }\end{array}$ & $\begin{array}{l}\text { Women should have an equal role with men in } \\
\text { running business, industry and government to } \\
\text { Women's place is in the home }\end{array}$ & A-K \\
\hline & $\begin{array}{ll}\text { Income } & \text { redistribution } \\
\text { (rinceq_q395) } & \end{array}$ & $\begin{array}{l}\text { Government should make much greater efforts to } \\
\text { make people's incomes more equal to Government } \\
\text { should be much less concerned about how equal } \\
\text { people's incomes are }\end{array}$ & A-K \\
\hline \multirow[t]{2}{*}{2001} & Tax (aq26a) & Cut taxes to spend more & $0-10$ \\
\hline & Euro currency (aq23) & $\begin{array}{l}\text { Definitely join; join if conditions are right; out for at } \\
\text { least } 4-5 \text { years; rule out on principle }\end{array}$ & $1-4$ \\
\hline \multirow[t]{4}{*}{2005} & Euro currency (aq29) & $\begin{array}{l}\text { Definitely join; join if conditions are right; out for at } \\
\text { least } 4-5 \text { years; rule out on principle }\end{array}$ & $1-4$ \\
\hline & EU membership (aq30a) & Definitely get out to definitely stay in & $0-10$ \\
\hline & Tax (aq31a) & Cut taxes to increase services & $0-10$ \\
\hline & Crime (bq40a) & Reduce crime to protect rights of accused & $0-10$ \\
\hline \multirow[t]{4}{*}{2010} & Tax (aq35_1) & Cut taxes to increase service & $0-10$ \\
\hline & Crime (aq38_1) & Reduce crime to protect rights & $0-10$ \\
\hline & Euro currency (bq38) & $\begin{array}{l}\text { Definitely join; join if conditions are right; out for at } \\
\text { least } 4-5 \text { years; rule out on principle }\end{array}$ & $1-4$ \\
\hline & $\begin{array}{l}\text { Black people and Asians } \\
\text { (bq74_1) }\end{array}$ & $\begin{array}{l}\text { Government should not take action to help to } \\
\text { Government should make every effort }\end{array}$ & $0-10$ \\
\hline
\end{tabular}




\section{Appendix C}

Table 6-3

Description of issue variables - Germany

\begin{tabular}{|l|l|l|l|}
\hline Election & Issue variables & Description & Score \\
\hline 1994 & Nuclear power (v174a) & $\begin{array}{l}\text { More nuclear power stations should be built to All } \\
\text { nuclear power stations should be closed down today }\end{array}$ & $1-11$ \\
\hline Immigration (v174b) & $\begin{array}{l}\text { Immigration should be facilitated to Immigration } \\
\text { should be restricted }\end{array}$ & $1-11$ \\
\hline 2001 & European Unification (v174c) & $\begin{array}{l}\text { Speed up European unification to European unification } \\
\text { is already going too fast }\end{array}$ & $1-11$ \\
\hline & Nuclear power (c174a) & $\begin{array}{l}\text { More nuclear power stations should be built to All } \\
\text { nuclear power stations should be closed down today }\end{array}$ & $1-11$ \\
\hline 2009 & $\begin{array}{l}\text { Immigration should be facilitated to Immigration } \\
\text { should be restricted }\end{array}$ & $1-11$ \\
\hline & $\begin{array}{l}\text { Eaxes and social welfare } \\
\text { services (vn193) }\end{array}$ & $\begin{array}{l}\text { Loweed up European unification to European unification } \\
\text { is already going too fast } \\
\text { social benefits }\end{array}$ & $1-11$ \\
\hline Immigration (vn195) & $\begin{array}{l}\text { Immigration should be facilitated to Immigration } \\
\text { should be restricted }\end{array}$ & $1-11$ \\
\hline 2013 & $\begin{array}{l}\text { Nuclear power (vn151) } \\
\text { Services (q67) }\end{array}$ & $\begin{array}{l}\text { More nuclear power stations should be built to All } \\
\text { nuclear power stations should be closed down today }\end{array}$ & $1-11$ \\
\hline Immigration (a68) & $\begin{array}{l}\text { Lower taxes, less social benefits to More taxes, more } \\
\text { social benefits }\end{array}$ & $1-11$ \\
\hline & $\begin{array}{l}\text { Immigration should be facilitated to Immigration } \\
\text { should be restricted }\end{array}$ & $1-11$ \\
\hline & $\begin{array}{l}\text { Climate change should definitely take precedence, } \\
\text { even if it impairs economic growth to Economic } \\
\text { growth should definitely take precedence, even if it } \\
\text { impairs the fight against climate change }\end{array}$ & $1-11$ \\
\hline
\end{tabular}




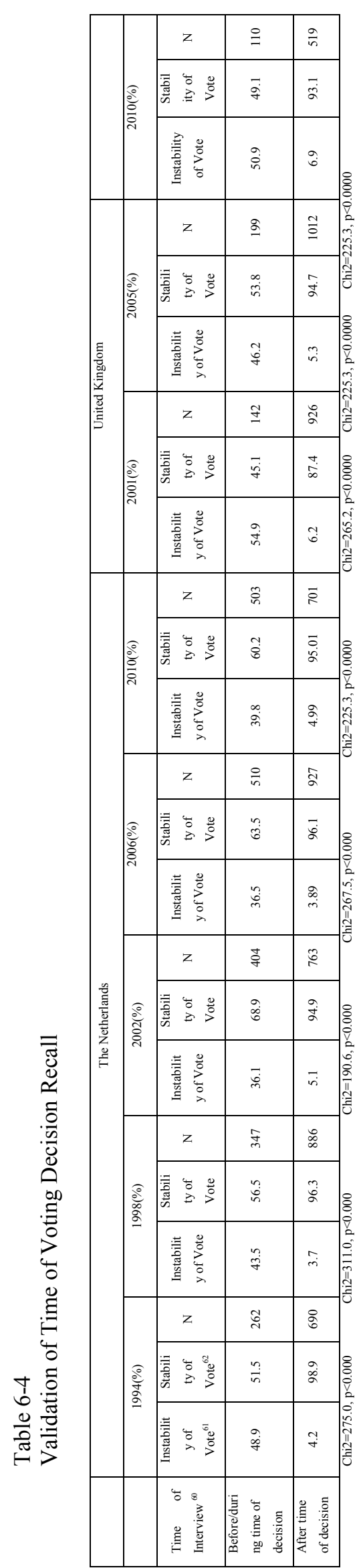

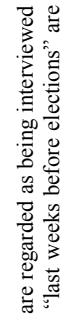

$\stackrel{-}{\Xi}$

造

흘

氖.

i

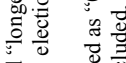

च.

密

表苟

势

运 $\Xi$.

空兽

范

गे

है ठี

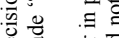

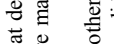

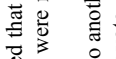

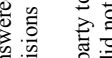

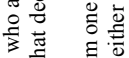

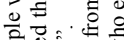

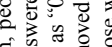

.ี้ चี

造

을 0

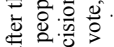

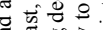

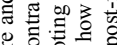

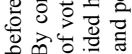

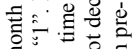

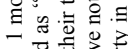

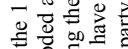

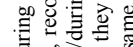

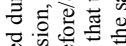

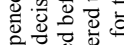

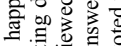

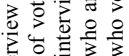

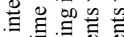

0.

焉焉 


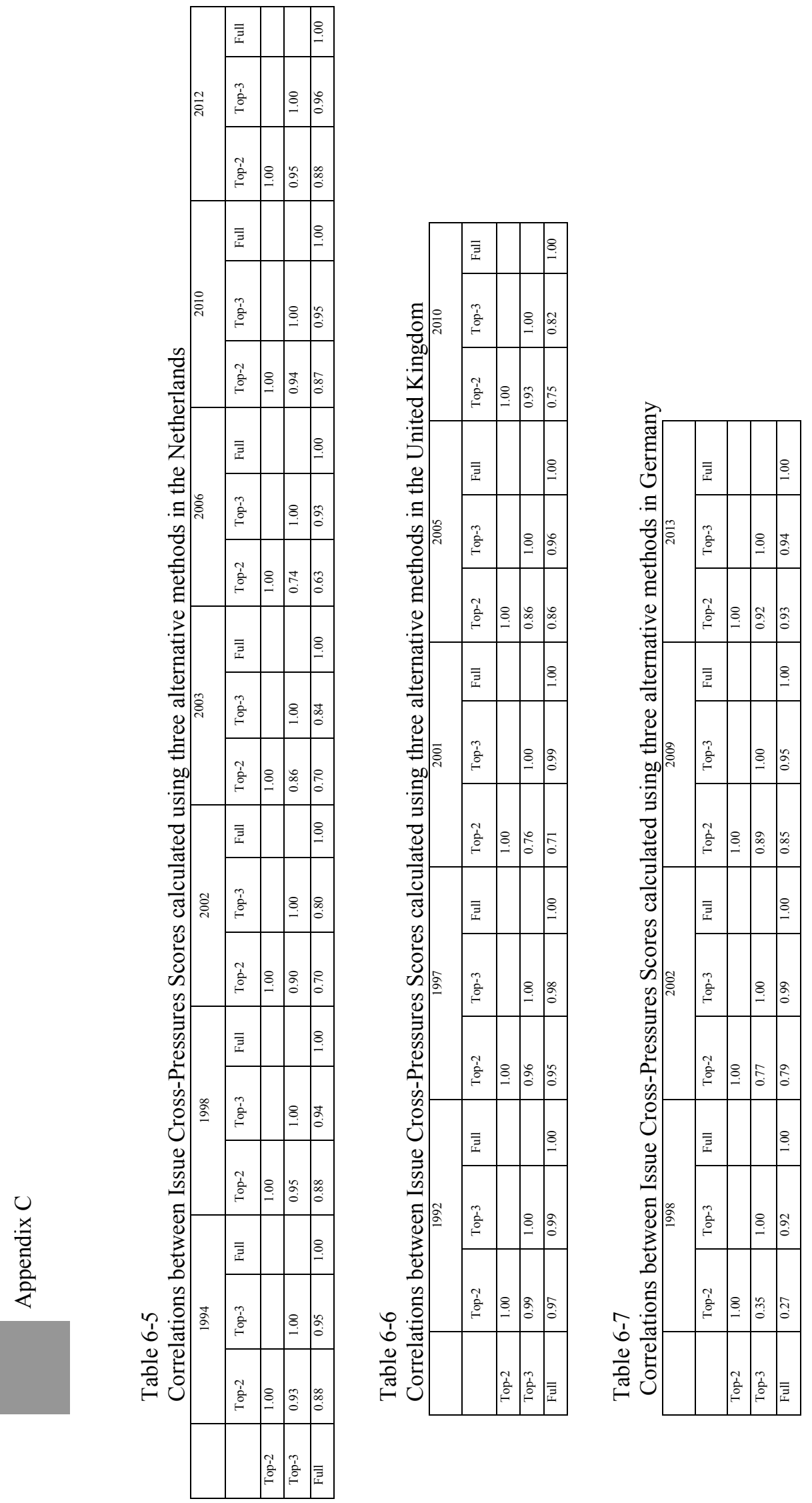



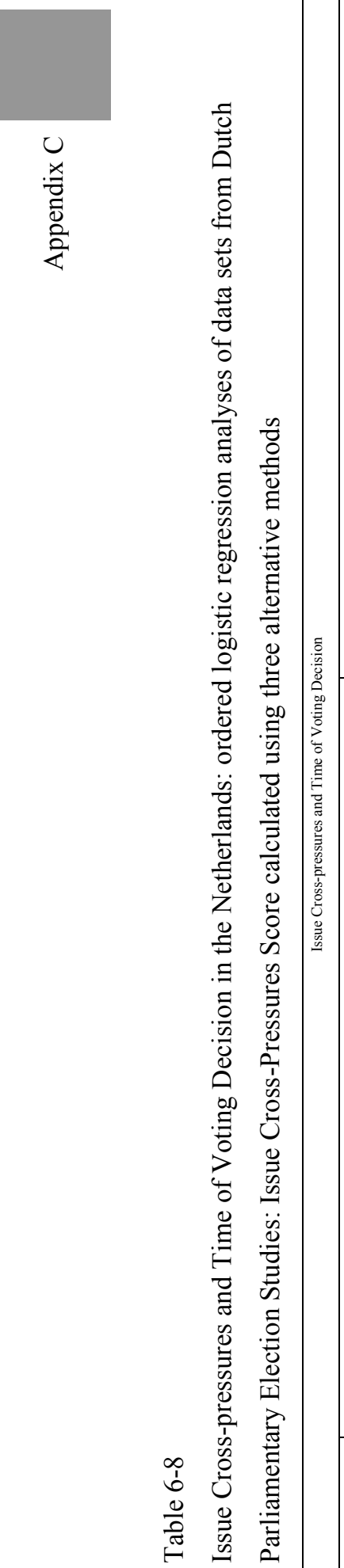

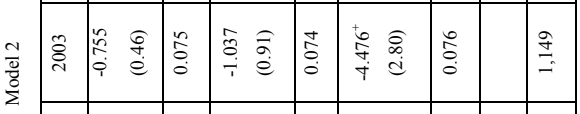

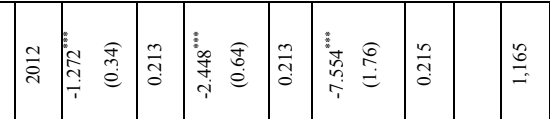

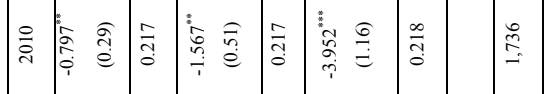

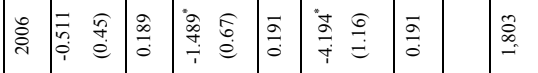




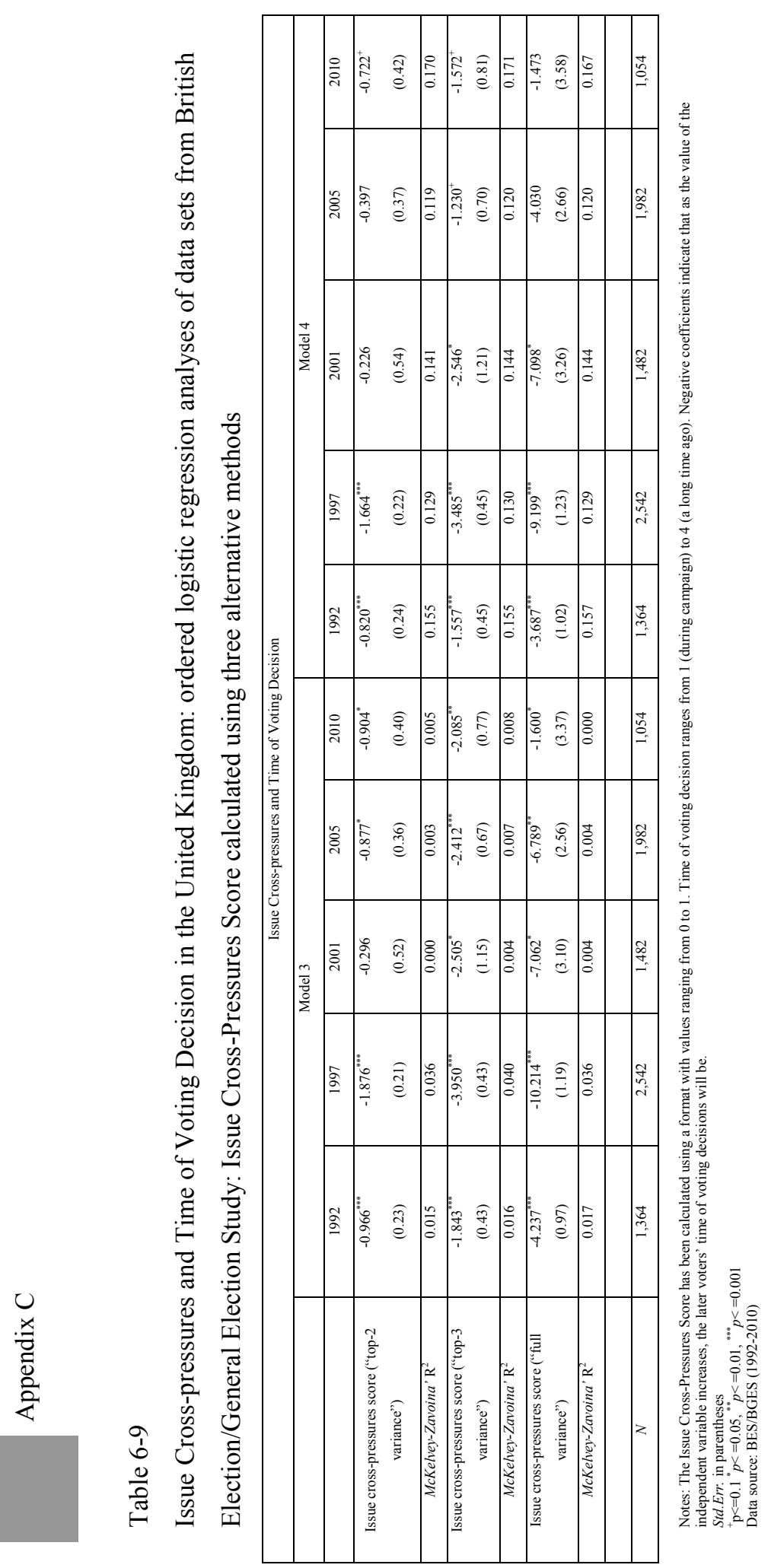




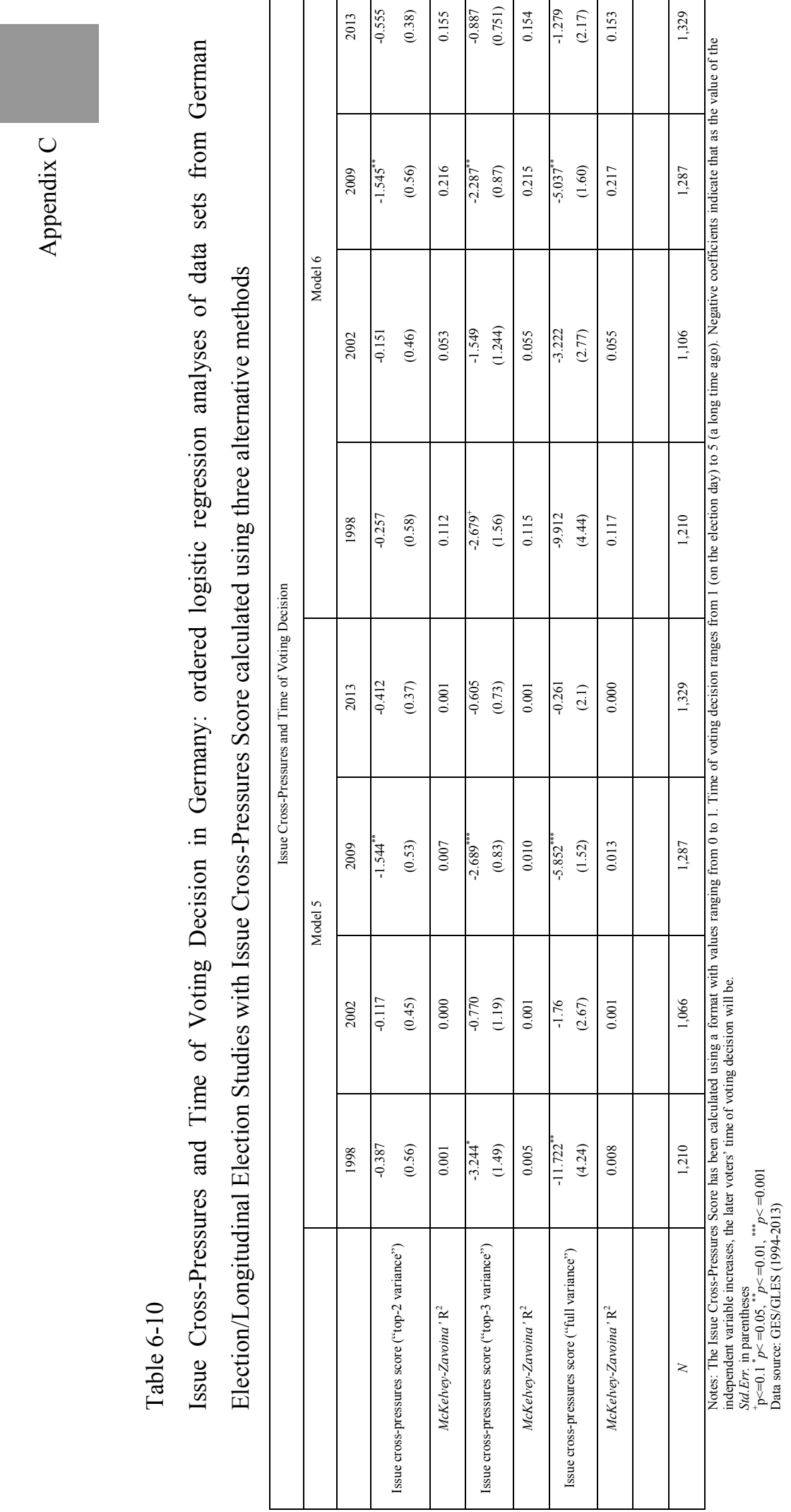




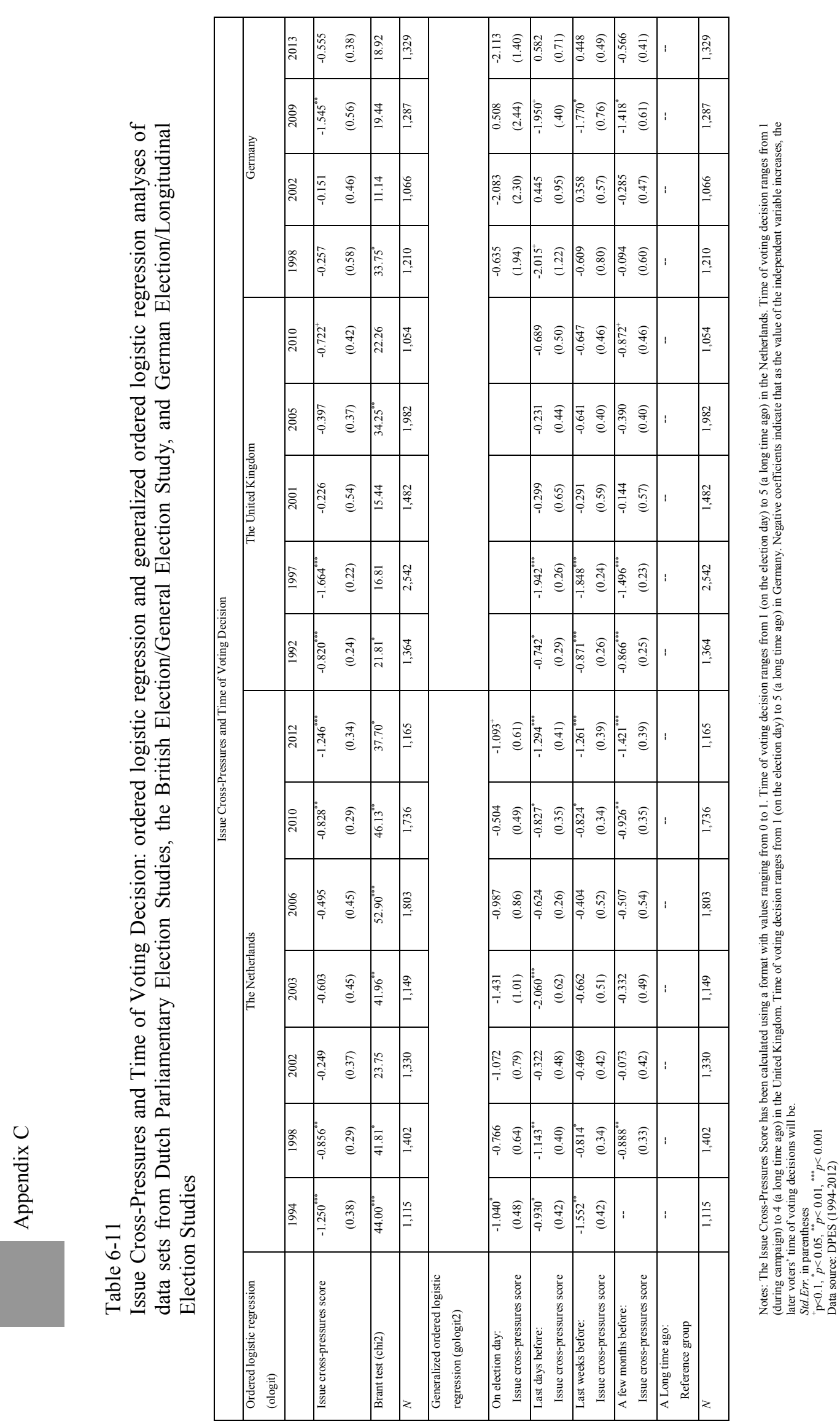




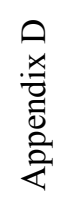

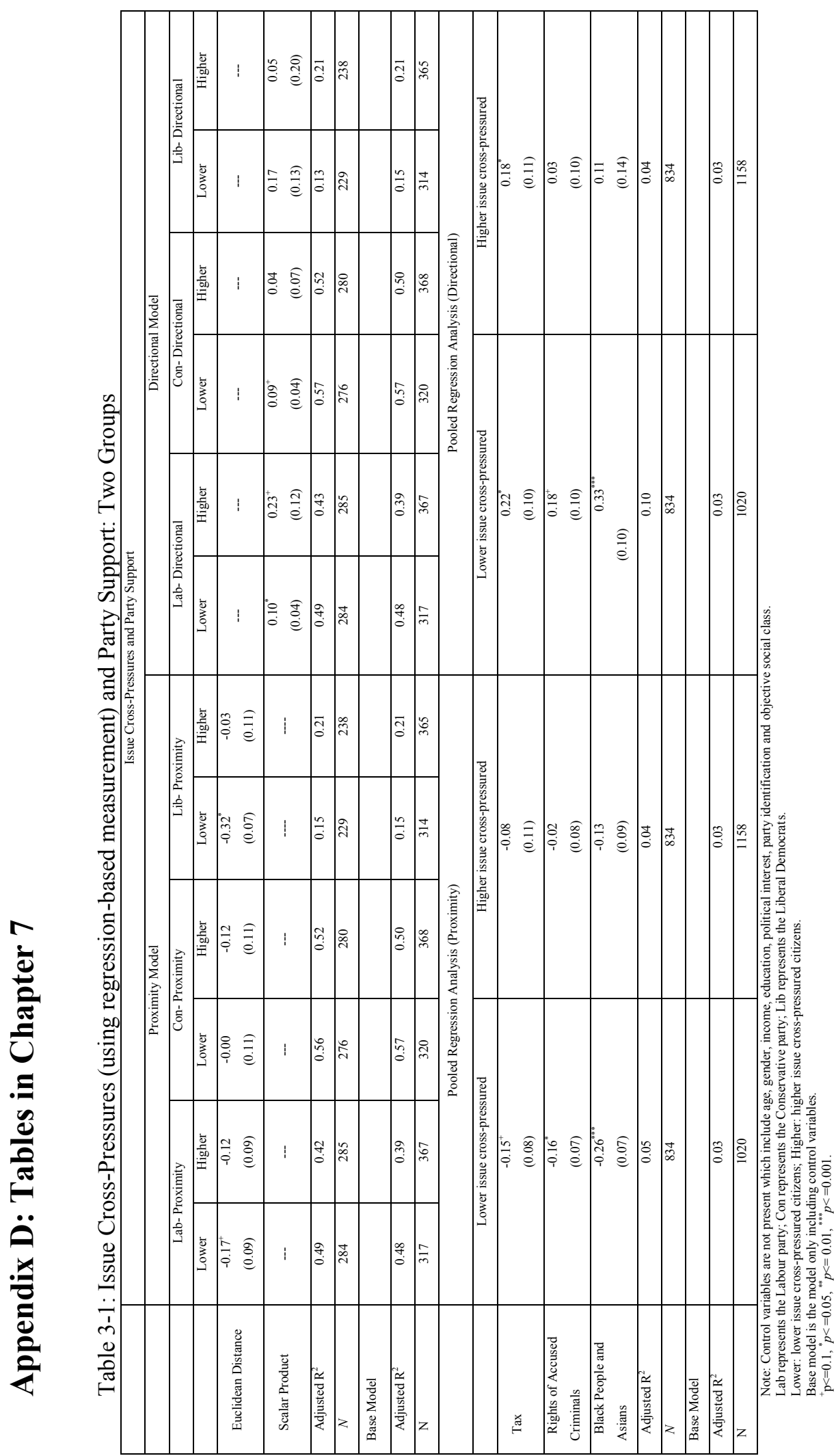


References

\section{References}

Aardal, B., \& Van Wjjnen, P. (2005) Issue voting. In J. Thomassen (Ed.), The European Voter (pp. 192-213). Oxford: Oxford University Press.

Aarts, K., \& Bernhard, W. (2005). Electoral turnout. In J. Thomassen (Ed.), The European voter: A comparative study of modern democracies (pp. 64-83). New York: Oxford University Press.

Aarts, K., MacDonald, S.E., \& Rabinowitz, G. (1999). Issues and party competition in the Netherlands. Comparative Political Studies, 32 (1): 63-99.

Abramowitz, A. I. (1995). It's abortion, stupid: Policy voting in the 1992 presidential election. Journal of Politics, 57 (1), 176-186.

Abramowitz, A. I., \& Saunders, K. L. (2008). Is polarization a myth? Journal of Politics, $70,542-555$.

Adams, J., Dow, J., \& Merrill III, S. (2006). The political consequences of alienation-based and indifference-based voter abstention: Applications to presidential elections. Political Behavior, 28 (1), 65-86.

Alvarez, R.M. (1997). Information and Elections. Ann Arbor: University of Michigan Press.

Alvarez, R.M., \& Nagler, J. (2004). Party system compactness: measurement and consequences. Political Analysis, 12 (1), 46-62.

Alvarez, R.M., \& Brehm, J. (2002). Hard Choices, Easy Answers: Values, Information, and American Public Opinion. Princeton, NJ: Princeton University Press.

Arzheimer, K. (2006). Dead men walking? Party identification in Germany, 1977-2002. Electoral Studies 25, 791-807.

Armitage, C.J., \& Conner, M. (2000). Attitudinal Ambivalence: A test of three key hypotheses. Personality and Social Psychology Bulletin, 26 (11), 1421-1432.

Barber, B. (2003). Strong Democracy: Participatory Politics for a New Age. Los Angeles: University of California Press.

Bartels, L. M. (2002). Beyond the Running Tally: Partisan Bias in Political Perceptions. Political Behavior, 24 (2), 117-50.

Bartle, J., \& Bellucci, P. (2009). Introduction: partisanship, social identity and individual attitudes. In J. Bartle \& P. Bellucci (Eds.), Political Parties and Partisanship: Social Identity and Individual Attitudes (pp.24-44). New York: Routledge. 
Bartolini, S., \& Mair, P. (1990). Identity, Competition, and Electoral Availability: the Stabilization of European Electorates 1885-1985. Cambridge: Cambridge University Press.

Basinger, S.J. \& Lavine, H. (2005). Ambivalence, information, and electoral choice. American Political Science Review, 99 (2), 169-184.

Beck, P. A., Baum, L., Clausen, A. R., \& Smith, C. E. (1992). Patterns and sources of ticket splitting in Sub-presidential voting. American Political Science Review, 86 (4), 916-928.

Benhabib, S. (2004). The Rights of Others: Aliens, Residents and Citizens. Cambridge: Cambridge University Press.

Berglund, F., Holmberg S., Schmitt, H., \& Thomassen, J. (2005). Party Identification and Party Choice. In J. Thomassen (Ed.), The European Voter (pp. 106-125). Oxford University Press, Oxford.

Berelson, B. B., Lazarsfeld, P. F., \& McPhee, W. N. (1954). Voting: A study of opinion formation in a presidential campaign (1st ed.). Chicago: University of Chicago Press.

Blais, A. (2000). To vote or not to vote: The merits and limits of rational choice theory. Pittsburgh: University of Pittsburgh Press.

Blais, A. (2006). What affects voter turnout. Annual Review of Political Science, 9, 111 125.

Blais, A., \& Kees, A. (2006). Electoral systems and turnout. Acta Politica, 41 (2), 180-196.

Blais, A., \& Rubenson, D. (2013). The source of turnout decline: New values or new contexts. Comparative Political Studies, 46 (1), 95-117.

Bischo_, C. S. (2013). Electorally Unstable by Supply or Demand?|An Examination of the Causes of Electoral Volatility in Advanced Industrial Democracies. Public Choice, $156(3 / 4), 537-561$.

Boix, C. (2007). The Emergence of Parties and Party Systems. In C. Boix \& S. Stokes (Eds.), The Oxford Handbook of Comparative Politics (pp. 449-522). New York: Oxford University Press.

Boyd, R. W. (1972). Popular Control of Public Policy: A Normal Vote Analysis of the 1968 Election. American Political Science Review, 66, 429-449.

Borre, O. (2001). Issue voting: An introduction. Aarhus: Aarhus University press. 
Brader, T., Tucker, J.A., \& Therriault, A. (2014). Cross pressure scores: An individuallevel measure of cumulative partisan pressures arising from social group memberships. Political Behavior, 36 (1), 23-51.

Brody, R.A. \& Page, B.I. (1972). Comment: the assessment of policy voting. American Political Science Review, 66 (2), 450-458.

Brody, R. A., \& Page, B. I. (1973). Indifference, alienation and rational decisions: The effects of candidate evaluations on turnout and the vote. Public Choice, 15 (1), 117.

Budge, I., Crewe, I., \& Farlie, D.J. (1974). Party Identification and Beyond: Representations of Voting and Party Competition. Colchester: ECPRC Press.

Budge, I., \& Farlie, D. (1976). A comparative analysis of factors correlated with turnout and voting choice. In I. Budge, I. Crewe \& D. Farlie (Eds.), Party identification and beyond: Representations of voting and party competition (pp. 103-127). London: Wiley.

Burden, B.C., \& Klofstad, C.A. (Dec 2005). Affect and Cognition in Party Identification. Political Psychology,26 (6), 869-886.

Campbell, A., Converse, P.E., Miller, W.E., \& Stokes, D.E. (1960). The American Voter. Chicago: The University of Chicago Press.

Cappella, J.N., Price, V., \& Nir, L. (2002). Argument Repertoire as a Reliable and Valid Measure of Opinion Quality: Electronic Dialogue During Campaign 2000. Political Communication, 19, 73-93.

Carsey, T, M., \& Layman, G. C. (2006). Changing Sides or Changing Minds? Party Identification and Policy Preferences in the American Electorate. American Journal of Political Science, 50 (2), 464-77.

Chaiken, S. (1980). Heuristic versus systematic information processing and the use of source versus message cues in persuasion. Journal of Personality and Social Psychology, 39 (5), 752-766.

Chaffee, S. H., \& Choe, S. Y. (1980). Time of Decision and Media Use During the FordCarter Campaign. Public Opinion Quarterly, 44, 53-69.

Clarke, H., Sanders, D., Stewart, M.C., \& Whiteley, P. (2004). Political Choice in Britain. Oxford: Oxford University Press. 
Conner, M., \& Sparks, P. (2002). Ambivalence and attitudes. European Review of Social Psychology, 12 (1), 37-70.

Conner, M., Sparks, P., Povey, R., James, R., Sheperd, R., \& Amitage, C.J. (2002). Moderator effects of attitudinal ambivalence on attitude behavior relationships. European Journal of Social Psychology, 32 (5), 705-718.

Converse, P.E. (2006). The nature of belief systems in mass publics (1964). Critical Review, 18 (1) 1-3, 1-74, DOI:10.1080/08913810608443650.

Converse, P.E., \& Dupeux, G. (1962). Politicization of the Electorate in France and the United States. Public Opinion Quarterly, 26 (1), 1-23.

Cooper, J., (2007). Cognitive Dissonance: Fifty Years of a Classic Theory. London: Athenaeum Press.

Cox, G. (2015). Electoral rules, mobilization, and turnout. Annual Review of Political Science, 18, 49-68.

Crewe, I. (1974). Party Identification theory and political change in Great Britain. In I. Budge, I. Crewe \& D. J. Farlie (Eds.), Party Identification and Beyond: Representations of Voting and Party Competition (pp. 33-63). Colchester: ECPRC Press.

Crewe, I., Sarlvik, B., \& Alt, J. (1977). Partisan Dealignment in Britain 1964-1974. British Journal of Political Science, 7 (2), 129-190.

Crewe, I. (1992). Changing Votes and Unchanging Voters. Electoral Studies,11 (4), 335345.

Davis, O. A., Hinich, M. J., \& Ordeshook, P. C. (1970). An expository development of mathematical model of the electoral process. American Political Science Review, 64 (2), 426-448.

Dalton, R.J. (1984). Cognitive mobilization and partisan dealignment in advanced industrial democracies. The Journal of Politics, 46 (1), 264-284.

Dalton, R.J. (2004). Democratic Challenges, Democratic Choices: The Erosion of Political Support in Advanced Industrial Democracies. Oxford: Oxford University Press.

Dalton, R.J. (2007). Partisan mobilisation, cognitive mobilisation and the changing American electorate. Electoral Studies, 26, 274-286.

Dalton, R.J. (2008). The quantity and the quality of party systems: Party system polarization, its measurement, and its consequences. Comparative Political Studies, 
References

41(7), 899-920.

Dalton, R.J. (2012) Apartisans and the Changing German Electorate. Electoral Studies,31, 35-45.

Dalton, R.J. (2013). The Apartisan American. Thousand Oaks: CQ Press.

Dalton, R.J. (2014). Citizen Politics: Public Opinion and Political Parties in Advanced Industrial Democracies. Thousand Oaks: CQ Press.

Dalton, R. J. (2014). Interpreting Partisan Dealignment in Germany. German Politics, 23 (1-2), 134-44.

Dalton, R.J., Flanagan, S.C., \& Beck, P.A. (Eds.) (1984). Electoral Change in Advanced Industrial Democracies: Realignment or Dealignment? Princeton, N.J.: Princeton University Press.

Dalton, R. J., McAllister, I., \& Wattenberg, M. P. (2002). The Consequences of Partisan Dealignment. In R. J. Dalton \& M. P. Wattenberg (Eds.), Parties without Partisans. Political Change in Advanced Industrial Democracies (pp. 37-63). Oxford: Oxford University Press.

Dalton, R.J., \& Wattenberg, M.P. (Eds.) (2002). Parties without Partisans: Political Change in Advanced Industrial Democracies. Oxford: Oxford University Press.

Dassonneville, R. (2012). Electoral Volatility, Political Sophistication, Trust and Efficacy: A Study on Changes in Voter Preferences during the Belgian Regional Elections of 2009. Acta Politica, 47 (1), 18-41.

Dassonneville, R. (2014). Political Sophistication and Vote Intention Switching: The Timing of Electoral Volatility in the 2009 German Election Campaign. German Politics. 23 (3), 174-95.

Dassonneville, R. \& Hooghe, M. (2017). Economic Indicators and Electoral Volatility. Economic Effects on Electoral Volatility in Western Europe, 1950-2013. Comparative European Politics, 15 (6) 1-25.

Dassonneville, R., \& Hooghe, M. (2016). Indifference and alienation: Diverging dimensions of electoral dealignment in Europe, doi:10.1057/ap.2016.3.

De Graaf, N.D., Heath, A., \& Need, A. (2001). Declining cleavages and political choices: the interplay of social and political factors in the Netherlands. Electoral Studies, 20, 1-15.

Dewey, J. (2004). Democracy and Education. Mineola, NY: Dover Publications. 
De Vries, C. E. (2010). The issue voting triangle: How issue linkage, issue competition and issue mobilization facilitate issue voting. Available at SSRN: http://ssrn.com/abstract=1666069 or http://dx.doi.org/10.2139/ssrn.1666069.

Drummond, A. J. (2006). Electoral Volatility and Party Decline in Western Democracies: 1970-1995. Political Studies, 54 (3), 628-647.

Downs, A. (1957). An Economic Theory of Democracy. New York: Harper.

Eagly, A.H. \& Chaiken, S. (1993). The Psychology of Attitudes. New York: Harcourt Brace. Edwards III, G. C., Mitchell, W., \& Welch, R. (1995). Explaining presidential approval: The significance of issue salience. American Journal of Political Science, 39 (1), 108-134.

Enelow, J. M., \& Hinich, M. J. (1984). The spatial theory of voting: An introduction. New York: Cambridge University Press.

Evans, J. (2004). Voters and Voting: An Introduction. London: Sage.

Eveland Jr., W. P., \& Hively, M. H. (2009). Political Discussion Frequency, Network Size, and 'Heterogeneity' of Discussion as Predictors of Political Knowledge and Participation. Journal of Communication, 59 (2), 205-224.

Fahmy, E. (2006). Young Citizens: Young People's Involvement in Politics and DecisionMaking. Gateshead: Athenaeum Press, Ltd.

Feldman, S. (1988). Structure and Consistency in Public Opinion: The Role of Core Beliefs and Values. American Journal of Political Science, 32 (2), 416-440.

Feldman, S., \& Zaller, J. (1992). The Political Culture of Ambivalence: Ideological Responses to the Welfare State. American Journal of Political Science, 36 (1), 268-307.

Feldman, S. (2003). Values, ideology, and the structure of political attitudes. In D. O. Sears, L. Huddy, \& R. Jervis (Eds.), Oxford handbook of political psychology (pp. 477508). New York, NY: Oxford University Press.

Feldman, S., \& Johnston, C. (2014). Understanding the determinants of political ideology: Implications of structural complexity. Political Psychology, 35 (3), 337-358.

Festinger, L. (1957). A Theory of Cognitive Dissonance. California: Stanford University Press. 
Fiske, S. T. \& Neuberg, S. L. (1990). A continuum of impression formation from categorybased to individuating processes: Influences of information and motivation on attention and interpretation. Advances in Experimental Social Psychology, 23, 1-74.

Fiske, S. T. \& Taylor, S. E. (1991). Social Cognition: from Brain to Culture (2nd ed.). New York: McGraw-Hill.

Fournier, P., Blais A., Nadeau R., Gidengil, E., \& Nevitte, N. (2003). Issue Importance and Performance Voting. Political Behavior, 25 (1), 51-67.

Fournier, P., Nadeau, R., Blais, A., Gidengil, E., \& Nevitte, N., 2001. Validation of Timeof-Voting-Decision Recall. Public Opinion Quarterly, 65, 95-107.

Fournier, P., Nadeau, R., Blais, A., Gidengil, E., \& Nevitte, N. (2004). Time of Voting Decision and Susceptibility to Campaign Effects. Electoral Studies, 23 (4), 661681.

Franklin, M. N. (1985). The decline of class voting in Britain: Changes in the basis of electoral choice, 1964-1983. USA: Oxford University Press.

Franklin, M. N., Mackie, T., \& Valen, H. (Eds.) (2009). Electoral Change-Responses to Evolving Social and Attitudinal Structures in Western Countries. Colchester: ECPR Press.

Gallagher, M., Laver, M., \& Mair, P. (2011). Representative Government in Modern Europe. New York: McGraw-Hill.

Glasgow, G. (1999). Issue publics in American politics. Pasadena: California Institute of Technology.

Gopoian, J. D., \& Hadjiharalambous, S. (1994). Late-Deciding Voters in Presidential Elections. Political Behavior, 16 (1), 55-78.

Greenleaf, E. A., \&Lehmann, D. R. (1995). Reasons for Substantial Delay in Consumer Decision Making. Journal of Consumer Research, 22 (2), 186-199.

Green-Pedersen, C. (2007). The growing importance of issue competition: The changing nature of party competition in Western Europe. Political Studies, 55 (3), 607-628.

Green, D., Palmquist, B., \& Schickler, E. (2002). Partisan Hearts and Minds. New Haven: Yale University Press.

Green, D. P., \& Schickler, E. (1993). Multiple Measure Assessment of Party Identification. The Public Opinion Quarterly,57 (4), 503-535. 
Green, D. P., \& Schickler, E. (2009). A spirited defence of party identification against its critics. In J. Bartle \& P. Bellucci (Eds.), Political Parties and Partisanship: Social Identity and Individual Attitudes (pp. 180-200). New York: Routledge.

Green, D. P., Palmquist, B., \& Schickler, E. (2002). Partisan Hearts and Minds: Political Parties and the Social Identities of Voters. New Haven, CT: Yale University Press.

Hagle, T. M., Mitchell II, G. E. (1992). Goodness-of-Fit Measures for Probit and Logit. American Journal of Political Science, 36(3), 762-784.

Hagopian, F. (2007). Parties and Voters in Emerging Democracies. In C. Boix \& S. Stokes (Eds.), The Oxford Handbook of Comparative Politics (pp. 582-604). New York: Oxford University Press.

Hansard Society (2012). Audit of Political Engagement 9: The 2012 Report; Part One, London: Hansard Society.

Hetherington, M. J. (2009). Review article: Putting polarization in perspective. British Journal of Political Science, 39, 413-448.

Hillygus, D. S., \& Shields, T. G. (2008). The persuadable voter: Wedge issues in presidential campaigns. Princeton, NJ: Princeton University Press.

Himmelweit, H.T., Biberian, M.J., \& Stockdale, J. (1978). Memory of Past Vote: Implications of a Study of Bias in Recall. British Journal of Political Science, 8 (3), 365-75.

Hinckley, B., Hofstetter R., \& Kessel, J. (1974). Information and the vote: A comparative electoral study. American Politics Quarterly, 2 (2), 131-158.

Hooghe, M. (2014). Citizenship and Participation. In L. LeDuc, R.G. Niemi \& P. Norris (Eds.), Comparing Democracies 4. Elections and Voting in the 21st century (pp. 59-75). Thousand Oaks: Sage.

Hooghe, M., \& Kern, A. (2016). The Tipping Point between Stability and Decline: Trends in Voter Turnout, 1950-1980-2012. European Consortium for Political Research.

Horan, P. M. (1971). Social Positions and Political Cross- Pressures: A Re-Examination. American Sociological Review, 36(August), 650-660.

Huckfeldt, R. R., \& Sprague, J. D. (1995). Citizens, politics, and social communication: Information and influence in an election campaign. Cambridge, U.K.: Cambridge University. 
Humphreys, M., \& Laver, M. (2010). Spatial models, cognitive metrics and majority rule equilibria. British Journal of Political Science, 40 (1), 11-30.

Hurwitz, J., \& Peffley, M. (1987). How Are Foreign Policy Attitudes Structured? A Hierarchical Model. American Political Science Review, 81 (4), 1099-1120.

Inglehart, R. (1977). The Silent Revolution: Changing Values and Political Studies Among Western Publics. Princeton: Princeton University Press.

Inglehart, R. (1990). Culture Shift in Advanced Industrial Society. Princeton, NJ: Princeton University Press.

Inglehart, R. (1997). Modernisation and Postmodernisation. Princeton, NJ: Princeton University Press.

Inglehart, R. F. (2008). Changing Values among Western Publics from 1970 to 2006. West European Politics,31(1-2), 130-146.

Inglehart, R., \& Abramson, P. R. (September 1999). Measuring Postmaterialism. American Political Science Review,93 (3), 665-677.

Inglehart, R., \& Welzel, C. (2005). Modernization, cultural change, and democracy: The human development sequence. New York: Cambridge University Press.

Irwin, G.A., \& Van Holsteyn, J.J.M. (2008a). What are they Waiting For? Strategic Information for Late Deciding Voters. International Journal of Public Opinion Research, 20 (4), 483-493.

Irwin, G.A., \& Van Holsteyn, J.J.M. (2008b). Scientific progress, educated guesses or speculation? On some old predictions with respect to electoral behavior in the Netherlands. Acta Politica, 43, 180-202.

Jang, S.-J. (2009). Are Diverse Political Networks Always Bad for Participatory Democracy? Indifference, Alienation, and Political Disagreements. American Politics Research, 37 (5), 879-899.

Karp, J. A., Vowles, J., Banducci, S. A., \& Donovan, T. (2002). Strategic voting, party activity, and candidate effects: testing explanations for split voting in New Zealand's new mixed system. Electoral Studies, 21 (1), 1-22.

Kedar, O. (2006). How voters work around institutions: policy balancing in staggered elections. Electoral Studies, 25 (3), 509-527.

Kelley Jr., S., \& Mirer, T. W. (1974). The Simple Act of Voting. American Political Science Review, 68 (2), 572-91. 
Knight, K. (1985). Ideology in the 1980 election: Ideological sophistication does matter. Journal of Politics, 47 (3), 825-853.

Kroh, M., Van der Brug, W. \& Van der Eijk, C. (2007). Prospects for electoral change. In W. van der Brug \& C. van der Eijk (Eds.), European Elections and Domestic Politics: Lessons from the Past and Scenarios for the Future (pp. 209-225). Notre Dame: University of Notre Dame Press.

Johns, R. (2010). Measuring issue salience in British elections: Competing interpretations of “most important issue”. Political Research Quarterly, 63 (1), 143-158.

Knoke, D. (1990). Political Networks: The Structuralist Perspective. New York: Cambridge University Press.

Konzelmann, L., Wagner, C., \& Rattinger, H. (2012). Turnout in Germany in the course of time: Life cycle and cohort effects on electoral turnout from 1953 to 2049. Electoral Studies, 31 (2), 250-261.

Kosmidis, S., \& Xezonakis, G. (2010). The Undecided Voters and the Economy: Campaign Heterogeneity in the 2005 British General Election. Electoral Studies, 29, 604-616.

Kroh, M., \& Selb, P. (2009). Individual and contextual origins of durable partisanship. In J. Bartle \& P. Bellucci (Eds.), Political Parties and Partisanship: Social Identity and Individual Attitudes (pp. 107-121). New York: Routledge.

Krosnick, J. A. (1988). The role of attitude importance in social evaluation: A study of policy preferences, presidential candidate evaluations, and voting behavior. Journal of Personality and Social Psychology, 55 (2), 196-210.

Laakso, M., \& Rein, T. (1979). Effective number of parties: a measure with application to west Europe. Comparative Political Studies, 12 (1), 3-27.

Lachat, R. (2011). Electoral competitiveness and issue voting. Political Behavior, 33 (4), 645-663.

Lachat, R. (2009). Issue ownership and issue salience effects: A two-stage model of the voting decision process. CIS Working Paper no. 50. Available at SSRN: $\underline{\text { http://ssrn.com/abstract }=1551838}$ or http://dx.doi.org/10.2139/ssrn.1551838.

Lavine, H. (2001). The electoral consequences of ambivalence toward presidential candidates. American Journal of Political Science, 45 (4), 915-929. 
Lavine, H. \& Gschwend, T. (2007). Issues, party and character: The moderating role of ideological thinking on candidate evaluation. British Journal of Political Science, 37 (1), 139-163.

Lau, R. R. \& Redlawsk, D. P. (2001). Advantages and disadvantages of using cognitive heuristics in political decision making. American Journal of Political Science, 45 (4), 951-971.

Lau, R. R. \& Redlawsk, D. P. (2006). How Voters Decide: Information Processing during Election Campaigns. UK: Cambridge University Press.

Lazarsfeld, P. F., Berelson, B., \& Gaudet, H. (1968). The people's choice: How the voter makes up his mind in a presidential campaign. New York: Columbia University Press.

LaDue Lake, R., \& Huckfeldt, R. (1998). Social Capital, Social Networks, and Political Participation. Political Psychology, 19 (3), 567-584.

Lefkofridi, Z., Wagner, M., \& Willmann, J. E. (2014). Left-Authoritarians and Policy Representation in Western Europe: Electoral Choice across Ideological Dimensions. West European Politics, 37 (1), 65-90

Lewis-Beck, M. S., Jacoby, W. G., Norpoth, H., \& Weisberg, H. E. (2008). The American Voter Revisited. Michigan: The University of Michigan Press.

Lipset, S. M., \& Rokkan, S. (1967). Party systems and voter alignments: Cross-national perspectives. New York: Free Press.

Long, J. S., \& Freese, J. (2005). Regression Models for Categorical Dependent Variables Using Stata (2nd ed.). Texas: Stata Press.

Luskin, R. C. (1990). Explaining political sophistication. Political Behavior, 12 (4), 331 361.

MacDonald, S. E., Listhaug, O., \& Rabinowitz, G. (1991). Issue and Party Support in Multiparty Systems. The American Political Science Review, 85 (4), 1107-1131.

MacDonald, S. E., Rabinowitz, G., \& Listhaug, O. (1995). Political Sophistication and Models of Issue Voting. British Journal of Political Science, 25 (4), 453-483.

Maheswaran, D. \& Chaiken, S. (1991). Promoting systematic processing in low-motivation settings: Effect of incongruent information on processing and judgment. Journal of Personality and Social Psychology, 61 (1), 13-25. 
Mayer, W. G. (2007). The swing voter in American presidential elections. American Politics Research, 35 (3), 358-388.

Mair, P. (2005). Democracy beyond Parties. Irvine, UC: Centre for the Study of Democracy, University of California.

Mair, P. (2008). Electoral Volatility and the Dutch Party System: A Comparative Perspective. Acta Politica, 43 (2/3), 235-253.

Mair, P. (2012). In the Aggregate: Mass Electoral Behaviour in Western Europe 1950-2000. In I. van Biezen (Ed.), On Parties, Party Systems and Democracy: Selected Writings of Peter Mair (pp. 305-25). Colchester: ECPR Press.

Mair, P. (2013). Ruling the Void. The Hollowing of Western Democracy. London: Verso.

Markus, G. B., \& Converse, P. E. (1979). A dynamic simultaneous equation model of electoral choice. American Political Science Review, 73 (4), 1055-1070.

Markus, G. B., \& Converse, P. E. (1979). A dynamic simultaneous equation model of electoral choice. American Political Science Review, 73 (4), 1055-1070.

Marsh, M. (2006). Party identification in Ireland: an insecure anchor for a floating party system. Electoral Studies, 25 (3), 489-508.

Matthes, J. (2012). Exposure to Counterattitudinal News Coverage and the Timing of Voting Decisions. Communication Research, 39 (2), 147-169.

McAllister, I. (2002). Calculating or Capricious? The New Politics of Late Deciding Voters. In M. F. David \& R. Schmitt-Beck (Eds.), Do Political Campaigns Matter? Campaign Effects in Elections and Referendums (pp. 22-41). London and New York: Routledge.

McCarty, N., Poole, K. T., \& Rosenthal, H. (2006). Polarized America: The Dance of Ideology and Unequal Riches. Cambridge, Mass.: The MIT Press.

McClurg, S. D. (2006). The Electoral Relevance of Political Talk: Examining Disagreement and Expertise Effects in Social Networks on Political Participation. American Journal of Political Science, 50 (3), 737-54.

McGraw, K. M., Hasecke, E., \& Conger, K. (2003). Ambivalence, Uncertainty, and Processes of Candidate Evaluation. Political Psychology, 24 (3), 421-448.

M $^{\mathrm{c} G r e g o r, ~ R . ~ M . ~(2012) . ~ V o t e r ~ S i n c e r i t y ~ a n d ~ t h e ~ T i m e-o f-V o t i n g-D e c i s i o n . ~ E l e c t i o n ~}$ Studies, 31 (4), 715-725. 
McLeod, J. M., Scheufele, D. A., \& Moy, P. (1999). Understanding Deliberation: The Effects of Discussion Networks on Participation in a Public Forum. Communication Research, 26 (6), 743-774.

Miller, W. E. (1976). The cross-national use of party identification as a stimulus to political inquiry. In I. Budge, I. Crewe \& D. J. Farlie (Eds.), Party Identification and Beyond: Representations of Voting and Party Competition (pp. 21-33). Colchester: ECPRC Press.

Miller, W. E., \& Shanks, J. M. (1996). The New American Voter. Cambridge: Harvard University Press.

Mutz, D. C. (2002). The consequences of cross-cutting networks for political participation. American Journal of Political Science, 46, 838-855.

Moon, D. (1990). What you use depends on what you have: Information effects on the determinants of electoral Choice. American Politics Research, 18 (1), 3-24.

Narud, H. M., \& Valen, H. (1996). Decline of electoral turnout: the case of Norway. European Journal of Political Research, 29, 235-256.

Neuman, W. R. (1986). The Paradox of Mass Politics: Knowledge and Opinion in the American Electorate. Cambridge: Harvard University Press.

Nir, L. (2005). Ambivalent Social Networks and their Consequences for Participation. International Journal of Public Opinion Research, 17 (4), 422-442.

Nie, N. H., Verba, S., \& Petrocik, J. R. (1976). The Changing American Voter. Cambridge, MA: Harvard University Press.

Nie, N. H., \& Rabjohn, J. N. (1979). Revisiting Mass Belief Systems Revisited: Or, Doing Research is Like Watching a Tennis Match. American Journal of Political Science, 23 (1), 139-175.

Niemi, R. G. \& Larry, M. B. (1985) New measures of issue salience: An evaluation. Journal of Politics, 47 (4), 1212-1220.

Nilson, S. S. (2002). Half a Century of Cross-pressures: A thesis Reconsidered. Political Studies, 50, 354-361.

Nir, L., \& Druckman, J. N. (2008). Campaign Mixed-Message Flows and Timing of Vote Decision. International Journal of Public Opinion Research, 20 (3), 326-346.

Norris, P. (2001). Digital Divide: Civic Engagement, Information Poverty and the Internet Worldwide. New York: Cambridge University Press. 
Norris, P. (2002). Democratic Phoenix: Reinventing Political Activism. New York: Cambridge University Press.

Norris, P. (2011). Democratic Deficit: Critical Citizens Revisited. New York: Cambridge University Press.

O’Neill, B. (2010). The media's role in shaping Canadian civic and political engagement. Policy and Society, 29, 37-45.

Orriols, L., \& Martinez, A. (2014). The role of the political context in voting indecision. Electoral Studies, 35, 12-13.

Oskarson, M. (2005). Social Structure and Party Choice. In J. Thomassen (Ed.), The European Voter (pp. 84-106). Oxford: Oxford University Press.

Page, B. I., \& Brody, R. A. (1972). Policy Voting and the Electoral Process: The Vietnam War Issue. American Political Science Review, 66 (3), 979-95.

Palfrey, T. R. \& Poole, K. T. (1987). The Relationship between Information, Ideology, and Voting Behavior. American Journal of Political Science, 31 (3), 511-530.

Peffley, M. A., \& Hurwitz, J. (1993). Models of Attitude Constraint in Foreign Affairs. Political Behavior, 15 (1), 61-90.

Perea, E. A. (2002). Individual characteristics, institutional incentives and electoral abstention in Western Europe. European Journal of Political Research, 41 (5), 643-673.

Plane, D. L., \& Gershtenson, J. (2004). Candidates' ideological locations, abstention, and turnout in U.S. midterm senate elections. Political Behavior, 26 (1), 69-93.

Pomper, G. M. (1972). From confusion to clarity: Issues and American voters, 1956-1968. American Political Science Review, 66 (2), 415-428.

Pomper, G. M. (1975). Voters' Choice: Varieties of American Electoral Behavior. New York: Harper \& Row.

Pool, I., Abelson, R. P., \& Popkin, S. (1965). Candidates, issues and strategies. Cambridge, MA:MIT Press.

Przeworski, A. (1991). Democracy and the Market: Political and Economic Reforms in Eastern Europe and Latin America. Cambridge: Cambridge University Press.

Putnam, R. (2000). Bowling Alone. The Collapse and Revival of American Community. New York: Simon and Schuster. 
Rabinowitz, G., \& Macdonald, S. E. (1989). A directional theory of issue voting. American Political Science Review, 83 (1), 93-121.

Rabinowitz, G., Prothro, J. W. \& Jacoby, W. (1982). Salience as a factor in the impact of issues on candidate evaluation. The Journal of Politics, 44 (1), 41-63.

RePass, D. E. (1971). Issue salience and party choice. American Political Science Review, 65 (2), 389-400.

Riker, W., \& Ordeshook, P. (1968). A Theory of the Calculus of Voting. American Political Science Review, 62 (1), 25-42.

Rokkan, S. (1962). The comparative study of political participation: Notes toward a perspective on current research. In A. Ranney (Ed.), Essays on the behavioral study of politics. Urbana, IL: University of Illinois Press.

Rose, R. \& McAllister, I. (1986). Voters Begin to Choose: From Closed Class to Open Elections in Britain. London: Sage.

Rose, R. \& McAllister, I. (1990). The Loyalties of Voters: A Lifetime Learning Model. London: Sage.

Scheufele, D. A., Hardy, B.W., Brossard, D., Waismel-Manor, I., \& Nisbet, E. (2006). Democracy Based on Difference: Examining the Links Between Structural Heterogeneity, Heterogeneity of Discussion Networks, and Democratic Citizenship. Journal of Communication, 56 (4), 728-753.

Schumpeter, J. (2013). Capitalism, Socialism and Democracy. Abingdon: Routledge.

Schmitt-Beck, R., \& Partheymüller, J. (2012). Why Voters Decide Late: a Simultaneous Test of Old and New Hypotheses at the 2005 and 2009 German federal elections. German Politics, 21 (3), 299-316.

Schmitt-Beck, R., \& Partheymüller, J. (2016). A Two-Stage Theory of Discussant Influence on Vote Choice in Multiparty Systems. British Journal of Political Science, 46, 321-348.

Sniderman, P. M., \& Piazza, T. (1993). The Scar of Race. MA: Harvard University Press, Cambridge.

Sniderman, P. M., Brody, R. A., \& Tetlock, P. E. (1993). Reasoning and Choice: Explorations in Political Psychology. Cambridge: Cambridge University Press. 
Sniderman, P. M., Glaser, J. M. \& Griffin, R. (1990). Information and electoral choice. In J.

A. Ferejohn \& J. H. Kuklinski (Eds.), Information and Democratic Processes. Urbana: University of Illinois Press.

Simon, H. A. (1976). Administrative Behavior: A Study of Decision-Making Process in Administrative Organizations. New York: Free Press.

Stimson, J. A. (1975). Belief systems: constraint, complexity, and the 1972 election. American Journal of Political Science, 19 (3), 393-417.

Sturgis, P., \& Tilley, J. (2004). Political sophistication and issue voting: An intra-individual level analysis. ESRC Research Methods Program Working Paper no15.

Stokes, D. (1963). Spatial Models of Party Competition. American Political Science Review, 57, 368-377.

Schmitt-Beck, R., Weick, S., \& Christoph, B. (2006). Shaky attachments: individual-level stability and change of partisanship among West German voters, 1984 - 2001. European Journal of Political Research, 45,581-608.

Schumpeter, J. (2013). Capitalism, Socialism, and Democracy. Abingdon: Routledge.

Taylor, S. E. (1981). The Interface of Cognitive and Social Psychology. In J. Harvey (Ed.) Cognition, Social Behavior, and the Environment (pp. 189-211). Hillsdale, NJ: Erlbaum.

Thomassen, J. (Ed.) (2005). The European Voter: a Comparative Study of Modern Democracies. Oxford: Oxford University Press.

Swedlow, B., \& Wyckoff, M. L. (2009). Value preferences and ideological structuring of attitudes in American public opinion. American Politics Research, 37 (6), 10481087.

Therriault, A., Tucker, J. A., \& Brader, T. (2011). Cross-Pressures and Political Participation. Paper presented at the 4th Annual Political Networks Conference. University of Michigan, Ann Arbor, MI.

Thomassen, J. A. (2012). The Blind Corner of Representation, Representation, 48 (1), $13-$ 27.

Tillie, J. (1995). Party Utility and Voting Behavior. Amsterdam: Het Spinhuis.

Van der Eijk, C., Van der Brug, W., Kroh, M., \& Franklin, M. (2006). Rethinking the dependent variable in voting behavior: On the measurement and analysis of electoral utilities. Electoral Studies, 25 (3), 424-447. 
Van Wijnen, P. (2001). Policy Voting in Advanced Industrial Democracies. The case of the Netherlands 1971-1998. Enschede: University of Twente.

Treier, S., \& Hillygus, D. S. (2009). The nature of political ideology in the contemporary electorate. Public Opinion Quarterly, 73 (4), 679-703.

Van der Brug, W., \& Van Spanje, J. (2009). Immigration, Europe and the "New Sociocultural Dimension”. European Journal of Political Research, 48 (3), 30934.

Van der Eijk, C., \& Franklin, M. N. (2009). Elections and Voters. Basingstoke: Palgrave Macmillan.

Vassil, K., Solvak, M., \& Ehin, P. (2016). More Choice, Higher Turnout? The Impact of Consideration Set Size and Homogeneity on Political Participation. Journal of Elections, Public Opinion and Parties, 26 (1), 78-95.

Verba, S., \& Nie, N. H. (1972). Participation in America: Political democracy and social equality. New York: Harper \& Row.

Verba, S., Nie, N., \& Kim, J. (1978). Participation and Political Equality: A Seven-Nation Comparison. New York: Cambrdige University Press.

Waldahl, R. \& Aardal, B., 2000. The Accuracy of Recalled Previous Voting: Evidence from Norwegian Election Study Panels. Scandinavian Political Studies, 23 (4), $373-89$.

Wattenberg, M. P. (2015). Is Voting for Young People? With a Postscript on Citizen Engagement. New York: Pearson Longman.

Welzel, C., \& Inglehart, R. (2005). Modernization, Cultural Change, and Democracy: The Human Development Sequence. New York: Cambridge University Press.

Wessels, B. (2014). Voters' Motivations: How and why short-term factors grow in importance. In B. Wessels, H. Rattinger \& S. Rossteutscher (Eds.), Voters on the Move or on the Run? (pp. 238-263). Oxford: Oxford University Press.

Weisberg, H. F. \& Nawara, S. P. (2010). How sophistication affected the 2000 presidential vote: Traditional sophistication measures versus conceptualization. Political Behavior, 32 (4), 547-565.

Whiteley, P. (2012). Political Participation in Britain: The Decline and Revival of Civic Culture. Basingstoke: Palgrave Macmillan. 
Wilson, T. (2012). Cross-pressured voters: reconciling ideologies in European Parliament Elections. Paper prepared for the ELECDEM closing conference, "Advancing Electoral Research", June 2012, European University Institute, Florence, Italy.

Windmeijer, F. A. G. (1995). Goodness-of-Fit Measures in binary choice models. Econometric Reviews, 14 (1), 101-116.

Wlezien, C. (2005). On the salience of political issues: The problem with 'most important problem'. Electoral Studies, 24 (4), 555-579.

Wolfinger, R. E. \& Rosenstone, S. J. (1980). Who Votes? New Haven, CT: Yale University Press.

Wong, K. T.-w. (2013). Swing Voter and Governing Party Alternation in Taiwan: Victory of Opposition KMT in the 2008 Presidential Election. Asian Journal of Political Science 21 (3), 285-305.

Zaller, J. R. (1992). The Nature and Origin of Mass Opinion. Cambridge: Cambridge University Press.

Zaller, J. (2004). Floating voters in U.S. presidential elections, 1948-2000. InW.E, Saris, \& P.M.Sniderman. (Ed) Studies in Public Opinion: Attitudes, Nonattitudes, Measurement Error, and Change. (pp.166-214). Cambridge: Cambridge University Press.

Zelle, C. (1995). Social Dealignment versus Political Frustration: Contrasting Explanations of the Floating Vote in Germany. European Journal of Political Research, 27 (3), 319-345.

Zipp, J. F. (1985). Perceived representatives and voting: An assessment of the impact of choices vs. echoes. American Political Science Review, 79 (1), 50-61. 


\section{English Summary}

When citizens' positions on some issues led them to support one party while their policy preferences on other issues pushed them toward another party, how would these kinds of voters behave in elections? Since their issue positions led them to inconsistent parties, compared to citizens whose positions on most issues generally pointed to the same party, would they rely less on individual issues and more on other cues such as political performance in order to make a decision? Would they have less motivation to go out to vote? Would they switch their voting choices more often between different elections? And would they even delay their voting decisions until the very last polling day? These were the central concerns of this dissertation. In simple terms, the overarching goal of this dissertation was to answer the following question: Do issue cross-pressures influence citizen's different kinds of electoral behavior, and, if so, how?

Facing changes and instability in electoral behavior across Western Europe, traditional party identification and social cleavages performed increasingly poorly in understanding and explaining the way in which voters made their voting choices. On the one hand, the increasing number of people who were not partisan, or who had a loose link to a particular social group, indicated that, on the basis of this information, voting behavior could be predicted much less accurately. On the other hand, long-term factors such as party identification and social group attachments could tell us a great deal about why one group of citizens behaved in a given way while another group of citizens behaved differently in the same election. However, it could tell us little about why some voters' behavior varied across different elections. This indicated that we must turn to other factors, especially shortterm variables, in order to have a better understanding of electoral behavior in contemporary advanced democracies. One possibility was to focus on issue cross-pressures. However, comparatively few studies have developed a theory and explored the consequences of cross-pressures emerging from holding contradictory voting predispositions based on various issues.

To answer the research questions, this dissertation has been separated into a theoretical part and an empirical part. The theoretical part developed a theory of issue cross-pressures, which clarified: What are issue cross-pressures? What are the preconditions for citizens to experience issue cross-pressures? How do individuals' issue 
cross-pressures arise? How do issue cross-pressures influence citizens' different kinds of electoral behavior? How should issue cross-pressures be measured? It defined issue crosspressures as cross-pressures resulted from holding policy preferences across various issues that pushed one in different political directions. For citizens to experience issue crosspressures, they should care about at least two different issues and their opinions on those issues should not be comprehensively constricted by a unidimensional ideology. Citizens' awareness of issue cross-pressures could come about because of conflicts between/among core values or in pursuing different self-benefits. When citizens experienced issue crosspressures, in order to make a voting decision they would employ different methods to reconcile or alleviate their cross-pressures, including: re-evaluating their stances on some issues, looking for additional attributes related to the parties, and reducing the importance of some issues. This process in turn influenced citizens' various kinds of electoral behavior, including issue voting, turnout, vote switching, and time of voting decision.

The empirical part examined the role of issue cross-pressures in electoral behavior. It firstly studied the question: Is the role of issues in citizens' voting choice moderated by citizens' issue cross-pressures? The theory of issue cross-pressures assumed that when citizens experienced issue cross-pressures, they would try to reconcile them in order to make a decision. They might re-evaluate their own stances on different issues to make certain that their issue positions point to a single party. They might reduce the importance of one or several of the issues in question to ensure that their positions on the most important issues lead them to a single party. They might consider several more, or all relevant attributes of the parties, such as the personality and political experience of party leaders, the party's performance in government and party identification, to align themselves more with a particular party. If citizens who experienced issue cross-pressures employed the third way to reconcile their cross-pressures, the role of issues in decision making might be largely moderated, since many other factors were taken into consideration. Analyzing survey data from the 2010 British Election Study, this dissertation found that the role of issues in citizens' voting choice was moderated by citizens' issue cross-pressures, and that the more issue cross-pressures voters experience, the less pronounced issue voting would be.

Secondly, it examined the relationship between issue cross-pressures and turnout to answer questions: Do issue cross-pressures decrease citizens' motivation to turn out to vote?, and: Is the role of issue cross-pressures in turnout moderated by the party system? 
When citizens experienced issue cross-pressures, they would seek to reduce these pressures in order to make a voting choice. As discussed before, citizens could employ three different methods to alleviate their cross-pressures when their positions on different issues led them to different parties. However, this did not mean that issue cross-pressured citizens could always reduce their cross-pressures and managed to make a decision. When issue crosspressured citizens could not reconcile their cross-pressures successfully, they would keep on struggling to decide which party to vote for, which might influence their motivation to go out to vote. To test this position, this dissertation analyzed survey data from five Dutch parliamentary elections (1994-2012) and three British general elections (1992-2010). The findings showed that issue cross-pressures had an impact on voters' motivations to turn out to vote. In terms of the conditioned role of the party system, the findings indicated that, although people might suffer more issue cross-pressures as the number of parties increases, the influence of issue cross-pressures on turnout would be more pronounced in almost twoparty dominated contexts than in multi-party contexts.

Thirdly, the empirical part of this thesis studied the role of issue cross-pressures in vote switching to answer questions: Do issue cross-pressures influence citizens' vote change across elections?, and: Is the role of issue cross-pressures in vote switching conditioned by different mobilization types? According to the theory of issue crosspressures, if issue cross-pressured citizens managed to reconcile or alleviate their crosspressures to a certain level, they would cast a vote. However, their voting choices would very much depend on how they reconciled their cross-pressures. Therefore, this dissertation suggested that issue cross-pressures might be a factor behind citizens' vote switching across elections. In other words, it argued that the voting choice of issue cross-pressured citizens across elections would be more unstable compared to those whose issue positions pushed them toward a single party. Based on the survey data from the long-term panel of the 20022009 and 2005-2013 German Longitudinal Election Study, the dissertation did not find a strong relationship between issue cross-pressures and vote switching, but it did show that the influence of issue cross-pressures on vote switching was moderated by different mobilization types. This influence was strong and significant among people without party identification and with higher cognitive ability, namely apartisans.

Lastly, the thesis examined the influence of issue cross-pressures on citizens' time of voting decision to answer questions: Are the time of voting decisions affected by 
issue cross-pressures?, and: Is the role of issue cross-pressures in the time of voting decision conditioned by political systems? When citizens did not experience issue crosspressures, they could make a voting choice directly without any additional considerations, whereas, when citizens' issue positions led them to several parties, they must employ one or more approaches to reconcile cross-pressures in order to reach a satisfactory voting choice. This process would obviously lead issue cross-pressured citizens to spend much more time on their decision, thereby delaying their time of voting decisions. Analyses of seven Dutch parliamentary elections (1994-2010), five British general elections (1992-2010) and four German parliamentary elections (1994-2013) showed that issue cross-pressures did influence people's time of voting decisions, regardless of their consideration set size, demographic background and political attributes, and variations in the effect of issue crosspressures on the time of voting decision in different political contexts could be partially explained by party systems

Summarily, the answers to the main research question in this dissertation: Do issue cross-pressures influence citizens' different kinds of electoral voting, and, if so, how?, are as follows. When citizens experienced issue cross-pressures, in order to make a voting decision, they would employ different ways to reconcile or alleviate cross-pressures, which include re-evaluating their stances on some issues, looking for additional attributes related to parties and reducing the importance of some issues. This process in turn influenced citizens' various kinds of electoral behavior, including issue voting, turnout, vote switching, and time of voting decision. Compared to citizens whose issues positions pointed to a single party, issue cross-pressured citizens would rely less on issues to make a decision, have less motivation to go out to vote, switch their voting choices more often between two elections (at least for those who did not have party ties and with a higher educational background), and delay their voting decisions even until the last polling day. Nevertheless, what could not be neglected was that these empirical findings were not always consistent with expectations. For example, the moderated effects of issue cross-pressures on issue voting were different in the proximity and directional models; the impact of issue crosspressures on turnout and time of voting decision varied not only across countries, but also among elections within a country etc. This all needed further exploration.

This dissertation implied that, (a) although the impact of issues on citizens' voting choices was not as great as expected, the important role of issues in electoral politics was 
still remarkable and must not be neglected; (b) modernization and cognitive mobilization might on the one hand make citizens more likely to make a decision independently of political elites and parties, which leads to an increase in issue voting; while on the other hand modernization and cognitive mobilization might also make citizens more likely to realize that their positions on different issues point to different parties, which could cause them to experience more issue cross-pressures. This might in turn decrease the overall level of issue voting, which goes against the optimistic view of the consequences of modernization and cognitive mobilization; (c) the decreasing stability in determinants and patterns of voting behavior was at least partially a result of a transformation in the nature of the demand side of politics. As such, the prospects for contemporary Western democracy were not as pessimistic as de-politicization theses have suggested. However, this did not mean that contemporary Western democracy faced no challenges. Given that a large group of issue cross-pressured citizens have not been fully captured by established parties across Western European countries, small parties would get a chance to develop and new parties would have an opportunity to emerge. Therefore, party systems in contemporary Western democracies might become unstable in the foreseeable future. 


\section{Nederlandse Samenvatting}

Als burgers standpunten hebben over bepaalde beleidsthema's waardoor ze een bepaalde partij steunen, terwijl ze op basis van hun voorkeuren bij andere beleidsthema's zouden uitkomen bij een andere partij, hoe stemmen deze kiezers dan tijdens verkiezingen? Indien ze door standpunten over thema's uitkomen bij verschillende partijen, zouden ze zich dan, in vergelijking met burgers wier standpunten hen over het algemeen allemaal naar dezelfde partij leiden, bij het maken van een keuze minder baseren op individuele beleidsthema's en meer op andere signalen, zoals politieke prestaties? Zijn ze minder gemotiveerd om te gaan stemmen? Zouden ze vaker anders stemmen bij opeenvolgende verkiezingen? En zouden ze het maken van hun keuze uitstellen tot de verkiezingsdag? Dit waren de centrale vragen van dit proefschrift. In het proefschrift worden zulke situaties aangeduid met de Engelse term issue cross-pressures, wat we vrij zouden kunnen vertalen als ambivalente politieke opvattingen. Kort gezegd was het overkoepelende doel van dit proefschrift het beantwoorden van deze vraag: beïnvloeden ambivalente politieke opvattingen verschillende soorten stemgedrag van burgers, en zo ja, hoe?

Met het oog op veranderingen en instabiliteit in electoraal gedrag in West-Europa, dragen traditionele partij-identificatie en sociale scheidslijnen steeds minder bij aan het begrijpen en verklaren van de manier waarop kiezers tot een keuze komen. Aan de ene kant was de groeiende groep mensen die niet een partij aanhing of die een losse band had met een bepaalde sociale groep een indicatie dat, op basis van deze informatie, stemgedrag veel minder nauwkeurig kon worden voorspeld. Aan de andere kant konden we veel opmaken uit langetermijnfactoren zoals partij-identificatie en binding met sociale groepen, over hoe een groep burgers zich op een bepaalde manier gedroeg en een andere groep burgers zich anders gedroeg tijdens dezelfde verkiezingen. Echter, we vonden weinig informatie over waarom het stemgedrag van sommige kiezers anders was bij verschillende verkiezingen. Dit was een teken dat we ons op andere factoren moesten richten, vooral kortetermijnfactoren, om stemgedrag in moderne democratieën beter te begrijpen. Eén van de opties was om ambivalente politieke opvattingen te onderzoeken. Echter, relatief weinig onderzoeken hebben een theorie ontwikkeld en de gevolgen onderzocht van ambivalentie die voortkomt uit het hebben van tegenstrijdige voorkeuren over verschillende beleidsthema's. 
Om de onderzoeksvragen te beantwoorden, is dit proefschrift opgesplitst in een theoretisch gedeelte en een empirisch gedeelte. In het theoretisch gedeelte wordt een theorie uiteengezet over ambivalente politieke opvattingen, die antwoord geeft op de vragen: Wat zijn ambivalente politieke opvattingen? Wat zijn de randvoorwaarden voor ambivalente politieke opvattingen? Hoe ontstaan ambivalente politieke opvattingen? Hoe beïnvloeden ambivalente politieke opvattingen verschillende soorten stemgedrag van burgers? Hoe kunnen ambivalente politieke opvattingen worden gemeten? Ambivalente politieke opvattingen worden gedefinieerd als ambivalentie in politieke voorkeuren over verschillende thema's, waardoor iemand in verschillende politieke richtingen wordt geduwd. De voorwaarden dat burgers ambivalente politieke opvattingen hebben, zijn dat ze zich bekommeren om minimaal twee verschillende beleidsthema's en dat hun meningen over deze thema's niet volledig te vatten zijn in een eendimensionale ideologie. Bewustzijn van burgers over ambivalente politieke opvattingen kan ontstaan door conflicten tussen kernwaarden of het nastreven van verschillende persoonlijke doelen. Als burgers ambivalente politieke opvattingen hebben kunnen ze, om tot een stemkeuze te komen, verschillende methoden toepassen om hun tegenstrijdige opvattingen te verenigen of de ambivalentie te verlichten. Bijvoorbeeld: heroverwegen van hun standpunten over bepaalde thema's, aanvullende kenmerken zoeken die te maken hebben met de partijen, bepaalde thema's minder belangrijk maken. Vervolgens beïnvloedt dit proces verschillende soorten stemgedrag van burgers, zoals beleidsgericht stemmen, opkomst, van keuze veranderen en tijdstip van stemkeuze.

In het empirisch gedeelte wordt de rol van ambivalente politieke opvattingen op stemgedrag onderzocht. Eerst werd er onderzoek gedaan naar deze vraag: Spelen beleidsthema's een kleinere rol bij het stemgedrag van burgers ten gevolge van ambivalente politieke opvattingen? De theorie van de ambivalente politieke opvattingen ging ervan uit dat als burgers ambivalente politieke opvattingen hadden, ze deze met elkaar zouden proberen te verenigen om tot een keuze te komen. Ze zouden hun eigen standpunten over bepaalde thema's kunnen heroverwegen om er zeker van te zijn dat hun standpunten over thema's uitkomen bij één partij. Ze kunnen een of meerdere thema's minder belangrijk maken om ervoor te zorgen dat ze door hun standpunten over de belangrijkste thema's bij één partij uitkomen. Ze zouden meerdere, of alle relevante kenmerken van de partijen kunnen overwegen, zoals de persoonlijkheid en politieke ervaring van de partijleiders, hoe 
de partij optreedt in de regering en partij-identificatie, om meer op één lijn te komen met een bepaalde partij. Als burgers met ambivalente politieke opvattingen de derde manier zouden toepassen om hun tegenstrijdige opvattingen te verbinden, zou de rol van thema's bij de besluitvorming veel kleiner kunnen worden, aangezien er rekening wordt gehouden met verschillende andere factoren. Uit een analyse van gegevens uit de British Election Study van 2010 bleek dat de rol van beleidsthema's op de stemkeuze van burgers kleiner werd door ambivalente politieke opvattingen van burgers en dat hoe meer ambivalente politieke opvattingen burgers hadden, hoe minder er uitgesproken thematisch werd gestemd.

Ten tweede werd de relatie tussen ambivalente politieke opvattingen en opkomst onderzocht om deze vragen te beantwoorden: 'Leiden ambivalente politieke opvattingen ertoe dat burgers minder motivatie hebben om te gaan stemmen?' en 'Wordt de rol van ambivalente politieke opvattingen bij opkomst kleiner door het partijsysteem?' Wanneer burgers ambivalente politieke opvattingen hadden, deden ze hun best om deze ambivalentie te verkleinen om tot een stemkeuze te komen. Zoals eerder besproken kunnen burgers drie verschillende methoden toepassen om hun ambivalentie te verlichten, als ze door hun standpunten over bepaalde thema's bij verschillende partijen uitkomen. Echter, dit betekende niet dat burgers die ambivalente politieke opvattingen hadden, hun ambivalentie altijd konden verminderen en een beslissing konden maken. Wanneer burgers met ambivalente politieke opvattingen hun tegenstrijdige opvattingen niet met succes konden verenigen, bleven ze worstelen met de beslissing op welke partij ze gingen stemmen, wat invloed zou kunnen hebben op hun motivatie om te gaan stemmen. Om dit idee te toetsen zijn gegevens van vijf Nederlandse verkiezingen voor de Tweede Kamer (1994-2012) en drie Britse verkiezingen voor het Lagerhuis (1992-2010) geanalyseerd. De resultaten toonden aan dat ambivalente politieke opvattingen invloed hadden op de motivatie van burgers om te gaan stemmen. Wat betreft de geconditioneerde rol van het partijstelsel toonden de resultaten aan dat, hoewel mensen last hebben van ambivalente politieke opvattingen wanneer het aantal partijen stijgt, de invloed van ambivalente politieke opvattingen op de opkomst groter is als er twee dominante partijen zijn dan als er een meerpartijenstelsel is.

Ten derde werd de rol van ambivalente politieke opvattingen op het veranderen van stemkeuze onderzocht in het empirische gedeelte van dit proefschrift, om deze vragen te beantwoorden: 'Beïnvloeden ambivalente politieke opvattingen het veranderen van 
stemkeuze bij verkiezingen?' en 'Wordt de rol van ambivalente politieke opvattingen bij het veranderen van stemkeuze geconditioneerd door verschillende type mobilisaties?' Volgens de theorie van ambivalente politieke opvattingen zouden burgers die tegenstrijdige opvattingen hadden, een stem uitbrengen als ze hun tegenstrijdige opvattingen tot op zekere hoogte konden verenigen of de ambivalentie konden verlichten. Echter, hun stemkeuze zou ten zeerste afhangen van hoe ze hun tegenstrijdige opvattingen hadden verenigd. Daarom werd er in dit proefschrift gesteld dat ambivalente politieke opvattingen een rol zouden kunnen spelen bij het veranderen van stemkeuze bij verschillende verkiezingen. Met andere woorden, er wordt gesteld dat de stemkeuze van burgers met ambivalente politieke opvattingen bij verschillende verkiezingen instabieler zou zijn in vergelijking met diegenen die door hun standpunten bij één partij uitkwamen. Onderzoeksgegevens van het langetermijnpanel van de German Longitudinal Election Study uit 2002-2009 toonden aan dat er geen sterk verband is tussen ambivalente politieke opvattingen en het veranderen van stemkeuze, maar er werd wel aangetoond dat de invloed van ambivalente politieke opvattingen op verandering van stemkeuze minder werd door verschillende type mobilisaties. Deze invloed was sterk en significant bij mensen zonder partij-identificatie en mensen met hogere cognitieve vaardigheden, namelijk mensen die geen partij aanhingen.

Tot slot is er in dit proefschrift onderzocht wat de invloed was van ambivalente politieke opvattingen op het tijdstip van stemkeuze om deze vragen te beantwoorden: 'Wordt het tijdstip van stemkeuze beïnvloed door ambivalente politieke opvattingen?' en 'Wordt de rol van ambivalente politieke opvattingen ten tijde van stemkeuze geconditioneerd door politieke stelsels?' Als burgers geen ambivalente politieke opvattingen hadden, konden ze direct een stemkeuze maken zonder verdere overwegingen. Daartegenover stond dat als burgers standpunten over beleidsthema's hadden waardoor ze uitkwamen bij verschillende partijen, ze een of meerdere benaderingen moesten toepassen om hun tegenstrijdige opvattingen te verenigen en tot een bevredigende stemkeuze te komen. Dit proces leidde er uiteraard toe dat burgers met ambivalente politieke opvattingen meer tijd besteedden aan hun beslissing, waardoor het tijdstip van stemkeuze werd uitgesteld. Analyses van zeven Nederlandse verkiezingen voor de Tweede Kamer (19942010), vijf Britse verkiezingen voor het Lagerhuis (1992-2010) en vier Duitse verkiezingen voor de Bondsdag (1994-2013) toonden aan dat ambivalente politieke opvattingen invloed hadden op het tijdstip van stemkeuze, onafhankelijk van het aantal partijen waarop men 
overwoog te stemmen, demografische achtergrond en politieke kenmerken van mensen. Daarnaast bleek dat verschillen in het effect op ambivalente politieke opvattingen op het tijdstip van stemkeuze, in verschillende politieke contexten gedeeltelijk kan worden verklaard door het partijstelsel.

Samenvattend is het antwoord op de centrale vraag in dit proefschrift 'Beïnvloeden ambivalente politieke opvattingen verschillende soorten stemgedrag van burgers, en zo ja, hoe?' als volgt: Als burgers ambivalente politieke opvattingen hebben zullen ze, om tot een stemkeuze te komen, verschillende methoden toepassen om hun tegenstrijdige opvattingen te verenigen of de ambivalentie te verlichten, zoals: heroverwegen van hun standpunten over bepaalde thema's, op zoek gaan naar aanvullende eigenschappen van de partijen en bepaalde thema's minder belangrijk maken. Vervolgens beïnvloedt dit proces verschillende soorten stemgedrag van burgers, waaronder thematisch stemmen, opkomst, veranderen van stemkeuze en tijdstip van stemkeuze. In vergelijking met burgers wier standpunten over thema's leiden tot één partij, zullen burgers die ambivalente politieke opvattingen hebben zich minder op thema's baseren om tot een keuze te komen, minder motivatie hebben om te gaan stemmen, hun stemkeuze vaker veranderen bij twee verkiezingen (tenminste diegenen die geen partij aanhangen en een hogere opleiding hebben) en hun stemkeuze uitstellen tot de verkiezingsdag. Desalniettemin kan niet worden verwaarloosd dat deze empirische bevindingen niet altijd overeenkwamen met de verwachtingen. Bijvoorbeeld: de gematigde effecten van ambivalente politieke opvattingen op thematisch stemmen waren anders in de nabijheids- en richtingsmodellen van beleidsgericht stemmen. De invloed van ambivalente politieke opvattingen op opkomst en tijdstip van stemkeuze varieerde niet alleen per land, maar ook per verkiezing in een land, etc. Dit vraagt om verder onderzoek.

Dit proefschrift stelt dat a) hoewel de invloed van thema's op stemkeuze van burgers niet zo groot was als verwacht, was de belangrijke rol van beleidsthema's bij electorale politiek nog steeds aanzienlijk en mag deze niet worden verwaarloosd; b) modernisering en cognitieve mobilisatie maken het waarschijnlijker dat burgers een beslissing maken onafhankelijk van politieke elites en partijen, wat leidt tot een toename in beleidsgericht stemmen. Aan de andere kant maken modernisering en cognitieve mobilisatie het waarschijnlijker dat burgers zich realiseren dat hun standpunten over verschillende beleidsthema's hen naar verschillende partijen leiden, waardoor ze meer ambivalente politieke opvattingen hebben. Dit zou vervolgens kunnen leiden tot 
verminderd beleidsgericht stemmen, wat indruist tegen de optimistische visie van de consequenties van modernisering en cognitieve mobilisatie; (c) de afnemende stabiliteit in bepalende factoren en patronen in stemgedrag was ten minste gedeeltelijk een resultaat van de verandering in de aard van de vraagzijde van de politiek. Als zodanig waren de vooruitzichten voor de moderne westerse democratie niet zo pessimistisch als proefschriften over depolitisering suggereerden. Dit betekent echter niet dat de moderne westerse democratie niet met uitdagingen werd geconfronteerd. Gezien het feit dat een grote groep burgers met ambivalente politieke opvattingen niet volledig zijn opgenomen in de gevestigde partijen in West-Europese landen, zullen kleine partijen een kans krijgen om zich te ontwikkelen en nieuwe partijen zullen een kans hebben om op te komen. Daarom zouden partijsystemen in de moderne westerse democratieën instabieler kunnen worden in de nabije toekomst. 